\title{
Analyse molekularer Marker und Signalwege in soliden Tumorzelllinien und ihre Bedeutung für die Tumorprogression und Metastasierung
}

\author{
Dissertation \\ zur Erlangung des mathematisch-naturwissenschaftlichen Doktorgrades \\ „Doctor rerum naturalium (Dr. rer. nat.)“ \\ im Promotionsprogramm Molekulare Medizin \\ der Georg-August-Universität-Göttingen
}

vorgelegt von

Jetcy Jose Arackal, geb. Malayil

aus

Witten 


\section{Prüfungskomitee:}

\section{Betreuer}

Prof. Dr. Claudia Binder

Hämatologie und Onkologie

Universitätsmedizin Göttingen

\section{Referent}

Prof. Dr. Michael Zeisberg

Nephrologie und Rheumatologie

Universitätsmedizin Göttingen

\section{Referent (bis 18.04.2015)}

Prof. Dr. Uwe-Karsten Hanisch

Neuropathologie

Universitätsmedizin Göttingen

\section{Referent (ab 16.07.2015)}

Prof. Dr.Heidi Hahn

Humangenetik

Universitätsmedizin Göttingen

Tag der Disputation: 


\section{AFFIDAVIT}

Hiermit erkläre ich, dass ich die vorliegende Dissertation mit dem Titel „Analyse molekularer Marker und Signalwege in soliden Tumorzelllinien und ihre Bedeutung für die Tumorprogression und Metastasierung" selbstständig verfasst und keine anderen als die angegebenen Hilfsmittel und Quellen benutzt habe.

Jetcy Jose Arackal

Göttingen, Februar 2016 


\section{Inhaltsverzeichnis}

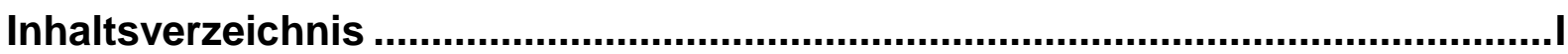

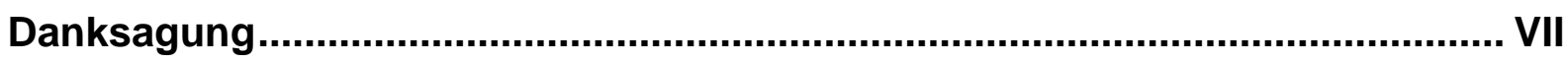

Zusammenfassung.......................................................................................... VII

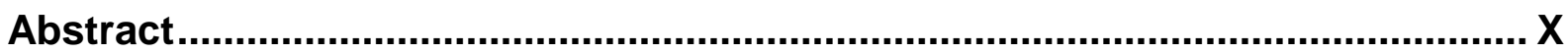

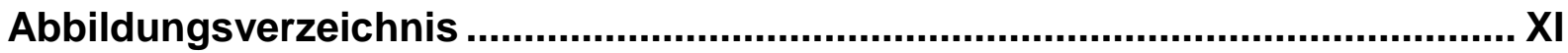

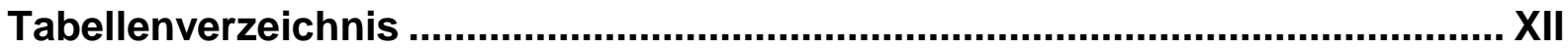

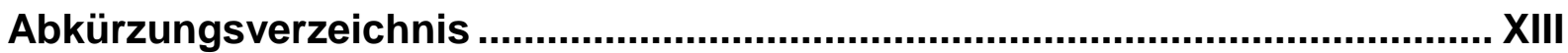

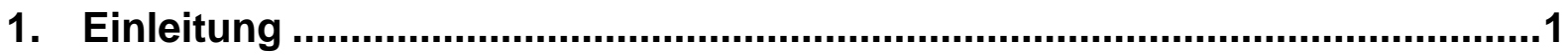

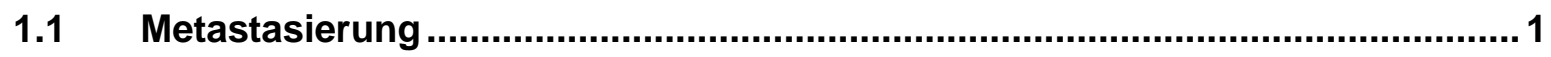

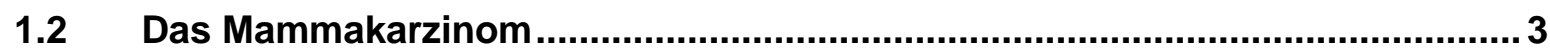

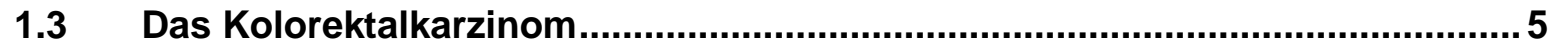

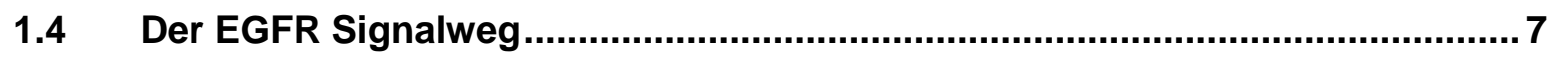

1.4.1 Der EGFR Signalweg in der Tumorprogression ...............................

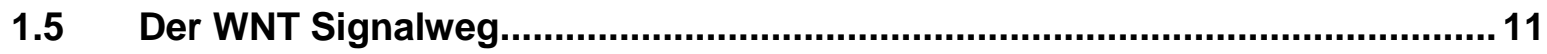

1.5.1 Der kanonischer WNT Signalweg …………...............................12

1.5.1.1 Der inaktive Zustand ............................................................12

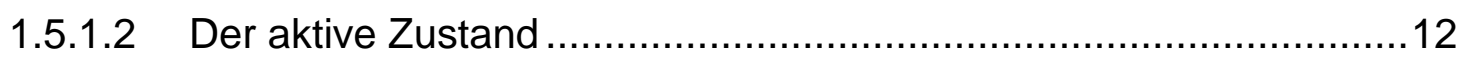

1.5.2 Die nicht-kanonischen WNT Signalwege ..........................................14

1.5.2.1 Planar-Cell-Polarity Signalweg .................................................. 15

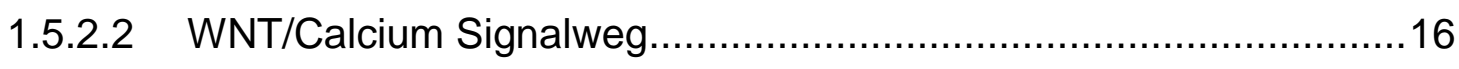

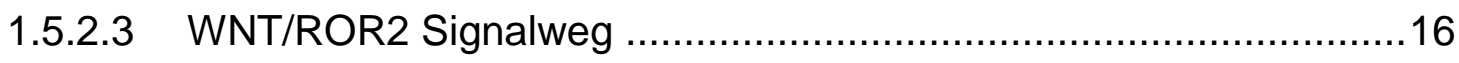

1.5.3 Der WNT Signalweg in der Tumorprogression ....................................17

1.6 „MetastaSys“ Projekt .................................................................................... 18

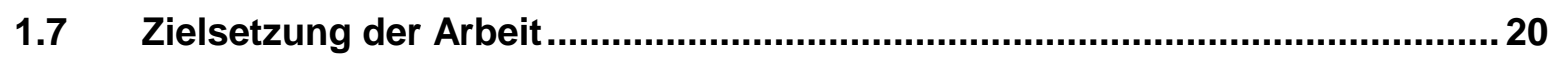

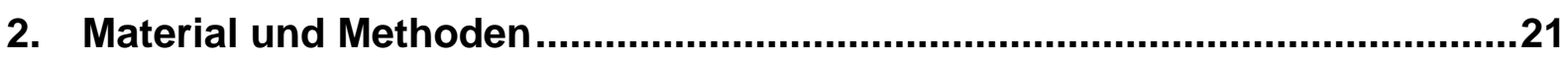

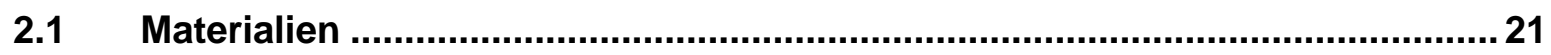

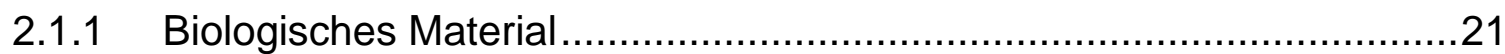




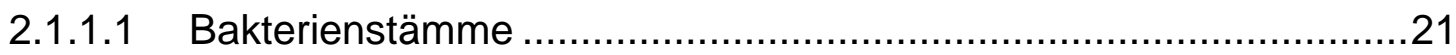

2.1.1.2 Eukaryotische Zelllinien ....................................................21

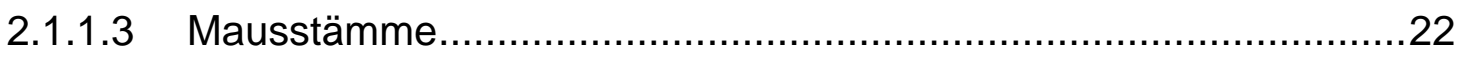

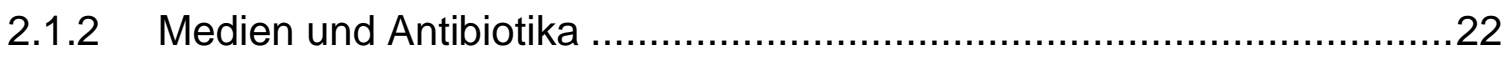

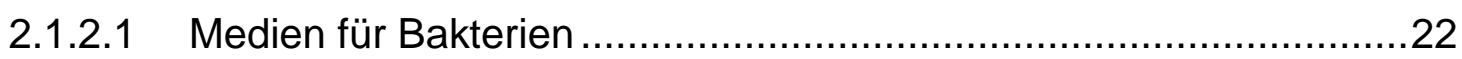

2.1.2.2 Medien für eukaryotische Zelllinien ..........................................23

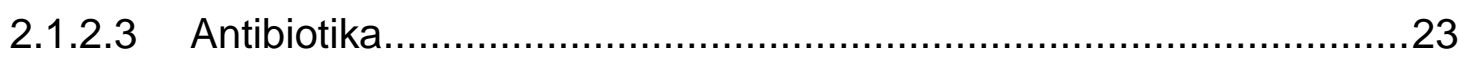

2.1.3 Chemikalien und rekombinante Proteine .........................................24

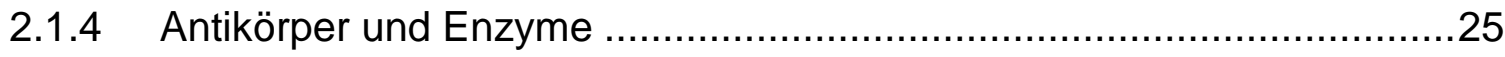

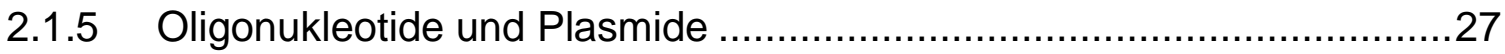

2.1.6 Kommerzielle Kits und Standards ....................................................30

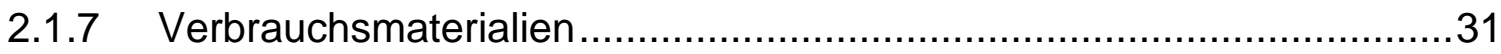

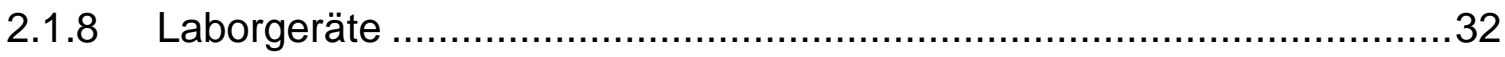

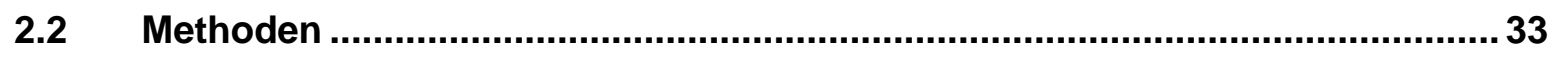

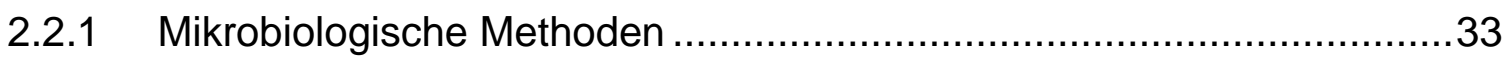

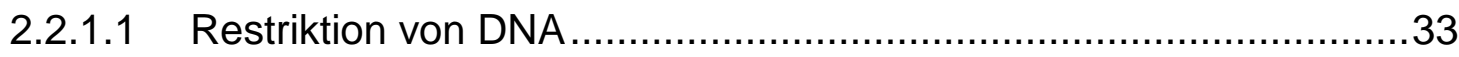

2.2.1.2 Agarose-Gelelektrophorese von DNA …....................................33

2.2.1.3 Ligation von DNA-Fragmenten ..................................................

2.2.1.4 Herstellung kompetenter Escherichia coli-Zellen ...........................34

2.2.1.5 Transformation kompetenter Escherichia coli-Zellen .....................35

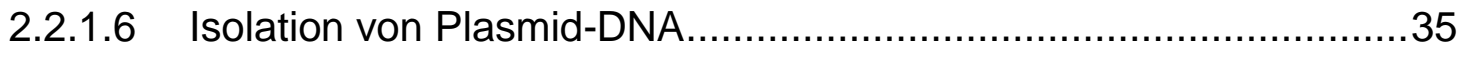

2.2.1.7 Isolation von Plasmid-DNA für die Transfektion eukaryotischer Zellen .36

2.2.1.8 Konzentrationsbestimmung von Nukleinsäuren .............................36

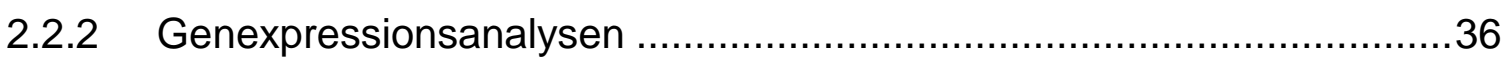

2.2.2.1 Isolation der Gesamt-RNA aus eukaryotischen Zellen ....................36

2.2.2.2 Isolation der Gesamt-RNA aus Geweben .....................................37

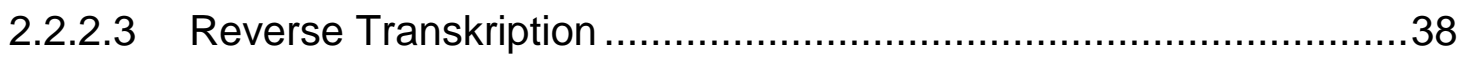


2.2.2.4 Quantitative real-time PCR (qRT-PCR) .....................................38

2.2.2.5 Qualitätskontrolle der qRT-PCRs .............................................. 40

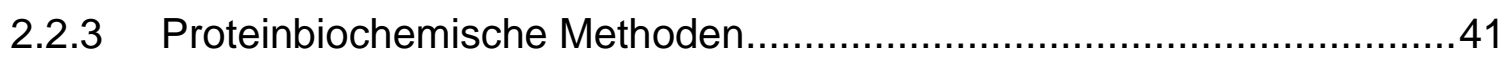

2.2.3.1 Isolation des Gesamtproteins aus eukaryotischen Zellen ...............41

2.2.3.2 Isolation des Gesamtproteins aus Geweben .................................41

2.2.3.3 Messung der Proteinkonzentration...............................................42

2.2.3.4 SDS-Polyacrylamidgelelektrophorese (SDS-PAGE) …..................42

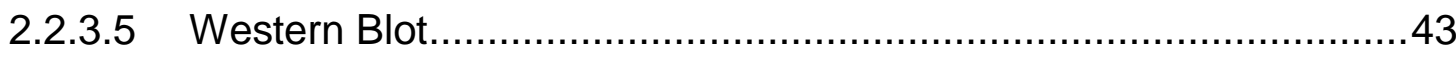

2.2.4 Zellbiologische Methoden ……........................................................ 45

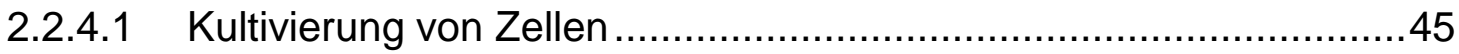

2.2.4.2 Biochemische Transfektion von eukaryotischen Zellen...................45

2.2.4.3 Physikalische Transfektion von eukaryotischen Zellen ..................45

2.2.4.4 Lentivirale Transfektion von eukaryotischen Zellen........................46

2.2.4.5 Messung der Viabilität und Proliferation .......................................46

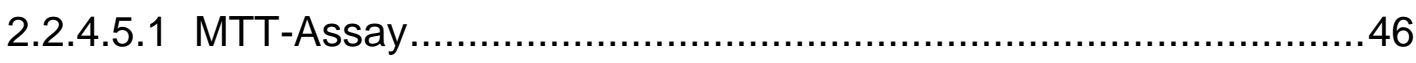

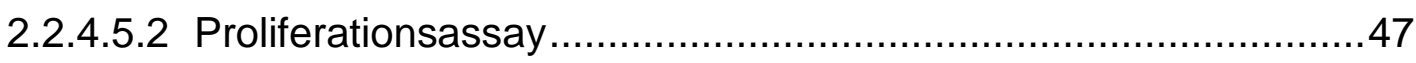

2.2.4.5.3 Soft Agar Colony Formation Assay ..........................................47

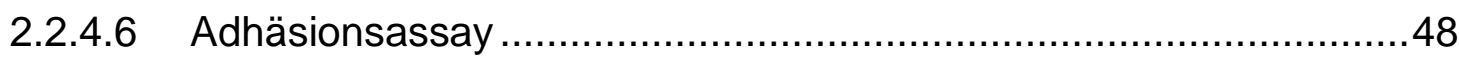

2.2.4.7 Boyden-Kammer-Assay .......................................................... 48

2.2.4.8 TOP/FOP flash Reporter-Assay .................................................49

2.2.4.9 Immunzytochemie und Immunfluoreszenz .................................50

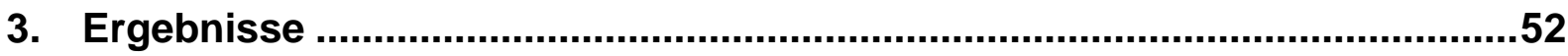

3.1 Charakterisierung der murinen Tumorzelllinien................................................53

3.1.1 Morphologische Charakterisierung der murinen Tumorzelllinien ............53

3.1.2 Molekulare Charakterisierung der murinen Tumorzelllinien ....................55

3.1.2.1 Charakterisierung der murinen Tumorzellinien auf ihren basalen EGFR- und $\beta$-Catenin-Status. 
3.1.2.2 Charakterisierung der murinen Tumorzelllinien auf Komponenten des WNT Signalwegs .56

3.1.2.3 Charakterisierung der murinen Tumorzelllinien auf EMT-Marker ....57

3.2 Etablierung der EGFR modulierten Tumorzelllinien 60

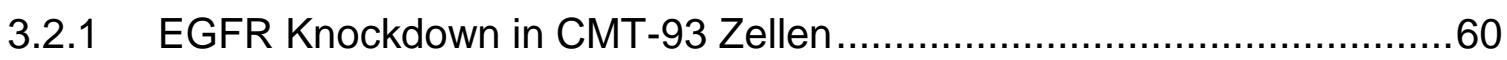

3.2.1.1 Charakterisierung der stabil transduzierten Zellen .........................60

3.2.1.2 Einfluss von EGFR auf die Proliferation, Invasion und

Signalweiterleitung. 61

3.2.2 EGFR Überexpression in 410.4 und CMT-93 Zellen ...........................62

3.2.2.1 Charakterisierung der stabil transduzierten Zelllinien.....................62

3.2.2.2 Einfluss von EGFR auf die Signalweiterleitung .............................64

3.2.2.3 Einfluss von EGFR auf die Invasion ...........................................64

3.3 Etablierung der WNT modulierten Tumorzelllinien ...........................................65

3.3.1 Etablierung der $\beta$-Catenin modulierten Tumorzelllinien .........................65

3.3.1.1 $\beta$-Catenin Knockdown in 410.4 und CMT-93 Zellen.......................66

3.3.1.1.1 Charakterisierung der stabil transduzierten Zelllinien..................66

3.3.1.1.2 Einfluss von $\beta$-Catenin auf die Invasion und Signalweiterleitung 67

3.3.1.2 $\beta$-Catenin Überexpression in 410.4 und CMT-93 Zellen .................68

3.3.2 Etablierung der WNT11 und ROR2 modulierten Tumorzelllinien...........69

3.3.2.1 Etablierung der WNT11 modulierten Tumorzelllinien .....................70

3.3.2.1.1 Wnt11 Expression in Mamma- und kolorektalen Karzinomzelllinien .70

3.3.2.1.2 Einfluss der Stimulation mit WNT11 auf die Invasion und

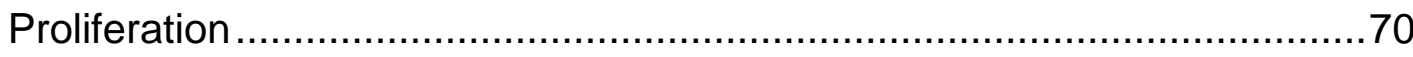

3.3.2.1.3 Klonierung des Leervektors ..................................................

3.3.2.1.4 Charakterisierung der stabil transfizierten Zellen .......................72

3.3.2.1.5 Einfluss von WNT11 auf die Invasion, Proliferation und das

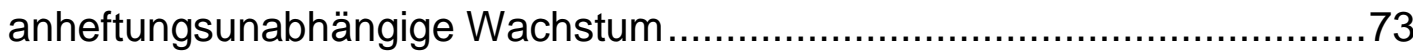

3.3.2.1.6 Einfluss von WNT11 auf das Zytoskelett und die Adhäsion .........74 
3.3.2.1.7 Einfluss von WNT11 auf die Aktivierung des kanonischen und nicht-kanonischen WNT Signalwegs. .75

3.3.2.1.8 Einfluss von WNT11 auf die Aktivierung des PI3K Signalwegs ..76

3.3.2.2 Etablierung der ROR2 modulierten Tumorzelllinien .77

3.3.2.2.1 Charakterisierung der stabil transfizierten Zellen 77

3.3.2.2.2 Einfluss von ROR2 auf Invasion, Proliferation, anheftungsunabhängige Wachstum und Adhäsion .78

3.3.2.2.3 Einfluss von ROR2 auf die Aktivierung des WNT Signalwegs und Expression von EMT-Markern 80

3.3.2.2.4 Einfluss von ROR2 auf die Aktivierung des PI3K Signalwegs.....82

3.4 Anwendbarkeit im Mausmodell 83

4. Diskussion .87

4.1 Identifikation der murinen Tumorzellinien zur Analyse der Tumorprogression 87

4.2 Die Charakterisierung der EGFR modulierten Tumorzellinien auf die Tumorprogression .90

4.2.1 Funktionelle Auswirkungen des EGFR Knockdowns in CMT-93 .90

4.2.2 Funktionelle Auswirkungen der EGFR Überexpression in 410.4 und CMT-93.

4.3 Die Charakterisierung der $\beta$-Catenin modulierten Tumorzelllinien auf die Tumorprogression 92

4.3.1 Funktionelle Auswirkungen des $\beta$-Catenin Knockdowns in 410.4 und CMT-93 .93

4.3.2 Funktionelle Auswirkungen der $\beta$-Catenin Überexpression in 410.4 und CMT-93.

4.4 WNT11 und ROR2 charakterisiert Tumorprogression .....................................95

4.4.1 WNT11 und ROR2 steigern die Invasion von 410.4 Zellen ..................95

4.4.2 Der Einfluss von WNT11 und ROR2 auf die Proliferation .....................96

4.4.3 WNT11 hat keinen Einfluss auf das anheftungsunabhängige Wachstum / ROR2 hat Einfluss auf das anheftungsunabhängige Wachstum 
4.4.4 WNT11 und ROR2 haben keinen Einfluss auf die Adhäsion an ECM und FN

4.4.5 WNT11 und ROR2 steigern die Invasion $\beta$-Catenin-unabhängig .98

4.4.6 WNT11 und ROR2 steigern die Invasion durch den RHOA/ROCK Signalweg .99

4.4.7 WNT11 und ROR2 haben einen Einfluss auf den PI3K Signalweg .....100

4.4.8 ROR2 hat einen Einfluss auf die Expression von EMT-Markern..........101

4.4.9 Zusammenfassung der Ergebnisse von WNT11 und ROR2 101

5. Fazit. .103

6. Literaturverzeichnis .105 


\section{Danksagung}

Frau Prof. Dr. Binder danke ich herzlich zum einen für die Bereitstellung des Arbeitsplatzes und die wissenschaftliche Unterstützung über den gesamten Zeitraum. Zum anderen möchte ich mich für das intensive, mühsame und häufige Korrekturlesen ganz besonders bedanken.

Mein besonderer Dank gilt meiner Betreuerin Dr. Kerstin Menck zum einen für die tolle Betreuung und Unterstützung bei der Bearbeitung des Themas. Vielen Dank für dein Vertrauen in mich und die nie endende Motivation, die zum Erfolg dieser Arbeit beigetragen haben.

Ein besonderer Dank geht an alle Mitglieder des "MetastaSys" Projektes. Insbesondere danke ich Dr. Tobias Pukrop und Dr. Annalen Bleckmann für die vielen hilfreichen wissenschaftlichen Diskussionen, die ebenfalls zum Erfolg dieser Arbeit führten.

Ich möchte Prof. Dr. Uwe-Karsten Hanisch, Prof. Dr. Michael Zeisberg und Prof. Dr. Heidi Hahn für die Teilnahme in meinem Thesiskomitee und ihre Unterstützung zur erfolgreichen Durchführung dieser Arbeit danken.

Ein besonderer Dank geht an allen ehemaligen und derzeitigen Mitgliedern der Arbeitsgruppe Binder: Florian, Eva, Gini, Raquel, Britta, Matthias, Lena, Meike, Daniela, Anke, Madlen, Jonas, Toni, Bianca und Kristin. Danke für die Unterstützung auf unterschiedlichste Weise, viele lustige Momente sowohl im Labor als auch im Büro und die ständige Versorgung mit kleinen Leckereien und Koffein. Weiterhin möchte ich mich bei allen Kolleginnen der Arbeitsgruppe Kube für das tolle und angenehme Arbeitsklima und die Unterstützung bedanken.

Danke an Rosemol und Neethu für die Freundschaft, Unterstützung und eine unvergessliche Zeit in Göttingen.

Zuletzt, aber zutiefst möchte ich mich besonders bei meinen Eltern für ihre finanzielle Unterstützung und bei meinen Schwiegereltern für ihre Motivation aus der Ferne bedanken, des Weiteren meinem Bruder Jobby, meiner Schwester Jisha, die immer ein offenes Ohr für mich hat, Familie Fesselmann, meinem Schwager Manuel und meiner Schwägerin Sylvia. Tausend Dank an Rest der Familie und allen meinen Freunden. Der größte Dank geht an meinen lieben Mann Robin für die bedingungslose Unterstützung. 


\section{Zusammenfassung}

Die Entwicklung von Fernmetastasen ist die Haupttodesursache bei Tumorerkrankten und der entscheidende klinisch relevante Schritt während der Tumorprogression. Die Seed and Soil Theorie von Stephen Paget besagt, dass verschiedene Tumorzellen spezifische Zielorgane während der Metatasierung bevorzugen. Während das häufigste Target der kolorektalen Karzinome die Leber ist, hat der triple-negative molekulare Subtyp von Brustkrebs die Neigung, in das Gehirn zu metastasieren. Interessanterweise spielen sowohl deregulierte EGFR (Epithelial growth factor receptor) als auch WNT Signalwege in diesen beiden Entitäten eine entscheidende Rolle. Das Ziel der Arbeit ist, die Rolle der beiden Signalwege in soliden Tumorzelllinien in Bezug auf die Tumorprogression und Kolonisation zu untersuchen.

Im Rahmen der molekularen Charakterisierung der Zelllinien zeigten sich die Mammakarzinomzelllinie 410.4 und die kolorektale Tumorzellinie CMT-93 als passende Modellsysteme für unsere Fragestellung. Anschließend wurden der EGFR und der WNT Signalweg in diesen Zellen im Sinne von gain of function und loss of function moduliert und die Auswirkungen auf Aspekte der Tumorprogression analysiert.

In CMT-93 Zellen wurde ein EGFR Knockdown etabliert. Während der Knockdown keinen Einfluss auf die Proliferation hat, vermindert er die Invasion der Zellen. Somit konnte dem effizienten Knockdown eine funktionelle Wirksamkeit zugeschrieben werden. Eine EGFR Überexpression konnte sowohl in 410.4 als auch in CMT-93 Zellen etabliert werden. Die Analyse der jeweiligen Signalkaskadenweiterleitung ergab zwar Änderungen und somit eine funktionelle Relevanz, dies blieb jedoch ohne Auswirkungen auf das Invasionspotential der Zelllinien.

Ein Knockdown von $\beta$-Catenin konnte in 410.4 zwar etabliert werden, blieb jedoch ohne funktionelle Auswirkungen. Eine stabile Überexpression von $\beta$-Catenin war nicht erfolgreich, da dies offenbar mit der Viabilität der Zellen interferierte. Die Relevanz des $\beta$-Catenin-abhängigen WNT Signalwegs in den beiden gewählten Zelllinien konnte somit nicht abschließend geklärt werden.

Des Weiteren wurde die Bedeutung des nicht-kanonischen WNT Signalwegs via ROR2 und WNT11 untersucht. Dabei ergab sich, dass die Überexpression von WNT11 und ROR2 in 410.4 Zellen deren Invasion durch einen RHOA-abhängigen Mechnismus steigert und einen Einfluss auf den PI3K Signalweg hat. Es ist 
anzunehmen, dass WNT11 als downstream Target über ROR2 induziert wird und über einen positiven Feedback-Loop via ROR2 eine autokrine Stimulation ausübt. 


\section{Abstract}

The development of distant metastases is the main leading cause of cancer death and the crucial adverse event in cancer progression. The "Seed and Soil" hypothesis by Stephen Paget states that different cancer cells prefer to metastasize into specific target organs. While the most frequent site of colorectal cancers is the liver, the triplenegative molecular subtype of breast cancer has a propensity to metastasize into the brain. Interestingly, in both of these tumors the WNT signaling as well as the EGFR signaling pathway play a pivotal role. In line with this, the aim of this study is to investigate the role of involved signaling pathways in solid tumor cell lines with respect to tumor progression and colonization.

The molecular characterization of the cell lines showed that the breast cancer cell line 410.4 and the colorectal cancer cell line CMT-93 are suitable model systems for purpose of our study. Subsequently, the EGFR and the WNT signaling pathway in these cells were manipulated in terms of gain of function and loss of function and the consequences were analyzed regarding their role in tumor progression.

In CMT-93 cells an EGFR knockdown was established. The knockdown has no influence on the proliferation, but it decreases the invasion potential of the cells. Consequently, the efficient knockdown has effect on biological functions. An EGFR overexpression was established in 410.4 as well as in CMT-93 cells. The analysis of the respective signal transduction proved changes and therefore a functional relevance, nevertheless, this remained without effects on the invasion potential of the cell lines.

Even though a knockdown of $\beta$-Catenin was achieved in 410.4 cell line, it has remained without functional consequences. A stable overexpression of $\beta$-Catenin was not successful, because it apparently interfered with the viability of the cells. Therefore the relevance of the $\beta$-Catenin-dependent WNT signaling pathway in both elective cell lines could not be analyzed exclusive.

Moreover the importance of the non-canonical WNT signaling pathway via ROR2 and WNT11 was examined. The investigation has revealed that overexpression of WNT11 and ROR2 in 410.4 cells enhanced their invasion rate through a RHOA-dependent manner and has an influence on PI3K signaling pathway. It is to be supposed that WNT11 is induced as a downstream target of ROR2 and indicates through a positive feedback loop via ROR2 an autocrine signaling. 


\section{Abbildungsverzeichnis}

Abb. 1.1: Metastasierung - ein komplexer Prozess aus aufeinanderfolgenden

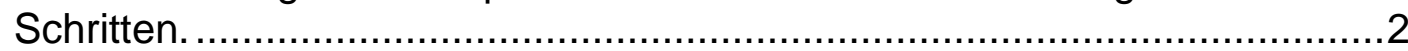

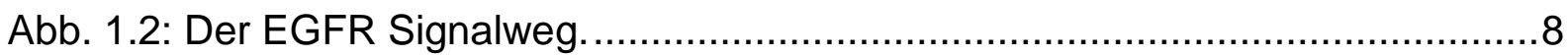

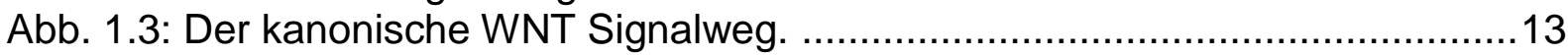

Abb. 1.4: Die nicht-kanonischen WNT Signalwege. .......................................... 15

Abb. 1.5: Experimentelle in vitro und in vivo Ansätze.......................................... 19

Abb. 3.1: Zellmorphologie der in Frage kommenden murinen Tumorzelllinien.........54

Abb. 3.2: Charakterisierung der murinen Tumorzellinien auf ihren basalen EGFRund $\beta$-Catenin-Status.

Abb. 3.3: Charakterisierung der murinen Tumorzelllinien auf Komponenten des WNT

Signalwegs.

Abb. 3.4: Epithelial-mesenchymale Charakterisierung der murinen Tumorzelllinien. 58

Abb. 3.5: Knockdown des EGFR in CMT-93.

Abb. 3.6: Proliferation, Invasion und Signalkaskadenuntersuchung des EGFR

Knockdowns in CMT-93.

Abb. 3.7: Überexpression des EGFR in 410.4 und CMT-93................................63

Abb. 3.8: Signalkaskadenuntersuchung der EGFR überexprimierenden Zellen.........64

Abb. 3.9: Invasion der EGFR überexprimierenden Zellen. ...................................65

Abb. 3.10: Knockdown des $\beta$-Catenins in 410.4 und CMT-93..............................66

Abb. 3.11: Die Invasion und Aktivierung des kanonischen WNT Signalwegs des $\beta$ -

Catenin Knockdowns in 410.4.

Abb. 3.12: Überexpression des $\beta$-Catenins in 410.4 und CMT-93...........................68

Abb. 3.13: Wnt11 Expression in Mamma- und kolorektalen Karzinomzelllinien. ........70

Abb. 3.14: Einfluss von WNT11 auf die Invasion und Proliferation in 410.4 ….........71

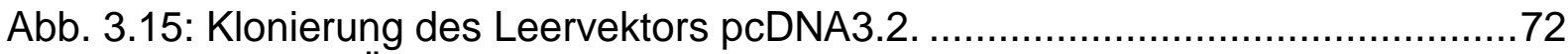

Abb. 3.16: WNT11 Überexpression in 410.4 ..................................................73

Abb. 3.17: Einfluss von WNT11 auf die Invasion, Proliferation und das

anheftungsunabhängige Wachstum in 410.4 .......................................74

Abb. 3.18: Einfluss von WNT11 auf die Adhäsion an ECM und FN und das Aktin-

Zytoskelett in 410.4 .........................................................................75

Abb. 3.19: Einfluss von WNT11 auf die Aktivierung des kanonischen und nicht-

kanonischen WNT Signalwegs in 410.4 ............................................76

Abb. 3.20: Einfluss von WNT11 auf die Aktivierung des PI3K Signalwegs in 410.4..77

Abb. 3.21. ROR2 Überexpression in 410.4 ......................................................78

Abb. 3.22: Einfluss von ROR2 auf Invasion, Proliferation, anheftungsunabhängige

Wachstum und Adhäsion in 410.4 ....................................................79

Abb. 3.23: Einfluss von ROR2 auf die Aktivierung des WNT Signalwegs und die

Expression von EMT-Markern in 410.4.

Abb. 3.24: Einfluss von ROR2 auf die Aktivierung des PI3K Signalwegs in 410.4 ...82

Abb. 3.25: Zusammenfassung der Ergebnisse von CMT-93 im Mausmodell .............83

Abb. 3.26: Cadherin16 Expression in Tumorzelllinien und in Geweben...................... 84

Abb. 3.27: Vergleich der CMT-93 Zelllinien auf die Aktivierung des kanonischen WNT

Signalwegs. 


\section{Tabellenverzeichnis}

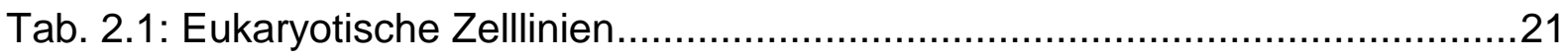

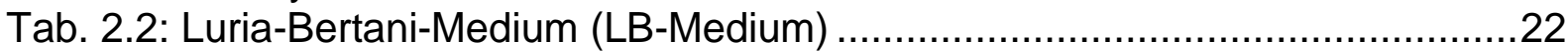

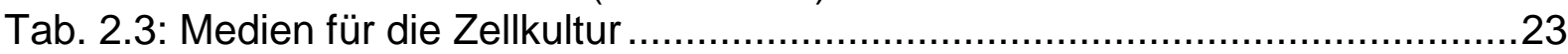

Tab. 2.4: Antibiotika für eukaryotische Zelllinien ...............................................23

Tab. 2.5: Chemikalien und rekombinante Proteine.............................................24

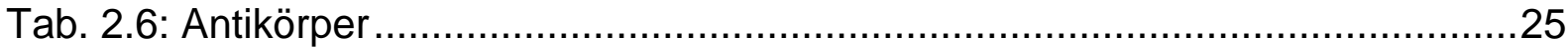

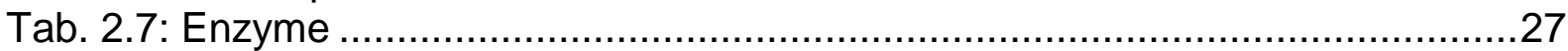

Tab. 2.8: Oligonukleotide für die qRT-PCR-Reaktionen ...................................27

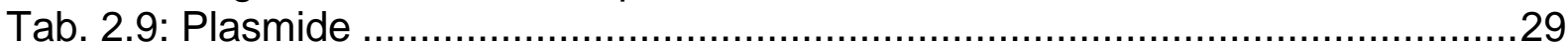

Tab. 2.10: Kommerzielle Kits und Standards .....................................................

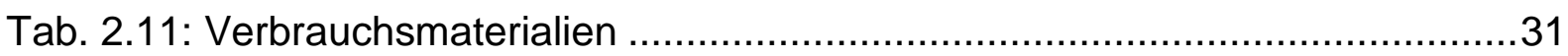

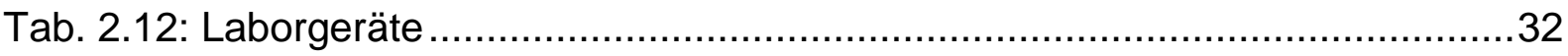

Tab. 3.1: Zusammenfassung der Ergebnisse zur molekularen Charakterisierung der murinen Tumorzelllinien. 


\section{Abkürzungsverzeichnis}

Abb.

Abbildung

AKT

Proteinkinase B

$A P C$

adenomatous-polyposis-coli

APS

Ammoniumpersulfat

ATCC

American Type Cell Collection

BCA

Bicinchoninsäure

bidest.

deionisiert

$\mathrm{BMBF}$

Bundesministerium für Bildung und Forschung

BRAF

$B$-Raf proto-ongogene

BSA

Bovine (Rinder-) Serumalbumin

bspw.

beispielsweise

bzgl.

bezüglich

bzw.

beziehungsweise

ca.

circa

$\mathrm{Ca}^{2+}$

Calcium

$\mathrm{CaCl}_{2}$

Calciumchlorid

CamKII

Ca2+/calmodulin-dependent protein kinase II

cdc42

Cell division cycle 42

cDNA

komplementäre DNA

Cdh

Cadherin

cGMP

zyklisches Guanosinmonophosphat

C-jun

jun Onkogen

CK1

Casein-Kinase 1

$\mathrm{CO}_{2}$

Kohlenstoffdioxid

CTNNB1

Catenin Beta 1 (Cadherin-associated Protein),

$\mathrm{C}_{\mathrm{t}}$-Wert

threshold cycle

DAG

Diacylglycerin

DAPI

4',6-Diamidino-2-phenylindol

DEP Domäne

Dishevelled, Egl-10 and Pleckstrin domain

DEPC

Diethylpyrocarbonat

d.h.

das heißt

DKK

Dickkopf

DMSO

dimethyl sulfoxide

DNA

Desoxyribonukleinsäure, desoxyribonucleic acid

dNTP

Desoxynukleotidtriphosphat 
dT

DTT

DVL

ECL

ECM

E. coli

EDTA

$\mathrm{EGF}(-\mathrm{R})$

EGFP

EMT

ER

ErbB1

ERK 1/2

et al.

$\mathrm{EtOH}$

FAP

FKS (FCS)

FN

fw

$\mathrm{Fz}$

GAPDH

GDP / GTP

GOI

GSK3 $\alpha / \beta$

h

hs

$\mathrm{H}_{2} \mathrm{O}$

$\mathrm{HCl}$

HER2

HK

HRP

$\mathrm{IP}_{3}$

JNK

K-RAS

LB

LEF

LP
Desoxythymidine

Dithiothreitol

dishevelled

enhanced chemiluminescence

Extrazelluläre Matrix; extra cellular matrix

Escherichia coli

Ethylendiamintetraacetat

epidermal growth factor (receptor)

enhanced green fluorescent protein

Epithelial-mesenchymale Transition

Östrogen

epithelial growth factor receptor

extracellular signal-regulated kinases 1/2

et aliae/et alii (und andere)

Ethanol

Familiäre Adenomatöse Polypse

Fötales Kälberserum, (fetal calf serum)

Fibronektin

Forward (Primer)

frizzled

Glyceraldehyde-3-Phosphate Dehydrogenase

Guanosindi(tri)phosphat

Gen von Interesse

Glykgensynthase-Kinase $3 \alpha / \beta$

hours

homo sapiens

Wassermolekül

Chlorwasserstoff

human epidermal growth factor receptor 2

Housekeeping Gene

horseradish peroxidase, Meerrettichperoxidase

Inositoltrisphosphat

$\mathrm{c}$-jun-N-terminale-Kinase

Kirsten rat sarcoma

Luria-Bertani-Medium

lymphoid enhancer factor

Lipoprotein 
LRP

N-RAS

MAPK

$\mathrm{MgCl}_{2}$

MEK 1/2

MET

MKK7

$\operatorname{MMP}(\mathrm{s})$

MMTV

MTT

$\mathrm{mm}$

$\mathrm{n}$

$\mathrm{NaCl}$

$\mathrm{NaOH}$

n.e.

NFAT

$\mathrm{Nr}$.

ns. ctrl.

OD

$\mathrm{p}$

PAGE

PBS

PCP

PCR

PDE

PDZ Domäne

PFA

$\mathrm{pH}$

$\mathrm{PI} 3 \mathrm{~K}(\mathrm{CA})$

$\mathrm{PIP}_{2} / \mathrm{PIP}_{3}$

PKC

PKG

PLC

PR

$\mathrm{P} / \mathrm{S}$

PVDF low density lipoprotein receptor related protein

Neuroblastoma RAS

mitogen-activated protein kinase

Magnesiumchlorid

mitogen-activated protien kinase kinase 1/2

Mesenchymal-epitheliale Transition

mitogen-activated protein kinase kinase 7

Matrix-Metalloproteinase(n)

mouse mammary tumor virus

3-(4,5-Dimethylthiazol-2-yl)-

2,5-diphenytetrazoliumbromid

mus musculus

Umfang der Stichprobe

Natriumchlorid

Natriumhydroxid

nicht exprimiert

nuclear factor of $T$ cells

Nummer

non-silencing control

optische Dichte

Signifikanzwert

Polyacrylamid-Gelelektrophorese

Phosphat-gepufferte Salzlösung, phosphate buffered saline planar cell polarity

Polymerase-Kettenreaktion, polymerase chain reaction

Phosphodiesterase

PSD-95, Dlg and ZO-1 domain

Paraformaldehyd

potentia Hydrogenii

Phosphoinositol-3-Kinase (catalytic, alpha polypeptide)

Phosphatidylinositol-4,5-bisphosphat / -triphosphat

Proteinkinase $\mathrm{C}$

cGMP-abhängige Proteinkinase $\mathrm{G}$

Phospholipase C

Progesteronrezeptoren

Penicillin / Streptomycin

polyvinylidenflorid 
qRT-PCR quantitative real-time polymerase chain reation

rh

recombinant human

RAC1

rho family, small GTP binding protein

RAF

Rapidly Accelerated Fibrosarcoma

$\mathrm{RHOA}$

Ras homolog gene family, member $A$

RIPA

radioimmunoprecipitation assay

RNA

Ribonukleinsäure, ribonucleic acid

ROCK

ROR 1/2

Rho-associated, coiled-coil containing protein kinase

RT

Receptor tyrosine kinase-like orphan receptor $1 / 2$

$\mathrm{RTK}(\mathrm{s})$

Raumtemperatur

rv

Rezeptortyrosinkinase(n)

s.

Reverse (Primer)

S.

siehe

s. Abb.

Seite

SDS

siehe Abbildung

SFRP

Natriumdodecylsulfat, sodium dodecyl sulfate

Secreted frizzled-related proteins

S. 0.

siehe oben

Seq

Sequencing

S. u.

siehe unten

TAE

Tris-Acetat-EDTA

$\operatorname{TAM}(\mathrm{s})$

Tumor-assoziierte Makrophage(n)

TBP

TATA Box Binding Protein

TBS-T

Tris-Buffered Saline Tween-20

TCF

cell-specific transcription factor

TEMED

Tetramethylethylendiamin

TGF- $\alpha$

transforming growth factor - $\alpha$

Tris

Tris(hydroxymethyl)-aminomethan

u. a.

unter anderem; unter anderen

u. U.

unter Umständen

Upm

Umdrehung pro Minute

UV

Ultraviolett

Vim

Vimentin

WB

Western Blot

$w g$

wingless

WIF1

Wnt inhibitory factor 1

WNT

wingless type MMTV integration site 
Wo

Woche/n

WP

working project

z. B.

zum Beispiel

\section{Maßeinheiten:}

$\begin{array}{ll}\%(\mathrm{v} / \mathrm{v}) & \text { \% Volumen pro Volumen } \\ \%(\mathrm{w} / \mathrm{v}) & \text { \% Gewicht pro Volumen } \\ \mathrm{bp} & \text { base pairs } \\ \mathrm{cm} & \text { Zentimeter } \\ { }^{\circ} \mathrm{C} & \text { degree Celsius } \\ \mathrm{g} & \text { Gramm (Gewichtsangabe), g-force (Fallbeschleunigung) } \\ \mathrm{I} & \text { Liter } \\ \mathrm{m} & \text { Meter } \\ \mathrm{mm} & \text { Millimeter } \\ \mathrm{M} & \text { Molar } \\ \mathrm{min} & \text { Minuten } \\ \mathrm{ml} & \text { Milliliter } \\ \mathrm{mM} & \text { Millimolar } \\ \mathrm{ng} & \text { Nanogramm } \\ \mathrm{nm} & \text { Nanometer } \\ \mathrm{sec} & \text { Sekunden } \\ \mathrm{U} & \text { Unit } \\ \mathrm{V} & \text { Volt } \\ \end{array}$

\section{Metrische Präfix:}

$\begin{array}{ll}\text { k } & \text { kilo; } 10^{3} \\ \text { c } & \text { zenti; } 10^{-2} \\ \text { m } & \text { milli; } 10^{-3} \\ \mu & \text { mikro; } 10^{-6} \\ \text { n } & \text { nano; } 10^{-9}\end{array}$




\section{Einleitung}

\section{$1.1 \quad$ Metastasierung}

Über $90 \%$ der tumorassoziierten Todesfälle sind durch die Entwicklung von Metastasen und nicht durch den Primärtumor selbst bedingt (Sporn, 1996). Als Metastasierung bezeichnet man den Prozess der Ablösung maligner Zellen von einem Primärtumor und Bildung von Tochtergeschwülsten des ursprünglichen Tumors in anderen entfernten Organen (Schirrmacher, 1985). Sie wurde als eines der sechs typischen Merkmale von Krebszellen von Hanahan und Weinberg definiert (Hanahan und Weinberg, 2000). Die Metastasierung hat einen Einfluss auf die vitale Funktion des entsprechenden Organs und führt $u$. U. zu einem vollständigen Organversagen (Weinberg, 2006). Obwohl es Fortschritte in der Entwicklung von neuen therapeutischen Maßnahmen und interdisziplinären Behandlungskonzepten gibt, führt dies in der Regel nicht zur Heilung der Patienten. Eine kurative Behandlung von Metastasen kann nur einem Teil dieser Patienten angeboten werden, während für den Großteil der Betroffenen nur noch die Palliativtherapie übrig bleibt (Weigelt et al., 2005).

Der Prozess der Metastasierung besteht aus mehreren aufeinanderfolgenden Schritten und ist in der Abbildung (Abb.) 1.1 dargestellt. Der Prozess beginnt mit dem Wachstum des Primärtumors. Dies wird durch die Neoangiogenese unterstützt, die wiederum einen Teil der vielfältigen Tumor-Stroma-Interaktionen darstellt. Eine wichtige Voraussetzung für die lokale Invasion ist die Fähigkeit der Tumorzellen, die extrazelluläre Matrix (ECM) mit Hilfe von Proteasen zu degradieren und sich aus dem Zellverband abzulösen (Weber, 2008). An diesem proteolytischen Abbau können sich Makrophagen beteiligen, indem sie Matrix-Metalloproteasen (MMPs) synthetisieren und in das Stroma abgegeben (Hagemann et al., 2004). Die Ablösung der Tumorzellen aus dem Verband setzt noch weitere Eigenschaften voraus, die für die Invasion essentiell sind. In einem als epithelial-mesenchymale Transition (EMT) bezeichneten Prozess erleben epitheliale Zellen des Primärtumors eine Reihe von morphologischen Veränderungen wie Verlust von Zell-Zell-Kontakten, Zunahme in Zellbeweglichkeit und Motilität, Verlust von epithelialen Markern, und sie nehmen einen mesenchymalen Phänotyp an (Guarino et al., 2007). 
Der nächste Schritt ist die Intravasation der Tumorzellen, während sie die Gefäßwand durchqueren und in die Gefäße des Blutsystems gelangen. Eine Intravasation kann nur stattfinden, wenn die Tumorzellen sich über die Adhäsionsproteine an die Basalmembran anheften. Überleben sie die Zirkulation, bis sie das Kapillarbett des Zielorgans, z. B. Knochen, Lunge oder Gehirn, erreichen, treten sie aus der Zirkulation aus. Das Verlassen der Gefäße und die Invasion in das darunterliegende Stroma über Adhäsionsproteine werden als Extravasation bezeichnet, wonach die Tumorzellen teilweise eine mesenchymal-epitheliale Transition (MET) durchlaufen. Nach der Invasion in das Zielorgan können disseminierte Tumorzellen über eine längere Latenzzeit als ruhende Tumorzellen (Dormancy) verbleiben oder direkt eine Metastase ausbilden (Hedley et al., 2009). Dieser letzte Schritt der Kolonisation stellt die größte Herausforderung für die Tumorzellen dar. Im Tiermodell konnte gezeigt werden, dass trotz einer Inokulation von mehreren Millionen Tumorzellen in den Blutkreislauf letztendlich nur weniger als 0,01\% dieser zirkulierenden Zellen Metastasen induzieren (Luzzi et al., 1998). Die Voraussetzung für eine erfolgreiche Metastasierung ist die Fähigkeit zur Induktion von Angiogenese, Proliferation, Inhibition von Apoptose sowie die Abwehr von Immunzellen in der neuen Mikroumgebung (Bacac und Stamenkovic, 2008).

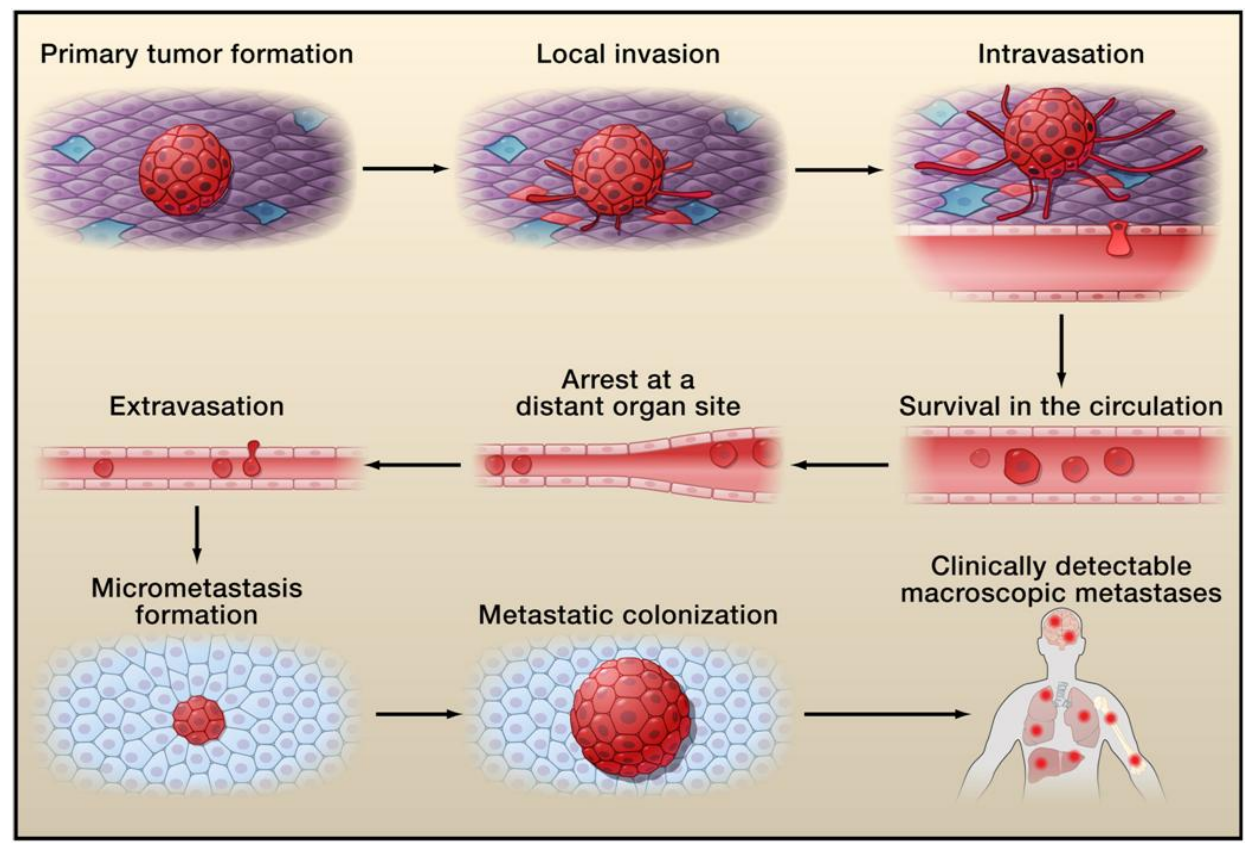

Abb. 1.1: Metastasierung - ein komplexer Prozess aus aufeinanderfolgenden Schritten.

Die Metastasierung ist ein komplexer Prozess aus mehreren aufeinanderfolgenden Schritten, der mit dem Wachstum des Primärtumors und mit der lokalen Invasion einzelner Tumorzellen beginnt. Die Tumorzellen durchqueren die Gefäßwand und gelangen in die Zirkulation des Blutsystems. Überleben sie die Zirkulation und gelangen in das Kapillarbett des Zielorgans, treten sie aus der Zirkulation aus, proliferieren in das Parenchym des angrenzenden Gewebes und bilden dort ein neues Tumorgewebe (Metastase). Abb. nach Valastyan und Weinberg (2011). 
Bereits im Jahr 1889 veröffentlichte der Chirurg Stephen Paget seine "Seed and Soil" Theorie, welche besagt, dass die Verteilung von Metastasen nicht dem Zufallsprinzip unterliegt, sondern dass bestimmte Organe bevorzugt werden. Er vergleicht die Tumorzellen mit Samen einer Pflanze, welche eine Sympathie für bestimmte Organe haben, weil sie den Samen ein kompatibles Milieu der Mikroumgebung, den fruchtbaren Boden, anbieten. Dieses Phänomen wird als Homing bezeichnet. Die häufigsten Zielorgane von Metastasen befinden sich in der Regel in dem dem Primärtumor nachgeschalteten Blutkreislauf wie z. B. Leber bei Kolonkarzinom und Lunge bei Nierenkarzinom. Viele Zielorgane besitzen eigene ortsständige Makrophagenpopulationen. Wie oben bereits erwähnt wurde, sind die Tumorassoziierten Makrophagen (TAMs) für die Metastasierung, insbesondere Schritte der Invasion und Intravasation, essentiell (De Nardo et al., 2008). Außerdem konnte im Mausmodell gezeigt werden, dass die metastasierenden Zellen bereits vor dem Schritt der eigentlichen Metastasierung ihr potentielles Zielorgan kennen (Hiratsuka et al., 2006). Es bleibt noch größtenteils unklar, ob die Bildung von Metastasen entweder durch die Eigenschaften des Primärtumors oder des Zielorgans vermittelt wird. Offenbar hängt die Lokalisation von Metastasen in den jeweiligen Organen von komplizierten Wechselwirkungen zwischen Signalwegen innerhalb der Tumorzellen sowie zwischen dem Primärtumor und der Mikroumgebung des Organs ab.

\subsection{Das Mammakarzinom}

Das Mammakarzinom ist der häufigste maligne Tumor bei Frauen in den westlichen Industrieländern und der weltweit zweithäufigste Tumor nach Lungenkrebs (Hutchinson, 2010). Das Mammakarzinom wird in nicht-invasive (Carcinoma in situ) und invasive Karzinome unterteilt. Entsprechend den histopathologischen Untersuchungen gibt es das duktale invasive Karzinom, welches $80 \%$ der Fälle ausmacht. Zusätzlich gibt es das lobuläre invasive Karzinom mit ca. 10\% und seltenere Formen. Etwa 5-6\% aller Mammakarzinome sind auf der Grundlage erblicher Faktoren entstanden, hauptsächlich durch Keimbahnmutationen im BRCA1/2 Gen (Malone et al., 1998).

Das gängige Modell der Karzinogenese beschreibt die Tumorprogression als einen mehrstufigen Prozess, der von der klonalen Expansion bis zum invasiven Karzinom und schließlich der Metastase reicht, und durch die sequenzielle Akkumulation von Mutationen gekennzeichnet ist (Fearon und Vogelstein, 1990). Die Charakterisierung 
des Mammakarzinoms erfolgt allerdings immer noch primär immunhistologisch über die Expression von Hormonrezeptoren, des HER2/neu (ErbB2/neu) Status und des Proliferationsmarkers (Ki67). Mit neueren Mikroarray-basierten Methoden lassen sich die Mammakarzinome nach Perou mindestens vier molekulare Subtypen unterscheiden (Perou et al., 2000): luminal A Subtyp, luminal B Subtyp, HER2/neupositive Subtyp und Hormonrezeptor- und HER2/neu-negative Subtyp mit oder ohne basalen Phänotyp (basal-like und normal-like). Diese Subtypen wirken sich auch auf die Überlebensprognose des Patienten aus (Sorlie et al., 2001).

Die Mehrheit der Mammakarzinome mit ca. 70\% weist eine Expression von Östrogen(ER) und/oder Progesteronrezeptoren (PR) auf (luminal A bzw. B). Diese kommen hauptsächlich bei älteren Frauen vor und haben eine bessere Prognose im Vergleich zu den Hormonrezeptor-negativen Subtypen (Dunnwald et al., 2007). Die Patienten werden mit einer endokrinen Therapie (z. B. Tamoxifen) behandelt und sprechen bis zu 80\% gut auf die Behandlung an (Senkus et al., 2013). Bei etwa 15-30\% aller Brustkrebspatientinnen liegt eine Amplifikation des Onkogens HER2 vor (Slamon et al., 1987). Obwohl dies mit einem aggressiveren Verlauf und folglich mit einer schlechteren Prognose einhergeht, haben neue HER2-spezifische Therapeutika wie der monoklonale Antikörper Trastuzumab die Prognose deutlich verbessert (Dawood et al., 2010; Saini et al., 2011). Der basal-like Subtyp ist negativ für ER, PR und HER2 und wird daher als triple-negativ bezeichnet. Dieser Typus der Tumore wird öfter bei jüngeren Frauen gefunden. Aufgrund der spezifischen biologischen Besonderheiten findet sich ein aggressiver Krankheitsverlauf. Diese Tumoren verursachen vermehrt Rezidive und sind vor allem einer endokrinen oder anti-HER2 Therapie nicht zugänglich und weisen somit eine schlechtere Prognose auf (Dunnwald et al., 2007).

Bis zu 15\% aller Brustkrebspatientinnen entwickeln Metastasen innerhalb von 3 Jahren nach der Primärtumordiagnose (Weigelt et al., 2005). Diese Metastasen werden bevorzugt in der Leber, der Lunge, dem Gehirn oder den Knochen gebildet (Lee, 1983). Der triple-negative Subtyp des Mammakarzinoms hat eine besondere Tendenz, in das Gehirn zu metastasieren (Dey et al., 2013). Danach beträgt die durchschnittliche Überlebenszeit zwischen 2-16 Monaten (Weil et al., 2005). Obwohl Fernmetastasen des Mammakarzinoms durchaus erfolgreich palliativ behandelt werden können, bedeutet das Auftreten von Hirnmetastasen immer noch eine sehr schlechte Prognose. Der Grund hierfür ist die verminderte Penetration vieler Chemotherapeutika und Antikörper durch die Bluthirnschranke (Neuwelt et al., 2008). 
Es ist daher von großer klinischer Bedeutung, die molekularen Grundlagen der Hirnmetastasierung genauer zu erforschen, um wirksame therapeutische Maßnahmen zu entwickeln.

\subsection{Das Kolorektalkarzinom}

Das Kolorektalkarzinom ist nach dem Lungen- und Mammakarzinom die dritthäufigste Krebserkrankung in den westlichen Industrieländern (Schmiegel et al., 2000). Mehr als $50 \%$ der westlichen Bevölkerung entwickeln bis zum 70. Lebensjahr kolorektale Adenome/ Polypen, wovon 10\% der Fälle in maligne Tumor übergehen (Kinzler und Vogelstein, 1996). Etwa 85-90\% aller Kolorektalkarzinome sind in der Regel Adenokarzinome, die sich aus Drüsenzellen des Darmepithels ableiten. Sonderformen sind das muzinöse Adenokarzinom mit einer Häufigkeit von etwa 10\% und das seltenere Siegelringkarzinom (1\%). Lediglich 5-10\% aller kolorektalen Karzinome sind durch erbliche Prädispositionen verursacht (Coleman und Tsongalis, 2006). Die häufigste erbliche Form des kolorektalen Karzinoms ist das HNPCC- (hereditary nonpolyposis colorectal cancer) Syndrom, welches durch Keimbahnmutationen in den Reparaturgenen, z. B. MSH1 und MCH1, entsteht (Kinzler und Vogelstein, 1996). Die seltenere Form ist die Familiäre Adenomatöse Polypose (FAP), die aus einer Inaktivierung des Tumorsuppressorgens APC (adenomatosis polyposis coli) resultiert.

Der Großteil aller malignen Kolonkarzinome (90-95\%) entwickelt sich jedoch sporadisch und verläuft durch eine aufeinanderfolgende Akkumulation von Mutationen in Tumorsuppressor- und/oder Onkogenen nach dem Adenokarzinom Modell nach Vogelstein (Fearon und Vogelstein, 1990; Vogelstein und Kinzler, 1993). Aufgrund von Berechnungen dieses Modells wird vermutet, dass minimal 6 Mutationen notwendig sind, bevor eine maligne Tumorzelle entstehen kann (Kinzler und Vogelstein, 1996). Aktuelle Arbeiten konnten zeigen, dass eine graduelle Anhäufung von Mutationen jedoch nicht in allen Zellen gleichermaßen vorliegt und dass es mehrere parallel verlaufende molekulargenetische Wege zur Entwicklung von Tumoren gibt (Alcock et al., 2003).

Ungefähr 80\% der kolorektalen Tumore weisen Mutationen im Tumorsuppressorgen $A P C$ auf, wodurch $\beta$-Catenin intrazellulär akkumuliert und somit der WNT Signalweg aktiviert wird (Smits et al., 1999). In etwa 10\% der kolorektalen Karzinome treten Mutationen direkt im CTNNB1 ( $\beta$-Catenin) Gen auf, die die für den Abbau notwendigen Phosphorylierungsstellen betreffen und somit eine konstitutive Aktivierung des WNT 
Signalwegs verursachen (Morin et al., 1997). Ein weiteres, in mehr als 70\% der kolorektalen Karzinome mutiertes Tumorsuppressorgen ist $p 53$, welches eine Rolle bei der Zellzyklus-Regulation und Apoptose spielt (lacopetta, 2003). Des Weiteren können die Onkogene $K-R A S$ in $40-50 \%$ und N-RAS in 3-5\% aller Kolorektalkarzinome mutiert sein (Bos et al., 1987; Schirripa et al., 2015), wodurch der MAPK (mitogen-activated protein kinase) Signalweg EGFR-unabhängig dauerhaft aktiviert wird und die Zellproliferation stimuliert (Smith et al., 2002). In Tumoren mit K-RAS-Wildtyp kann der EGFR Signalweg mit einer gegen den EGFR gerichteten Therapie, wie z. B. den Antikörpern Cetuximab oder Panitumumab, blockiert werden (Heinemann et al., 2009). Aufgrund der therapeutischen Relevanz fällt die Detektion des K-RAS- und N-RASStatus im kolorektalen Karzinom unter die Routinediagnostik. Bei der Progression des kolorektalen Karzinoms spielen u. a. auch Mutationen im PI3KC- und BRAF-Gen eine Rolle, was ebenfalls zu erhöhter Zellproliferation und Wachstum führt (Roock et al., 2010).

Bis zu 70\% der Patienten entwickeln Lebermetastasen synchron oder metachron innerhalb von 2 Jahren (Arnold et al., 2010). Je nach Stadium des Tumors kann eine chirurgische Resektion des Primärtumors und gegebenenfalls vorhandener Fernmetastasen als Therapie des kolorektalen Karzinoms erfolgen. Alle Patienten mit fortgeschrittener Erkrankung bekommen post-operativ verschiedene adjuvante Therapiemaßnahmen, wie z. B. eine Kombination aus Radio- und Chemotherapie. Im Gegensatz zum Mammakarzinom ist eine kurative Resektion von Lebermetastasen u. U. möglich und ermöglicht für die Patienten eine 5-Jahres-Überlebensrate von $40 \%$ (Jonas et al., 2007). Mehr als 50\% der operierten Patienten bilden allerdings Rezidive. Außerdem sind nur bei etwa $10-20 \%$ der Patienten die Metastasen resektabel. Aus diesem Grund besteht auch hier ein großer Bedarf, die molekularen Mechanismen zur Entstehung der Metastasierung zu verstehen.

Zur weiteren Abklärung dieser molekularen Mechanismen liegt der Fokus im Folgenden auf den EGFR und WNT Signalweg, da diese beiden Signalwege sowohl im Mamma- als auch im Kolonkarzinom eine besondere Bedeutung haben. 


\subsection{Der EGFR Signalweg}

Der epitheliale Wachstumsfaktorrezeptor EGFR oder ErbB1 (Cohen et al., 1980) gehört zur Familie der ErbB-Rezeptoren, welche neben dem EGFR noch aus den drei weiteren homologen Rezeptoren HER2/neu oder ErbB2 (Coussens et al., 1985), HER3 (ErbB3; Kraus et al., 1989) und HER4 (ErbB4; Plowman et al., 1993) besteht. Die ErbB-Rezeptoren stellen Transmembranrezeptoren mit Protein-TyrosinkinaseAktivität (Rezeptortyrosinkinasen, RTKs) dar und induzieren Proliferation, Zelldifferenzierung, Migration und Apoptose nach der Aktivierung des Rezeptors durch die Bindung der Liganden. Die Liganden der EGFR setzen sich aus EGF (epidermal growth factor), TGF- $\alpha$, Amphiregulin und Epigen zusammen (Prigent und Lemoine, 1992). In Abhängigkeit von den gebundenen Liganden bilden sich Homo- bzw. Heterodimere zwischen den verschiedenen Rezeptoren der ErbB-Familie aus und ermöglichen eine Aktivierung der intrazellulären Tyrosinkinasedomänen, wodurch eine Autophosphorylierung der Tyrosinresten der C-terminalen Region des Rezeptors ausgelöst wird (Olayioye et al., 2000). In Abhängigkeit von der Phosphorylierung werden intrazellulär verschiedene Signalproteine rekrutiert und somit verschiedene Signalwege downstream aktiviert. Der PI3K/AKT (Phosphoinositol-3Kinase/Proteinkinase B) und der MAPK Signalweg werden bevorzugt angeschaltet, wie in der Abb. 1.2 dargestellt.

Beim PI3K/AKT Signalweg wird PI3K durch die Bindung an phosphorylierten Stellen des Rezeptors phosphoryliert und damit aktiviert. Die katalytische Untereinheit der aktivierten PI3K, PIK3CA, setzt Phosphatidylinositol- 4,5-Bisphosphat ( $\left.\mathrm{PIP}_{2}\right) \mathrm{zu}$ Phosphatidylinositol-3,4,5-Trisphosphat ( $\left.\mathrm{PIP}_{3}\right)$ um, welches wiederum die Serin/Threoninkinase AKT (Proteinkinase B) durch Phosphorylierung aktiviert. Diese phosphoryliert erneut andere Signalproteine, die Überleben, Proliferation, Migration, Zellzyklus, Angiogenese und die Inhibition von Apoptose regulieren.

Beim MAPK Signalweg wird das Adapterprotein Grb2 (growth factor receptor-bound protein 2) mit seiner SH2 Domäne (Src-homology 2) an die phosphorylierten Tyrosinreste des Rezeptors rekrutiert. An Grb2 bindet der GDP/GTP-Austauschfaktor SOS (son of sevenless), und SOS aktiviert Ras durch den GDP/GTP-Austausch, wodurch die Serinkinase RAF aktiviert wird. RAF aktiviert MEK1/2 (mitogen-activated protein kinase kinase 1/2) durch die Phosphorylierung, welches zur Aktivierung von ERK1/2 (extracellular signal-regulated kinase 1/2) führt. Aktives ERK1/2 veranlasst 
Transkription vieler Gene, welche in der Zellmotilität und Zellzyklusprogression involviert sind.

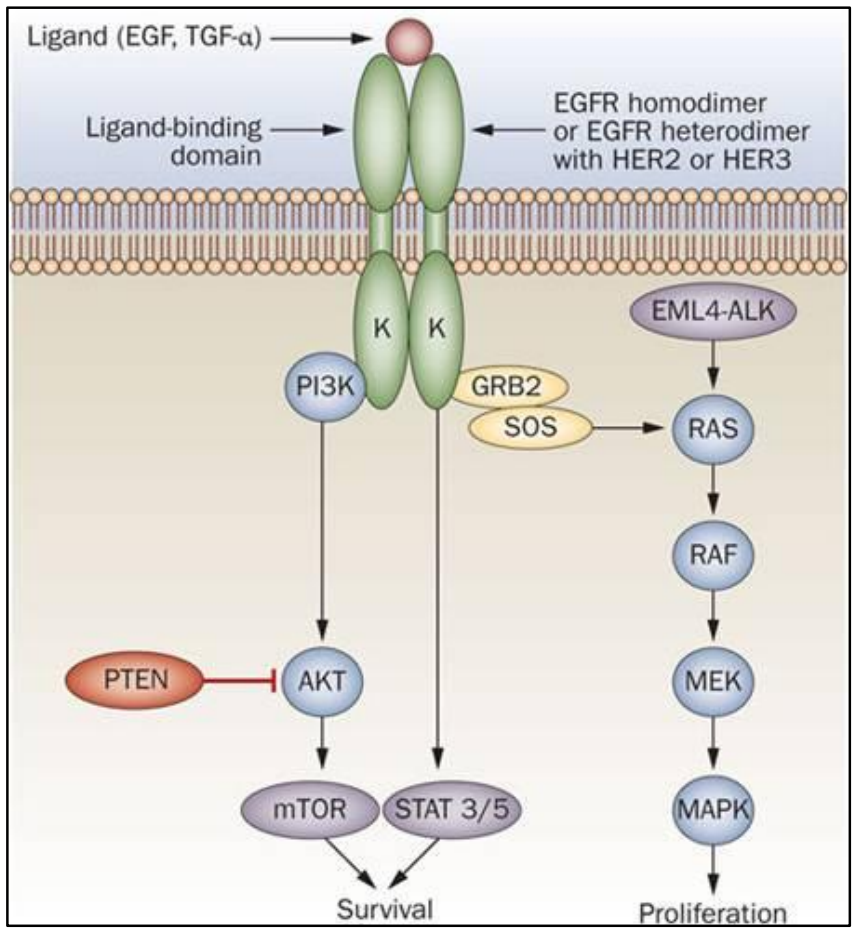

Abb. 1.2: Der EGFR Signalweg.

Durch die Bindung von spezifischen Liganden erfolgen die Dimerisierung der Rezeptoren und die Autophosphorylierung bestimmter Tyrosinreste der Kinasedomäne (K), wodurch spezifische Signalproteine rekrutiert und verschiedene Signalwege aktiviert werden. Die nachgeschaltete Signalkaskade vermittelt unterschiedliche Zellprozesse wie Proliferation, Migration und Invasion. Abb. nach Janku et al. (2010).

Zu den weiteren EGFR Signalwegen gehören die PKC (Proteinkinase C) und STAT(signal transducer and activator of transcription) Signalkaskaden, welche ebenso an Zellprozessen wie Zellproliferation, Differenzierung und Überleben beteiligt sind.

\subsubsection{Der EGFR Signalweg in der Tumorprogression}

Die Wichtigkeit des EGFR Signalwegs in der Tumorprogression und Metastasierung wurde bereits in mehreren Arbeiten beschrieben. Wie bereits oben beschrieben, die Aktivierung des EGFR Signalwegs reguliert zelluläre Prozesse wie Zellwachstum, Migration und Differenzierung. Eine Dysregulation des Signalwegs spielt aufgrund der beschriebenen Funktionen eine entscheidende Rolle bei der malignen Tumorprogression. Eine Überexpression von EGFR konnte vielfach in verschiedenen humanen Tumoren, u. a. in Lungen-, Kolon-, Mamma-, Prostata-, Ovarialkarzinom, in Kopf-Hals-Tumoren und Glioblastomen gezeigt werden und korreliert mit einer schlechteren Prognose (Moscatello et al., 1995; Nicholson et al., 2001). Zumeist liegt 
eine transkriptionelle Überexpression mit gesteigerter Proteinexpression vor (Bharagava et al., 2005). Eine solche Genamplifikation kann in etwa 50\% aller Glioblastome nachgewiesen werden (Wong et al., 1987) und ist nur in einem kleinen Teil, etwa 5\%, der Mammakarzinome berichtet (Bharagava et al., 2005). Eine Reihe von Mutationen in den Domänen des humanen EGF-Rezeptors ist beschrieben (Moscatello et al., 1995). Die häufigste Mutation entsteht durch eine Deletion der Exone 2-7, wodurch der Verlust der Ligandenbindedomäne (EGFRvIII) und somit eine konstitutive Aktivierung des EGFR Signalwegs induziert wird (Pedersen et al., 2001). Das EGFRvIII Protein ist vor allem (50\%) in Glioblastoma multiforme (Gan et al., 2009) und sehr selten (4\%) im Mammakarzinom nachzuweisen (Nieto et al., 2007). Eine Überexpression von EGFRvIII in humanen Glioblastom Zellen zeigt eine erhöhte Tumorprogression, indem die Zellproliferation und die Inhibition der Apoptose beeinflusst werden (Nagane et al., 1996; Nishikawa et al., 1994). Eine EGFR Überexpression kann mit der gleichzeitigen Erhöhung der ErbB Liganden als positiver Rückkopplungseffekt hervorgerufen werden (Ekstrand et al., 1991). Im Gegensatz zum EGFR ist in etwa 25\% aller Mammakarzinome der HER2 Rezeptor überexprimiert. Durch die Überexpression von HER2 können bei geringen EGF-Konzentrationen Heterodimere aus EGFR und HER2 gebildet und ständig Signale zur Proliferation und Zellteilung weitergeleitet werden. Diese Überexpression in Mammakarzinomen korreliert mit der Tumorprogression und ist folglich mit einer schlechten Prognose für die Patienten verbunden (Slamon et al., 1987). Eine Stimulation der humanen Tumorzellen mit EGF fördert die Zellmotilität und -migration, indem die Zell-ZellKontakte durch die Endozytose von E-Cadherin durchbrochen werden (Lu et al., 2003). Diese Störung der Zell-Zell-Interaktion erleichtert die EMT und die Zellmigration (Thiery und Sleeman et al., 2006). Die EGFR Aktivierung bewirkt eine verstärkte Expression der Matrix Metalloproteinase 9 (MMP9) in humanen Tumorzelllinien und fördert die Invasion der Tumorzellen in vitro (Zuo et al., 2011). Der Abbau der ECM wird durch die Interaktion mit Makrophagen verstärkt, welche die Invasivität der Tumorzellen steigert (Hagemann et al., 2004). Eine weitere Interaktion zwischen den beiden Zelltypen basiert auf von Makrophagen sezernierten EGF, welche wiederum die Invasion und Migration der Tumorzellen steigert (Goswami et al., 2005).

Das triple-negative Mammakarzinom ist oft mit einer Gehirnmetastasierung assoziiert (Heitz et al., 2009). In einer Studie an Patienten mit invasivem Brustkrebs, welche Gehirnmetastasierung entwickelten, war die Expression von EGFR und Zytokeratin5/6 
in den Tumoren, verglichen mit dem Kollektiv, das keine Hirnmetastasen aufweist, erhöht (Hicks et al., 2006). Eine EGFR Überexpression im Mammakarzinom wurde in $50 \%$ des triple-negativen Subtyps mit fortgeschrittenen Stadien der Metastasen nachgewiesen (Alvarez et al., 2010; Rimawi et al., 2010). Weiterhin konnten Bos et al. 17 Gene in zerebralen Metastasen des Mammakarzinoms identifizieren, einschließlich des EGF Rezeptors Ligand HB-EGF. Es konnte ebenfalls gezeigt werden, dass EGF selbst in Zellen des Mammakarzinoms, die in das Gehirn metastasiert waren, im Vergleich zu Zellen des Primärtumors deutlich hochreguliert ist (Bos et al., 2009). Damit spielt der EGF Signalweg nicht nur in den ersten Schritten der Tumorprogression, sondern auch im letzten Schritt der Kolonisation eine entscheidende Rolle.

Eine Mutation von EGFR in kolorektalen Karzinomen ist derzeit nicht beschrieben (Barber et al., 2004), dennoch ist der EGFR Signalweg beim Kolonkarzinom am häufigsten dereguliert. Das Onkogen $K-R A S$ ist allerdings in bis zu $50 \%$ aller Kolorektalkarzinome (Bos et al., 1987) und $N$-RAS in selteneren Fällen mit 5\% mutiert (Schirripa et al., 2015), wodurch unabhängig von einer Stimulation über EGFR zelluläre Prozesse wie Zellproliferation und -differenzierung konstitutiv stimuliert werden (Smith et al., 2002). In etwa 5-10\% aller kolorektalen Karzinome liegt eine Mutation im BRAF-Gen vor, welche ebenfalls EGFR-unabhängig zu erhöhter Zellproliferation und Wachstum führt und oft sehr aggressiv verläuft (Roock et al., 2010). Eine andere Mutation im PI3KCA kommt in etwa 14-18\% aller kolorektalen Tumoren vor, welche ebenso wie die anderen Mutationen EGFR-unabhängig eine konstitutive Aktivierung des EGFR Signalwegs resultiert. Diese Mutationen stimulieren letztendlich zelluläre Prozesse wie Proliferation, Wachstum und Differenzierung. Die RAS Mutationen der Kolorektalkarzinome zeigen eine signifikant hohe Inzidenz für Lungen-, Knochen- und Hirnmetastasen (Yaeger et al., 2014).

In $80-97 \%$ aller kolorektalen Karzinome mit fortgeschrittenen Stadien konnte eine EGFR Überexpression nachgewiesen werden, welche mit einer schlechteren Prognose der Patienten assoziiert waren (Spano et al., 2005). Es konnte ebenfalls gezeigt werden, dass die EGFR Expression in humanen kolorektalen Tumorzelllinien das Risiko für die Bildung von Lebermetastasen erhöht (Radinsky et al., 1995). 
In beiden Tumorentitäten spielt der EGFR Signalweg eine wichtige Rolle in fortgeschrittenen Stadien der Tumorprogression und bewirkt folglich eine schlechte Prognose für die Patientinnen.

\subsection{Der WNT Signalweg}

Die Wnt Moleküle gehören zu einer evolutionär hoch konservierten Familie von Signalmolekülen, welche sowohl in der Embryonalentwicklung das Zellwachstum als auch im adulten Organismus die Homöostase unterschiedlicher Gewebe koordinieren (Clevers, 2006). Ursprünglich wurde das wingless (wg) Gen der Fruchtfliege Drosophila melanogaster in der Segmentpolarisierung während der Larvenentwicklung identifiziert (Nüsslein-Volhard und Wieschaus, 1980). Einige Jahre später wurde das Wnt Molekül Int-1 als Integrationsstelle für das mouse mammary tumor virus (MMTV), welches Mammakarzinom in einem Mausmodell induziert, beschrieben (Nusse und Varmus, 1982). Rijsewijk et al. konnten zeigen, dass das wg Gen und das murine Protoonkogen Int-1 homolog sind (Rijsewijk et al., 1987). Aus den Begriffen wingless und Int-1 ergab sich die Bezeichnung Wnt1, wodurch der Name für die Familie der Wnt Gene geprägt wurde.

Derzeit konnten 19 verschiedene Wnt Gene in den Säugetieren identifiziert werden, welche für sekretierte Cystein-reiche Glykoproteine mit einer Länge von 350-400 Aminosäuren kodieren. Diese posttranslationale Modifikation ist wichtig für ihre Funktionalität und die Freisetzung der Proteine (Willert et al., 2003). Sie vermitteln die Signalweiterleitung überwiegend als Kurzstrecken-Ligand sowohl autokrin als auch parakrin. Der hydrophobe Charakter der Wnt Proteine wird durch Palmitoylierung an konservierten Cysteinreste bewerkstelligt und erfordert verschiedene Transportmöglichkeiten der Wnt Moleküle, um den Konzentrationsgradienten aufzubauen. Die freigesetzten Proteine binden an Heparansulfat, ein Proteoglykan der Extrazellulären Matrix, und können direkt von Zelle zu Zelle transportiert werden (Yan und Lin, 2009). Neue Studien belegen, dass Wnt Moleküle nicht nur als KurzstreckenLigand gelten, sondern durchaus größere Distanzen überwinden können. Hierfür binden die Wnt Moleküle an Lipoproteinpartikel und werden somit solubilisiert (Panakova et al., 2005). Eine weitere Möglichkeit stellen extrazelluläre Membranvesikel wie Exosomen (50-100 nm) und Mikrovesikel (100-1000 nm) dar. Dabei werden Wnt Moleküle in einem Komplex mit sog. Cargo-Proteinen, wie z. B. Evi, von einer Zelle zur anderen transferiert (Gross et al., 2012; Menck et al., 2013). Die 
Wnt Moleküle können an verschiedene Rezeptoren binden. Die Aktivierung des WNT Signalwegs ist wesentlich vom Rezeptor und zellulären Kontext abhängig. Traditionell werden die WNT Signalwege in zwei Klassen eingeteilt, den kanonischen und den nicht-kanonischen WNT Signalweg.

\subsubsection{Der kanonischer WNT Signalweg}

Der kanonische WNT Signalweg ist der bekannteste und am besten erforschte Signalweg, und die zentrale Komponente des Signalwegs ist der Kotranskriptionsfaktor $\beta$-Catenin (Clevers, 2006). Daher wird er auch als „klassischer" oder $\beta$-Catenin-abhängiger Signalweg bezeichnet. Wnt1, Wnt3 und Wnt8a stellen die klassischen Vertreter des kanonischen WNT Signalwegs dar (Rigo-Watermeier et al., 2012).

\subsubsection{Der inaktive Zustand}

In der Abwesenheit der Wnt Liganden liegt $\beta$-Catenin in einem Degradationskomplex gebunden vor, der aus den Proteinen AXIN, APC, CK1 (Casein-Kinase 1) und GSK3 $\alpha / \beta$ (Glykogensynthase-Kinase 3 $\alpha / \beta$ ) besteht. In diesem Komplex phosphoryliert CK1 vorerst cytosolisches $\beta$-Catenin an Serin45, und anschließend erfolgt die Phosphorylierungen an Thyrosin41, Serin37 und Serin33 durch GSK3 $\alpha / \beta$ (Liu et al., 2002). Aufgrund der mehrfachen Phosphorylierungen wird $\beta$-Catenin von $\beta$ - $\operatorname{TrCP}(\beta$ transducin repeats containing protein), einer Komponente der Ubiquitin Ligase, ubiquitinyliert, wodurch $\beta$-Catenin zur Degradation im 26S Proteasom markiert wird (Aberle et al., 1997). Aufgrund des Abbaus von $\beta$-Catenin kommt es zur Erniedrigung der freien cytosolischen und nukleären Konzentration dieses Proteins, welche zur Inhibition der Expression der Wnt Targetgene im Zellkern führt (s. Abb. 1.3 a).

\subsubsection{Der aktive Zustand}

Die bereits beschriebenen Wnt Moleküle haben eine Vielzahl von Bindungspartnern an der Zelloberfläche. Beim kanonischen WNT Signalweg besteht der Rezeptorkomplex aus einem Mitglied der Sieben-TransmembrandomänenRezeptoren der Fz (Frizzled)-Familie und den Ko-Rezeptoren LRP5 bzw. LRP6 (lipoprotein related protein 5/6) (Pinson et al., 2000). 


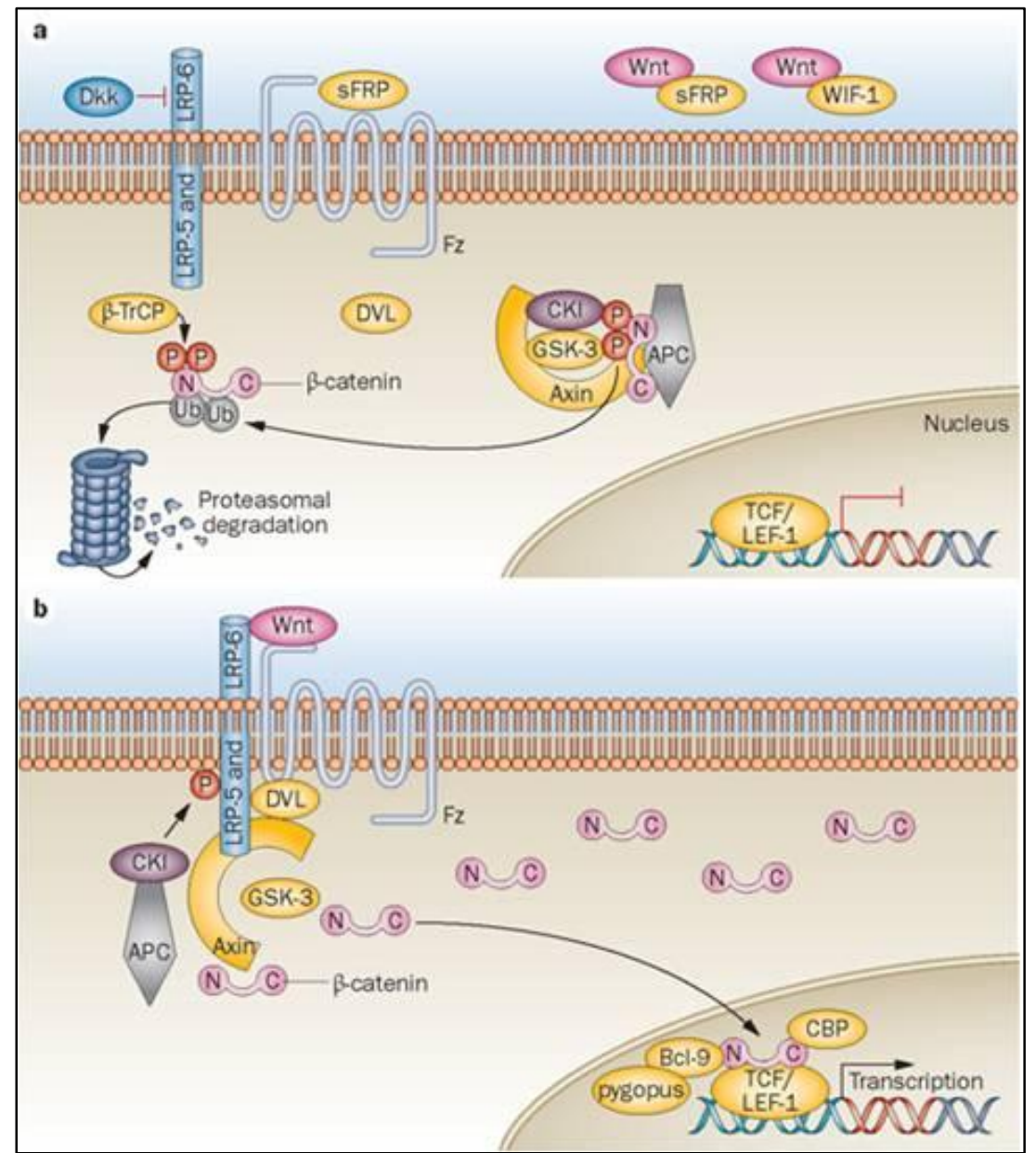

Abb. 1.3: Der kanonische WNT Signalweg.

a) Im inaktiven Zustand, d.h. in Abwesenheit der Wnt Liganden, wird $\beta$-Catenin durch den Degradationskomplex phosphoryliert, als Folge wird das Protein durch das Proteasom degradiert. b) Nach Aktivierung des Signalwegs durch Bindung eines Wnt Liganden wird die Phosphorylierung von $\beta$ Catenin inhibiert, wodurch das Protein im Zytoplasma akkumuliert und in den Zellkern transloziert wird. Die Interaktion mit LEF/TCF-Transkriptionsfaktoren aktiviert die Transkription der entsprechenden Targetgene. Abb. nach Kypta und Waxman (2012).

Die Aktivierung des Signalwegs erfolgt über die Bindung von Wnt Molekülen an den Rezeptorkomplex und bewirkt die Rekrutierung des zytoplasmatischen Proteins DVL (dishevelled) an Fz und die Hyperphosphorylierung des Proteins durch CK1, wodurch

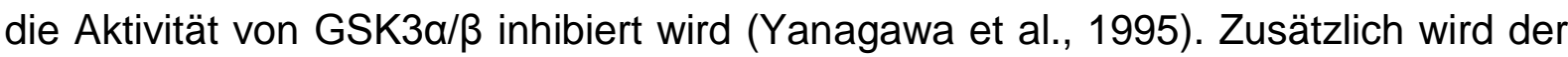
Ko-Rezeptor LRP5/6 durch CK1 und GSK3 $/ \beta$ phosphoryliert, womit eine Bindungsstelle für Axin geschaffen wird und es zur Anlagerung von Axin an den zytoplasmatischen Teil von LRP5/6 kommt (Tamai et al., 2004). Die Rekrutierung von Axin an LRP5/6 und phosphoryliertes DVL führen zu einem Abbau von Axin und insgesamt zu einer Dissoziation des Degradationskomplexes (Clevers, 2006). Dadurch wird $\beta$-Catenin nicht mehr phosphoryliert, und so im Zytoplasma akkumuliertes $\beta$-Catenin wird in den Zellkern transportiert (Staal et al., 2002). Im Zellkern interagiert der Ko-faktor $\beta$-Catenin mit Transkriptionsfaktoren der LEF/TCF 
(lymphoid enhancer factor/T cell factor)-Familie mit weiteren Aktivatoren und initiert die Transkription der zahlreichen Targetgene (Behrens et al., 1996) (s. Abb. 1.3 b). Beispiele für primäre Targetgene sind die Onkogene c-Myc und c-Jun und die den Zellzyklus regulierende Kinase Cyclin D1 (He et al., 1998; Mann et al., 1999; Tetsu und McCormick, 1999). Die primären und die sekundären Targetgene kodieren Proteine mit sehr unterschiedlichen Funktionen, welche in verschiedene Gruppen zusammengefasst werden. Diese Gene gehören zu der Gruppe der Zellproliferation bzw. des Zellzyklus, der Apoptose, der Zelladhäsionsmoleküle, der Gewebereorganisation bzw. Tumorprogression und der Feedback Mechanismen des WNT Signalwegs.

Entsprechend ihrer vielfältigen Funktionen erfordert eine disziplinierte Aufrechterhaltung der Wnt-Homöostase. Eine Hemmung des WNT Signalwegs kann durch zwei unterschiedliche Klassen der Wnt-Inhibitoren hervorgerufen werden. Die erste Klasse umfasst die Proteine der Dickkopf (DKK)-Familie, welche an die KoRezeptoren LRP5/6 binden und so die Interaktion mit Fz verhindern (Glinka et al., 1998). Zu der zweiten Klasse gehören die SFRPs (soluble frizzled-related proteins), WIF1 (Wnt inhibitory factor 1) und Cerberus sequester, welche die freien WNT Moleküle komplexieren und so ihre Bindung an den Rezeptor unterdrücken. SFRPs können u. a. auch direkt an den Fz Rezeptor binden und so den WNT Signalweg inhibieren (Lin et al., 1997; s. Abb. 1.3 a).

\subsubsection{Die nicht-kanonischen WNT Signalwege}

Die Signaltransduktion des nicht-kanonischen WNT Signalwegs ist $\beta$-Cateninunabhängig und wird grob in zwei Signalkaskaden unterteilt, den PCP (planar-cellpolarity) Signalweg und den WNT/Calcium Signalweg (s. Abb. 1.4 A). Diese Signalwege werden durch die Bindung von nicht-kanonischen Wnts sowie Wnt4, Wnt5a und Wnt11 an Fz Rezeptoren (Rigo-Watermeier et al., 2012) und die Aktivierung des Proteins DVL stimuliert. Als Ko-Rezeptoren für die nicht-kanonischen WNT Signalwege sind u. a. Ror2 (Receptor tyrosine kinase-like orphan receptor 2) (Minami et al., 2010) und Ryk (receptor-like tyrosine kinase; Kim et al., 2008) beschrieben. Diese Ko-Rezeptoren können außerdem Fz-unabhängig durch die Bindung von nicht-kanonischen Wnts Signale weiterleiten (s. Abb. 1.4 B).

Wie bereits erwähnt, gehört WNT11 zu dem Vertreter der nicht-kanonischen WntLiganden und aktiviert den PCP, Wnt/Calcium oder JNK (JUN-N-terminale Kinase) 
Signalweg. Aus der Vielzahl der möglichen Rezeptor-Konstellationen kann WNT11 mehr als einen Typ des WNT Signalwegs aktivieren. Eine Interaktion von WNT11 mit $\mathrm{Fz}$ ist essentiell für die Regulation der konvergenten Extension während der Gastrulation in Vertebraten (Habas et al., 2003). Weitere nennenswerte Rezeptoren von WNT11 sind Ror2, Ryk oder Glypican 4, welche downstream den nichtkanonischen Wnt Signalweg stimulieren (Hikasa et al., 2002). Alle Signalwege regulieren die Zellmigration bzw. Zellpolarität und vermitteln somit Veränderungen in der Zellmorphologie (Van Amerongen, 2012).

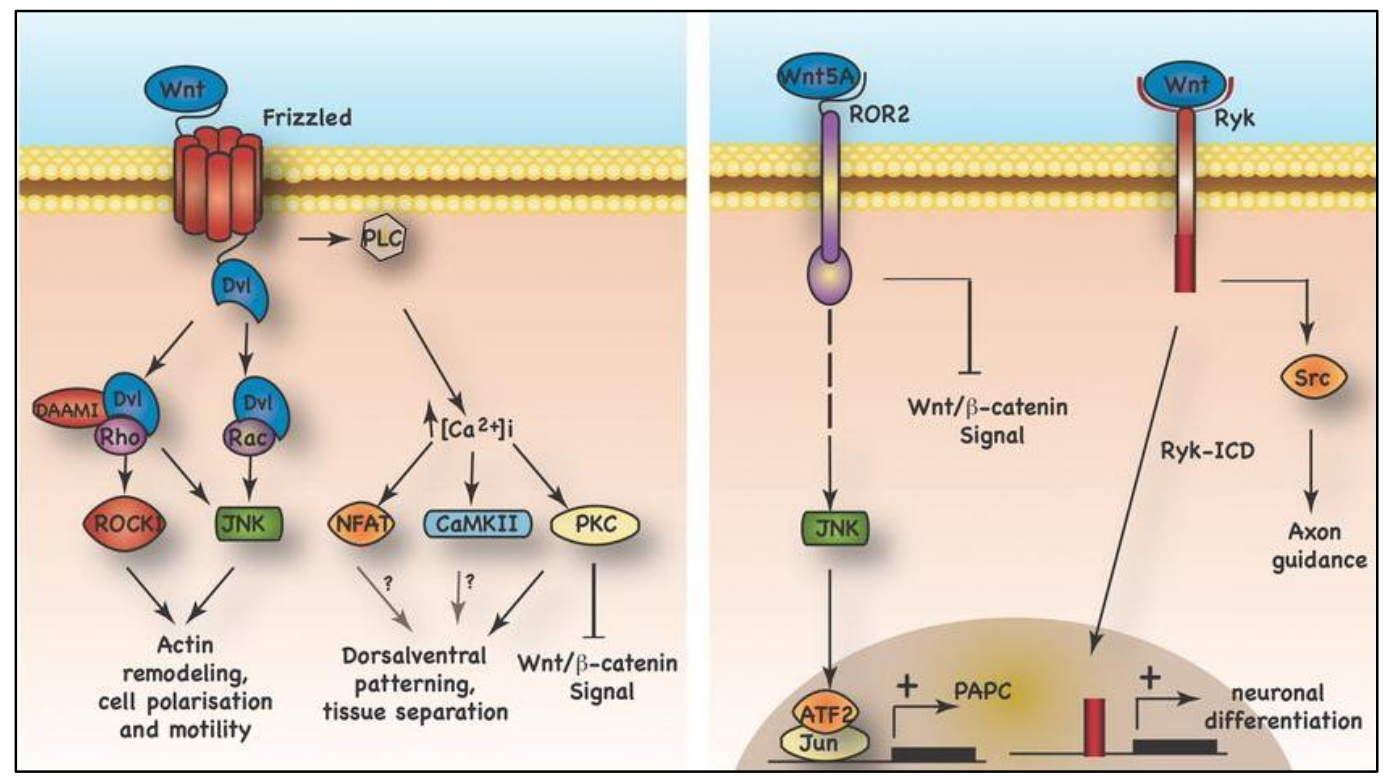

Abb. 1.4: Die nicht-kanonischen WNT Signalwege.

A) Der PCP Signalweg führt zur Aktivierung der kleinen GTPasen RHOA und RAC1, wodurch die Kinasen ROCK und JNK aktiviert werden. Diese vermitteln die Strukturierung des Zytoskelettes und Veränderungen der Zelladhäsion und -motiliät. Der Wnt/Calcium Signalweg induziert eine erhöhte intrazelluläre $\mathrm{Ca}^{2+}$ Konzentration, wodurch die Aktivierung der PKC, CamKII und der Phosphatase Calcineurin vermittelt wird. B) Die Wnt Moleküle können u. a. an Rezeptoren wie ROR2 und Ryk binden und das Signal intrazellulär weitereiten. Abb. nach Sethi und Vidal-Puig (2010).

\subsubsection{Planar-Cell-Polarity Signalweg}

Die Aktivierung des PCP Signalwegs rekrutiert DVL an den zytoplasmatischen Teil des Fz Rezeptors und erfolgt über zwei distinkte Domänen von DVL. Die DEP Domäne von DVL aktiviert die kleine GTPase RAC1, wodurch das Effektorprotein JNK aktiviert wird und dieses daraufhin den Transkriptionsfaktor c-Jun phosphoryliert und somit die Transkription zahlreicher Gene initiiert (Boutros et al., 1998). Alternativ interagiert das Protein Daam (Dishevelled associated activator of morphogenesis) mit DVL (PDZ Domäne) und führt zur Aktivierung der kleinen GTPase RHOA (Ras-Homologue Gene Family Member A), welche wiederum die Kinase ROCK (RHO-Associated Coiled-CoilContaining Protein Kinase) aktiviert (Habas et al., 2003). Sowohl RHOA als auch Rac 
regulieren die planare Zellpolarität und die Reorganisation des Aktin Zytoskelettes als Voraussetzung für die Zellmigration (s. Abb. 1.4 A).

\subsubsection{WNT/Calcium Signalweg}

Der WNT/Calcium Signalweg kann durch die Bindung der Wnt Moleküle an Fz Rezeptoren aktiviert werden, wodurch DVL an den Rezeptor rekrutiert wird. Es kommt zu einer Dissoziation eines rezeptorständigen heterotrimeren G-Proteins. Durch die freigesetzten $\beta / \gamma$-Untereinheiten werden die Phospholipase $C$ (PLC) aktiviert, welche Phosphatidylinositol-4,5-bisphosphat ( $\left.\mathrm{PIP}_{2}\right)$ zu Diacylglycerol (DAG) und Inositol1,4,5-trisphosphat $\left(\mathrm{IP}_{3}\right)$ spalten. Der sekundäre Messenger IP $\mathrm{P}_{3}$ bewirkt einen erhöhten intrazellulären $\mathrm{Ca}^{2+}$ Spiegel, in dessen Folge durch DAG die Calcium-sensitive Proteinkinase $C$ (PKC) aktiviert werden kann. Zum anderen führt der Anstieg der $\mathrm{Ca}^{2+}$ Spiegel zur Aktivierung anderer Calcium-sensitiven Proteine wie Calmodulinabhängigen Proteinkinase II (CamKII) und der Proteinphosphatase Calcineurin, welche den Transkriptionsfaktor nuclear factor of T cells (NFAT) dephosphoryliert und so die Genexpression im Zellkern reguliert (Kühl et al., 2000). Die $\alpha$-Untereinheit des G-Proteins aktiviert die Phosphodiesterase (PDE), welche einen Abfall des cGMPSpiegels bewirkt, wodurch die cGMP abhängige Guanylcyclase, PDEs und die Proteinkinase G (PKG) aktiviert werden (Wang und Malbon, 2004) (s. Abb. 1.4 A).

\subsubsection{WNT/ROR2 Signalweg}

Der nicht-kanonische Wnt5a/Ror2 Signalweg kann durch die Bindung von Wnt5a an den Transmembranrezeptor ROR2 Mitglied der Rezeptortyrosinkinasen aktiviert werden (Mikels und Nusse, 2006; Oishi et al., 2003). Dieser Signalweg hat einen starken Einfluss auf die konvergenten Extension und das Migrationsverhalten einer Zelle. Die Signalweiterleitung erfolgt über die Phosphoinositide 3 Kinase (PI3K), Cell division cycle 42 (cdc42) und MKK7 und führt zur Aktvierung der JNK Signalkaskade. JNK vermittelt die Aktivierung der Transkriptionsfaktoren ATF2 (activating transcription factor 2) und c-Jun und initiiert somit die Expression des Paraxialen Protocadherins (PAPC) (s. Abb. 1.4 B). Dieser Signalweg hat somit einen starken Einfluss auf die Koordination der Zellpolarität (Schambony und Wedlich, 2007). In Vertebraten kann der ROR2 Signalweg zur Inhibition des $\beta$-Catenin-abhängigen Wnt Signalweg führen. 


\subsubsection{Der WNT Signalweg in der Tumorprogression}

Der WNT Signalweg spielt eine wichtige Rolle in der Embryonalentwicklung und in der Homöostase von Geweben, der u. a. die Zellproliferation und Zellmigration beeinflusst. Eine Deregulation des Signalwegs fördert dementsprechend die Tumorentstehung und -progression, welche durch vermehrtes Zellwachstum und -motilität bedingt sind. Mutationen des Tumorsuppressorgens $A P C$ wurden ursprünglich in Patienten mit dem hereditären Syndrom FAP identifiziert, bei dem sich hunderte kleine Polypen im Dickdarm ausbilden, welche sich ohne Behandlung zu malignen Kolonkarzinomen entwickeln (Kinzler und Vogelstein, 1996). In ungefähr 80\% der sporadisch entwickelten kolorektalen Karzinome konnten diese Mutation nachgewiesen werden und stellt ein erstes wichtiges Ereignis für die Initiation maligner Kolonkarzinome dar (Fodde et al., 2001). Mutationen in $\beta$-Catenin sind ein alternativer Weg zur konstitutiven Aktivierung des WNT Signalwegs und Tumorinitiation. Neben Mutationen von $\beta$-Catenin sind auch Mutationen in Axin in verschiedenen humanen Karzinomen, u. a. auch im Kolonkarzinom, zu finden (Salahshor und Woodgett, 2005). Es konnte gezeigt werden, dass Mutationen des $\beta$-Catenins in Kolonkarzinomen in Abwesenheit von Mutationen des APC Gens vorkamen (Polakis, 2012). Die Mutationen in Komponenten des kanonischen WNT Signalwegs verstärken die Stabilisierung von $\beta$ Catenin und die Transaktivierung von TCF/LEF-1 (Polakis, 2000).

Obwohl ähnliche Mutationen nicht im Mammakarzinom vorkommen, führt die Aktivierung von Wnt1 durch das MMTV zur Tumorentstehung in der Maus (Rijsewijk et al., 1987). Weiterhin konnte nachgewiesen werden, dass eine Aktivierung des WNT Signalwegs signifikant mit einer schlechten Prognose der Brustkrebspatienten korreliert (Lin et al., 2000). Eine Überexpression von LEF1 in Mammakarzinomzellen steigert die Invasion in vitro (Nguyen et al., 2005). Eine mögliche Erklärung für die Überaktivierung des Wnt Signalwegs kann eine erhöhte Konzentration von klassischen Wnt Liganden sein (Van de Vijver und Nusse, 1991). Es konnte gezeigt werden, dass die Überexpression bzw. Inhibition von Wnt5a die Motilität und Invasion in malignen Melanomzellen, UACC 1273, verstärkt bzw. hemmt (Weeraratna et al., 2002). Eine Überexpression von Wnt11 wurde bereits in Magen-, Nierenzellkarzinomen und primären kolorektalen Adenokarzinomen nachgewiesen (Kirikoshi et al., 2001). Die Funktion der nicht-kanonischen Wnt Liganden Wnt5a und Wnt11 ist sehr kontextabhängig, da die Liganden sowohl Tumor fördernde als auch inhibierende Eigenschaften nachwiesen. 
Die erste Assoziation des WNT Signalwegs mit der Metastasierung konnte die Arbeitsgruppe Massague belegen. Eine erhöhte Aktivität des WNT Signalwegs in das Lungenadenokarzinom führte zur malignen Progression und schließlich zur Metastasierung in das Gehirn und die Knochen (Nguyen et al., 2009). Ein deregulierter WNT Signalweg in kolorektalen Tumoren, bedingt durch Mutationen im Tumorsuppressorgen APC (Fodde et al., 2001) oder im $\beta$-Catenin selbst (Brabletz et al., 1998), führt nicht nur zur Tumorinitiation, sondern repräsentiert das Merkmal der metastatischen Kaskade. Obwohl ähnliche Mutationen im Mammakarzinom nicht vorkommen, führt die Aktivierung des WNT/ $\beta$-Catenin Signalwegs im „basal-like“ Brustkrebs Subtyp zur verstärkten Metastasierung, u. a. in das Gehirn (Smid et al., 2008).

Zusammenfassend lässt sich somit sowohl im Mammakarzinom als auch im Kolonkarzinom eine Aktivierung des WNT Signalwegs in Stadien der Tumorprogression und der Metastasierung postulieren.

\section{6 „MetastaSys“ Projekt}

Die vorliegende Arbeit war eingebettet in ein systembiologisches Verbundprojekt, gefördert vom Bundesministerium für Bildung und Forschung (BMBF). Dieses BMBF „MetastaSys“ Konsortium, bestehend aus 8 Working Projects (WPs), analysiert die molekularen Marker und die Signalwege in Tumorzelllinien und ihrer Mikroumgebung, welche das Schicksal und die Lokalisation der davon ausgehenden Metastasen bestimmen. Während bis zu 70\% der kolorektalen Krebszelllinien in die Leber metastasieren, hat der triple-negative Subtyp des Mammakarzinoms eine Tendenz, in das Gehirn zu metastasieren. Interessanterweise verfügen diese beiden Entitäten über gemeinsame deregulierte Signalwege im Primärtumor, nämlich den EGFR und WNT Signalweg, sodass beide Entitäten als Modell für die spezifische Organkolonisation untersucht werden können. Aus diesem Grund war das Ziel, die zugrundeliegenden Signalwege in diesen beiden Entitäten zu manipulieren und anschließend die Auswirkung auf die Organkolonisation zu untersuchen. Der experimentelle Ansatz des mich betreffenden Teilprojektes WP2 ist in der Abb. 1.5 dargestellt. Es sollte jeweils eine murine Mamma- und kolorektale Karzinomzelllinie identifiziert und bezüglich ihres WNT- und EGFR-Status charakterisiert werden. Entsprechend dem EGFR- und WntRepertoire sollten diese Zellinien dann durch lentivirale Überexpression oder Knockdown genetisch modifiziert und in einen komplementären Phänotyp überführt 
werden. So war geplant, in kolorektalen Tumorzelllinien, in denen gewöhnlich eine Hochregulation von $\beta$-Catenin nachgewiesen wird, dieses herunter und EGFR hoch zu regulieren. Umgekehrt sollte in Brustkrebszelllinien, wo keine $\beta$-Catenin Überexpression sondern häufig eine vermehrte Bildung von EGFR beschrieben ist, vorgegangen werden. Diese Zelllinien sollten für WP3 und 4 bereit gestellt werden, in denen mittels Inokulation in Leber und Gehirn die funktionellen Auswirkungen im Rahmen der Tumorprogression und Metastasierung in vivo zu bestimmt werden sollten (s. Abb. 1.5).

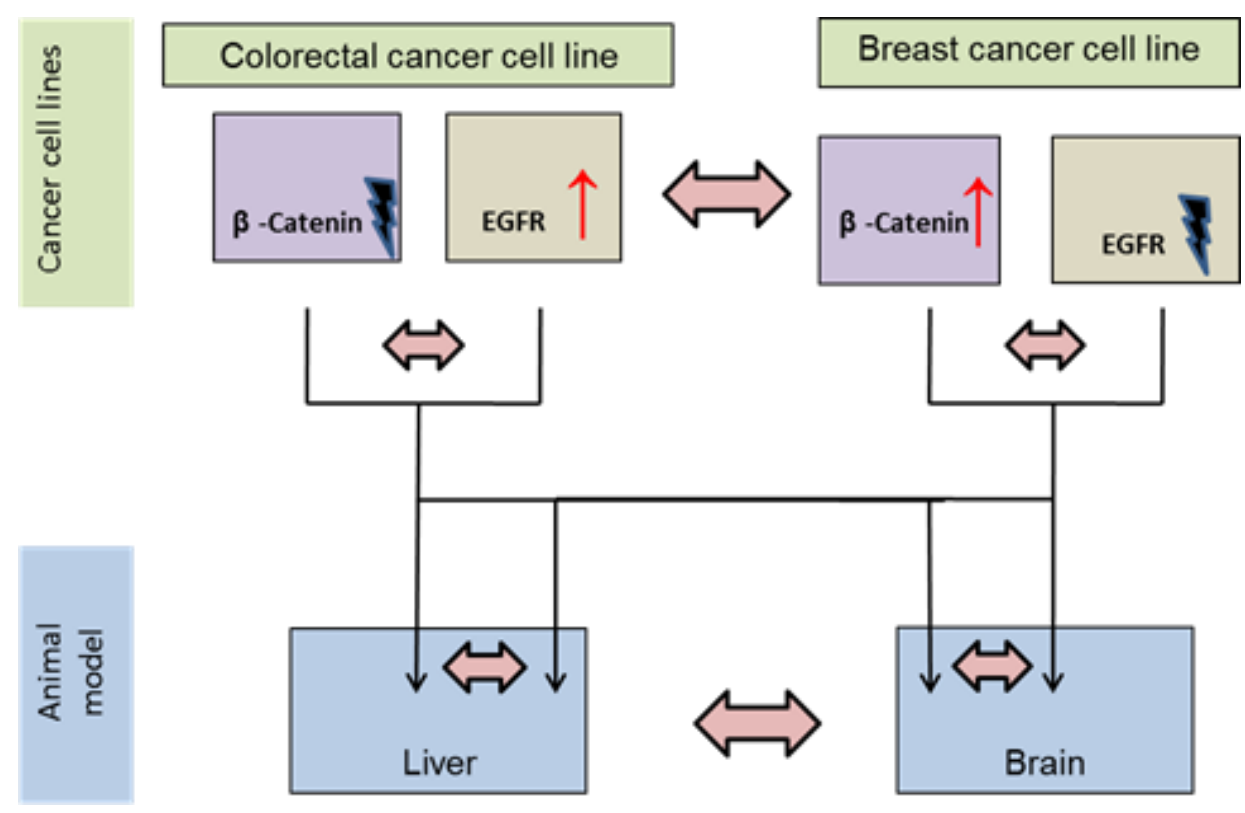

Abb. 1.5: Experimentelle in vitro und in vivo Ansätze.

Das Zeichen Blitz stellt Knockdown und Pfeil nach oben stellt Überexpression in den jeweiligen Zelllinien dar. Doppelpfeile weisen auf die vergleichende Analyse zwischen Zelllinien und Entitäten. 


\subsection{Zielsetzung der Arbeit}

Als Teil dieses Verbundprojektes sollte in der vorliegenden Arbeit die Bedeutung des EGFR und WNT Signalwegs anhand von gain of function und loss of function in Mamma- und kolorektale Zelllinien und ihre Bedeutung für die Tumorprogression und Metastasierung in vitro untersucht werden.

Diese Fragestellung sollte in folgenden Schritten bearbeitet werden:

1. Identifikation je einer murinen Tumorzellinie, welche in Bezug auf den EGFR und WNT Signalweg als charakteristisch für die jeweilige Entität anzunehmen ist. Dabei sollte diese Zellinie für die spätere Inokulation in ein syngenes Mausmodell geeignet sein.

2. Gegenläufige Modifikation des EGFR und WNT Signalwegs in den identifizierten Zelllinien durch lentivirale Überexpression oder Knockdown.

3. Untersuchung der funktionellen Auswirkungen in Bezug auf die Invasion, Proliferation und Signaltransduktion in vitro.

4. Charakterisierung weiterer molekularer Variablen, die sich im Laufe der Experimente ergeben würden (wie z. B. WNT11 und ROR2). 


\section{Material und Methoden}

\subsection{Materialien}

\subsubsection{Biologisches Material}

\subsubsection{Bakterienstämme}

Der kompetente Bakterienstamm Escherichia coli (E. coli) DH5a (Invitrogen, Darmstadt) wurde zur Vervielfältigung des Plasmids eingesetzt.

\subsubsection{Eukaryotische Zelllinien}

Die verwendeten Zelllinien für diese Arbeit sind in der Tab. 2.1 aufgelistet.

Tab. 2.1: Eukaryotische Zelllinien

\begin{tabular}{|c|c|c|c|c|}
\hline Zelllinie & $\begin{array}{l}\text { Spezies / } \\
\text { Ursprung }\end{array}$ & $\begin{array}{l}\text { Merkmal / } \\
\text { Mausstamm }\end{array}$ & $\begin{array}{l}\text { Herkunft / } \\
\text { Zur } \\
\text { Verfügung } \\
\text { gestellt von }\end{array}$ & Referenz \\
\hline HEK 293T & $\begin{array}{l}\text { humane embryonale } \\
\text { Nierenzelle }\end{array}$ & $\begin{array}{l}\text { konstitutiv aktives } \\
\text { SV40 T Antigen }\end{array}$ & ATCC, Wesel & $\begin{array}{l}\text { Graham et al., } \\
1977\end{array}$ \\
\hline SW480 & $\begin{array}{l}\text { humane Kolorektal- } \\
\text { adenokarzinom-Zelle }\end{array}$ & $\begin{array}{l}\text { konstitutiv aktives } \beta \text { - } \\
\text { Catenin }\end{array}$ & ATCC, Wesel & $\begin{array}{l}\text { Leibovitz et al., } \\
1976\end{array}$ \\
\hline 410.4 & $\begin{array}{l}\text { murine Mamma- } \\
\text { adenokarzinom-Zelle }\end{array}$ & $\mathrm{BALB} / \mathrm{c}$ & $\begin{array}{l}\text { Prof. F. Balkwill, } \\
\text { London, UK }\end{array}$ & $\begin{array}{l}\text { Miller et al., } \\
1983\end{array}$ \\
\hline $4 \mathrm{~T} 1$ & $\begin{array}{l}\text { murine Mamma- } \\
\text { adenokarzinom-Zelle }\end{array}$ & $\mathrm{BALB} / \mathrm{c}$ & ATCC, Wesel & $\begin{array}{l}\text { Aslakson und } \\
\text { Miller, } 1992\end{array}$ \\
\hline E0771-LG & $\begin{array}{l}\text { murine Mamma- } \\
\text { adenokarzinom-Zelle }\end{array}$ & C57BL/6 & $\begin{array}{l}\text { Prof. J. Pollard } \\
\text { Edinburgh, UK }\end{array}$ & Pollard, 2013 \\
\hline $1638 \mathrm{~N}-\mathrm{T} 1$ & $\begin{array}{l}\text { murine Kolorektal- } \\
\text { adenokarzinom-Zelle }\end{array}$ & $\begin{array}{l}\text { konstitutiv aktives } \beta \text { - } \\
\text { Catenin, C57BL/6 }\end{array}$ & $\begin{array}{l}\text { Prof. R. Smits, } \\
\text { Rotterdam, } \\
\text { Niederlande }\end{array}$ & $\begin{array}{l}\text { Smits et al., } \\
1997\end{array}$ \\
\hline
\end{tabular}




\begin{tabular}{lllll}
\hline CMT-93 & murine rektale & C57BL/6 & ATCC, & Franks und \\
& $\begin{array}{l}\text { Polyploidkarzinom- } \\
\text { Zelle }\end{array}$ & & Manassas, USA & Hemmings, \\
& & & 1978 \\
CMT-93var & murine rektale & C57BL/6 & Dr. med. & Franks und \\
& Polyploidkarzinom- & & C.Hackl, & Hemmings, \\
& Zelle & & Regensburg & 1978 \\
CT26 & murine & N-nitroso-N-methyl- & ATCC & Brattain et al., \\
& Kolorektalkarzinom- & urethan induziert, & & 1980 \\
& Zelle & BALB/c & &
\end{tabular}

Zur langfristigen Lagerung wurden die Zellen in fetalem Kälberserum (FKS) mit 10\% (v/v) DMSO aufgenommen und bei $-150^{\circ} \mathrm{C}$ eingefroren.

\subsubsection{Mausstämme}

Für die in vivo Experimente wurden Mäuse mit demselben Hintergrund, BALB/c oder C57BL/6, wie die zu injizierenden Zellen, wovon sie ursprünglich generiert worden sind, von der Firma Charles River, Hannover bezogen. Die Haltung der Tiere erfolgte unter kontrollierten spezifisch pathogenfreien (SPF) Bedingungen mit einem zwölfstündigen Hell-Dunkel-Rhythmus.

\subsubsection{Medien und Antibiotika}

\subsubsection{Medien für Bakterien}

Für die Anzucht der Mikroorganismen wurden folgende Komponenten eingewogen, in Aqua bidest gelöst und zur Keimabtötung für 20 min bei $121^{\circ} \mathrm{C}$ und 2 bar autoklaviert. Zur Herstellung von Agarplatten wurde dem LB-Medium vor dem Autoklavieren 1,5\% (w/v) Agar zugesetzt.

Tab. 2.2: Luria-Bertani-Medium (LB-Medium)

\begin{tabular}{ll}
\hline Bestandteil & Masse oder Volumen \\
\hline Pepton & $10 \mathrm{~g}$ \\
Hefeextrakt & $5 \mathrm{~g}$ \\
$\mathrm{NaCl}$ & $10 \mathrm{~g}$ \\
$\mathrm{H}_{2} \mathrm{O}$ & $\mathrm{ad} \mathrm{1 \textrm {I }}$ \\
\hline
\end{tabular}




\subsubsection{Medien für eukaryotische Zelllinien}

Die Medien zur Kultivierung eukaryotischer Zelllinien wurden vor Gebrauch, wenn nicht anders angegeben, mit 10\% (v/v) hitzeinaktiviertem FKS versetzt. Dem Kulturmedium für die 1638N-T1 Zellen wurde 15\% nicht hitzeinaktiviertes FKS und 1\% (v/v) InsulinTransferrin-Selenium zugegeben.

Tab. 2.3: Medien für die Zellkultur

\begin{tabular}{lll}
\hline Medium & Zelllinie & Firma \\
\hline RPMI-1640 & SW480, 4T1, E0771-LG, CT26 & Gibco, Darmstadt \\
DMEM High Glucose & CMT-93, CMT-93Var, 1638N-T1 & Gibco, Darmstadt \\
DMEM & HEK 293T, 410.4 & Biochrom, Berlin \\
\hline
\end{tabular}

\subsubsection{Antibiotika}

Zur Selektion von transformierten Bakterienstämmen wurden die Kulturen je nach Antibiotikaresistenz zusätzlich mit Ampicillin oder Kanamycin behandelt. Sie wurden als 1.000-fach konzentrierte Stammlösung in Aqua bidest angesetzt und mit einem Spritzenfilter („Filtropur S 0,2“, Sarstedt, Nümbrecht) steril filtriert. Die Lagerung erfolgte bei $-20^{\circ} \mathrm{C}$. Den Medien wurden sie in einer Konzentration von $100 \mu \mathrm{g} / \mathrm{ml}$ Ampicillin bzw. $50 \mu \mathrm{g} / \mathrm{ml}$ Kanamycin direkt vor Gebrauch zugesetzt.

Antibiotika, die zur Selektion eukaryotischer Zellen dienten, wurden als Gebrauchslösung käuflich erworben und in der nachfolgenden Tab. 2.4 aufgeführt. Den Kulturmedien wurden zum Schutz vor Fremdbewuchs Penicillin und Streptomycin (P/S) zugesetzt (1\% v/v).

Tab. 2.4: Antibiotika für eukaryotische Zelllinien

\begin{tabular}{lll}
\hline Antibiotika & Konzentration & Firma \\
\hline Penicillin/Streptomycin (P/S) & $100 \mathrm{U} / \mathrm{ml} / 100 \mathrm{mg} / \mathrm{ml}$ & Biochrom, Berlin \\
Puromycin & $4 \mu \mathrm{g} / \mathrm{ml}$ & Invivogen, Toulouse, France \\
Genetcin (G418) & $800 \mu \mathrm{g} / \mathrm{ml}$ & Roche, Mannheim \\
Zeocin & $100 \mu \mathrm{g} / \mathrm{ml}$ & Invitrogen, Darmstadt \\
\hline
\end{tabular}




\subsubsection{Chemikalien und rekombinante Proteine}

Alle verwendeten Chemikalien wurden von der Firma Sigma-Aldrich, München erworben, anderenfalls sind sie in der Tab. 2.5 angegeben.

Tab. 2.5: Chemikalien und rekombinante Proteine

\begin{tabular}{|c|c|}
\hline Produkt & Firma \\
\hline Agarose HEEO Ultra & Roth, Karlsruhe \\
\hline APMBT (2-(4-Aminophenyl)-6-methylbenzothiazol) & City Chemical, West Haven, USA \\
\hline Benzyl-Coelenterazin & SynChem, Elk Grove Village, USA \\
\hline Bradford Reagenz & BioRad, München \\
\hline Buffer $B(10 x)$ & Thermos Scientific, Bonn \\
\hline CutSmart Buffer (10 x) & New England Biolabs, Frankfurt a. M. \\
\hline DNase I Incubation Buffer (10 x) & Roche, Mannheim \\
\hline ECLPrime Western Blot Detection Reagenz & GE Healthcare, Freiburg \\
\hline ECM & R\&D Systems, Wiesbaden \\
\hline EDTA (ethylenediaminetetraacetate) & Merck, Darmstadt \\
\hline Essigsäure & Merck, Darmstadt \\
\hline Ethanol & Merck, Darmstadt \\
\hline Fibronektin & AthenaES, Baltimore, USA \\
\hline Insulin-Transferrin-Selenium & Invitrogen, Darmstadt \\
\hline Isopropanol & J.T.Baker, Center Valley, USA \\
\hline JNK-Inhibitor II (SP600125) & Calbiochem, Darmstadt \\
\hline Kristallviolett & Th. Geyer, Hamburg \\
\hline Laemmli loading buffer Roti®-Load 1, reducing $(4 \mathrm{x})$ & Roth, Karlsruhe \\
\hline Laemmli loading buffer, non-reducing $(4 \mathrm{x})$ & bioPLUS, Mol, Belgien \\
\hline Loading Dye Solution $(6 \mathrm{x})$ & Fermentas, St. Leon Rot \\
\hline Magermilchpulver & BioRad, München \\
\hline Methanol & Merck, Darmstadt \\
\hline $\mathrm{Na}_{4} \mathrm{PPi}$ (Sodium pyrophosphate) & Roth, Karlsruhe \\
\hline
\end{tabular}




\begin{tabular}{ll}
\hline NaCl (Sodium chloride) & Merck, Darmstadt \\
Passive lysis buffer $(5 \mathrm{x})$ & Promega, \\
PBS & PAN Biotech, Aidenbach \\
PFA (Paraformaldehyd) & Merck, Darmstadt \\
Phenol/Chloroform/lsoamyl Alkohol (25:24:1) & Roth, Karlsruhe \\
Phosphatase inhibitor PhosSTOP (10 x) & Roche, Mannheim \\
Ponceau S & Merck, Darmstadt \\
Protease Inhibitor cocktail tablets, EDTA free & Roche, Mannheim \\
rekombinantes humanes EGF & R\&D Systems, Wiesbaden \\
rekombinantes humanes Wnt11 & R\&D Systems, Wiesbaden \\
rekombinantes humanes Wnt3a & R\&D Systems, Wiesbaden \\
Rinderserumalbumin & Roth, Karlsruhe \\
SERVA DNA Stain G & Serva, Heidelberg \\
SYBR green & Roche, Mannheim \\
Trypanblau & Gibco, Darmstadt \\
\hline
\end{tabular}

\subsubsection{Antikörper und Enzyme}

Tab. 2.6: Antikörper

\begin{tabular}{lll}
\hline Antikörper & Verdünnung & Firma \\
\hline Primärantikörper & WB $(1: 1000)$ & \#sc-366108, Santa Cruz, Heidelberg \\
Cadherin-16 (H-293) & WB $(1: 1000)$ & \#9165, Cell Signaling, Frankfurt a. M. \\
c-Jun (60A8) & WB $(1: 1000)$ & \#9402, Cell Signaling, Frankfurt a. M. \\
c-Myc & WB $(1: 1000)$ & \#ab2074, abcam, Cambridge, UK \\
Cxcr4 & WB $(1: 1000)$ & \#3218, Cell Signaling, Frankfurt a. M. \\
DVL3 & WB $(1: 2000)$ & \#610181, BD Heidelberg \\
e-Cadherin (Cdh1) & WB (1:1000) & \#4267, Cell Signaling, Frankfurt a. M. \\
\hline EGFR (D38B1) & & \\
\hline
\end{tabular}




\begin{tabular}{|c|c|c|}
\hline ERa (Esr1; H-184) & WB $(1: 600)$ & \#sc-7207, Santa Cruz, Heidelberg \\
\hline HDAC1 & WB $(1: 1000)$ & \#2062, Cell Signaling, Frankfurt a. M. \\
\hline HER2/neu (erb-B2) & WB $(1: 1000)$ & \#2165, Cell Signaling, Frankfurt a. M. \\
\hline JNK & WB $(1: 1000)$ & \#9252, Cell Signaling, Heidelberg \\
\hline p38 & WB $(1: 1000)$ & \#9212, Cell Signaling, Frankfurt a. M. \\
\hline P-Akt (D9E) & WB $(1: 1000)$ & \#4060, Cell Signaling, Frankfurt a. M. \\
\hline P-C-Jun & WB $(1: 1000)$ & \#9261, Cell Signaling, Frankfurt a. M. \\
\hline P-JNK & WB $(1: 1000)$ & \#9251S, Cell Signaling, Frankfurt a. M. \\
\hline PKC & WB $(1: 1000)$ & \#sc-10800, Santa Cruz, Heidelberg \\
\hline P-p38 & WB $(1: 1000)$ & \#9211, Cell Signaling, Frankfurt a. M. \\
\hline P-PKC & WB $(1: 1000)$ & \#9371, Cell Signaling, Frankfurt a. M. \\
\hline Progestron (PR C-20) & WB $(1: 600)$ & \#sc-539, Santa Cruz, Heidelberg \\
\hline P-S6 & WB $(1: 1000)$ & \#sc-2211, Cell Signaling, Heidelberg \\
\hline $\mathrm{RHOA}$ & WB $(1: 1000)$ & \#sc-418, Santa Cruz, Heidelberg \\
\hline ROR1 (P-288) & WB $(1: 1000)$ & \#sc-130867, Santa Cruz, Heidelberg \\
\hline ROR2 & WB $(1: 1000)$ & \#sc-98486, Santa Cruz, Heidelberg \\
\hline S6 (5G10) & WB $(1: 1000)$ & \#sc-2217, Cell Signaling, Heidelberg \\
\hline Tubulin & WB $(1: 5000)$ & \#05-829, Millipore, Darmstadt \\
\hline Wnt11 & WB $(1: 1000)$ & \#ab31962, abcam, Cambridge, UK \\
\hline Wnt3A & WB $(1: 1000)$ & \#MAB1324, R\&D Systems, Wiesbaden \\
\hline Wnt5a & WB $(1: 2000)$ & \#MAB645, R\&D Systems, Wiesbaden \\
\hline$\beta$-Catenin (E-5) & WB $(1: 500)$ & \#sc-7963, Santa Cruz, Heidelberg \\
\hline
\end{tabular}

\section{Sekundärantikörper}

$\begin{array}{lll}\text { goat anti-mouse lgG-HRP } & \text { WB (1:6000) } & \text { \#sc-2005, Santa Cruz, Heidelberg } \\ \text { goat anti-rabbit IgG-HRP } & \text { WB (1:6000) } & \text { \#sc-2004, Santa Cruz, Heidelberg } \\ \text { goat anti-rat lgG-HRP } & \text { WB (1:6000) } & \text { \#sc-2006, Santa Cruz, Heidelberg }\end{array}$


Tab. 2.7: Enzyme

\begin{tabular}{ll}
\hline Enzym & Firma \\
\hline BamHI-HF & New England Biolabs, Frankfurt a. M. \\
Coenzym A & AppliChem, Darmstadt \\
D-Luciferin & SynChem, Elk Grove Village, USA \\
DNase I $(10 \mathrm{U} / \mu \mathrm{l})$ & Roche, Mannheim \\
rapid T4-DNA-Ligase $(10 \times)$ & Fermentas, St. Leon-Rot \\
RNase OUT $(40 \mathrm{U} / \mathrm{\mu l})$ & Invitrogen, Darmstadt \\
Sacll $($ Cfr42I) & Thermo Fisher Scientific, Bonn \\
Scal & New England Biolabs, Frankfurt a. M. \\
Trypsin-EDTA & Biochrom, Berlin \\
\hline
\end{tabular}

\subsubsection{Oligonukleotide und Plasmide}

Die folgende Tab. 2.8 listet alle für diese Arbeit verwendeten synthetischen Oligonukleotide auf. Ein Teil der folgenden Oligonukleotide waren bereits in der Arbeitsgruppe vorhanden. Die mit einem Stern $\left(^{*}\right)$ gekennzeichneten synthetischen Oligonukleotide wurden nach meinen Vorgaben bei der Firma Iba, Göttingen, hergestellt. Die Auswahl der Sequenzen erfolgte mit Hilfe des Programmes „PerlPrimer" (http://perlprimer.sourceforge.net).

Tab. 2.8: Oligonukleotide für die qRT-PCR-Reaktionen

\begin{tabular}{|c|c|}
\hline $\begin{array}{l}\text { Oligonukleotide mit Fragmentlänge } \\
\text { (bp) }\end{array}$ & Sequenz $\left(5^{c} \rightarrow 3^{c}\right)$ \\
\hline eGFP_fw (120) & CAAGATCCGCCACAACATCG \\
\hline eGFP_rv (120) & GACTGGGTGCTCAGGTAGTG \\
\hline hsCTNNB1_fw (127) & ATCTGTCTGCTCTAGTAATAAGCC \\
\hline hsCTNNB1_rv (127) & CTGAAAGATTCCTGAGAGTCCA \\
\hline hsEGFR_fw (84) & GCTATGAGATGGAGGAAGAC \\
\hline hsEGFR_rv (84) & CCAATACCTATTCCGTTACAC \\
\hline hsROR2_fw (143) & TTCTTCTTGGTTTGCATGTG \\
\hline
\end{tabular}




\begin{tabular}{|c|c|}
\hline hsROR2_rv (143) & CTGATCTCTTTGAGTTTGGC \\
\hline hsWNT11_fw (102)* & CTCGGAACTCGTCTATCTG \\
\hline hsWNT11_rv (102)* & GTTGGATGTCTTGTTGCAC \\
\hline mmAxin2_fw (129) $)^{*}$ & ACGATTCCATGTCCATGAC \\
\hline mmAxin2_rv (129)* & AATGAGGTAGAGACACTTGG \\
\hline mmCdh16_fw $(124)^{*}$ & CTTTACCAGACATGTTCCAG \\
\hline mmCdh16_rv (124)* & CATGTCCTTGACCTGTACC \\
\hline mmc-Jun_fw (123) & GACTGCAAAGATGGAAACGA \\
\hline mmc-Jun_rv (123) & CAGGTTCAAGGTCATGCTC \\
\hline mmc-Myc_fw (169) & GACCTAACTCGAGGAGGAGCTGGAATC \\
\hline \multirow[t]{2}{*}{ mmc-Myc_rv (169) } & AAGTTTGAGGCAGTTAAAATTATGGCTGAAG \\
\hline & C \\
\hline mmCtnnb1_fw (102) & TACGAGCACATCAGGACAC \\
\hline mmCtnnb1_rv (102) & CCAGTACACССTTCTACTATСTC \\
\hline mmEgfr_fw (91) & CTACGAAGTGGAAGAAGATGG \\
\hline mmEgfr_rv (91) & TAAATTCACCAATGCCTATGCC \\
\hline mmEvi_fw (69) & GGAGATAAAGGACATTCGGT \\
\hline mmEvi_rv (69) & CATAGCAAACCATACCTTAGTG \\
\hline mmGapdh_fw (146) & CATCTTGGGCTACACTGAG \\
\hline mmGapdh_rv (146) & CTGTAGCCGTATTCATTGTC \\
\hline mmLef1_fw (98) & TCATCCAGCTATTGTAACACCT \\
\hline mmLef1_rv (98) & TGCTCCTTTCTCTGTTCGT \\
\hline mmPorc_fw $(72)^{*}$ & CTTGTCAAAGCGTTGTCTG \\
\hline mmPorc_rv $(72)^{*}$ & CAAGTTTAAGGCTCGTACC \\
\hline mmRor1_fw (99) & GTCAGAGGACAGAATGTGGA \\
\hline mmRor1_rv (99) & АTTCTTCCATGAAACGCACAG \\
\hline mmRor2_fw (100) & CATCAGCCAGCACAAACAG \\
\hline mmRor2_rv (100) & CTTTGTAGACCTTGCCAAACC \\
\hline
\end{tabular}




\begin{tabular}{|c|c|}
\hline mmSnai1_fw (133) & TGAAGATGCACATCCGAAGC \\
\hline mmSnai1_rv (133) & CAGTGGGAGCAGGAGAATG \\
\hline mmTbp_fw (133) & TTCCCAGCTAAGTTCTTAGAC \\
\hline mmTbp_rv (133) & CCAGGAAATAATTCTGGCTC \\
\hline mmTcf7_fw (97) & TCTGACCTCAGGCAGCAT \\
\hline mmTcf7_rv (97) & GTGCTGTCTATATCCGCAGG \\
\hline mmTwist_fw (58) & GTACATCGACTTCCTGTACCA \\
\hline mmTwist_rv (58) & TTGCCATCTTGGAGTCCAG \\
\hline mmWnt11_fw $(106)^{*}$ & TGAAGGACTCAGAACTTGTG \\
\hline mmWnt11_rv (106)* & GGAAGTCTTGTTGCACTG \\
\hline$m m W n t 3 a \_f w(84)^{*}$ & ATCTTTGGCCСTGTTCTG \\
\hline mmWnt3a_rv $(84)^{*}$ & TCACTGCGAAAGCTACTC \\
\hline mmWnt5a_fw (72) & TTACACAACAATGAAGCAGG \\
\hline mmWnt5a_rv (72) & ACACTCCATGACACTTACAG \\
\hline mmWnt5b_fw (101) & GAGAAGAACTTTGCCAAGG \\
\hline mmWnt5b_rv (101) & GACATCAGCCATCTTATACAC \\
\hline mmWnt6_fw (116) & GGTTCGAGAATGTCAGTTCC \\
\hline mmWnt6_rv (116) & ATTGCAAACACGAAAGCTG \\
\hline mmZeb1_fw (77) & CAGTATTACCAGGAGGCA \\
\hline mmZeb1_rv (77) & CACACTCGTTGTCTTTCAC \\
\hline
\end{tabular}

Tab. 2.9: Plasmide

\begin{tabular}{lll}
\hline Plasmid & $\begin{array}{l}\text { Eigenschaften oder } \\
\text { Genotyp }\end{array}$ & $\begin{array}{l}\text { Herkunft / Zur } \\
\text { Verfügung gestellt von }\end{array}$ \\
\hline pcDNA3.1/Zeo(+) & Expressionsvektor & Prof. Dr. H. Bastians, Göttingen \\
pcDNA3.2 & Expressionsvektor & diese Arbeit \\
pcDNA ROR2 & Expressionsvektor mit hsROR2 & PD Dr. A. Schambony, \\
& & Erlangen-Nürnberg \\
\hline
\end{tabular}




\begin{tabular}{|c|c|c|}
\hline pcDNA WNT11 & $\begin{array}{l}\text { Expressionsvektor mit } \\
\text { hsWNT11 }\end{array}$ & Addgene, Cambridge, USA \\
\hline pGIPZns.ctrl. & Lentiviraler Vektor & Dr. S. Eberth, Göttingen \\
\hline pGIPZshRNA-Egfr & $\begin{array}{l}\text { Lentiviraler Vektor mit shRNA } \\
\text { gerichtet gegen mmEgfr }\end{array}$ & Thermo Fisher Scientific, Bonn \\
\hline pGIPZshRNA- $\beta$ cat \#2 & $\begin{array}{l}\text { Lentiviraler Vektor mit shRNA } \\
\text { gerichtet gegen mm } \beta \text {-Catenin }\end{array}$ & Thermo Fisher Scientific, Bonn \\
\hline pGIPZshRNA- $\beta$ cat \#4 & $\begin{array}{l}\text { Lentiviraler Vektor mit shRNA } \\
\text { gerichtet gegen mmß-Catenin }\end{array}$ & Thermo Fisher Scientific, Bonn \\
\hline pLenti-III-2A-EGFR-GFP & Lentiviraler Vektor mit hsEGFR & abmgood, Richmond, Kanada \\
\hline pLenti-III-2A-GFP & Lentiviraler Vektor & Dr. S. Eberth, Göttingen \\
\hline pLenti-III-2A- $\beta C A T-G F P$ & $\begin{array}{l}\text { Lentiviraler Vektor mit hs } \beta \text { - } \\
\text { Catenin mit der Mutation S33Y }\end{array}$ & abmgood, Richmond, Kanada \\
\hline $\mathrm{pCMV} \Delta \mathrm{r} 8.91$ & Packaging Vektor & Addgene, Cambridge, USA \\
\hline pVSG-G & Envelope Vektor & Addgene, Cambridge, USA \\
\hline pTOPflash & $\begin{array}{l}\text { drei Kopien des optimalen TCF } \\
\text { Bindemotivs, Luciferase } \\
\text { Reporter }\end{array}$ & Van de Wetering et al., 1991 \\
\hline pFOPflash & $\begin{array}{l}\text { drei Kopien eines mutierten } \\
\text { TCF Bindemotivs, Luciferase } \\
\text { Reporter }\end{array}$ & Van de Wetering et al., 1991 \\
\hline pRL-TK & Renilla Luciferase Reporter & Promega, Mannheim \\
\hline
\end{tabular}

\subsubsection{Kommerzielle Kits und Standards}

Tab. 2.10: Kommerzielle Kits und Standards

\begin{tabular}{ll}
\hline Produkt & Firma \\
\hline Amaxa® Cell Line Nucleofector® Kit V & Lonza, Basel \\
DC Protein Assay Kit & Bio-Rad, München \\
EndoFree Plasmid Maxi Kit & Qiagen, Hilden \\
GeneRulerTM 100bp Plus DNA Ladder & Thermo Fisher Scientific, Bonn \\
\hline
\end{tabular}




\begin{tabular}{ll}
\hline GeneRulerTM 1kb Plus DNA Ladder & Thermo Fisher Scientific, Bonn \\
High Pure RNA Isolation kit & Roche, Grenzach-Wyhlen \\
innuPREP DYEpure Kit & Analytik Jena, Jena \\
iScript cDNA synthesis kit & Bio-Rad, München \\
Nanofectin Kit & PAA, Cölbe \\
Precision Plus Dual-Color protein standard & Bio-Rad, München \\
QIAquick Gel Extraction Kit & Qiagen, Hilden \\
QIAquick PCR Purification Kit & Qiagen, Hilden \\
\hline
\end{tabular}

\subsubsection{Verbrauchsmaterialien}

Tab. 2.11: Verbrauchsmaterialien

\begin{tabular}{ll}
\hline Produkt & Firma \\
\hline 10 cm Zellkulturpetrischale (beschichtet) & Nunc, Langenselbold \\
12-well-Zellkulturschalen & Sarstedt, Nümbrecht \\
24-well-Zellkulturschalen & Becton Dickinson, Heidelberg \\
6-well-Zellkulturschalen & Nunc, Langenselbold \\
96-well-Zellkulturschalen & Becton Dickinson, Heidelberg \\
Auslaufpipetten (5 / 10 / $25 \mathrm{ml})$ & Sarstedt, Nümbrecht \\
Glaspasteurpipetten (150 / 230 mm) & WU Laborglaswaren, Mainz \\
Mikroliterpipetten $(10 / 100 / 1000 ~ \mu l)$ & Eppendorf, Hamburg \\
Pipettenspitzen & Sarstedt, Nümbrecht \\
Reaktionsgefäße $(0,5 / 1,5 / 2 \mathrm{ml})$ & Sarstedt, Nümbrecht \\
Zellkulturflaschen $\left(25 / 75 / 175 \mathrm{~cm}{ }^{2}\right)$ & Sarstedt, Nümbrecht \\
Zellschaber $(25 / 39,4 \mathrm{~cm})$ & Sarstedt, Nümbrecht \\
Zentrifugenröhrchen (15 / $50 \mathrm{ml})$ & Sarstedt, Nümbrecht \\
\hline
\end{tabular}




\subsubsection{Laborgeräte}

Tab. 2.12: Laborgeräte

\begin{tabular}{|c|c|}
\hline Produkt & Firma \\
\hline ABI 7900HT Fast Real-Time PCR System & Applied Biosystems, Weiterstadt \\
\hline Autoklav Varioklav & Thermo Scientific, Bonn \\
\hline $\mathrm{CO}_{2}$-Inkubator $\mathrm{CB} 150$ & Binder, Tuttlingen \\
\hline FACS Canto II Durchflusszytometrie & Becton Dickinson, Heidelberg \\
\hline ImageQuant LAS-4000 & Fujifilm, Freiburg \\
\hline Magnetrührer REO basic $\mathrm{C}$ & IAK Werk, Staufen \\
\hline NanoDrop ND-1000 Spektrophotometer & Peqlab, Erlangen \\
\hline Photometer infinite F50 & Tecan, Crailsheim \\
\hline Pipettierhilfe & Integra Biosciences, Femwald \\
\hline PowerPack P25 & Biometra, Göttingen \\
\hline Sicherheitswerkbank UVF 6.12S & BDK, Sonnenbühl-Genkingen \\
\hline Thermal cycler T3000 & Biometra, Göttingen \\
\hline Thermomixer 5437 & Eppendorf, Hamburg \\
\hline Transilluminator-CCD-Kamera & Intas, Göttingen \\
\hline TriStar LB 946 Multimode Mikroplattenreader & Berthold Tecnologies, Bad Wildbad \\
\hline UV-Transilluminator TI3 & Biometra, Göttingen \\
\hline Vortexer Genius 3 & IKA Labortechnik, Staufen \\
\hline Wasserbad & Köttermann, Uetze, Hänigsen \\
\hline Wasservollentsalzungsanlage & Millipore, Schwalbach \\
\hline Zählkammer Neubauer Improved & LO Laboroptik, Friedrichsdorf \\
\hline Zentrifuge $1-15 \mathrm{~K}$ & Sigma, München \\
\hline Zentrifuge $5415 \mathrm{C}$ & Eppendorf, Hamburg \\
\hline Zentrifuge Multifuge 3 L-R Heraeus & Thermo Scientific, Bonn \\
\hline Zentrifuge Universal 30RF & Hettich, Tuttlingen \\
\hline
\end{tabular}




\subsection{Methoden}

\subsubsection{Mikrobiologische Methoden}

Methoden und Herstellungsanweisungen für den mikrobiologischen Teil wurden, wenn nicht anders angegeben, dem Handbuch „Molecular Cloning“ (Sambrook et al., 1989) entnommen.

\subsubsection{Restriktion von DNA}

Die zu schneidenden Plasmide wurden mit der jeweiligen Restriktionsenzymen im entsprechenden Puffer nach Herstellerangaben (s. Tab. 2.7) im Heizblock bei $37^{\circ} \mathrm{C}$ inkubiert. Die Restriktionsreaktion erfolgte in einem Gesamtvolumen von 20-50 $\mu \mathrm{l}$ mit einem DNA-Gehalt von 100-1000 ng. Die restringierte DNA wurden anschließend mittels "QIAquick PCR Purification Kit" (Qiagen; Hilden) aufgereinigt oder auf einem Agarosegel (s. u.) aufgetrennt.

\subsubsection{Agarose-Gelelektrophorese von DNA}

Die Gelelektrophorese dient zur Analyse von Nukleinsäuren und beruht auf der gerichteten Bewegung geladener Moleküle im elektrischen Feld. Die Ladungsträger sind dabei die negativ geladenen Phosphatgruppen des Zucker-Phosphat-Rückgrats der Nukleinsäuren. Um DNA-Fragmente unterschiedlicher Größe aufzutrennen, wurden $0,8 \%-2 \%(\mathrm{w} / \mathrm{v})$ Agarose in $1 \times$ TAE-Puffer in der Mikrowelle aufgekocht, die kleinen DNA-Fragmenten gegenüber größeren ein schnelleres Durchwandern ermöglichen. Nach dem Abkühlen auf ca. $50^{\circ} \mathrm{C}$ wurde der Lösung ca. $0,1 \%(\mathrm{v} / \mathrm{v})$ „SERVA DNA Stain G“ (Serva, Heidelberg) zupipettiert, das die doppelsträngigen DNA-Fragmente markiert und im Gel durch UV-Licht sichtbar gemacht wird. Mit der temperierten Lösung wurde zum Polymerisieren ein etwa $3 \mathrm{~mm}$ dickes Gel in eine horizontale Elektrophorese-Kammer (Biotec-Fischer, Reiskirchen) gegossen und nach dem vollständigen Aushärten des Gels in der Laufkammer mit TAE-Puffer bedeckt. Nachdem die Proben mit $6 \times$ Probenpuffer (Loading Dye, Fermentas, St. Leon Rot) versetzt und beladen wurden, erfolgte die Auftrennung der DNA-Fragmente bei 100 120 V. Ein wichtiges Hilfsmittel zur Charakterisierung der Fragmentgrößen sind Längenstandards „1kb DNA Ladder“ oder „100bp DNA Ladder" (GeneRuler, 
Fermentas, St. Leon Rot), die Fragmente definierter Größe enthalten und parallel mit den zu untersuchenden Proben auf dem Agarosegel aufgetrennt wurden. Anschließend wurde das Gel unter UV-Licht ausgewertet und dokumentiert. Bei Bedarf wurden die Banden mit der erwarteten Größe (bspw. restringierte Plasmide) ausgeschnitten und mit Hilfe des „innuPREP DYEpure Kit“ (Analytik Jena, Jena) nach Angaben des Herstellers eluiert.

$\begin{array}{lll}10 \times \text { TAE-Puffer: } & \text { Tris- } \mathrm{HCl} & 0,4 \mathrm{M} \\ & \text { Essigsäure } & 0,2 \mathrm{M} \\ & \text { EDTA }(\mathrm{pH} 8,5) & 0,01 \mathrm{M}\end{array}$

\subsubsection{Ligation von DNA-Fragmenten}

Die Ligationsreaktion dient zur Verknüpfung von doppelsträngigen Polynukleotiden. Vorzugsweise werden Polynukleotide mit „sticky ends", d.h. mit komplementären Enden, verbunden. Sie dient hier zur Religation des Plasmides, welches vorher mit dem Enzym, Sacll, geschnitten wurde. Für die Ligationsreaktion wurde die „rapid T4DNA-Ligase“ (Fermentas, St. Leon-Rot) eingesetzt, die die Bildung einer Phosphodiester-Bindung zwischen einer 5'-Phosphatgruppe und einer 3'Hydroxylgruppe von doppelsträngigen DNA katalysiert. Die Reaktionsansätze wurden nach Herstellerangaben in einem Gesamtvolumen von 20-50 $\mu \mathrm{l}$ mit einem DNA-Gehalt von 5-100 ng gemischt und für 20 min bei $22^{\circ} \mathrm{C}$ inkubiert und anschließend für die Transformation von E. coli (s. 2.2.1.5) eingesetzt.

\subsubsection{Herstellung kompetenter Escherichia coli-Zellen}

Die Fähigkeit der Zellen, freie DNA aufzunehmen, wird als Kompetenz bezeichnet. Zur Herstellung kompetenter E. coli-Zellen wurde die Calciumchlorid $\left(\mathrm{CaCl}_{2}\right)$-Behandlung nach Cohen et al., 1972, verwendet. Hierfür wurden 200 ml LB-Medium (s. 2.1.2.1) mit $2 \mathrm{ml}$ Übernacht-Kultur von $E$. coli $\mathrm{DH} 5 \alpha$ angeimpft und bei $37^{\circ} \mathrm{C}$ unter permanentem Schütteln (225 Upm) inkubiert. Diese Kultur wurde bis zu einer $\mathrm{OD}_{600}$ von 0,3 gezogen, auf $50 \mathrm{ml}$ Falcon-Gefäße verteilt und für $10 \mathrm{~min}$ auf Eis inkubiert, wobei sie gelegentlich geschüttelt wurde. Die Zellen wurden anschließend $10 \mathrm{~min}$ bei $4.500 \times \mathrm{g}$ und $4^{\circ} \mathrm{C}$ zentrifugiert, das Zellpellet in $20 \mathrm{ml}$ einer $100 \mathrm{mM} \mathrm{CaCl}$-Lösung resuspendiert und nochmals für 20 min auf Eis inkubiert. Die Zellen wurden erneut wie beschrieben abzentrifugiert. Das Zellpellet wurde in einem Gesamtvolumen von $4 \mathrm{ml} 100 \mathrm{mM}$ 
$\mathrm{CaCl}_{2}$-Lösung, die 15\% (v/v) Glycerin enthielt, resuspendiert und $15 \mathrm{~min}$ auf Eis inkubiert. Anschließend wurden die Zellen zu je $200 \mu \mathrm{l}$ Aliquot in flüssigem Stickstoff schockgefroren und bei $-80^{\circ} \mathrm{C}$ gelagert.

\subsubsection{Transformation kompetenter Escherichia coli-Zellen}

Als Transformation bezeichnet man bei Prokaryonten die Aufnahme freier DNA aus der Umgebung und dient hier zur Einführung von Fremd-DNA über Plasmidvektoren in E. coli-Zellen nach der Hitzeschock-Methode (Hanahan, 1983). Für diesen Vorgang wurden $100 \mu \mathrm{l}$ kompetenter E. coli-Zellen (s. o.) für ca. 10 min auf Eis aufgetaut und mit 10-100 ng Plasmid-DNA vorsichtig gemischt und für 45 min auf Eis inkubiert. Nach einem Hitzeschock für $45 \mathrm{sec}$ bei $42^{\circ} \mathrm{C}$ wurden die Zellen für 2 min auf Eis gekühlt, anschließend mit $400 \mu \mathrm{l}$ sterilem LB-Medium (s. 2.1.2.1) versetzt und im Schüttelinkubator eine weitere Stunde bei $225 \mathrm{Upm}$ und $37^{\circ} \mathrm{C}$ inkubiert. Auf LBAgarplatten mit entsprechenden Antibiotika wurden anschließend $50 \mu \mathrm{l}$ und der aufkonzentrierte Rest des Transformationsansatzes zur Vereinzelung ausplattiert. Die Platten wurden über Nacht bei $37^{\circ} \mathrm{C}$ bebrütet.

\subsubsection{Isolation von Plasmid-DNA}

Zur schnellen Überprüfung auf Anwesenheit des Plasmidvektors mit der gewünschten Fremd-DNA (Insert) im Wirt wurde zunächst eine geringe Menge Plasmid-DNA mittels alkalischer Lyse nach der Methode von Birnboim \& Doly (1979) isoliert. Dazu wurden zunächst Zellen einzelner Kolonien der ausplattierten Transformationsansätze mit einer sterilen Pipettenspitze abgenommen, auf eine neu beschriftete LB-Agarplatte mit entsprechenden Antibiotika an definierter Stelle ausgestrichen und die Pipettenspitze mit verbliebenen Zellen in das Röhrchen mit $3 \mathrm{ml}$ vorgelegten LB-Medium eingeworfen und bei $37^{\circ} \mathrm{C}$ im Schüttelinkubator inkubiert. Am nächsten Tag wurde diese ÜbernachtKultur für 10 min bei $4.600 \times g$ pelletiert. Die Pellets wurden in $250 \mu$ kalter Puffer P1 resuspendiert. Die Zellen wurden durch Zugabe von $250 \mu \mathrm{l}$ Puffer P2 lysiert und für 5 min bei Raumtemperatur (RT) inkubiert. Zur Fällung genomischer DNA wurden $300 \mu \mathrm{l}$ kalter Puffer P3 zugegeben, erneut durch Invertieren gemischt und für 20 min auf Eis inkubiert. Die Entfernung der genomischen DNA, sowie eines Großteil der Proteine erfolgte durch Zentrifugation für $10 \mathrm{~min}$ bei $16.000 \times \mathrm{g}$ und $4^{\circ} \mathrm{C}$. Der Überstand, in dem sich die Plasmid-DNA befand, wurde in ein frisches Gefäß überführt und mit $525 \mu \mathrm{l}$ Isopropanol durch 20 min Inkubation bei RT gefällt und anschließend für $10 \mathrm{~min}$ bei 
$16.000 \times \mathrm{g}$ und $4^{\circ} \mathrm{C}$ abzentrifugiert. Das DNA-Pellet wurde mit $500 \mu \mathrm{l} 70 \%$ Ethanol gewaschen, abschließend für $10 \mathrm{~min}$ bei $16.000 \times$ g zentrifugiert und der Überstand entfernt. Das Pellet wurde anschließend vollständig getrocknet und dann in $50 \mu$ Aqua bidest aufgenommen.

$\begin{array}{lll}\text { Puffer P1: } & \text { Tris-HCl }(\mathrm{pH} 8,0) & 50 \mathrm{mM} \\ & \text { EDTA } & 10 \mathrm{mM} \\ & \text { RNase A } & 100 \mu \mathrm{g} / \mathrm{ml} \\ & \text { Lagerung bei } 4^{\circ} \mathrm{C} & \\ \text { Puffer P2 } & \mathrm{NaOH} & 0,2 \mathrm{M} \\ & \text { SDS } & 1 \%(\mathrm{w} / \mathrm{v}) \\ \text { Puffer P3 } & \text { Natriumacetat }(\mathrm{pH} 5,5) & 3 \mathrm{M}\end{array}$

\subsubsection{Isolation von Plasmid-DNA für die Transfektion eukaryotischer Zellen}

Zur Transfektion eukaryotischer Zellen wurde das "EndoFree Plasmid Maxi Kit“ (Qiagen, Hilden) nach Herstellerangaben verwendet, um große Mengen an hochreiner Plasmid-DNA zu isolieren. Denn mittels dieses Kits wird die DNA über Anionenaustausch-Membranen isoliert und gleichzeitig die Konzentration an Endotoxinen, die eine störende Auswirkung auf die Transfektion von eukaryotischen Zellen haben können, stark reduziert.

\subsubsection{Konzentrationsbestimmung von Nukleinsäuren}

Die Konzentration von Nukleinsäuren wurde photometrisch bei einer Wellenlänge von $\lambda=260$ nm mit Hilfe des „Spectrophotometer ND-1000“ (PeqLab, Erlangen) bestimmt. Aus dem Verhältnis von $\mathrm{OD}_{260}$ zu OD 280 erhält man eine Aussage über die Reinheit der Nukleinsäuren. Ein Ko-effizient zwischen 1,9 und 2,2 deutet auf reine RNA, und ein Wert zwischen 1,7 und 2,0 ist für reine DNA beschrieben.

\subsubsection{Genexpressionsanalysen}

\subsubsection{Isolation der Gesamt-RNA aus eukaryotischen Zellen}

Die Gesamt-RNA-Isolation aus eukaryotischen Zellen erfolgte mit dem „High Pure RNA Isolation Kit“ (Roche, Mannheim). Bei diesem Kit wird die RNA affinitätschromatographisch über Säulen aufgereinigt. Es wurde nach Herstellerprotokoll verfahren. 


\subsubsection{Isolation der Gesamt-RNA aus Geweben}

Die Isolation von Gesamt-RNA aus murinen Geweben erfolgte mittels einer Trizol (Invitrogen, Darmstadt) basierten Methode. Dazu wurde das Gewebe in $1 \mathrm{ml}$ Trizol mit einem Handgewebehomogenisator zerkleinert. Nachdem der Lösung $200 \mu \mathrm{l}$ Chloroform zugefügt wurden, wurde diese sehr gut gemischt, für 5 min bei RT inkubiert und für 15 min bei $20.000 \times g$ und $4^{\circ} \mathrm{C}$ zentrifugiert. Die obere, klare Phase, die die RNA enthielt, wurde in ein neues Gefäß überführt und dem Ansatz $500 \mu \mathrm{l}$ Isopropanol zugefügt. Die Fällung der RNA erfolgte für $10 \mathrm{~min}$ bei $\mathrm{RT}$ und anschließender Zentrifugation für $30 \mathrm{~min}$ bei $13.000 \times \mathrm{g}$ und $4^{\circ} \mathrm{C}$. Das RNA-Pellet wurde einmal mit $1 \mathrm{ml}$ $70 \%$ Ethanol gewaschen und nochmals für $10 \mathrm{~min}$ bei $20.000 \times \mathrm{g}$ und $4^{\circ} \mathrm{C}$ pelletiert und vollständig getrocknet. Anschließend wurde ein DNase I-Verdau durchgeführt, da diese RNA für Expressionsanalysen mittels qRT-PCR (s. 2.2.2.4) verwendet werden sollte. Hierfür wurde das RNA-Pellet in ein DNase I-Verdau-Ansatz (s. u.) aufgenommen und für 20 min bei $37^{\circ} \mathrm{C}$ inkubiert. Nach Verdau wurde dem Ansatz $150 \mu \mathrm{l} \quad \mathrm{H}_{2} \mathrm{O} \quad$ (RNase-frei) zugefügt und anschließend $200 \mu \mathrm{l}$ Phenol/Chloroform/lsoamylalkohol. Nachdem die Lösung $30 \mathrm{sec}$ gevortext wurde, wurde sie für 2 min bei $20.000 \times g$ und $4^{\circ} \mathrm{C}$ zentrifugiert. Die obere, klare Phase, die die RNA enthält, wurde in ein neues Gefäß überführt und mit $20 \mu l 3 \mathrm{M}$ Natriumacetat $(\mathrm{pH}$ $4,8)$ und $200 \mu$ Isopropanol versetzt. Die Fällung der RNA erfolgte für 30 min bei $4^{\circ} \mathrm{C}$ und anschließender Zentrifugation für $30 \mathrm{~min}$ bei $20.000 \times \mathrm{g}$ und $4^{\circ} \mathrm{C}$. Zur Aufreinigung der RNA wurde das RNA-Pellet zweimal mit $1 \mathrm{ml} 70 \%$ EtOH gewaschen und für $5 \mathrm{~min}$ bei $20.000 \times \mathrm{g}$ und $4^{\circ} \mathrm{C}$ pelletiert. Abschließend wurde das RNA-Pellet vollständig bei RT getrocknet und in $15 \mu \mathrm{l} \mathrm{H}_{2} \mathrm{O}$ (RNase-frei) aufgenommen. Mit Hilfe des "Spectrophotometer ND-1000" (PeqLab, Erlangen) wurde photometrisch die Konzentration der RNA gemessen (s. 2.2.1.8). Die isolierte RNA wurde bei $-80^{\circ} \mathrm{C}$ aufbewahrt.

$\begin{array}{ll}\text { Bestandteil } & \text { Volumen } \\ \text { DNase I }(10 \mathrm{U} / \mu \mathrm{l}) & 1 \mu \mathrm{l} \\ \text { RNase OUT }(40 \mathrm{U} / \mu \mathrm{l}) & 0,5 \mu \mathrm{l} \\ 10 \text { x DNase I Incubation Buffer } & 5 \mu \mathrm{l} \\ \mathrm{H}_{2} \mathrm{O} \text { (nuklease-frei) } & \text { ad } 50 \mu \mathrm{l}\end{array}$




\subsubsection{Reverse Transkription}

Zur Genexpressionsanalyse mittels qRT-PCR wurde isolierte RNA in einen DNAStrang, die sogenannte cDNA, mit dem iScript cDNA Synthese Kit (Bio-Rad) umgeschrieben. Hierbei wurde eine RNA-abhängige DNA-Polymerase eingesetzt. Für eine cDNA-Synthese wurden $1 \mu \mathrm{g}$ RNA eingesetzt. Das Reaktionsgemisch wurde nach folgendem Schema in einem Gesamtvolumen von $20 \mu \mathrm{l}$ Ansatz zusammenpipettiert.

$\begin{array}{ll}\text { Bestandteil } & \text { Volumen } \\ 5 \mathrm{x} \text { iScript reaction mix } & 4 \mu \mathrm{l} \\ \text { iScript reverse Transkriptase } & 1 \mu \mathrm{l} \\ \text { mRNA-Template }(1 \mu \mathrm{g}) & \mathrm{x} \mu \mathrm{l} \\ \mathrm{H}_{2} \mathrm{O} \text { (nuklease-frei) } & \text { ad } 20 \mu \mathrm{l}\end{array}$

Die Umschreibung in die cDNA erfolgte in Thermo cycler des Typs „T3000“ (Biometra, Göttingen). Das Gemisch aus Oligo(dT) und Random Hexamer-Primer, das im Kit enthalten sind, lagert sich an den Poly-A-Schwanz oder willkürlich an den mRNAs an und diente dabei als Startpunkt für die Reverse Transkriptase. Dabei wurde der Ansatz für 5 min auf $25^{\circ} \mathrm{C}$ erhitzt, gefolgt von der Umschreibung für $30 \mathrm{~min}$ bei $42^{\circ} \mathrm{C}$. Der Ansatz wurde abschließend für 5 min auf $85^{\circ} \mathrm{C}$ erhitzt, um die Reverse Transkriptase $z u$ inaktivieren und die Proben daraufhin gekühlt. Jede Probe wurde in einem Verhältnis 1:5 mit nuklease-freiem Wasser verdünnt und bei $-20^{\circ} \mathrm{C}$ gelagert. Diese cDNA konnte nun als Ausgangsmaterial für die geplanten Real-Time PCR-Reaktionen dienen (s. u.).

\subsubsection{Quantitative real-time PCR (qRT-PCR)}

Mit der Real-Time-PCR ist es möglich mRNA aus Zellen oder Geweben zu quantifizieren. Dafür wurde zunächst die mRNA durch eine Reverse Transkription in cDNA umgeschrieben (s. 2.2.2.3) und anschließend mit dieser als Matrize eine konventionelle PCR Reaktion durchgeführt. Zur Quantifizierung eines spezifischen Produkts ist bei dieser PCR dem Reaktionsansatz u. a. der Fluoreszenzfarbstoff SYBR $^{\circledR}$ Green zugesetzt, der unspezifisch an doppelsträngiger DNA unter Veränderung des Fluoreszenzspektrums bindet. Somit lässt sich bei jedem Zyklus der PCR in Echtzeit die Fluoreszenz als Maß für die Produktentstehung verfolgen. Bei der qRT-PCR ist jede einzelne Reaktion durch den Zyklus charakterisiert. Die Anzahl des 
Zyklus, ab der die Fluoreszenz erstmalig über die Hintergrundfluoreszenz ansteigt und sich die Kurve im exponentiellen Bereich der Reaktion befindet, wird als $\mathrm{C}_{\mathrm{t}}$-Wert (threshold cycle) bezeichnet. Eine absolute Quantifizierung erfolgt anhand der jeweils gleichzeitig ermittelten Standardkurve, die Aufschluss über die Ausgangsmenge der amplifizierten Sequenz gibt. Alternativ kann eine relative Quantifizierung vorgenommen werden, bei der die $\mathrm{C}_{\text {t-Werte }}$ zweier Proben unter zwei Bedingungen in Bezug auf ein Referenzgen miteinander verglichen wird. Je höher der $C_{t}-$ Wert beispielsweise ist, also je mehr Zyklen notwendig sind, um den einer bestimmten Produktmenge entsprechenden Fluoreszenzwert zu erreichen, desto geringer war die Ausgangsmenge der amplifizierten DNA. Am Ende der Reaktion kann zudem eine Dissoziationskurve des Produktes erstellt werden, indem die Änderung des Fluoreszenzsignals gegen die Temperatur aufgetragen wird. Unspezifisch entstandene Produkte lassen sich damit detektieren.

In dieser Arbeit wurde die relative Quantifizierung durchgeführt. Somit wurde die Expression eines Gens in zwei unterschiedlichen Bedingungen miteinander verglichen. Mit der folgenden Formel kann der Expressionsunterschied (fold change) über die $\mathrm{C}_{\mathrm{t}}$-Werte des zu untersuchenden Gens in beiden Bedingungen im Vergleich zu den $C_{t}-$ Werten eines Referenzgens ermittelt werden (Talaat et al., 2002).

$$
\text { fold change }=2^{-\Delta \Delta C \mathrm{t}}
$$

mit $\Delta \Delta \mathrm{C}_{\mathrm{t}}=\left[\mathrm{C} \mathrm{t}(\right.$ Targetgen $\left.)-\mathrm{C}_{\mathrm{t}(\text { Referenzgen })}\right]$ Bedingung1 $-\left[\mathrm{C} \mathrm{t}(\right.$ Targetgen $\left.)-\mathrm{C}_{\mathrm{t}(\text { Referenzgen })}\right)$ Bedingung2

Die Normalisierung der unterschiedlichen Syntheserate erfolgte durch die Referenzgene Tbp und Gapdh, welche konstitutiv exprimiert werden. Die verwendeten Oligonukleotide sind in Tab. 2.8 aufgeführt. Zur Durchführung der quantitativen RealTime-PCR für jedes Gen wurde ein Gemisch aus allen benötigten Komponenten mit Ausnahme der cDNA (s. PCR-Reaktionsmix) angesetzt und jeweils $8 \mu \mathrm{l}$ in Triplikaten in die Vertiefungen einer 384-Mikrotiterplatte pipettiert. Abschließend wurde $2 \mu \mathrm{l}$ cDNA (10 ng) verdünnt in nuklease-freiem Wasser in jede Vertiefung hinzugefügt. Die 384Mikrotiterplatte wurde zugesiegelt, abzentrifugiert und gemäß dem folgenden Protokoll im Taqman ABI PRISMA 7900 HT detection system (Applied Biosystems) ausgeführt. Die Daten wurden mit Hilfe der Software "SDS Version 2.4“ (Applied Biosystems, Darmstadt) ausgewertet. 


$\begin{array}{lll}10 \times \text { PCR-Puffer: } & \text { Tris- } \mathrm{HCl}(\mathrm{pH} \mathrm{8,8)} & 0,75 \mathrm{M} \\ & \text { Ammoniumsulfat } & 0,2 \mathrm{M} \\ & \text { Tween-20 } & 0,1 \%(\mathrm{v} / \mathrm{v}) \\ \text { SYBR } \circledast \text { Green Master Mix: } & 10 \times \mathrm{PCR}-\text { Puffer } & 2,5 \mathrm{ml} \\ & 25 \mathrm{mM} \mathrm{MgCl} 2 & 3 \mathrm{ml} \\ & \text { SYBR green }(1: 100) & 31.3 \mu \mathrm{l} \\ & 20 \mathrm{mM} \text { dNTP-Mix } & 250 \mu \mathrm{l} \\ & 5 \mathrm{U} / \mu \mathrm{l} \text { Taq-Polymerase } & 100 \mu \mathrm{l} \\ 10 \% \text { Triton X-100 } & 652 \mu \mathrm{l} \\ 1 \mathrm{M} \text { Trehalose } & 7,5 \mathrm{ml}\end{array}$

Alle Lösungen wurden mit DEPC- $\mathrm{H}_{2} \mathrm{O}$ angesetzt. Die Trehalose wurde in $10 \mathrm{mM}$ Tris$\mathrm{HCl} \mathrm{pH} \mathrm{8,0} \mathrm{gelöst.}$

PCR-Reaktionsmix:

PCR-Programm:

Aktivierung Taq-Polymerase

Denaturierung

Annealing / Elongation

Schmelzkurvenanalyse

$\begin{array}{ll}\text { SYBR } \AA \text { Green Master Mix } & 5,6 \mu \mathrm{l} \\ \text { fw-Primer }(10 \mu \mathrm{M}) & 0,3 \mu \mathrm{l} \\ \text { rv-Primer }(10 \mu \mathrm{M}) & 0,3 \mu \mathrm{l} \\ \text { nuklease-freies Wasser } & 1,8 \mu \mathrm{l}\end{array}$

$95^{\circ} \mathrm{C}$

$95^{\circ} \mathrm{C}$

$60^{\circ} \mathrm{C}$

$95^{\circ} \mathrm{C}$

$60-95^{\circ} \mathrm{C}$

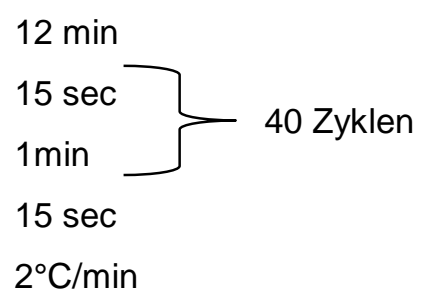

\subsubsection{Qualitätskontrolle der qRT-PCRs}

Bei der Auswahl von Primern für die qRT-PCR sollte ihre Schmelztemperatur möglichst $60^{\circ} \mathrm{C}$ und die Fragmentlänge zwischen 50-150bp ergeben. Da die qRT-PCR nach der $\Delta \Delta C_{t}$-Methode (s. 2.2.2.4) ausgewertet wurde, wurde abschließend ihre Effizienz geprüft. Eine Primereffizienz von 100\% bedeutet, dass sich die PCRProduktmenge mit jedem PCR-Zyklus unter optimalen Bedingungen verdoppelt. Um die Effizienz zu überprüfen, wurde eine Zelllinie oder Gewebe mit hohen Expression des zu untersuchenden Gens in BioGPS Datenbank (Wu et al., 2009) ausgesucht und eine Verdünnungsreihe mit bekannten cDNA-Konzentrationen erstellt. Die gemessenen $\mathrm{C}_{\mathrm{t}}$-Werte wurden gegen die entsprechenden cDNA-Konzentration aufgetragen und so die Steigung der Gerade mit Hilfe der Software „SDS Version 2.4" ermittelt. Die Effizienz wurde mit der folgenden Formel errechnet: 


$$
\text { Effizien } z=10^{\left(-\frac{1}{\text { slope }}\right)}-1
$$

Bei einem Slope-Wert von -3,32 ergibt sich dabei eine Effizienz von 100\%. Primer, bei der die Effizienz zwischen $90-110 \%$ lagen, wurden in der qRT-PCR eingesetzt. Außerdem wurde für jedes Primer-Paar das PCR-Produkt auf einem 2\% Agarosegel analysiert, um nachzuprüfen, dass nur ein einziges Genprodukt mit der richtigen Größe erzeugt wurde.

\subsubsection{Proteinbiochemische Methoden}

\subsubsection{Isolation des Gesamtproteins aus eukaryotischen Zellen}

Für die Proteinisolation wurden grundsätzlich die Zellen so ausgesät, dass sie zum Zeitpunkt der Aufarbeitung eine Konfluenz von 70-80\% aufwiesen. Zur Untersuchung des Gesamtproteins wurden die Zellen einmal mit kaltem PBS gewaschen und anschließend mit RIPA-Puffer lysiert. Dem Puffer wurden immer frisch Proteaseinhibitoren („100x Proteaseinhibitor Cocktail“, Roche, Mannheim) und Phosphataseinhibitoren („PhosStop“, Roche, Mannheim) laut Herstellerangaben zugegeben. Die Zellen wurden daraufhin mit einem Zellschaber abgelöst und in ein $1,5 \mathrm{ml}$ Gefäß überführt. Das Lysat wurde für 30 min auf Eis inkubiert, kurz gevortext und die Zelltrümmer für $10 \mathrm{~min}$ bei $13.000 \mathrm{Upm}$ und $4^{\circ} \mathrm{C}$ abzentrifugiert. Der proteinhaltige Überstand wurde in ein neues $1,5 \mathrm{ml}$ Gefäß überführt und ein Aliquot zur Bestimmung der Proteinkonzentration eingesetzt.

\begin{tabular}{|c|c|c|}
\hline \multirow[t]{5}{*}{ RIPA-Puffer: } & Tris & $50 \mathrm{mM}$ \\
\hline & $\mathrm{NaCl}$ & $150 \mathrm{mM}$ \\
\hline & SDS & $0,1 \%(w / v)$ \\
\hline & Natriumdeoxycholat & $0,5 \%(w / v)$ \\
\hline & Triton X-100 & $1 \%(v / v)$ \\
\hline
\end{tabular}

\subsubsection{Isolation des Gesamtproteins aus Geweben}

Das jeweilige Gewebestück wurde zweimal mit eiskaltem PBS gewaschen, anschließend in ein $1,5 \mathrm{ml}$ Gefäß überführt und mit $300 \mu$ RIPA-Lysepuffer versetzt. Die Probe wurde mit einem Hand-Homogenisator zerkleinert und $2 \mathrm{~h}$ in einem Überkopfschüttler bei $4^{\circ} \mathrm{C}$ rotiert. Danach wurde die Probe für $30 \mathrm{~min}$ bei $14.000 \mathrm{Upm}$ und $4^{\circ} \mathrm{C}$ zentrifugiert. Nach der Zentrifugation erhielt man ein Pellet aus Debris und 
DNA, eine Interphase mit Proteinen, sowie eine obere Lipidschicht. Die Interphase mit ausschließlich Proteinen wurde in ein neues Gefäß überführt. Bei einer sehr dicken Lipidschicht können die Proben noch ein zweites Mal zentrifugiert werden, um die Lipide restlos aus dem Lysat zu trennen. Die Messung der Proteinkonzentration erfolgte wie in 2.2.3.3 beschrieben.

\subsubsection{Messung der Proteinkonzentration}

Die Bestimmung der Proteinkonzentration in einem Zelllysat erfolgte mit Hilfe des „BCA Pierce Protein Assay Kit“ nach Herstellerangaben. Die Methode beruht auf der kolorimetrischen Detektion von $\mathrm{Cu}_{1+-}$-lonen durch Bicinchoninsäure (BCA). In einem alkalischen Milieu wurde $\mathrm{Cu}_{2+-}$ Ionen zu $\mathrm{Cu}_{1_{+}-}$Ionen durch Proteine reduziert. $\mathrm{Cu}_{1_{+}-}$ Ionen bildeten mit Bicinchoninsäure einen Farbkomplex mit einem Absorptionsmaximum von $562 \mathrm{~nm}$.

\subsubsection{SDS-Polyacrylamidgelelektrophorese (SDS-PAGE)}

Um Proteine in Zelllysaten nachzuweisen, wurden diese in Abhängigkeit vom Molekulargewicht per SDS-Polyacrylamidgel-Elektrophorese nach Laemmli (1970) aufgetrennt. Die hierfür verwendeten Polyacrylamidgele setzen sich aus einem Trenngel zur Auftrennung von Protein mit basischem $\mathrm{pH}-$ Wert und einem darüber liegenden Sammelgel zum Fokussieren der Proben mit neutralem pH-Wert zusammen. Die Proteine wandern in einem elektrischen Feld durch die Poren eines Polyacrylamidgels je nach Molekülgröße. Um dieses zu ermöglichen, wurden die Proteine vor dem Auftragen auf das Gel mit SDS Probenpuffer inkubiert, indem das anionische Detergenz SDS über hydrophobe Wechselwirkungen an Proteine proportional zu ihrer Größe bindet und ihnen seine anionische Kopfgruppe eine hohe negative Ladung verleiht.

Die Gele wurden nach den unten angegebenen Zusammensetzungen gegossen. Zunächst wurde das Trenngel zwischen zwei abgedichteten Glasplatten bis auf $1,5 \mathrm{~cm}$ unterhalb der Oberkante der Deckplatte gegossen. Anschließend wurde das Gel vorsichtig mit Isopropanol überschichtet, um es vor Austrocknung zu schützen und eine gerade Linie des Gels zu erzielen. Nach Polymerisierung wurde das Isopropanol vollständig entfernt und das Sammelgel oberhalb des Trenngels gegossen. 


$\begin{array}{lll}\text { Sammelgel (5\%): } & \text { 1,5 M Tris }+2 \% \text { SDS }(\mathrm{pH} \mathrm{6,8)} & 630 \mu \mathrm{l} \\ & \text { Acrylamid/Bisacrylamid 30\% } & 830 \mu \mathrm{l} \\ & \text { APS (10\% w/v) } & 50 \mu \mathrm{l} \\ & \text { TEMED } & 5 \mu \mathrm{l} \\ & \mathrm{H}_{2} 0 \text { (A. bidest) } & 3,45 \mathrm{ml} \\ \text { Trenngel (10\%): } & \text { 1,5 M Tris + 2\% SDS }(\mathrm{pH} 8,8) & 5 \mathrm{ml} \\ & \text { Acrylamid/Bisacrylamid 30\% } & 6,7 \mathrm{ml} \\ & \text { APS (10\% w/v) } & 200 \mu \mathrm{l} \\ & \text { TEMED } & 20 \mu \mathrm{l} \\ & \mathrm{H}_{2} 0 \text { (A. bidest) } & 7,9 \mathrm{ml}\end{array}$

Vor dem Auftragen wurden die zu untersuchenden Proteine mit $4 \times$ konzentriertem Probenpuffer „Roti-Load 1“ (Roth, Karlsruhe) versetzt und für $5 \mathrm{~min}$ bei $95^{\circ} \mathrm{C}$ im Heizblock denaturiert. Nach Aushärten wurde das Gel in einer vertikalen MinigelElektrophoresekammer (Biometra, Göttingen) eingespannt, mit Elektrophoresepuffer eingefüllt. Das Einlaufen der Proben im Sammelgel erfolgte ca. 30 min bei $90 \mathrm{~V}$, die Auftrennung im Trenngel für $90 \mathrm{~min}$ bei $140 \mathrm{~V}$. Zum Abschätzen des Molekulargewichts der Proteine wurde parallel ein Proteinmarker („Precision Dual Color Protein Standard“, Biorad, München) mit aufgetrennt.

$\begin{array}{lll}\text { 1× Elektrophoresepuffer: } & 25 \mathrm{mM} \text { Tris } & 3 \mathrm{~g} \\ & 192 \mathrm{mM} \text { Glycin } & 14,4 \mathrm{~g} \\ & \mathrm{SDS} & 1 \mathrm{~g} \\ & \mathrm{H}_{2} \mathrm{O} \text { (A. bidest) } & \text { ad } 1 \mathrm{I}\end{array}$

\subsubsection{Western Blot}

Der Western Blot ist eine Methode, bei der elektrophoretisch aufgetrennte Proteine aus einem Trenngel auf einen geeigneten Träger, z. B. Nitrozellulose (Towbin et al., 1979) oder PVDF, übertragen werden. In dieser Arbeit erfolgte der elektrophoretische Transfer auf Nitrozellulosemembranen „Hybond-C Extra“ (Amersham Biosciences, Freiburg) mit dem Semidry-Blot-System. Für den Semidry-Blot wurden eine Nitrozellulosemembran und das Gel für ca. $15 \mathrm{~min}$ in Transferpuffer äquilibriert. Zunächst wurden sechs Whatman-Papiere "GB33Whatman-Papier B003" (Heinemann Labortechnik, Duderstadt) mit Transferpuffer angefeuchtet und anschließend das Sandwich luftblasenfrei aufgebaut, beginnend mit 3 Lagen Whatman-Papier, darauf die Membran und das Gel, welches wiederum mit drei Lagen 
Whatman-Papier abgedeckt wurde. Nach dem Schließen der Blotkammer (Biometra, Göttingen) mit der Kathode erfolgte der Transfer in die Membran durch einen konstanten Strom von $10 \mathrm{~V}$ für $90 \mathrm{~min}$. Um den erfolgreichen Proteintransfer zu kontrollieren, erfolgte ein reversibler visueller Nachweis der Proteinbanden auf der Nitrozellulosemembran mit einer Ponceau-S-Lösung (Merck, Darmstadt), die unspezifisch alle Proteine anfärbt.

Auf der Membran lassen sich die transferierten Proteine mit geeigneten Antikörpern nachweisen. Die hier verwendeten Antikörper sind unter Tab. 2.6 aufgeführt. Die Membran wurde zunächst für $1 \mathrm{~h}$ bei RT in 5\% (w/v) Magermilchpulver (Bio-Rad) in TBS-T inkubiert, um die unspezifischen Proteinbindungsstellen abzublocken. Nachfolgend wurde die Membran mit dem in 5\% (w/v) Magermilchpulver in TBS-T verdünnten Primärantikörper nach Herstellerangaben über Nacht bei $4^{\circ} \mathrm{C}$ inkubiert. Vor der Inkubation mit dem Sekundärantikörper wurden die ungebundenen restlichen Primärantikörper durch dreimaliges Waschen je 5 min mit TBS-T entfernt. Es folgte eine 1-stündige Inkubation bei RT mit einem HRP-gekoppelten (HRP, horseradish peroxidase) Sekundärantikörper, der gegen den Fc-Teil des Primärantikörpers gerichtet ist. Die Membran wurde daraufhin dreimal für 5 min mit TBS-T gewaschen, um ungebundene Antikörper zu entfernen. Zur Sichtbarmachung der Proteine wurde die Membran anschließend für 5 min mit dem luminolhaltigen Detektionsreagenz „ECL Plus“ (GE Healthcare, Freiburg) im Volumenverhältnis 1:1 für 2 min inkubiert. Das Substrat in der ECL-Lösung reagierte mit HRP und setzt ein lichtemittierendes Präzipitat um den Antigen-Antikörper-Komplex um, welches mit Hilfe des „LAS 4000 Imager“ (Fujifilm/GE Healthcare, Freiburg) sichtbar gemacht werden kann.

1× Transferpuffer:

TBS-T:

$\begin{array}{ll}25 \mathrm{mM} \text { Tris } & 3 \mathrm{~g} \\ 192 \mathrm{mM} \text { Glycin } & 14,4 \mathrm{~g} \\ \text { Methanol } & 20 \%(\mathrm{v} / \mathrm{v}) \\ \left.\mathrm{H}_{2} \mathrm{O} \text { (A. bidest; } \mathrm{pH} 8,3\right) & \text { ad } 1 \mathrm{I} \\ 20 \mathrm{mM} \text { Tris } & 2,5 \mathrm{~g} \\ 137 \mathrm{mM} \mathrm{NaCl} & 8 \mathrm{~g} \\ \mathrm{H}_{2} \mathrm{O}(\text { A. bidest; } \mathrm{pH} 7,6) & \text { ad } 1 \mathrm{I} \\ \text { Tween-20 } & 0,1 \%(\mathrm{v} / \mathrm{v})\end{array}$




\subsubsection{Zellbiologische Methoden}

\subsubsection{Kultivierung von Zellen}

Die verwendeten Zellen wurden bei $37^{\circ} \mathrm{C}$ unter $5 \% \mathrm{CO}_{2}$ Partialdruck in einer wassergesättigten Atmosphäre inkubiert. Die Zellen wurden bei einer $90 \%$-igen Konfluenz passagiert. Dazu wurde die Kultur einmal mit PBS gewaschen und mit $1 \mathrm{ml}$ 1×Trypsin/EDTA-Lösung durch Inkubation im Brutschrank abgelöst. Die enzymatische Reaktion wurde durch Zugabe von $9 \mathrm{ml}$ Kulturmedium abgestoppt und im Verhältnis 1:10 in eine neue beschriftete Kulturflasche überführt.

\subsubsection{Biochemische Transfektion von eukaryotischen Zellen}

Als Transfektion bezeichnet man das Einbringen von RNA oder DNA in eukaryotische Zellen. Man unterscheidet zwischen transienter und stabiler Transfektion. Bei der transienten Transfektion integriert das genetische Material nicht in das Genom der Zielzelle, während bei der stabilen Transfektion DNA in das Wirtsgenom eingebaut wird. Die biochemische Transfektion wurde mit Hilfe des „Nanofectin Kit“ (PAA, Cölbe) nach Herstellerangaben durchgeführt. Diese Methode beruht auf positiv geladenen Polymeren, die einen Komplex mit den Nukleinsäuren bilden, welche wiederum in Nanopartikeln eingelagert und durch Endozytose in die Zelle aufgenommen werden. Dieses Kit wurde für transiente Transfektionen eingesetzt, wobei $50 \mathrm{ng}$ DNA-Menge und das DNA:Nanofectin Verhältnis von 1:3,2 verwendet wurde. Da sie transient transfiziert wurde, wurden sie 24 - $48 \mathrm{~h}$ nach Transfektion für die folgenden Versuche eingesetzt.

\subsubsection{Physikalische Transfektion von eukaryotischen Zellen}

Die physikalische Transfektion wurde mit Hilfe des „Amaxa ${ }^{\circledR}$ Cell Line Nucleofector $®$ Kit V“' (Lonza, Basel) nach Herstellerangaben durchgeführt. Nukleofektion ist eine spezielle Form der Elektroporation, bei der die Zellmembran durch elektrische Impulse kurzzeitig Poren bildet. Die Nukleofektor-Lösung ermöglicht der DNA direkt in den Zellkern zu gelangen. Dieses Kit wurde für stabile Transfektionen eingesetzt, wobei $2 \mu \mathrm{g}$ DNA-Menge und das Nucleofektor-Programm T-024 verwendet wurde. Für die stabile Transfektion von Zellen wurde dem Kulturmedium 24 - 48 h nach Transfektion das entsprechende Selektionsantibiotikum zugefügt. 


\subsubsection{Lentivirale Transfektion von eukaryotischen Zellen}

Lentivirale Vektoren können als Retroviren sowohl proliferierende als auch ruhende Zellen infizieren und ihr genetisches Material in das Wirtsgenom integrieren. Mit dieser Methode wurden in dieser Arbeit sowohl stabile Knockdown als auch Überexpression von gewünschten Genen generiert. Zur Virusherstellung wurde zunächst die HEK 293T Zellen transient durch Ca-Phosphat Präzipitation mit Plasmiden wie pVSG-G (Envelope) und pCMV $\triangle$ R8.91 (Packaging), welche die Gene für die Virusherstellung exprimieren, und das Plasmid mit Gen von Interesse (Vektor) (s. Tab.2.9) in einem Verhältnis von Vektor:Packaging:Envelope 3:2:1 ko-transfiziert. Hierbei wurde am darauffolgenden Tag dem Medium Na-Butyrat (1:50) als Induktor der lytischen Replikation zugegeben. Die viralen Partikel, die von den Zellen in den Überstand abgesondert wurden, wurden $48 \mathrm{~h}$ nach der Ko-transfektion mit dem lentiviral enrichment Reagenz (MoBiTec) nach Herstellerangaben aufkonzentriert und abschließend eingesetzt, um die Zielzellen zu transduzieren. Die erfolgreich transduzierten Zellen wurden durch Zugabe von Puromycin (Sigma Aldrich) in das Kulturmedium $48 \mathrm{~h}$ nach Transfektion selektioniert.

\subsubsection{Messung der Viabilität und Proliferation}

\subsection{MTT-Assay}

Der MTT-Assay wird zur Bestimmung der Viabilität der eukaryotischer Zellen eingesetzt (Mosmann, 1983). Der gelbe, membrangängige Farbstoff MTT (3-(4,5Dimethylthiazol-2-yl)-2,5-diphenyltetrazoliumbromide) wird durch mitochondriale Dehydrogenasen stoffwechselaktiver Zellen in schwerlösliche, blauviolette FormazanKristalle umgesetzt. Nach Solubilisierung der Kristalle kann der Farbstoff anschließend durch kolorimetrische Messung bei $540 \mathrm{~nm}$ in einem Plattenphotometer "Sunrise“ (Tecan, Männedorf, Schweiz) gemessen werden.

Die Zellen wurden in einem well einer 24-well Platte ausgesät und zur Bestimmung der Toxizität mit der zu testenden Substanz behandelt. Grundsätzlich wurde nach $96 \mathrm{~h}$ das Kulturmedium entfernt und das mit $10 \%$ MTT-Reagenz $(5 \mathrm{mg} / \mathrm{ml})$ versetzte Medium in einem Gesamtvolumen von $500 \mu \mathrm{l}$ vorsichtig auf die Zellen gegeben und für weitere $3 \mathrm{~h}$ bei $37^{\circ} \mathrm{C}$ und $5 \% \mathrm{CO}_{2}$ inkubiert. Anschließend wurden die Zellen mit $500 \mu \mathrm{l} \mathrm{5 \%}$ Ameisensäure + 63\% Isopropanol + 32\% DMSO lysiert bzw. solubilisiert und zur photometrischen Bestimmung eingesetzt. 


\subsection{Proliferationsassay}

Der xCELLigence Assay ermöglicht die Proliferation, Zelladhäsion und Zellmorphologie kontinuierlich in Echtzeit zu quantifizieren. Diese Methode beruht auf der Messung des Wechselstromwiderstandes (Impedanz) von Zellen, welcher sich je nach Anzahl, Adhäsion und Form der Zellen verändert. Dabei wurden sie nach Herstellerangaben je nach Zelllinie in einer Dichte von $1-5 \times 10^{3}$ Zellen/well auf die dafür vorgesehenen Platten (E Plate16; Roche, Mannheim), welche mit Gold beschichtet sind, ausgesät und an dem „xCELLigence RTCA DP-System“ (Roche, Mannheim) für $96 \mathrm{~h}$ gemessen.

\subsection{Soft Agar Colony Formation Assay}

Der Soft Agar Colony Formation Assay (Hamburger und Salmon, 1977) prüft das anheftungsunabhängige Wachstum (anchorage independent growth) von Zellen, indem sie in einem halbfesten Soft Agar Nährboden ausgesät werden, wodurch der Zellkontakt zwischen benachbarten Zellen und auch die Anheftung an das Wachstumssubstrat inhibiert werden. Da nicht transformierte Epithelzellen in der Regel abhängig von der Anheftung an das Substrat sind, gehen sie in einem Soft Agar Nährboden zugrunde. Im Gegensatz dazu bilden transformierte Zellen aus einer Einzelzellsuspension Kolonien aus, welche ein Kennzeichen von Malignität sind. Je größer und zahlreicher die Kolonien sind, desto aggressiver ist der aufgewiesene Phänotyp.

Für den Soft Agar Colony Formation Assay wurde zunächst das entsprechende Kulturmedium mit 0,6\% aufgekochter Agarose (Bottom Agar) vermischt und $2 \mathrm{ml}$ dieser Lösung in einem 6-well beschichtet und dieser zur Aushärtung für mindestens 30 min bei RT inkubiert. Anschließend wurde für die obere Schicht (Top Agar) das entsprechende Kulturmedium mit 0,33\% aufgekochter Agarose zusammen pipettiert, in dem die zu prüfenden Zellen aufgenommen wurden. Je nach Zelllinie wurden sie in einer Dichte von $2 \times 10^{4}-50 \times 10^{4}$ in einem Volumen von $1,5 \mathrm{ml}$ auf das Bottom Agar vorsichtig überschichtet. Die Platte wurde erneut zur Aushärtung für mindestens 30 min bei RT inkubiert, bevor ihr Wachstum für $2-3 \mathrm{Wo}$ bei $37^{\circ} \mathrm{C}$ und $5 \% \mathrm{CO}_{2}$ verfolgt wurde, wobei nur bei Bedarf $200 \mu$ Kulturmedium zugegeben wurde. Zur Darstellung der Kolonien wurden sie mit $500 \mu \mathrm{l}$ 0,005\% Kristallviolett gefärbt, unter Verwendung einer Digitalkamera fotografiert und mit Hilfe der Software „ImageJ“ ausgewertet. 


\subsubsection{Adhäsionsassay}

Die Fähigkeit von Zellen, auf Matrixproteinen zu adhärieren, wurde mit Hilfe des Adhäsionsassays analysiert (Stefansson und Lawrence, 1996). Je nach Matrixprotein wurden das 1:16 in serum-freies Medium verdünntes ECM (R\&D Systems, Wiesbaden) oder das in gelöster Form vorliegende Fibronektin (FN, AthenaES, Baltimore, USA) $30 \mu \mathrm{l}$ ohne Luftblasen in einem 96-well beschichtet und die Platte für 30 min bei RT inkubiert. Auf diese Matrix wurden $10 \times 10^{4}$ Zellen ausgesät und je Zelllinie für 10 - 30 min bei $37^{\circ} \mathrm{C}$ unter $5 \% \mathrm{CO}_{2}$ Partialdruck adhärieren gelassen. Nicht adhärente Zellen wurden anschließend zusammen mit dem Medium abgesaugt und die Zellen mit PBS gewaschen. Nachdem die Zellen mit $100 \mu \mathrm{l} \%$ Essigsäure in Ethanol für 10 min bei RT fixiert wurden, wurden sie mit 0,1\% Kristallviolett 20 min bei RT gefärbt. Anschließend wurden die Platten mehrmals gründlich mit $\mathrm{H}_{2} \mathrm{O}$ gewaschen und für $24 \mathrm{~h}$ im Wärmeschrank getrocknet. Mit Hilfe von 10\% Essigsäure wurde das Kristallviolett aus den Zellen für 5 - 10 min gelöst und die Extinktion photometrisch bei $560 \mathrm{~nm}$ gemessen.

\subsubsection{Boyden-Kammer-Assay}

Die Messung der Zellinvasion in vitro wurde anhand des Boyden-Kammer-Assays (Hagemann et al., 2004) durchgeführt. Zur Analyse von Invasion werden die Anzahl der Tumorzellen bestimmt, die die Basalmembran infiltrieren. Die Boyden-Kammer besteht aus einem oberen und einem unteren Teil, der durch eine Polycarbonatmembran mit $10 \mu \mathrm{m}$ Porendurchmesser (Nucleopore, Pleasanton, USA) getrennt wurde. Die Membran wurde zuvor mit 1:4 in serum-freies Medium verdünntes Matrigel, ECM überschichtet, welche die Basalmembran simuliert. Die unteren Kompartimenten wurden mit Kulturmedium befüllt und die oberen wurden mit $1 \times 10^{5}$ Zellen ausgesät und gegebenenfalls mit rekombinanten Proteinen oder Makrophagen zusätzlich stimuliert. Für eine Ko-Kultur mit Makrophagen wurden 2×105 Makrophagen in einem Zellkultur-insert (Millipore, Darmstadt) ausgesät, das anschließend in das Kompartiment mit den Tumorzellen gestellt wurde. Die Boyden-Kammer wurde anschließend für $96 \mathrm{~h}$ bei $37^{\circ} \mathrm{C}$ und $5 \% \mathrm{CO}_{2}$ inkubiert, und die Anzahl der invasiven Zellen im Unterteil wurde bestimmt. 


\subsubsection{TOP/FOPflash Reporter-Assay}

Die Aktivität des kanonischen WNT Signalwegs kann mit Hilfe des TOP/FOPflash Reporter-Assays gemessen werden. Der Assay basiert auf der biochemischen Transfektion von eukaryotischen Zellen mit einem dual-luciferase repoter System (Hampf und Gossen 2006), bestehend aus firefly Luciferase und renilla Luciferase, welche proportional zu der Menge an über die Aktivierung des Promotors erzeugten Luciferase Licht produzieren. Die Zellen wurden entweder mit dem firefly Luciferase enthaltenden Plasmid pTOPflash oder pFOPflash zusammen mit dem renilla Luciferase enthaltenden Plasmid pRL-TK ko-transfiziert. Dabei wurde im ersten Schritt die firefly Luciferaseaktivität unter Verwendung der P/Rluc-A Lösung gemessen. Anschließend wurde die renilla Luciferaseaktivität unter Verwendung der P/Rluc-B Lösung gemessen, wobei die firefly Luciferasaktivität gedämpft wurde. Das Plasmid pTOPflash kodiert drei Kopien einer optimalen TCF-Bindestelle, welche in Anwesenheit eines aktiven kanonischen WNT Signalwegs von $\beta$-Catenin gebunden werden und so die Expression von Luciferase ermöglichen. Als Negativkontrolle enthält das Plasmid pFOPflash drei Kopien einer mutierten TCF-Bindestelle (Korinek et al., 1997), sodass sie auch in Anwesenheit eines aktiven kanonischen WNT Signalwegs nicht von $\beta$-Catenin gebunden werden und somit keine Luciferase exprimieren. Das Plasmid pRL-TK diente als eine interne Transfektionskontrolle.

Für den Assay wurden $1 \times 10^{5}$ Zellen in einem 24-well ausgesät und über Nacht bei $37^{\circ} \mathrm{C}$ und $5 \% \mathrm{CO}_{2}$ inkubiert. Am folgenden Tag erfolgte die Ko-transfektion mittels Nanofectin (s. 2.2.4.2) mit den Plasmiden. Nach 24 h Inkubation wurden den Zellen $50 \mu \mathrm{l}, 1 \times$ Passiv Lysis Buffer" (Promega, Mannheim) zugegeben, mit einem Zellschaber lysiert und abzentrifugiert. Anschließend wurden $40 \mu \mathrm{l}$ des Lysats in ein 96-well überführt und die Luciferaseaktivität mit Hilfe des „TriStar LB 941 Multimode Microplate Reader" (Berthold Technologies, Bad Wildbad) gemessen.

\begin{tabular}{|c|c|c|}
\hline \multirow[t]{8}{*}{ P/Rluc-A Lösung: } & $\mathrm{MgSO}_{4}$ & $15 \mathrm{mM}$ \\
\hline & EDTA & $0,1 \mathrm{mM}$ \\
\hline & Dithiothreitol (DTT) & $25 \mathrm{mM}$ \\
\hline & ATP & $1 \mathrm{mM}$ \\
\hline & Coenzym A & $200 \mu \mathrm{M}$ \\
\hline & Luciferin & $200 \mu \mathrm{M}$ \\
\hline & Tris/HCl & $200 \mathrm{mM}$ \\
\hline & $\mathrm{pH} 8,0$ & \\
\hline
\end{tabular}




$\begin{array}{lll}\text { P/Rluc-B Lösung } & \text { Natriumacetat } & 10 \mathrm{mM} \\ & \text { EDTA } & 15 \mathrm{mM} \\ & \mathrm{NaCl} & 500 \mathrm{mM} \\ & \text { Phenylbenzothiazol (APMBT) } & 50 \mu \mathrm{M} \\ & \mathrm{Benzylcoelenterazin} & 4 \mu \mathrm{M} \\ & \mathrm{Na}_{2} \mathrm{SO}_{4} & 500 \mathrm{mM} \\ & \mathrm{Na4PPi} & 25 \mathrm{mM} \\ & \mathrm{pH} 5,0 & \\ \text { Programmeinstellungen: } & \text { P/Rluc-A Lösung } & 100 \mu \mathrm{l} \\ & \text { Inkubation } & 0,5 \mathrm{sec} \\ & \text { firefly Luciferasemessung } & 10 \mathrm{sec} \\ & \text { P/Rluc-B Lösung } & 75 \mu \mathrm{l} \\ & \text { Inkubation } & 0,5 \mathrm{sec} \\ & \text { Renilla Luciferasemessung } & 10 \mathrm{sec}\end{array}$

\subsubsection{Immunzytochemie und Immunfluoreszenz}

Die immunzytochemische und immunfluoreszente Analyse ermöglicht den Nachweis eines Proteins mit Hilfe von Antikörpern an fixierten Zellen. Dadurch ist nicht nur eine Aussage über die Expressionsstärke eines Proteins in Zellen, sondern auch über seine intrazelluläre Lokalisation möglich. Das Verfahren beruht auf der spezifischen AntigenAntikörper-Reaktion. Einerseits kann an den Sekundärantikörper ein Stoff gekoppelt sein, welcher durch biochemische Verfahren wie z. B. eine Peroxidase-Reaktion sichtbar gemacht werden kann. Die Auswertung der immunzytochemisch gefärbten Präparate erfolgte lichtmikroskopisch. Andererseits kann an den Sekundärantikörper ein Fluoreszenzfarbstoff gekoppelt sein, der mittels Fluoreszenzmikroskopie mit Hilfe der Software ausgewertet wurde.

Zu diesem Zweck wurden 3-5×104 Zellen auf sterile Deckgläschen $(\mathrm{d}=12 \mathrm{~mm})$ in einzelnen Vertiefungen einer 24-well Platte ausgesät und über Nacht inkubiert, bevor sie am nächsten Tag fixiert wurden. Dazu wurde das überschüssige Medium abgesaugt und die Zellen $2 \times$ mit je $1 \mathrm{ml}$ PBS gewaschen. Anschließend erfolgte die Fixierung durch 4\% Paraformaldehyd (PFA) in PBS für 20 min bei RT. Durch erneutes Waschen mit PBS wurden eventuelle Reste von PFA entfernt. Anschließend wurden die Zellen für 30 min mit PBS + 0,2\% Triton X-100 permeabilisiert und für 30 min mit PBS $+0,2 \%$ Triton X-100 + 1\% BSA inkubiert, um unspezifische Bindungsstellen zu blockieren. Der primäre und sekundäre Antikörper wurde - wie unter Tab. 2.6 
angegeben - in PBS/Triton X-100/BSA verdünnt und jeweils ca. $20 \mu \mathrm{l}$ pro Deckglas eingesetzt. Die Inkubation des primären Antikörpers erfolgte für $1 \mathrm{~h}$ bei RT. Die ungebundenen Antikörper wurden durch dreimaliges Waschen mit PBS/Triton X-100 entfernt ( $1 \times 10$ min, $2 \times 5$ min). Der sekundäre Fluoreszenz-gekoppelte Antikörper wurde für $1 \mathrm{~h}$ auf den Zellen inkubiert. Da der Fluoreszenzfarbstoff lichtempfindlich ist, wurden die Zellen ab diesem Schritt mit Alufolie lichtdicht abgedeckt. Auch hier wurden nach der Inkubationszeit die ungebundenen Antikörper durch dreimaliges Waschen mit PBS/Triton X-100 entfernt ( $2 \times 5$ min, $1 \times 10$ min). Für die Zellkernfärbung wurden die Deckgläschen mit DAPI (1:1000 in PBS verdünnt) für 5 min bei $37^{\circ} \mathrm{C}$ inkubiert. Nach einem Waschschritt mit PBS/Triton X-100 wie oben beschrieben wurden die Deckgläschen luftblasenfrei auf einem Objektträger mit einem Tropfen des Eindeckmittels „DAKO Fluorescent Mounting Medium“ (DAKO, Hamburg) platziert. Die Objektträger wurden über Nacht bei RT getrocknet und konnten dann an einem Axiophot Fluoreszenzmikroskop mit entsprechenden Filtern analysiert werden. Die entsprechenden Aufnahmen mit Hilfe der Software „Axiovision Rel 4.6.3“ (Zeiss, Göttingen) ausgewertet. 


\section{Ergebnisse}

Die hier vorliegende Arbeit analysierte molekulare Marker und Signalwege in soliden Tumorzellinien und ihre Bedeutung für die Tumorprogression und Metastasierung, welche im Folgenden in vier Abschnitten strukturiert sind.

Im ersten Abschnitt wurden verschiedene in Frage kommende murine Mamma- und kolorektale Tumorzelllinien sowohl morphologisch als auch molekular in Bezug auf den EGFR und den WNT Signalweg charakterisiert. Hierfür wurden konventionelle molekularbiologische Methoden wie Western Blot, Immunfärbungen oder quantitative Real-Time PCR eingesetzt. Anhand der Charakterisierung wurden je eine Tumorzelllinie identifiziert, welche als charakteristisch für die jeweilige Entität anzunehmen sind.

Im zweiten und dritten Abschnitt wurden die Rolle des EGFR Signalwegs und des WNT Signalwegs in der Tumorprogression und Metastasierung untersucht. Der letztere wurde in zwei Teile eingeteilt. Im ersten Teil lag ein besonderes Augenmerk auf der Rolle des $\beta$-Catenin-abhängigen WNT Signalwegs und im zweiten Teil auf der des $\beta$ Catenin-unabhängigen WNT Signalwegs via WNT11 und. ROR2. Zu diesem Zweck wurden entsprechend des EGFR- und WNT-Repertoires der Zelllinien Ziele für die Modulation der beiden Signalwege ausgewählt. Somit wurden im Rahmen dieser Arbeit Knockdown- und Überexpressionslinien mittels Transduktion von lentiviralen RNA-Konstrukten oder Nukleofektion und Selektion stabiler Klone etabliert. Diese stabil transfizierten Zelllinien wurden mittels Western Blot Analysen charakterisiert. Im weiteren Schritt wurden sie hinsichtlich ihrer funktionellen Auswirkungen auf die Tumorprogression und Metastasierung anhand verschiedener Methoden wie BoydenKammer-Assay, xCELLigence und Soft Agar Colony Formation Assay untersucht.

Abschließend wurde ihre Anwendbarkeit im Mausmodell im Rahmen des "MetastaSys" Konsortiums geprüft, um ihre Rolle in der jeweiligen Organ-Kolonisation gründlich zu erforschen. 


\subsection{Charakterisierung der murinen Tumorzelllinien}

Das Hauptziel dieser Arbeit ist es den intrinsischen Einfluss von EGFR und WNT Signalwegen in soliden Tumorzelllinien, die zur Tumorprogression und spezifischen Organkolonisation führen, zu untersuchen. Hierfür wurden Mamma- und kolorektale Tumorzelllinien bezüglich ihren EGFR- und WNT-Status charakterisiert und anschließend mit einem komplementären Phänotyp genetisch modifiziert. Zur Untersuchung von Metastasierung wurden Mäuse mit den modifizierten Zellen, die aus demselben Hintergrund hervorgehen, geimpft. Der Vorteil von einer syngenen Transplantation ist es, dass mit intaktem Immunsystem die Interaktion zwischen Tumorzellen und Stromazellen mit einbezogen werden kann. Dadurch, dass ein syngenes Modell im Projekt angewendet werden sollte, war die Auswahl an murinen Mamma- und kolorektale Tumorzelllinien begrenzt. Es wurde sowohl auf lokal verfügbare Zelllinien als auch auf externe Linien, welche durch Kooperationspartner zur Verfügung gestellt wurden, zurückgegriffen. Die Zelllinien wurden morphologisch und molekular in Bezug auf den EGFR und WNT Signalwegen charakterisiert. Die Zellen sollten typische Charakteristika der jeweiligen Tumorentität aufweisen. Z. B. sollten in den kolorektalen Zelllinien, wo gewöhnlich eine Hochregulation von $\beta$ Catenin, und in den Brustkrebszellinien, wo eine vermehrte Bildung von EGFR beschrieben wird, die jeweilige Nachweise dieser Erscheinung erbracht werden. Außerdem sollten sie in vivo einen tumorigenen Phänotyp aufzeigen.

\subsubsection{Morphologische Charakterisierung der murinen Tumorzelllinien}

In der Abbildung 3.1 sind die Zellmorphologie der murinen Mamma- und kolorektalen Tumorzelllinien dargestellt. Bei der Zelllinie 410.4 (A) handelt es sich um eine Mammakarzinomzellinie, welche aus einem Lungenkarzinom einer Maus auf dem Hintergrund von BALB/c isoliert wurde. Die Zellen besitzen eine pflastersteinartige Anordnung. Ihr metastatisches Derivat 4T1 (B) ist eine 6-Thioguanin-resistente Zelllinie ohne mutagene Behandlung. Diese beiden Zelllinien können spontan stark in die Lunge, Leber und das Gehirn metastasieren. Sie nehmen eine fibroblastenähnliche Form mit teils erhaltenen Zell-Zell-Kontakten an. E0771-LG (C) ist eine Mammakarzinomzellinie, welche ursprünglich aus experimentellen Lungenmetastasen auf dem Hintergrund von C57BL/6 Inzuchtmäusen isoliert wurde. Sie weist einen mesenchymalen Phänotyp auf. 


\section{Brustkrebszelllinien}

A

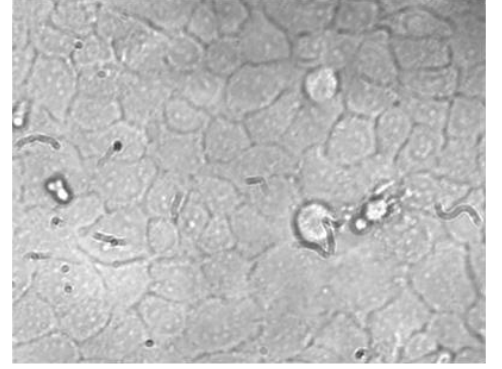

410.4 (40x)

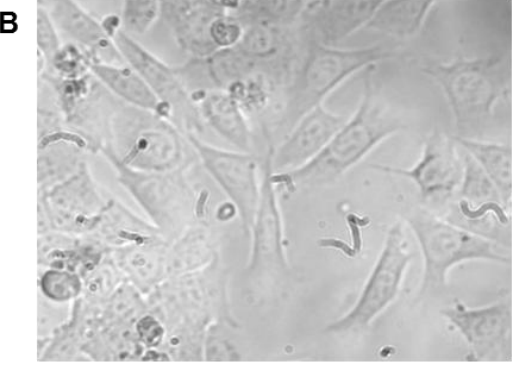

$4 T 1(40 x)$

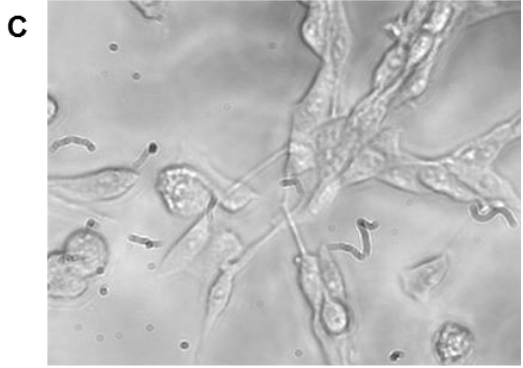

E0771-LG (40x)

Kolorektale Krebszelllinien

D

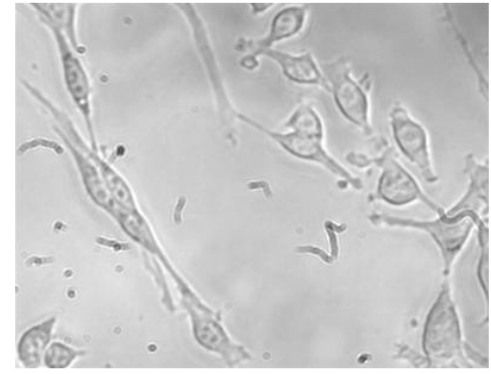

CT26 (40x)

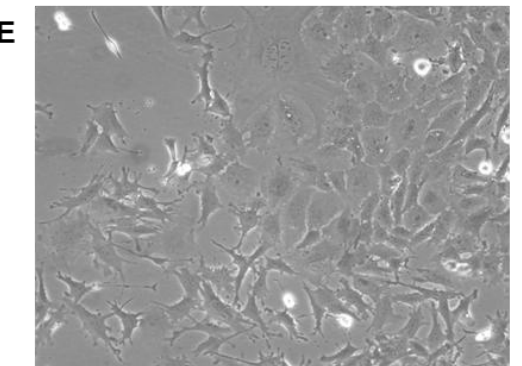

$1638 \mathrm{~N}-\mathrm{T} 1(40 \mathrm{x})$

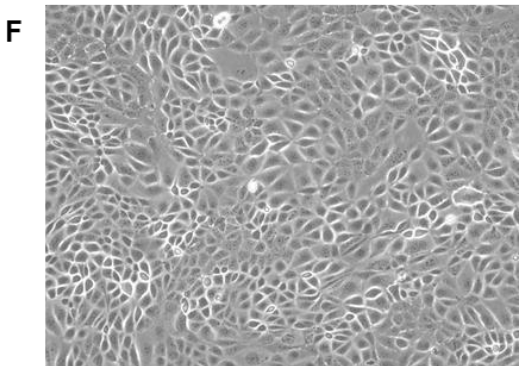

CMT-93 (20x)

Abb. 3.1: Zellmorphologie der in Frage kommenden murinen Tumorzelllinien.

Die Morphologie der in Frage kommenden Zelllinien wurde mittels Hellfeld-Mikroskopie dokumentiert. Dargestellt sind drei Mammakarzinomzelllinie (A-C) und drei kolorektale Tumorzelllinien (D-F).

CT26 (D) ist eine durch N-Nitroso-N-Methylurethan (NMU) induzierte undifferenzierte Adenokarzinomzelllinie des Kolons aus der Balb/c-Maus. Diese Zellen erschienen ideal auf Grund ihrer potenten Fähigkeit zur Tumorinitiierung. Ihre Zellmorphologie zeigte einen robusten mesenchymalen Phänotyp.

In den kolorektalen Tumorzelllinien war insbesondere die Linie 1638N-T1 auf dem C57BI/6Jlco Hintergrund (E) aus der Arbeitsgruppe von Ron Smits von Interesse. Diese Zellen wurden ursprünglich aus dem Adenokarzinom einer transgenen Apc1638N Maus isoliert, welche über eine Mutation im Apc Gen verfügte und vermutlich zu einem invasiven Karzinom resultierte. Die Zellen nehmen in konfluenter Kultur partiell Pflasterstein-Morphologie an. Eine weitere polyploide kolorektale Linie, CMT-93 Zellen (F) auf dem C57/BL6 Hintergrund, welche uns durch eine Kooperation mit Fr. Dr. med. Christina Hackl zur Verfügung gestellt wurde, wurde auf Grund ihrer Bildung von Lebermetastasen in in vivo Experimenten (persönliche Mittteilung) ausgewählt. Diese Zellen weisen die klassische polygonale Pflastersteinform auf. Zusammenfassend zeigten 410.4 und CMT-93 Zellen eine epitheliale Morphologie, während die anderen Zellen nicht die klassische epitheliale Anordnung nachwiesen. 


\subsubsection{Molekulare Charakterisierung der murinen Tumorzellinien}

\subsubsection{Charakterisierung der murinen Tumorzellinien auf ihren basalen EGFR- und $\beta$-Catenin-Status}

Nach der morphologischen Charakterisierung wurden die Zelllinien molekular auf ihren basalen EGFR- und WNT-Status geprüft. Aufgrund der spärlichen Datenlage zu dem Hormonrezeptorstatus in den Mammakarzinomzellinien wurde zunächst eine Charakterisierung der Zelllinien hinsichtlich ihres Hormonrezeptorstatus mittels Western Blot Analysen durchgeführt (s. Abb. 3.2 A). Es konnte gezeigt werden, dass in allen Mammakarzinomzelllinien 410.4, 4T1 und E0771-LG weder Rezeptoren für Östrogen (ER) noch für Progesteron (PR) vorhanden sind. In 410.4 und 4T1 konnten keine HER2-Rezeptoren (Erbb2) nachgewiesen werden, wobei E0771-LG HER2 positiv und somit keine triple-negative Mammakarzinomzellinie ist.

A

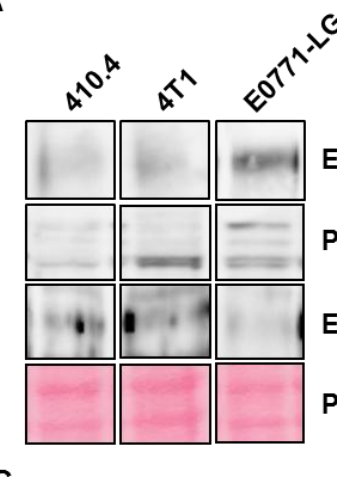

C

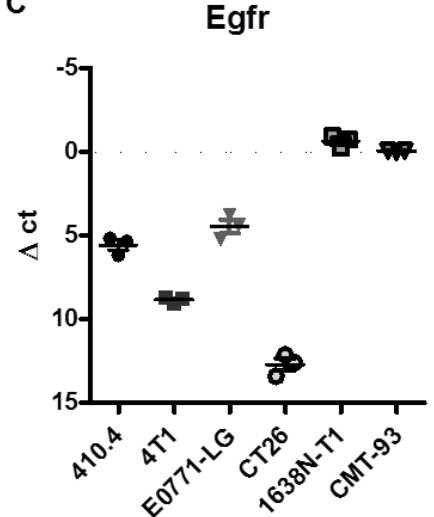

B

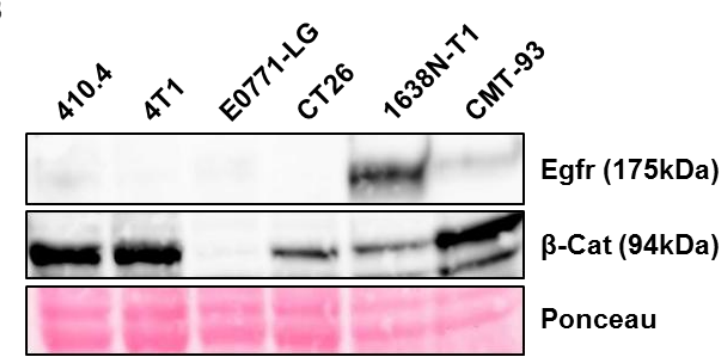

D $\beta-$ Cat

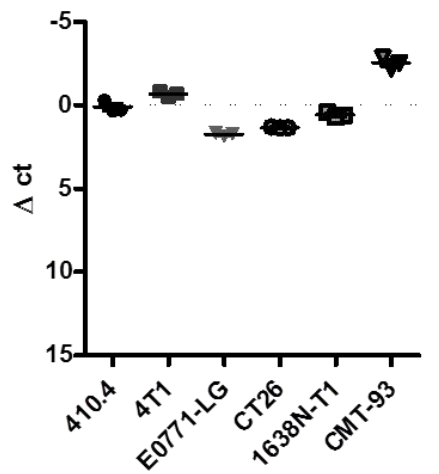

Abb. 3.2: Charakterisierung der murinen Tumorzellinien auf ihren basalen EGFR- und $\beta$-CateninStatus.

A) Die Mammakarzinomzelllinien wurden hinsichtlich ihres Hormonrezeptorstatus auf die Expression des Östrogenrezeptors (ER), des Progesteronrezeptors (PR) und des humanen epidermalen Wachstumsfaktorrezeptors 2 (HER2). mittels Western Blot geprüft. B) In den Mammakarzinomzelllinien und kolorektalen Tumorzellinien wurden ihre basale Expression von EGFR und $\beta$-Catenin mittels Western Blot untersucht. Für eine Ladekontrolle wurde die Membran mit Ponceau S gegengefärbt. CD) Parellel erfolgte die Genexpressionsanalyse von EGFR und $\beta$-Catenin mitttels qRT-PCR. Auf der yAchse ist der $\Delta$ ct, d.h. ct, Gen von Interesse (GOI) - ct, Housekeeping Gene (HK) aufgetragen. Housekeeping Gene sind Tbp und Gapdh. 
Die Zelllinien wurden mittels Western Blot und qRT-PCR Analysen auf die EGFR und $\beta$-Catenin Expression untersucht (s. Abb. 3.2 B-D). Die Mammakarzinomzelllinien und die kolorektale Tumorzellinie CT26 exprimieren EGFR sehr schwach, während 1638N-T1 und CMT-93 eine gewisse Expression nachwiesen. Alle untersuchten Zelllinien außer E0771-LG zeigten eine klare Expression von $\beta$-Catenin. Auffallend ist, dass 410.4 und $4 \mathrm{~T} 1$ Zellen verglichen zu kolorektalen Zelllinien mehr $\beta$-Catenin exprimieren.

\subsubsection{Charakterisierung der murinen Tumorzelllinien auf Komponenten des WNT Signalwegs}

Zugleich wurden die Zelllinien hinsichtlich der Anwesenheit des kanonischen und nicht-kanonischen WNT Signalwegs überprüft. Als klassische kanonische Komponenten des WNT Signalwegs wurden zunächst die Expression von Wnt3a, Tcf7, Lef1 und Axin2 mit Hilfe von Western Blot und qRT-PCR Analysen untersucht (s. Abb. 3.3 A, D-G). Wnt3a, der klassische Wnt Ligand für den kanonischen WNT Signalweg konnte weder auf der Proteinebene noch auf der mRNA Ebene in den Zellen nachgewiesen werden. Dieses Ergebnis deutet darauf hin, dass eine Aktivierung des kanonischen WNT Signalwegs nicht über Wnt3a erfolgt (s. Abb. 3.3 A und D), während die Transkriptionsfaktoren des kanonischen WNT Signalwegs, Tcf7 und Lef1 mittels qRT-PCR Analysen detektiert werden können (s. Abb. 3.3 E und F). Das Targetgen und zugleich negativer Regulator des kanonischen WNT Signalwegs, Axin2, scheint nicht in den Mammakarzinomzellinien zu exprimieren, dagegen ist erwartungsgemäß in den kolorektalen Tumorzellinien außer CT26 hoch exprimiert (s. Abb. 3.3 G). Im Rahmen der nicht-kanonischen Komponenten des WNT Signalwegs wurde die Expression von c-Jun und Wnt5a/b mit Hilfe von Western Blot und qRT-PCR Analysen untersucht (s. Abb. 3.3 A-C). Es zeigte sich, dass das Protein c-Jun in den Mammakarzinomzelllinien und CT26 massiv und in den kolorektalen Tumorzellinien wenig exprimiert ist. Der klassische Wnt-Ligand für den nicht-kanonischen WNT Signalweg, Wnt5a, schien nicht in 410.4, 4T1 und CT26 Zellen vorhanden zu sein, während in E0771-LG, 1638N-T1 und CMT-93 Zellen Wnt5a exprimiert ist. Generell lässt sich sagen, dass der nicht-kanonische WNT Signalweg sowohl in Mammakarzinomzelllinien als auch in den kolorektalen Tumorzellinien teilweise vorhanden ist. 
A

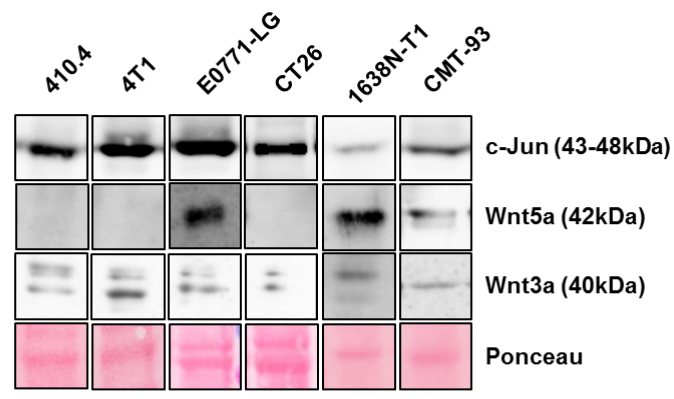

D

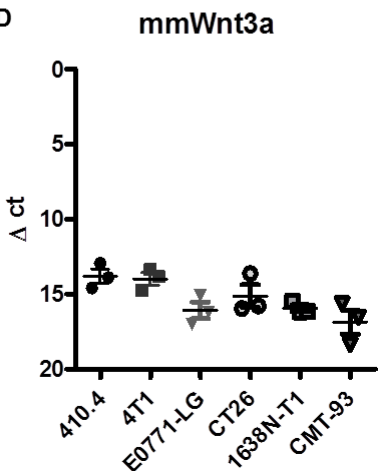

E
B
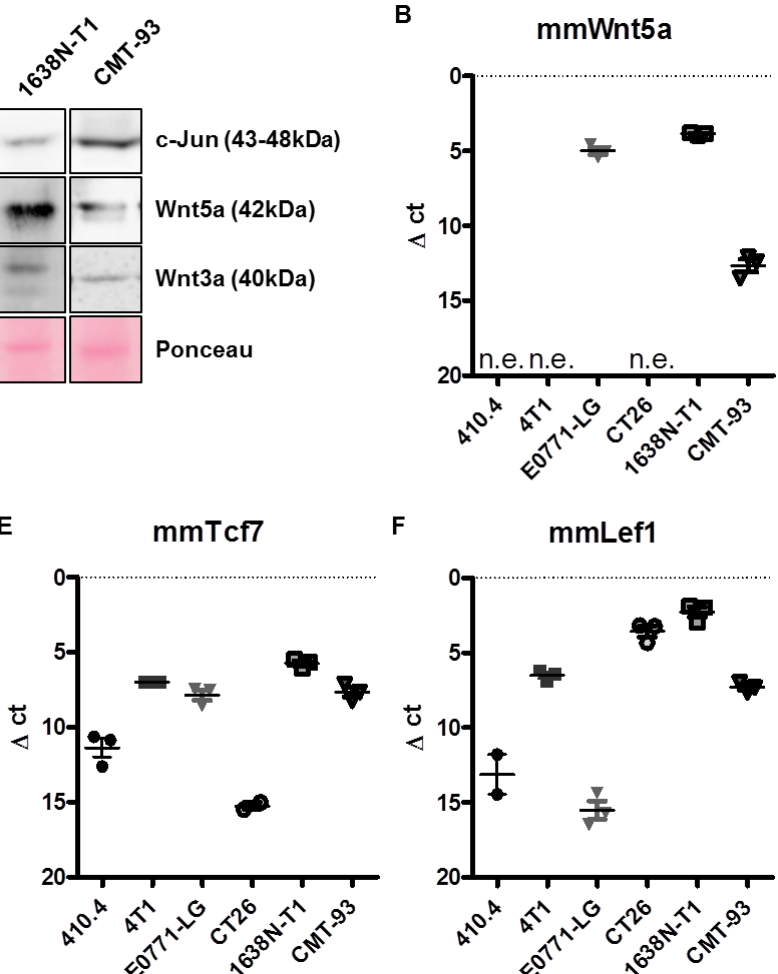

$\mathbf{F}$

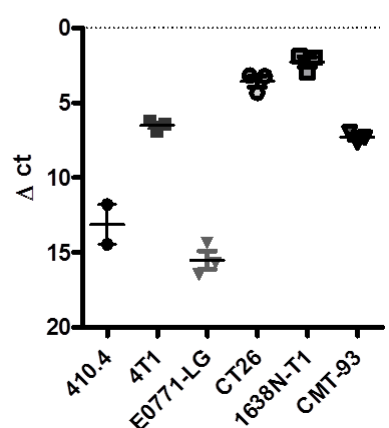

C mmWnt5b

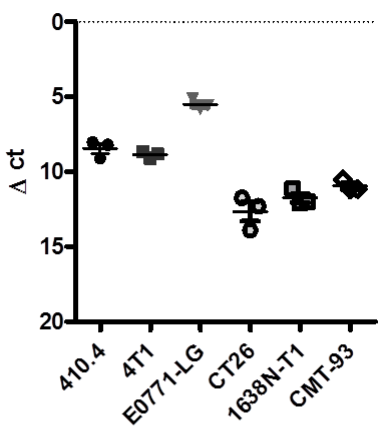

G

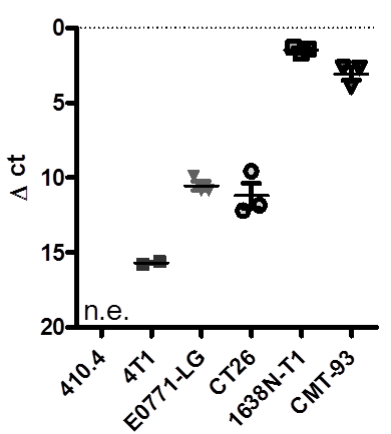

Abb. 3.3: Charakterisierung der murinen Tumorzelllinien auf Komponenten des WNT Signalwegs.

A) Western Blot Analyse für Proteine c-Jun, Wnt5a und Wnt3a und B-G) qRT-PCR Analyse für Wnt5a/b, Wnt3a, Tcf7, Lef1 und Axin2 wurden in Bezug auf das Vorhandensein des kanonischen und nichtkanonischen WNT Signalwegs durchgeführt. Auf der y-Achse ist der $\Delta$ ct abgebildet; n.e. = nicht exprimiert.

\subsubsection{Charakterisierung der murinen Tumorzelllinien auf EMT-Marker}

Es ist bereits beschrieben, dass Epithelial-mesenchymale Transition (EMT) ein Phänomen der fortschreitenden Metastase ist (Thiery, 2002). Aus diesem Grund wurden die Zelllinien auf EMT-Markern wie Vimentin und das Zelladhäsionsprotein ECadherin (Cdh1) analysiert und ihr EMT-Status definiert. 410.4, 4T1, 1638N-T1 und CMT-93 waren epithelial, wobei E0771-LG und CT26 einen massiven mesenchymalen Phänotyp aufwiesen (s. Abb. 3.4 A-C), welche mit der Zellmorphologie korrelieren (s. Abb. 3.2). Alle Zelllinien außer 410.4 zeigten eine hohe Expression an Vimentin (s. Abb. 3.4 C). 
A

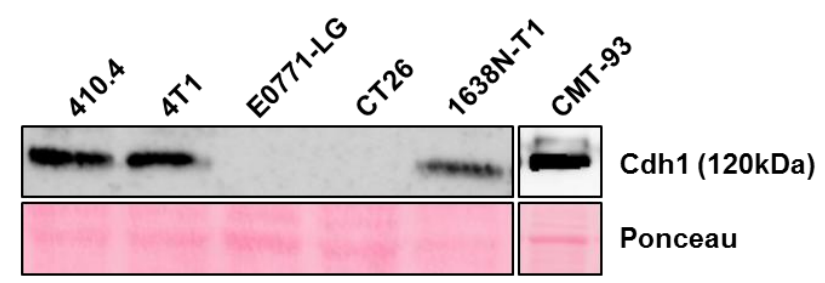

B

Cdh1

C

Vim
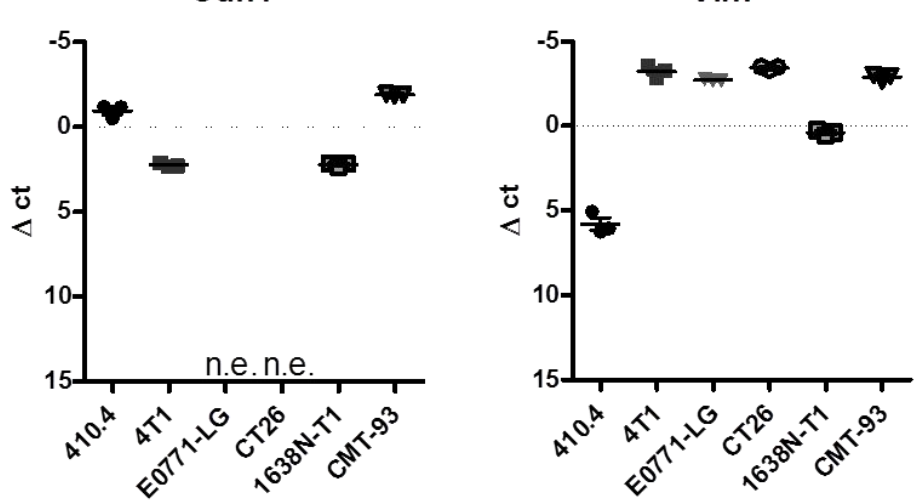

Abb. 3.4: Epithelial-mesenchymale Charakterisierung der murinen Tumorzelllinien.

A) Die murinen Zelllinien wurden auf der Proteinebene auf die Expression des Zelladhäsionsproteins ECadherin (Cdh1) mittels Western Blot untersucht. B) Außerdem wurden sie auf der mRNA-Ebene mittels qRT-PCR auf den mesenchymalen Marker, Vimentin untersucht. Auf der y-Achse ist der $\Delta c$ ct, d.h. ct, Gen von Interesse (GOI) - ct, Housekeeping Gene (HK) als Mittelwert von drei biologischen Replikaten dargestellt; n.e. = nicht exprimiert. Housekeeping Gene sind Tbp und Gapdh.

Anhand der Ergebnisse erfolgte eine Zuordnung der Linien zu molekularen Subtypen des Mammakarzinoms. 410.4 und 4T1 konnten als triple-negative Linien zugeordnet werden, während E0771-LG HER2 positiv war. Favorisiert wurde eine triple-negative Mammakarzinomzelllinie für diese Fragestellung, da dieser Subtyp eine Tendenz zeigt, in das Gehirn zu metastasieren. Darüber hinaus wurde eine typische Mammakarzinomzellinie, die vermehrt EGFR exprimiert und epithelial ist, bevorzugt. Bedauerlicherweise wurde in keiner der untersuchten Zelllinien eine vermehrte EGFR Expression nachgewiesen. 410.4 und 4T1 zeigten ein epitheliales Wachstumsmuster und waren positiv für E-Cadherin, während E0771-LG einen mesenchymalen Phänotyp und keine Expression von E-Cadherin aufwies. In Betracht gezogen wurden Zellen, die eine epitheliale Form haben und zu einem mesenchymalen Phänotyp transformieren könnten.

Innerhalb des untersuchten Panels an Mammakarzinomzellinien zeigten sich die parentale Linie 410.4 und ihr metastatisches Derivat 4T1 als passende Modellsysteme. Diese beiden Linien unterscheiden sich einerseits bezüglich ihres Invasionsverhaltens, weisen andererseits aber auch eine differentielle Expression von Mitgliedern des kanonischen und nicht-kanonischen WNT Signalwegs auf. Dies wurde durch in vivo 
Experimenten und durch RNA Seq. Analysen bestätigt. Da die Zelllinie 410.4 im Gegensatz zu 4T1 moderat invasiv ist, wurde sie aus den Mammakarzinomzelllinien ausgewählt, um mittels Modifikationen die maligne Progression zu verstärken.

In den kolorektalen Tumorzelllinien waren insbesondere die 1638N-T1 und CMT-93 von Interesse, da CT26 eine mesenchymale Charakteristik aufwies. Dies galt als ein wichtiges Ausschlusskriterium für die Auswahl der Zelllinie. 1638N-T1 war eine typische kolorektale Zelllinie, die epitheloid wuchs und eine Hochregulation von $\beta$ Catenin aufwies. Während die Aktivierung des kanonischen WNT Signalwegs durch eine Mutation im Apc Gen in 1638N-T1 Zellen bestätigt werden konnte, zeigte die Zelllinie in den in vivo Experimenten im Rahmen des Verbundprojektes (WP3 und 4) leider keinen tumorigenen Phänotyp und kam somit nicht in Frage. Schließlich wurde die kolorektale Tumorzelllinie CMT-93 angesichts ihrer epithelialen Form, der gesteigerten $\beta$-Catenin Expression und der Metastasen-bildende Eigenschaft im Tiermodell ausgesucht.

Tab. 3.1: Zusammenfassung der Ergebnisse zur molekularen Charakterisierung der murinen Tumorzelllinien.

Vergleich der Protein- bzw. Genexpression in den Zelllinien von sehr wenig - bis sehr viel + +.

\begin{tabular}{c|c|c|c|c|c|c} 
Gen & 410.4 & $4 T 1$ & E0771- & CT26 & 1638N-T1 & CMT-93 \\
\hline ER & - & - & - & & & \\
\hline PR & - & - & - & & & \\
\hline HER2 & - & - & + & & + & $(+)$ \\
\hline EGFR & - & - & - & - & + & ++ \\
\hline B-Catenin & ++ & ++ & - & + & + & + \\
\hline Wnt3a & - & - & - & - & + & + \\
\hline Tcf7 & $(-)$ & + & + & $(-)$ & + & + \\
\hline Lef1 & $(-)$ & + & $(-)$ & + & + & + \\
\hline Axin2 & - & - & $(-)$ & $(-)$ & + & $+(+)$ \\
\hline C-Jun & + & + & + & + & + & + \\
\hline Wnt5a & - & - & + & - & + & + \\
\hline
\end{tabular}




\begin{tabular}{c|c|c|c|c|c|c}
\hline Wnt5b & + & + & + & $(+)$ & $(+)$ & $(+)$ \\
\hline Cdh1 & + & + & - & - & + & + \\
\hline Vim & $(+)$ & + & + & + & + & +
\end{tabular}

\subsection{Etablierung der EGFR modulierten Tumorzelllinien}

Nachdem die Zelllinien anhand der molekularen Charakterisierung ausgewählt wurden, wurden sie mittels stabiler Transduktion moduliert. Es wurden die Knockdownund Überexpressionslinien von EGFR etabliert und anschließend die Proliferation, Invasion und Signalweiterleitung untersucht.

\subsubsection{EGFR Knockdown in CMT-93 Zellen}

Da in Western Blot und qRT-PCR Analysen gezeigt werden konnte, dass 410.4 wenig oder gar nicht EGFR exprimieren (s. Abb. 3.2), wurde in diesen Zellen keine Knockdown von EGFR generiert. Im Folgenden wurde ein shRNA vermittelter Knockdown von EGFR in CMT-93 Zellen etabliert und anschließend ihre funktionelle Wirksamkeit untersucht.

\subsubsection{Charakterisierung der stabil transduzierten Zellen}

Um die Funktion von EGFR Knockdown in CMT-93 Zellen näher zu untersuchen, wurden die Zellen stabil lentiviral mit dem Leervektor oder mit dem Plasmid shEgfr transduziert. Der Knockdown von EGFR wurde abschließend mittels Western Blot und qRT-PCR Analysen kontrolliert. Man sieht auf dem Western Blot, dass in den Knockdownlinien verglichen zu ns. ctrl. eine Reduktion von EGFR vorlag (s. Abb. 3.5 A). Auf der entsprechenden Transkriptomanalyse sah man eine Reduktion der Egfr mRNA Expression bis zu 25\% (s. Abb. 3.5 B). Um ihren funktionellen Signifikanz feststellen zu können, wurden weitere Assays durchgeführt. 
A

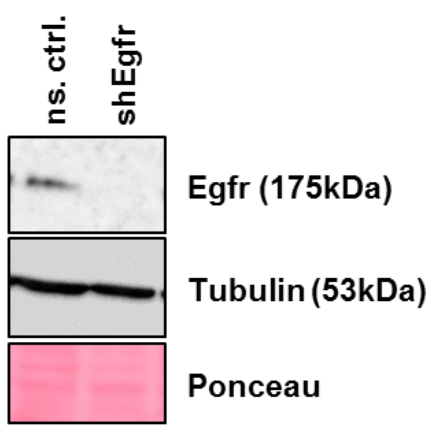

B

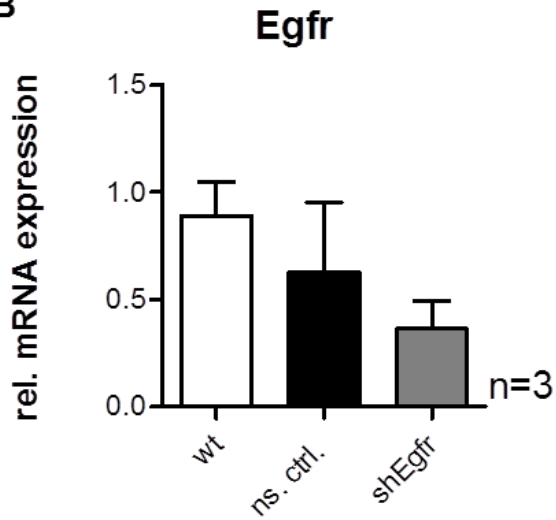

Abb. 3.5: Knockdown des EGFR in CMT-93.

In CMT-93 Zellen wurden EGFR Knockdown und die Kontrolle (ns. ctrl.) mittels lentiviraler Transduktion mit shKonstrukt gegen EGFR etabliert. Zum Nachweis der erfolgreichen Transduktion wurden die Zellen auf EGFR Expression mittels Western Blot (A) und mittels qRT-PCR (B) geprüft.

\subsubsection{Einfluss von EGFR auf die Proliferation, Invasion und Signalweiterleitung}

Für die Untersuchung der Proliferation der stabil transduzierten Zellen wurden sowohl Messungen unter Verwendung der xCELLigence als auch MTT-Assays durchgeführt. Die xCELLigence Messung zeigte, dass das Wachstum der Knockdownlinien und ns. ctrl. sich nicht unterschieden (s. Abb. 3.6 A). Der MTT-Assay wurde insgesamt für $96 \mathrm{~h}$ durchgeführt, wobei die Werte von $24 \mathrm{~h}$ auf 100\% gesetzt wurden. Bei dieser Assay zeigte sich, dass der Knockdown von EGFR eine verminderte Proliferation verglichen zu ns. ctrl. aufwies (s. Abb. 3.6 B). Weiterhin wurde die Änderungen des EGFRPhänotyps hinsichtlich ihrer Invasionsfähigkeit und Weiterleitung des Signals untersucht. Das Invasionsverhalten wurde mittels Boyden-Kammer-Assay mit und ohne EGF Behandlung zur Stimulation der EGFR Signalwege untersucht. Die Stimulation mit EGF in ns. ctrl. Zellen führte zu einer erhöhten Invasion dieser Zellen, während die Stimulation mit EGF in Knockdownlinien die Invasionsrate auf die Ausgangsbasis verringerte. Dies war ein starker Hinweis, dass der effiziente Knockdown funktionell wirksam ist (s. Abb. 3.6 C). 
A

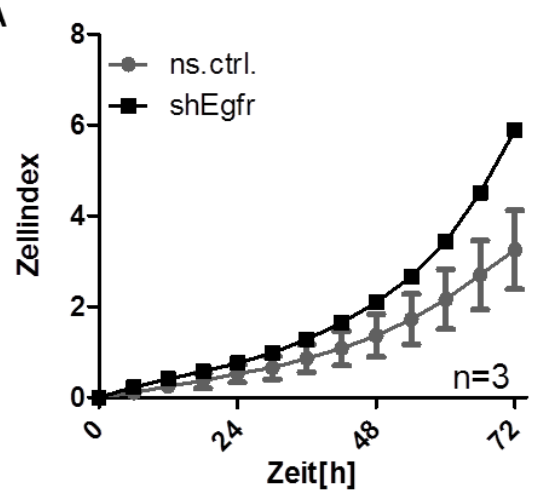

C

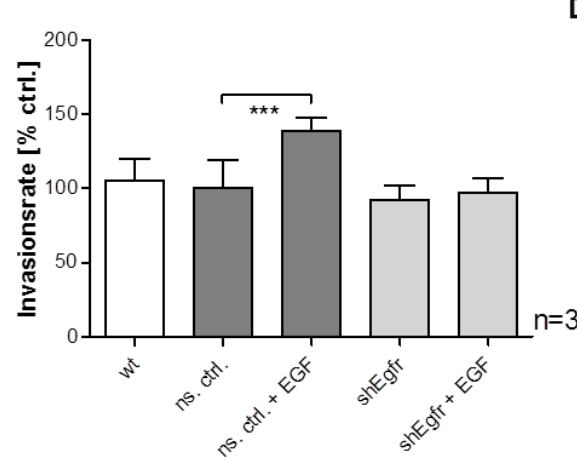

B

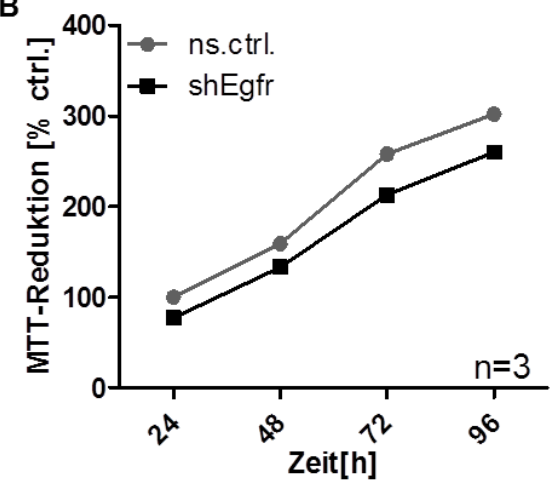

D

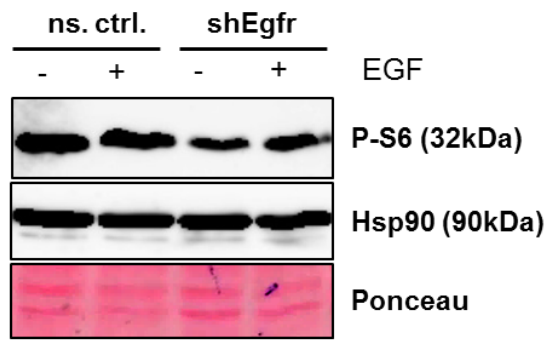

Abb. 3.6: Proliferation, Invasion und Signalkaskadenuntersuchung des EGFR Knockdowns in CMT-93.

Biologische Auswirkungen wie Proliferation wurden in xCELLigence-Messung (A) und in der MTT-Assay (B) überprüft. Auf der $x$-Achse ist die Zeit in Stunden (h) aufgetragen, auf der y-Achse die relative Proliferation in Form des Zellindexes. Die MTT-Reduktion wurde auf $24 \mathrm{~h}$ Kultur normalisiert, die auf $100 \%$ gesetzt wurde. Die Invasion in der Boyden-Kammer (C) und die Signalweiterleitung mittels Western Blot (D) mit EGF Behandlung $(20 \mathrm{ng} / \mathrm{ml})$ zur Stimulation der EGFR Signalwege wurden getestet.

Darüber hinaus wurde die Weiterleitung des EGFR Signalwegs in diesen Zellen untersucht, indem sie für 10 min mit den EGF-Liganden versetzt, das Protein lysiert und anschließend die Aktivierung von downstream Proteinen mit Phosphospezifischen Antikörpern analysiert wurde. Die Analyse der S6 Aktivierung ergab eine deutliche Abnahme der Phosphorylierung von S6 in den EGFR Knockdown Zellen, auch nach EGF Stimulation (s. Abb. 3.6 D). Somit konnte dem effizienten Knockdown mittels dieser Assays eine funktionelle Wirksamkeit zugeschrieben werden.

\subsubsection{EGFR Überexpression in 410.4 und CMT-93 Zellen}

\subsubsection{Charakterisierung der stabil transduzierten Zelllinien}

Es sollte nun geklärt werden, welche Folgen eine Überexpression von EGFR in 410.4 und CMT-93 Zellen hat. Analog zu oben wurden die Zellen stabil mit dem Leervektor oder mit dem EGFR überexprimierenden Plasmid transduziert. Eine EGFR 
Überexpression konnte in beiden Zelllinien sowohl im Western Blot als auch in der qRT-PCR Analyse nachgewiesen werden (s. Abb. 3.7 A-B; D-E). Da die Entwicklung von Metastasen im Tiermodell bis hin zu 8 Wochen dauert, war es wichtig, die Stabilität der Transduktion über den gesamten Zeitraum zu überprüfen. Zu diesem Zweck wurden die Zellen über einen Zeitraum von 8 Wochen ohne Zusatz von Selektionsantibiotika, Puromycin im Medium kultiviert. Es wurden alle 7 Tage bis nach 4 Wochen und als Endpunkt nach 8 Wochen Proteinlysate entnommen und mittels Western Blot Analysen geprüft. Der Stabilitätstest in beiden Zelllinien zeigte eine Plasmidbeständigkeit bis nach 4 Wochen, wogegen nach 8 Wochen eine leichte Reduktion von EGFR zu sehen war (s. Abb. 3.7 C; F).

410.4

A

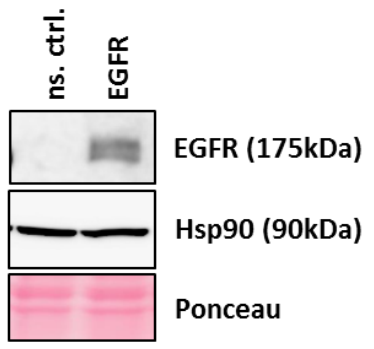

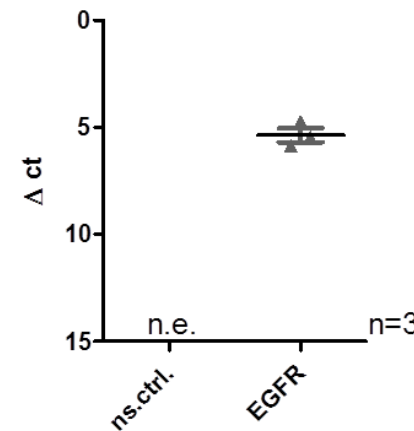

CMT-93

D

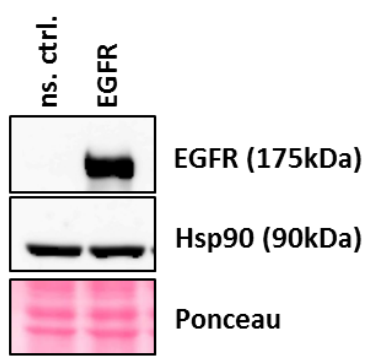

E

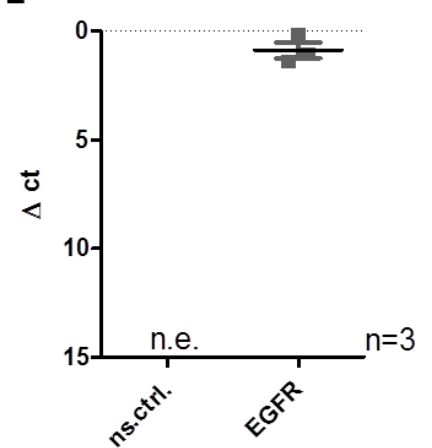

C

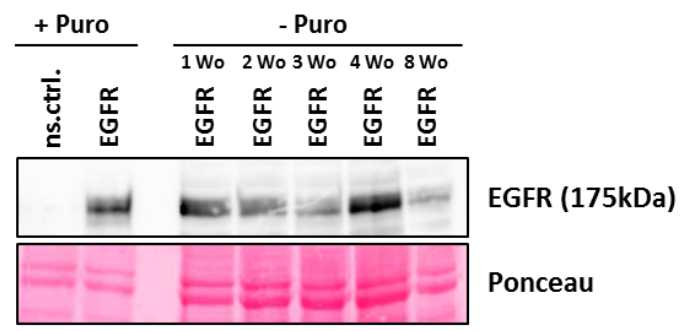

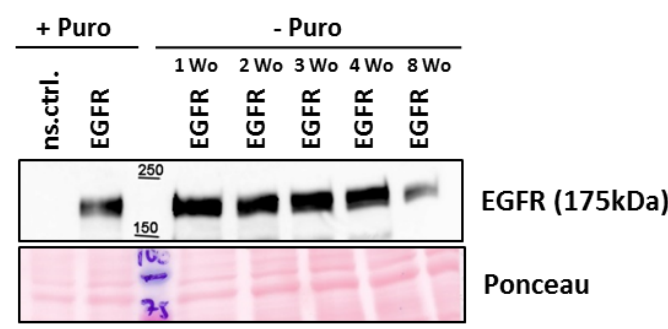

Abb. 3.7: Überexpression des EGFR in 410.4 und CMT-93.

410.4 und CMT-93 Zellen wurden stabil mittels lentiviraler Transduktion mit dem Leervektor pLenti-GFP (ns. ctrl.) und mit dem Plasmid pLenti-EGFR-GFP transfiziert. EGFR Überexpression wurde mittels Western Blot (A, D) und mittels qRT-PCR (B, E) geprüft. C, F) Um die Stabilität der Transduktion zu testen, wurden Zellen über einen Zeitraum von 8 Wochen ohne Zusatz von Selektionsantibiotika, Puromycin im Medium kultiviert. Alle 7 Tage wurden Proteine aus den Zellen isoliert und ein Western Blot für EGFR durchgeführt. 


\subsubsection{Einfluss von EGFR auf die Signalweiterleitung}

Auch im Falle der EGFR Überexpression stellte sich die Frage, welchen Einfluss diese gesteigerte Expression auf die Weiterleitung des EGFR Signalwegs hat. Um dieser Frage nachzugehen, wurde zunächst die Proteinexpression der EGFR-Zielgene, c-Jun und c-Myc untersucht. EGFR Überexpression in beiden Zelllinien führte zu einer erhöhten Proteinexpression von c-Jun, während c-Myc nur in kolorektalen Zelllinien hoch exprimiert wurde (s. Abb. 3.8 A; C). Außerdem wurde hinsichtlich ihrer funktionellen Bedeutung innerhalb der Signalkaskadenweiterleitung untersucht. p38 und S6 waren generell nach Stimulation mit EGF aktivierbar. Die EGFR überexprimierenden Zellen zeigten eine hohe endogene Expression von P-p38 und PS6 verglichen zu ns. ctrl (s. Abb. 3.8 B; D).

410.4

A

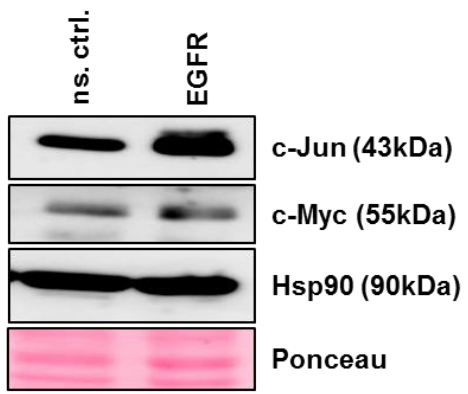

B

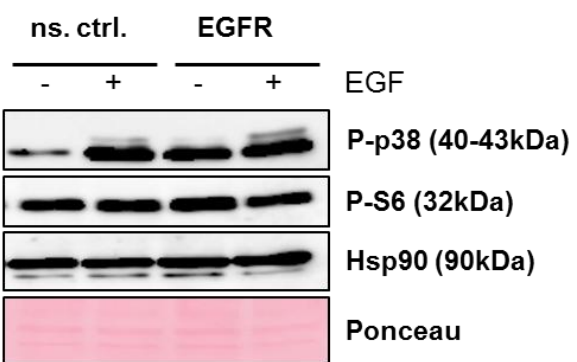

CMT-93

C

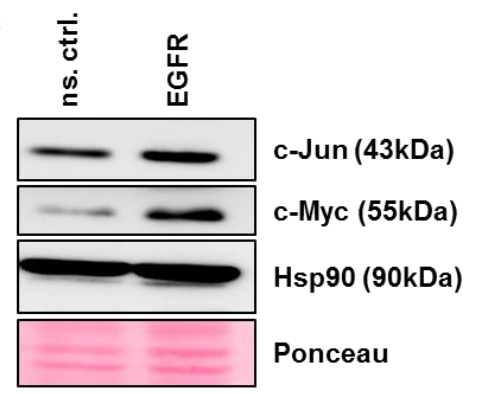

D

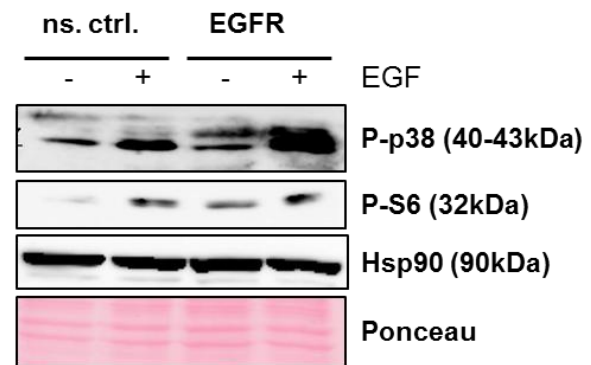

Abb. 3.8: Signalkaskadenuntersuchung der EGFR überexprimierenden Zellen.

A, C) Die Targetgene, c-Jun und c-Myc in den Zellen wurden mittels Western Blot untersucht. B, D) Der Einfluss auf Signalweiterleitung der EGFR Signalwege wurde mit und ohne EGF Stimulation $(20 \mathrm{ng} / \mathrm{ml})$ geprüft. Die Aktivierung wurde für die Proteine p38 und S6 mit Phospho-spezifischen Antikörpern mittels Western Blot analysiert.

\subsubsection{Einfluss von EGFR auf die Invasion}

Als weiterer funktioneller Read-Out für die Überprüfung der effizienten Überexpression wurde das Invasionspotential der Zellen gemessen. In diesem Zusammenhang wurden die Zellen ebenfalls mit und ohne EGF $(10 \mathrm{ng} / \mathrm{ml})$ stimuliert. Eine EGF Stimulation steigert die Invasion der 410.4 Zellen, allerdings unabhängig von der 
EGFR Überexpression (s. Abb. 3.9 A). Für CMT-93 Zellen konnte kein Einfluss von EGF und EGFR Überexpression auf die Invasion nachgewiesen werden (s. Abb. 3.9 B).
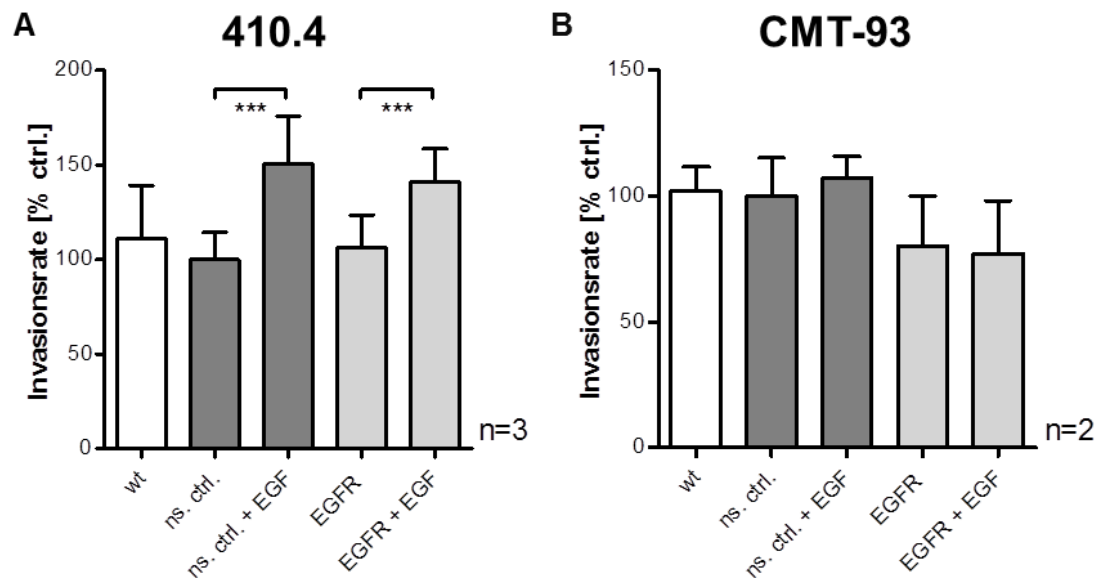

Abb. 3.9: Invasion der EGFR überexprimierenden Zellen.

A, B) Der Einfluss auf die Invasion wurde mit und ohne EGF Stimulation $(10 \mathrm{ng} / \mathrm{ml})$ geprüft. Die Zellen wurden in der Boyden-Kammer für $96 \mathrm{~h}$ kultiviert. Die Invasionsrate wurde auf die Invasion der ns. ctrl. Zellen bezogen, die auf $100 \%$ gesetzt wurde.

Zusammenfassend konnte eine funktionelle Relevanz in der Signalkaskadenweiterleitung festgestellt werden, wenn auch ohne Niederschlag in der in vitro Invasion.

\subsection{Etablierung der WNT modulierten Tumorzelllinien}

Im Folgenden wurde sowohl die Rolle der $\beta$-Catenin-abhängigen als auch der $\beta$ Catenin-unabhängigen WNT Signalwege in der Tumorprogression untersucht. Um die Rolle von $\beta$-Catenin-abhängigen WNT Signalweg in der Tumorprogression zu überprüfen, wurde die Expression von $\beta$-Catenin moduliert. In einem weiteren Schritt wurde der $\beta$-Catenin-unabhängige WNT Signalweg, nämlich die Komponenten WNT11 und ihre möglichen Rezeptor ROR2 in den Zellen analysiert.

\subsubsection{Etablierung der $\beta$-Catenin modulierten Tumorzelllinien}

Hierbei sollten die Auswirkungen der Signalwege basierend auf Knockdown und Überexpression des $\beta$-Catenins mittels Transduktion bzw. Transfektion hinsichtlich der Proliferation und Invasionsfähigkeit näher untersucht werden. 


\subsubsection{1 $\beta$-Catenin Knockdown in 410.4 und CMT-93 Zellen}

\subsection{Charakterisierung der stabil transduzierten Zelllinien}

Um die Rolle von $\beta$-Catenin in der Tumorprogression zu untersuchen, wurden die $\beta$ Catenin positiven Zelllinien mit shKonstrukten gegen $\beta$-Catenin stabil lentiviral transduziert. Um die Knockdown-Effizienz zu erhöhen, wurden die Zellen einfach und doppelt, d.h. mit zwei verschiedenen Konstrukten, gleichzeitig transduziert. Der Nachweis des jeweiligen Knockdowns erfolgte sowohl auf Proteinebene (s. Abb. 3.10 A, C) als auch auf mRNA Ebene (s. Abb. 3.10 B, D) mittels Western Blot und qRT-pCR Analyse. Dabei konnte in 410.4 Zellen mit dem Konstrukt 4 eine deutliche Abnahme der Proteinexpression von $\beta$-Catenin erzielt werden. Auf der entsprechenden Transkriptomanalyse konnte mit demselben Konstrukt eine Reduktion bis auf 25\% nachgewiesen werden, während die doppelte Transduktion nicht zu einem höherem Knockdown-Effekt führte. (s. Abb. 3.10 A, B).

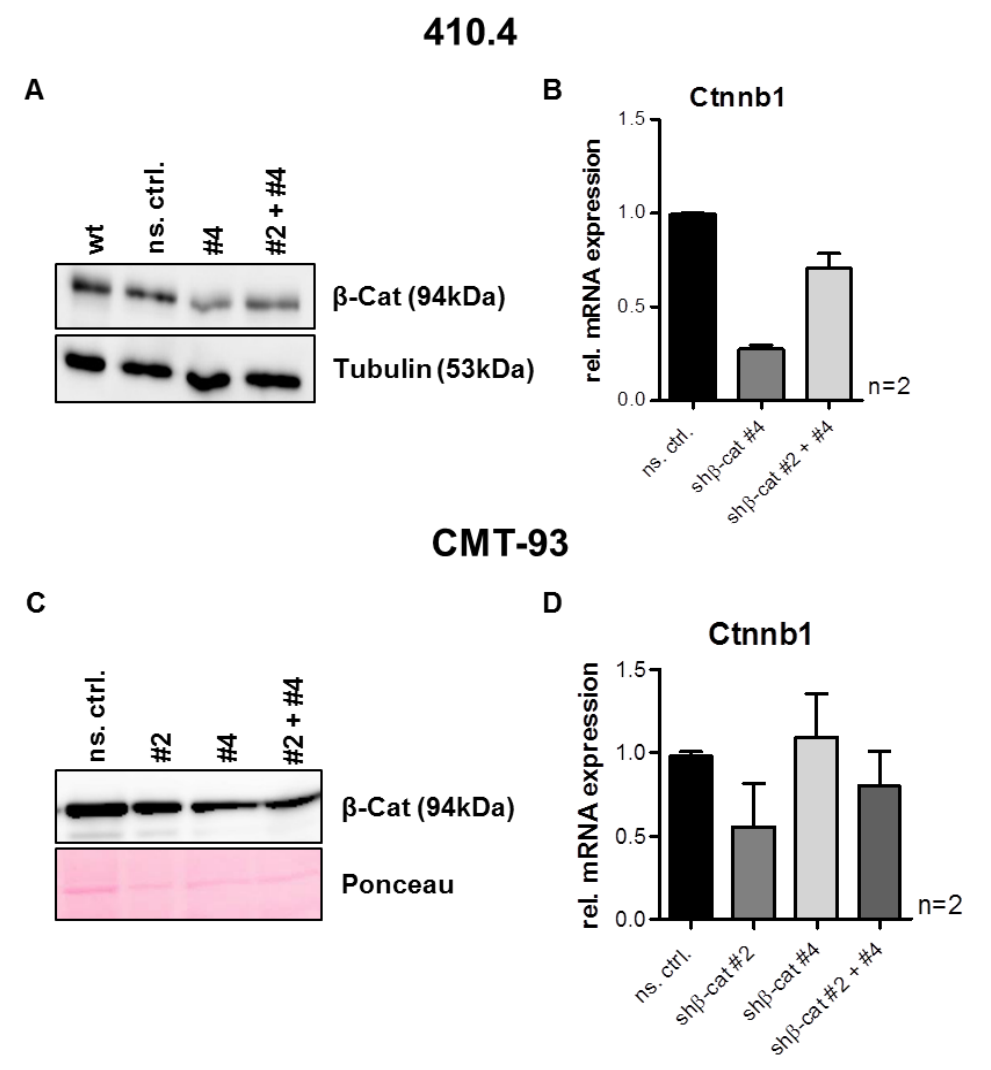

Abb. 3.10: Knockdown des $\beta$-Catenins in 410.4 und CMT-93.

In den 410.4 und CMT-93 Zellen wurde $\beta$-Catenin Knockdown stabil mit verschiedenen shKonstrukten gegen $\beta$-Catenin (\#2, \#4 und \#2 + 4) etabliert. Die erfolgreiche Transduktion wurde mittels Western Blot $(A, C)$ und mittels qRT-PCR $(B, D)$ für $\beta$-Catenin getestet.

Der $\beta$-Catenin Knockdown in CMT-93 Zellen war nicht erfolgreich. Obwohl man eine Reduktion auf der mRNA-Ebene mit dem Konstrukt 2 von teilweise bis zu 50\% 
nachweisen konnte, blieb dennoch die Proteinexpression von $\beta$-Catenin verglichen zu ns.ctrl. unverändert (s. Abb. 3.10 C, D). Es könnte bei einer Doppeltransfektion sein, dass die shKonstrukte gegen $\beta$-Catenin sich komplementär anlagerten und somit keinen inhibitorischen Effekt ausüben konnten. Es deutet generell darauf hin, dass der shRNA vermittelte Knockdown weniger spezifisch ist.

\subsection{Einfluss von $\beta$-Catenin auf die Invasion und Signalweiterleitung}

Um die funktionelle Bedeutung der Reduktion von $\beta$-Catenin in 410.4 Zellen zu ermitteln, wurde das Invasionsverhalten in der Boyden-Kammer bestimmt. Der Knockdown von $\beta$-Catenin zeigte keinen Einfluss auf die Invasion der Tumorzellen, weder unstimuliert noch nach Zugabe von rekombinantem WNT3a, welches als $\beta$ catenin-abhängiger WNT Signalweg Aktivator dient (s. Abb. 3.11 A). Außerdem wurde die Aktivität des kanonischen WNT Signalwegs anhand des TOP/FOP Assays gemessen. Um sicher zu gehen, dass der Assay erfolgreich durchgeführt wurde und die unveränderte Aktivität nicht auf einen systematischen Fehler zurückzuführen war, wurde dieser mit SW480 Zellen, einer menschlichen kolorektalen Tumorzellinie, die aufgrund ihrer Mutation im APC Gen gewöhnlich eine konstitutive Aktivierung des WNT Signalwegs zeigt, durchgeführt. Dieser Assay demonstriert, dass in der 410.4 der kanonische WNT Signalweg generell nur sehr wenig aktiv ist, so dass sich diese Zelllinien für diese Fragestellung als ungeeignet erwiesen (s. Abb. 3.11 B).

A

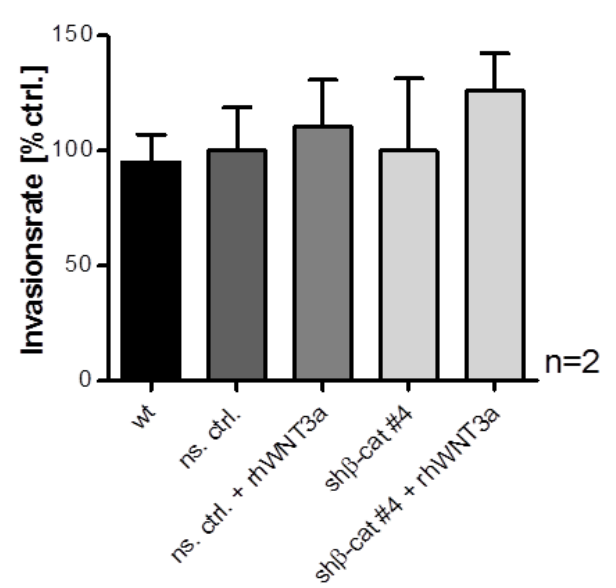

B

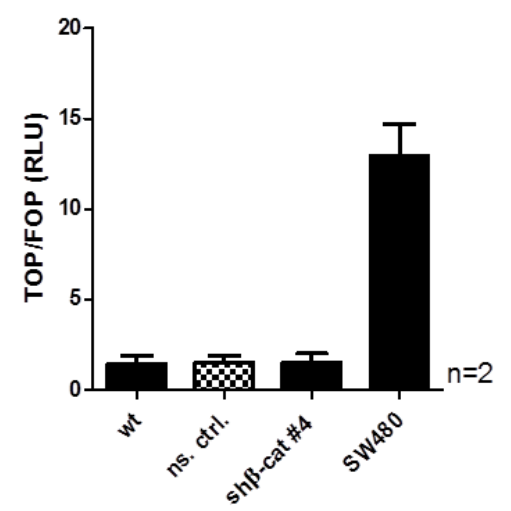

Abb. 3.11: Die Invasion und Aktivierung des kanonischen WNT Signalwegs des $\beta$-Catenin Knockdowns in 410.4 .

A) Der Einfluss von $\beta$-Catenin auf die Invasion wurde mit rhWNT3A Stimulation in der Boyden-Kammer Assay geprüft. Die Invasionsrate wurde auf die Invasion der Kontrollzellen bezogen. B) Die Aktivierung des kanonischen WNT Signalwegs wurde mittels TOP/FOP Assay untersucht. Auf der y-Achse ist das Verhältnis der TOPflash und FOPflash Aktivität aufgetragen. 
Eine leichte Reduktion von $\beta$-Catenin in 410.4 Zellen konnte nachgewiesen werden, jedoch ohne funktionelle Wirkung in der Boyden-Kammer und in dem TOP/FOP Assay.

\subsubsection{2 $\beta$-Catenin Überexpression in 410.4 und CMT-93 Zellen}

Parallel dazu erfolgte eine Überexpression von humanem $\beta$-Catenin unter Anwendung verschiedener Methoden wie lentivirale Transduktion und Nukleofektion. Nach einer lentiviralen Transduktion der beiden Zelllinien, 410.4 und CMT-93 konnte keine erhöhte Expression von $\beta$-Catenin in den Western Blot beobachtet werden (s. Abb. 3.12 A). Aufgrund der Tatsache, dass das Überexpressionskonstrukt, pLenti-III-2A$\beta C$ at-GFP, zusätzlich ein GFP-Reportergen enthält, wurde eine Kombination aus Nukleofektion und Sorting per Durchflusszytometrie ausgeführt, um eine reine Population von transfizierten Zellen zu erhalten. Nach der Transfektion wurde nur die Fraktion der GFP-positiven Zellen mittels Durchflusszytometrie erfolgreich sortiert und für eine weitere Woche kultiviert.

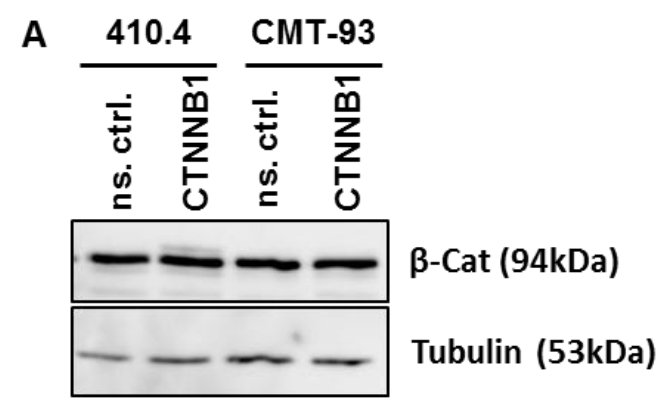

B

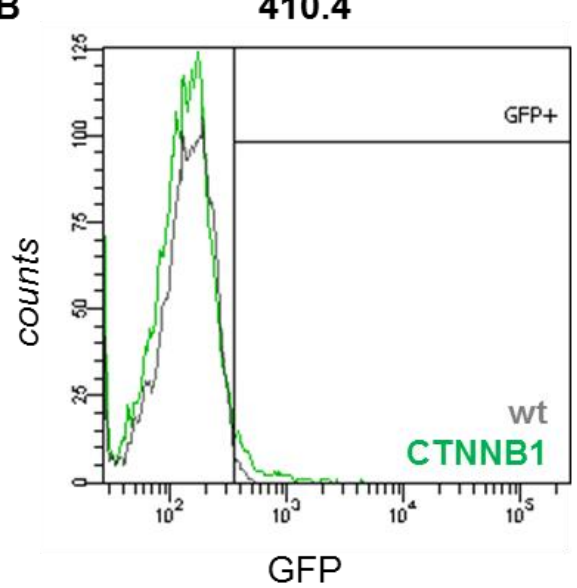

C

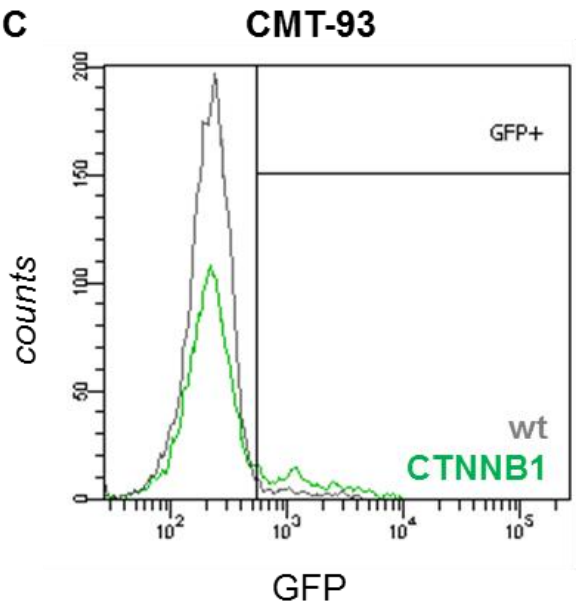

Abb. 3.12: Überexpression des $\beta$-Catenins in 410.4 und CMT-93.

410.4 und CMT-93 wurden stabil mittels lentiviraler Transduktion mit dem Leervektor pLenti-GFP (ns. ctrl.) oder mit dem Plasmid pLenti- $\beta$ Cat-GFP transduziert. A) $\beta$-Catenin Expression in den Zellen wurde mittels Western Blot analysiert. Die GFP-positiven Zellen wurden mittels Durchflusszytometrie gesortet und für eine 1 Woche kultiviert. B) Anschließend wurden sie erneut für GFP (angezeigt im Grün) charakterisiert. Die entsprechende Wildtyp-Kontrolle wurde im Grau dargestellt. 
Abschließend wurden die Zellen mittels Durchflusszytometrie wiederholt auf GFPPositivität kontrolliert (s. Abb. 3.12 B; C). Das Histogramm ermöglicht den Vergleich zwischen GFP-negativen (graue Kurve) und GFP-positiven (grüne Kurve) Zellen. Im Fall einer GFP-Positivität erwartet man eine Rechtsverschiebung der Population auf der $x$-Achse, welche nicht für beide Zellen eintritt. Somit müssten die Zellen $\beta$-Catenin mit der Zeit verloren haben. Es zeigte sich, dass das Überexpressionskonstrukt von den Zellen jeweils rasch eliminiert wurde und eine $\beta$-Catenin Überexpression technisch nicht möglich war.

Sowohl zu wenig als auch zu viel an $\beta$-Catenin in den Zellen scheint somit ungünstig für die Zellen zu sein, da sie offenbar von einen Kontext angepassten $\beta$-CateninNiveau abhängig sind. Somit konnte der $\beta$-Catenin-abhängige WNT Signalweg nicht moduliert werden.

\subsubsection{Etablierung der WNT11 und ROR2 modulierten Tumorzelllinien}

In Vorarbeiten unserer Arbeitsgruppe konnte gezeigt werden, dass WNT5a durch TAMs die Invasion der schwach invasiven Brustkrebszelllinie MCF-7 steigert (Pukrop et al., 2006). Sowohl die hoch invasiven Zelllinie MDA-MB231 als auch die Hirnmetastasen zeigten eine gesteigerte Expression von WNT5a/b und alternativen WNT Rezeptoren ROR1 und ROR2 (Klemm et al., 2011). Weiterhin konnte gezeigt werden, dass eine Überexpression von ROR2 in MCF-7 Zelllinien die Invasion steigert (Kerstin Menck, nicht veröffentlicht). Parallel erfolgte die Analyse von diesen Zellen, basierend auf einem Geninteraktionsnetzwerk, und zeigte eine gesteigerte Expression von WNT11 (Annalen Bleckmann und Micaela Bayerlova, persönliche Mitteilung). Des Weiteren wiesen die Hirnmetastasen aus Brustkrebs und Lungenkrebs eine hohe Expression von Wnt11, ROR1 und ROR2 auf (Kerstin Menck, nicht veröffentlicht). Dieses Ergebnis konnte durch RNA Seq. Analyse von Patientenmaterial validiert werden (Alexander Wolff).

Ausgehend von den beschriebenen Beobachtungen sollte die Rolle von Wnt11 und Ror2 in murinen Mammakarzinomzelllinien in der Tumorprogression und Metastasierung untersucht werden. 


\subsubsection{Etablierung der WNT11 modulierten Tumorzelllinien}

\subsection{Wnt11 Expression in Mamma- und kolorektalen Karzinomzelllinien}

Zur Untersuchung, inwieweit die Wnt11 Expression in soliden Tumorzelllinien vorhanden ist, wurde mittels qRT-PCR die Wnt11 Expression untersucht. Es konnte gezeigt werden, dass eine unterschiedlich ausgeprägte Expression in den Zelllinien detektierbar war (s. Abb. 3.13).

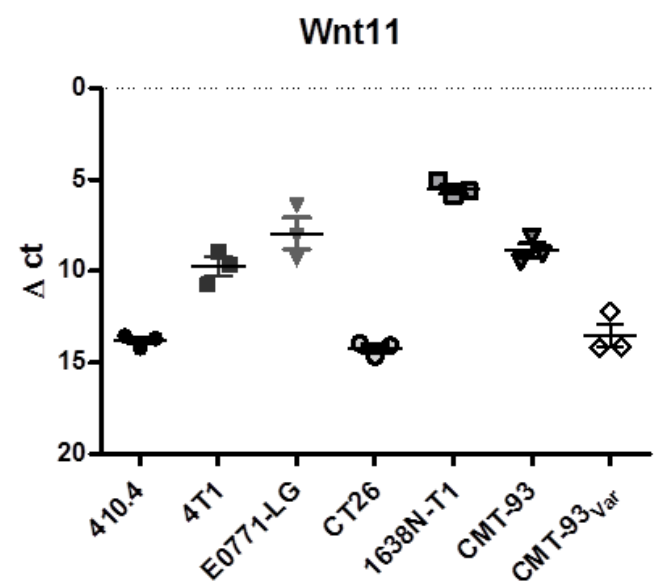

Abb. 3.13: Wnt11 Expression in Mamma- und kolorektalen Karzinomzelllinien.

Murine Mamma- und kolorektale Karzinomzelllinien wurden mittels qRT-PCR hinsichtlich der Expression von Wnt11 charakterisiert. Auf der y-Achse ist der $\Delta \mathrm{ct}$ Wert $(\Delta \mathrm{ct}=\mathrm{ct}$ (Gen von Interesse) ct (Housekeeing Gene)) als Mittelwert von drei Experimenten aufgetragen.

\subsection{Einfluss der Stimulation mit WNT11 auf die Invasion und Proliferation}

Aufgrund der oben beschriebenen Daten stellten wir die Hypothese auf, dass eine gesteigerte Expression von Wnt11 zur vermehrten Invasion führen kann. Aus diesem Grund analysierten wir die 410.4 Zellen nach der Stimulation mit rhWNT11 und/oder WNT5a auf die Invasion in der Boyden-Kammer-Assays. Es konnte gezeigt werden, dass eine Exposition gegenüber einer zunehmenden Konzentration an rhWNT11 die Invasion von 410.4 Zellen steigert. Eine Kombination aus WNT5a und WNT11 scheint keinen additiven Effekt zu haben (s. Abb. 3.14 A). Im Folgenden wurde die Proliferation der Zellen nach Stimulation mit rhWNT11 untersucht, während rhWNT11 keinen Einfluss auf die Proliferation hat (s. Abb. 3.14 B). 
A

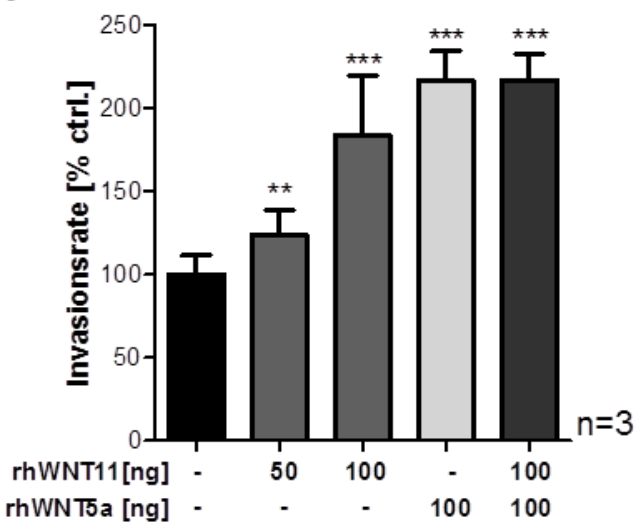

B

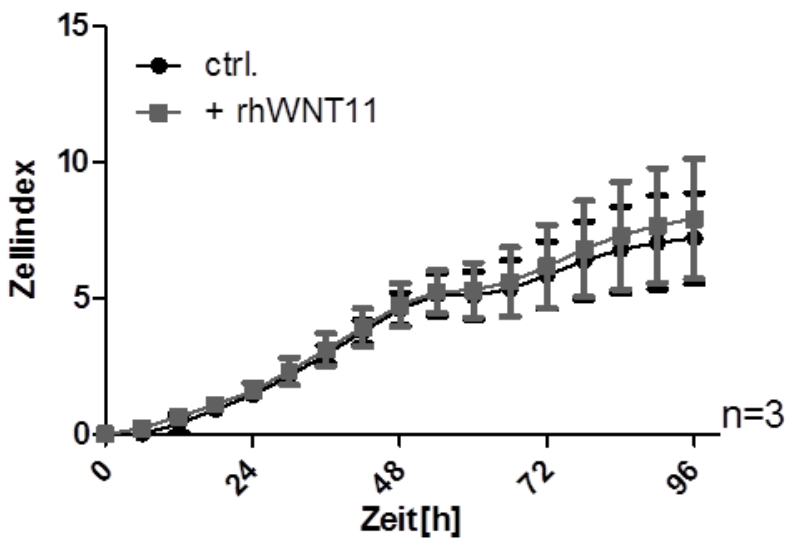

Abb. 3.14: Einfluss von WNT11 auf die Invasion und Proliferation in 410.4 .

A) 410.4 Zellen wurden für $96 \mathrm{~h}$ mit rhWnt11 oder rhWNT5a mit den angegebenen Konzentrationen stimuliert. Die Invasionsrate wurde dabei auf die unstimulierten Zellen bezogen, die auf $100 \%$ gesetzt wurde. Dargestellt sind die Mittelwerte aus drei unabhängigen Experimenten \pm Standardabweichung. ${ }^{* *} \mathrm{P}<0,01 ;{ }^{* * *} \mathrm{P}<0,001$. B) Die Proliferation wurde mittels $\mathrm{XCELLigence} \mathrm{Assay} \mathrm{für} 96 \mathrm{~h}$ mit und ohne rhWNT11 in 410.4 Zellen gemessen.

\subsection{Klonierung des Leervektors}

Wie in Abb. 3.14 A gezeigt, erhöht rhWNT11 das Invasionspotenzial der Tumorzelllinien. Daher sollte eine Überexpression von WNT11 in 410.4 Zellen herbeigeführt werden und auf die Veränderung des Phänotyps untersucht werden. Auf Grund der 97\%-igen Homologie zwischen murinen und humanen Wnt11, wurde ein humanes WNT11 Plasmid von der Firma addgene (pcDNA3.2 WNT11) erworben. Um die entsprechende Leerkontrolle (pcDNA3.2) zu konstruieren, wurde WNT11 aus dem Plasmid mit dem Enzym Sacll herausgeschnitten. Der Restriktionsverdau ist in der Abbildung 3.15 A dargestellt. Nach der Aufreinigung über das Agarosegel wurde das Plasmid ligiert und in den Bakterienstamm E. coli Dh5a transformiert. Zur Überprüfung der erfolgreichen Klonierung wurde das Plasmid mit BamHI und Scal geschnitten. Hierbei schneiden die Enzyme BamHI außerhalb und die Enzyme Scal innerhalb der Wnt11 Region. Sowohl das Plasmid pcDNA3.2 WNT11 als auch die klonierte Kontrolle wurde unter Verwendung von den beiden Enzymen, BamHI und Scal, geschnitten. Das Plasmid pcDNA3.2 WNT11 zeigt ungeschnitten eine einzige Bande (Bahn Nr.2) und geschnitten zwei Banden (Bahn Nr.3), während die Kontrolle nur eine Bande (Bahn Nr.4) zeigt. Somit wurde die Leervektorkontrolle erfolgreich kloniert. Anschließend wurden die 410.4 Zellen mit je einem Plasmid mittels Nukleofektion stabil transfiziert. 
A

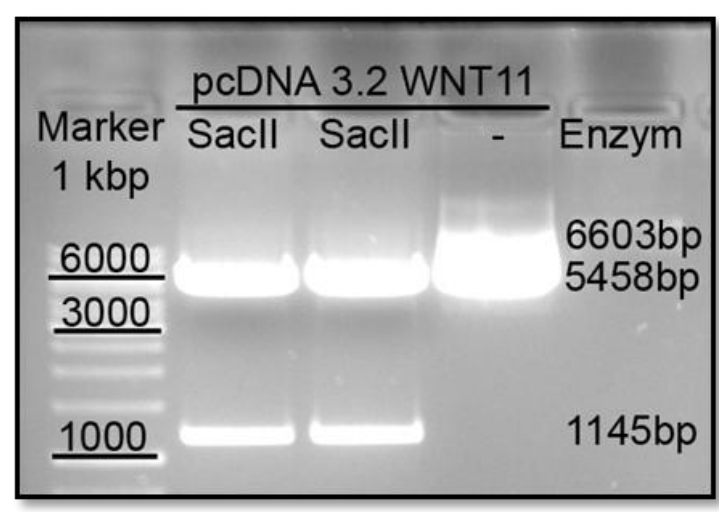

B

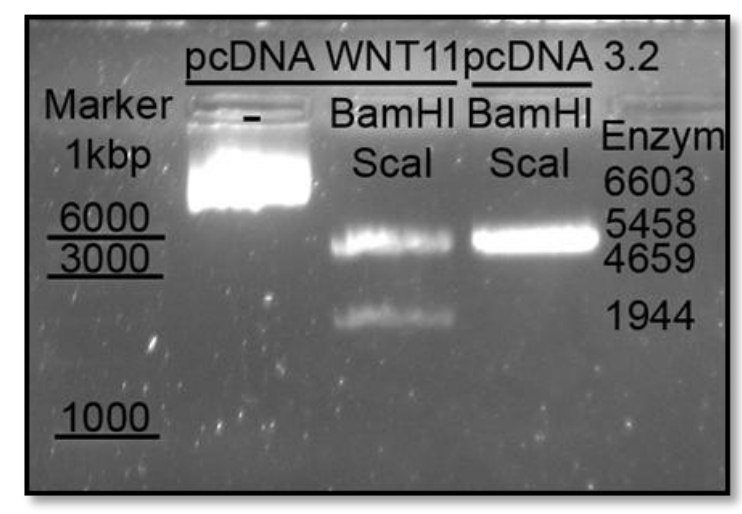

Abb. 3.15: Klonierung des Leervektors pcDNA3.2.

Das WNT11 Fragment wurde aus dem Plasmid pcDNA3.2 WNT11 unter Verwendung von Sacll herausgeschnitten $(A)$ und über ein Agarosegel aufgereinigt. Anschließend wurde der Vektor ligiert und in den E. coli DH5a transformiert. B) Zur Überprüfung der erfolgreichen Klonierung wurden die Plasmide isoliert und im Anschluss ein Restriktionsverdau mit BamHI und Scal durchgeführt.

\subsection{Charakterisierung der stabil transfizierten Zellen}

410.4 Zellen wurden mittels Nukleofektion mit dem Leervektor, pcDNA3.2 oder mit dem Plasmid pcDNA WNT11 transfiziert. Die Überprüfung der erfolgreichen Transfektion sollte üblicherweise mittels Western Blot und qRT-PCR Analyse geschehen. Trotz des Einsatzes verschiedener kommerziell erhältlichen polyklonalen Antikörper gegen WNT11 (R\&D Systems und Santa Cruz) anhand aktueller Literatur als Ausgangspunkt gelang es nicht, Wnt11 mittels Western Blot nachzuweisen. Im Rahmen der Optimierungen wurden verschiedene Blockierungslösungen und Verdünnungen des Antikörpers ausgetestet. WNT11 Antikörper der Firma Abcam führte nur vereinzelt zur erfolgreichen Immunoblots. Somit wurde zur Überprüfung der Überexpression von WNT11 auf die qRT-PCR Analyse eingeschränkt. Die Abbildung 3.16 zeigte, dass eine WNT11 Überexpression verglichen zu ns. ctrl. vorhanden war. Dieses Ergebnis deutet daraufhin, dass WNT11 in den Zellen überexprimiert werden und demzufolge die funktionellen Auswirkungen einer gesteigerten WNT11 Expression analysiert werden kann. 


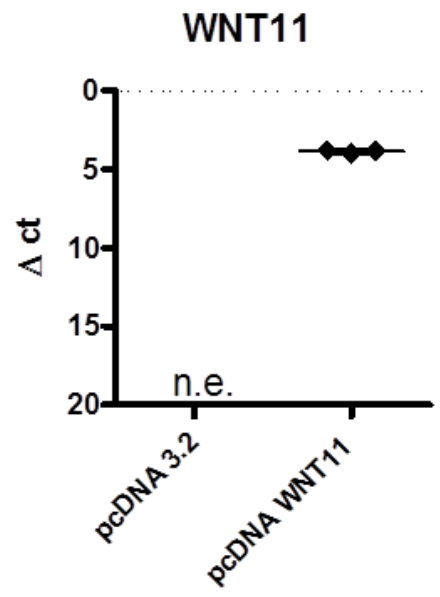

Abb. 3.16: WNT11 Überexpression in 410.4 .

410.4 Zellen wurden mittels Nukleofektion mit dem Leervektor, pcDNA3.2 oder mit dem Plasmid pcDNA WNT11 transfiziert. A) Zum Nachweis der erfolgreichen Transfektion wurde WNT11 Expression mittels qRT-PCR geprüft. Auf der y-Achse ist der $\Delta \mathrm{ct}$, d.h. ct, Gen von Interesse (GOI) - ct, Housekeeping Gene $(\mathrm{HK})$ als Mittelwert von drei biologischen Replikaten dargestellt; n.e. $=$ nicht exprimiert.

\subsection{Einfluss von WNT11 auf die Invasion, Proliferation und das anheftungsunabhängige Wachstum}

Nachdem sich gezeigt hatte, dass die Zugabe des rekombinanten WNT11 zur gesteigerten Invasion der 410.4 Zellen führte (s. 3.3.2.1.2), sollte im Folgenden untersucht werden, ob eine Überexpression von WNT11 auch die Invasion von 410.4 beeinflusst. Aus diesem Grund wurden die WNT11-überexprimierenden 410.4 Zellen in der Boyden-Kammer-Assay getestet. Wie erwartet führte die Überexpression von WNT11 zu einer erhöhten Invasion der Zellen (s. Abb. 3.17 A). Um herauszufinden, ob WNT11 einen Einfluss auf die Proliferation hat, wurde mittels xCELLigence Assay nachgeprüft. Es zeigte sich, dass WNT11 überexprimierende Zellen verglichen zu ns. ctrl. ein vermindertes Wachstum aufwiesen (s. Abb. 3.17 B). Dadurch, dass Proliferation und Invasion wesentliche Bestandteile der Tumorprogression darstellen, wurde erwartet, dass die Überexpression von WNT11 in 410.4 auch zu einer gesteigerten Proliferation der Zellen führen würde. Um auszuschließen, dass das durch WNT11-vermittelte verminderte Wachstum der Zellen nicht auf einer Viabilitätsminderung beruht, wurden die Zellen nach Beendigung des Experiments unter dem Mikroskop angeschaut, und es gab kein Anzeichen von Apoptoseinduktion. Es lässt sich vermuten, dass die Überexpression von WNT11 in irgendeiner Weise die Zelladhäsion bzw. Zellmorphologie beeinträchtigt. 
A

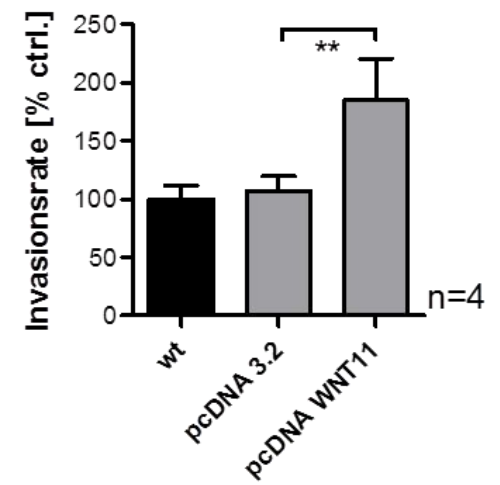

C

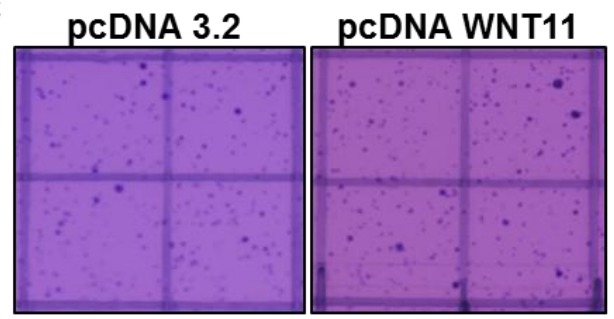

B

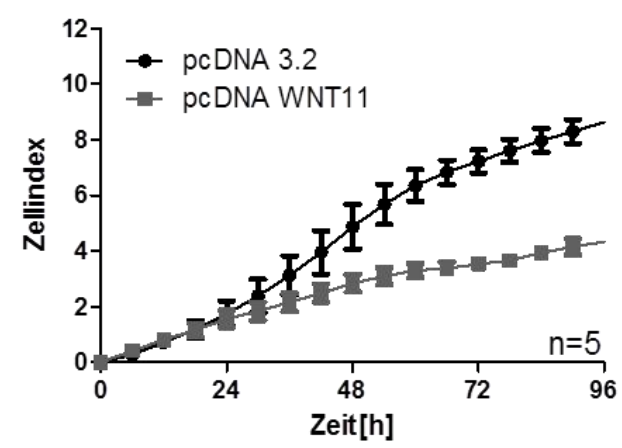

D

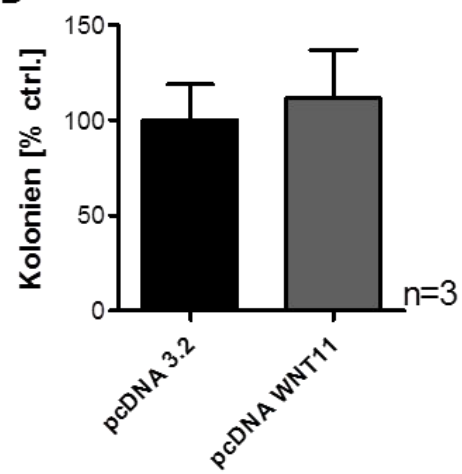

Abb. 3.17: Einfluss von WNT11 auf die Invasion, Proliferation und das anheftungsunabhängige Wachstum in 410.4 .

(A) Die Zellen wurden in der Boyden-Kammer für $96 \mathrm{~h}$ kultiviert, und die Invasionsrate wurde auf die Kontrolle bezogen $\left({ }^{* *} \mathrm{P}<0,01\right)$. B) Die Proliferation wurde mittels $x C E L L i g e n c e$ ebenfalls für $96 \mathrm{~h}$ ermittelt. Die Abbildung ist als Mittelwert von fünf Versuchen mit jeweils vier technischen Replikaten dargestellt. C, D) Die Zellen wurden in einem semi-soliden Kulturmedium ausgesät und für 2 Wochen inkubiert. Die Anzahl und Größe der Kolonien wurden mittels der Fotografie dokumentiert. Anschließend wurde das Wachstum der Kolonien auf die Kontrolle normalisiert, die auf 100\% gesetzt wurde.

Eine weitere Eigenschaft, die Aggressivität der Tumorzellen auszeichnet, ist, in einem semi-soliden Medium Kolonien bilden zu können. Hierzu wurden die Zellen entsprechend ausgesät und für zwei Wochen inkubiert. Die Anzahl und Größe der gebildeten Kolonien sahen ähnlich aus (s. Abb. 3.17 C). Das Ergebnis ist in Abb. 3.19 D dargestellt. Es deutet darauf hin, dass kein signifikanter Unterschied zwischen den Zellen nachzuweisen war. (s. Abb. 3.17 D).

\subsection{Einfluss von WNT11 auf das Zytoskelett und die Adhäsion}

Eine weitere Methode, um die Wirkung von WNT11 in der xCELLigence Messung (s. Abb. 3.17 B) zu untersuchen, bietet die Adhäsionsassay. Hierfür wurden die Zelllinien an einer ECM oder FN beschichteten Platte adhärieren lassen und nach einer bestimmten Zeit die Extinktion gemessen. Der Assay zeigte keinen Unterschied zwischen Kontrolle und WNT11 überexprimierende 410.4 Zellen (s. Abb. 3.18 A; B). 
A

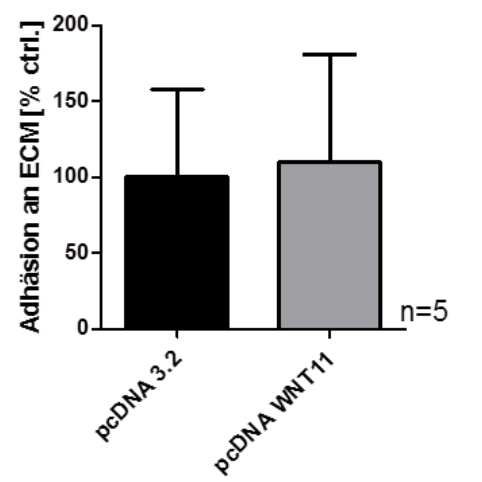

C

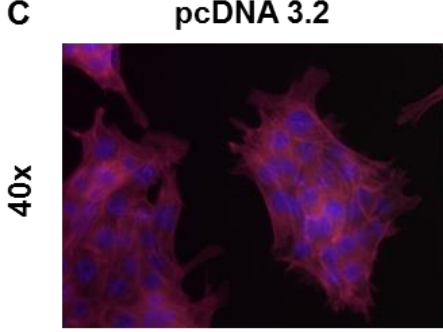

$\stackrel{x}{\bullet}$

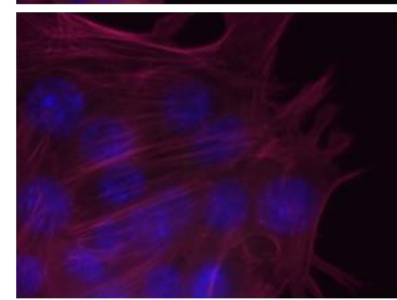

B

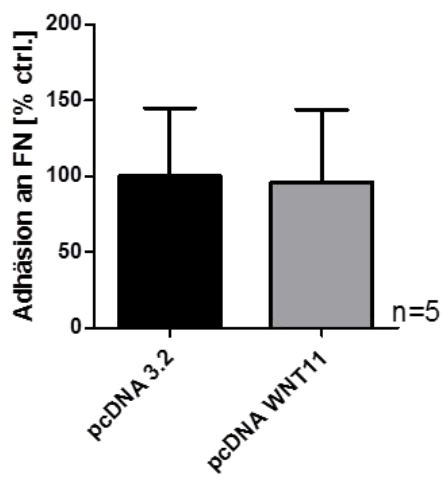

D
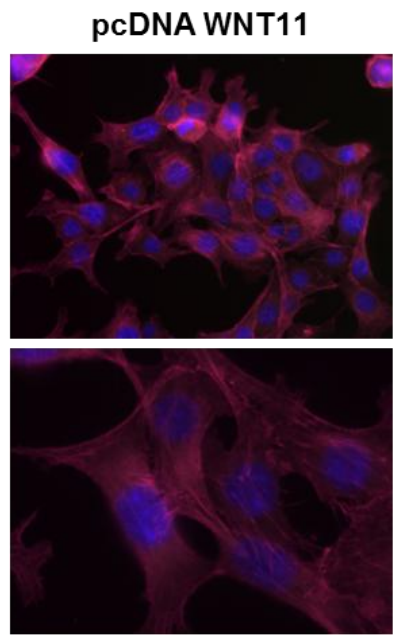

DAPI

Phalloidin

Abb. 3.18: Einfluss von WNT11 auf die Adhäsion an ECM und FN und das Aktin-Zytoskelett in 410.4 .

A, B) Die Adhäsionsfähigkeit der Zellen an ECM und FN wurde nach 30 min ermittelt, wobei die gemessenen Extinktionswerte der Leervektorkontrollen bei $562 \mathrm{~nm}$ auf $100 \%$ gesetzt wurden. Dargestellt sind die Mittelwerte aus fünf unabhängigen Experimenten. C, D) Die Zellen wurden mit Phalloidin (TRITC, rot) und DAPI Kernfärbung (blau) gefärbt und unter Fluoreszenzmikroskop dokumentiert (20x und 60x).

Zusätzlich wurde eine Phalloidinfärbung der Zellen zur Beurteilung des Zytoskeletts durchgeführt. Hierfür wurden die Zellen auf Deckgläschen ausgesät und anschließend für Phalloidin (pink), welches direkt an das F-Aktin bindet, und für Kernfärbung DAPI (blau) gefärbt. Die Aktin Darstellung (s. Abb. 3.18 C; D) zeigte keinen Unterschied in ihrem Zytoskelett-Aufbau zwischen den Zellen.

\subsection{Einfluss von WNT11 auf die Aktivierung des kanonischen und nicht- kanonischen WNT Signalwegs}

Um zu klären, inwieweit die Überexpression von WNT11 einen Einfluss auf die Komponenten des kanonischen und nicht-kanonischen WNT Signalwegs hat, wurden die Zellen auf Expression des entsprechenden Komponenten mittels Western Blot Analysen untersucht (s. Abb. 3.19 A). Die Expression von Gesamt $\beta$-Catenin blieb unverändert. Die Komponenten des nicht-kanonischen WNT Signalwegs wie PKC und 
JNK zeigten ebenfalls keinen Unterschied, während RHOA etwas mehr, verglichen zu ns. ctrl., exprimiert war.

A

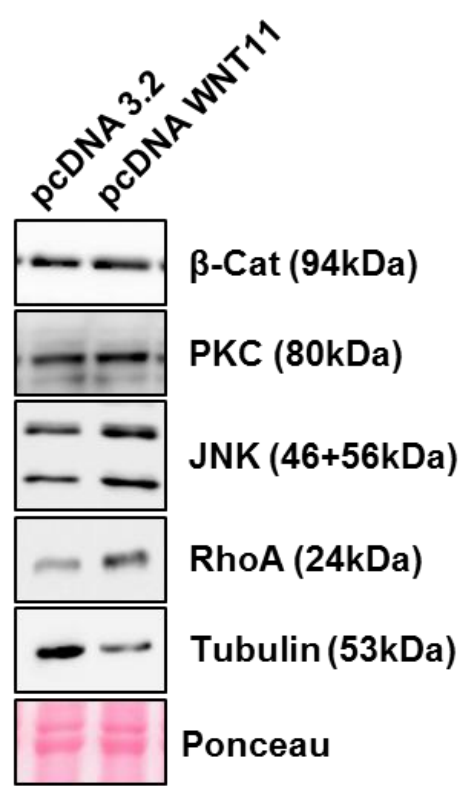

B

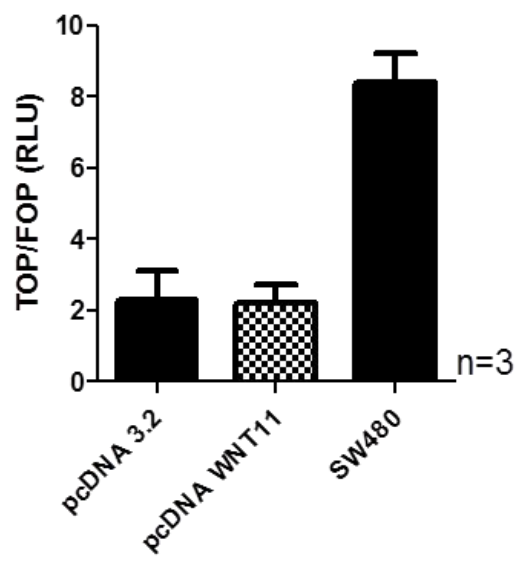

Abb. 3.19: Einfluss von WNT11 auf die Aktivierung des kanonischen und nicht-kanonischen WNT Signalwegs in 410.4.

A) Die Aktivierung des kanonischen und nicht-kanonischen WNT Signalwegs wurde mittels Western Blot innerhalb der Signalweiterleitung analysiert. B) Die Aktivierung des kanonischen WNT Signalwegs wurde mittels TOP/FOPflash Reporterassay gemessen. Aufgetragen ist das Verhältnis der TOPflash und FOPflash Aktivität als Mittelwert von mindestens drei unabhängigen Experimenten.

Um auszuschließen, dass WNT11 zur Aktivierung des $\beta$-Catenin-abhängigen WNT Signalwegs führt, wurde der TOP/FOP Assay durchgeführt. Als Positivkontrolle wurde dieser Assay ebenfalls mit SW480 Zellen, welche eine konstitutive Aktivierung des kanonischen WNT Signalwegs aufweist, durchgeführt. Wie Abb. 3.19 B zu entnehmen ist, konnte eine Überexpression von WNT11 in den Zellen keine gesteigerte Aktivierung des kanonischen WNT Signalwegs auslösen. Es lässt sich vermuten, dass die WNT11 induzierte Invasion nicht über $\beta$-Catenin vermittelt wird.

\subsection{Einfluss von WNT11 auf die Aktivierung des PI3K Signalwegs}

Es ist beschreiben, dass die Inhibition des Phosphoinositide 3 Kinase (PI3K) Signalwegs die Invasion hemmt. Im Fall einer Aktivierung erwartet man eine hohe Expression von P-Akt und P-S6. Die Western Blot Analyse zeigte, dass P-Akt hochreguliert wird, während P-S6 keinen Unterschied in der Expressionsstärke aufwies (s. Abb. 3.20 A). Des Weiteren wurde versucht, durch den Antagonisten des PI3K Signalwegs, BKM120 die Invasivität der Zellen zu hemmen. Die Steigerung der 
Invasivität durch WNT11 kann durch die Anwesenheit von BKM120 inhibiert werden (s. Abb. 3.20 B).

A

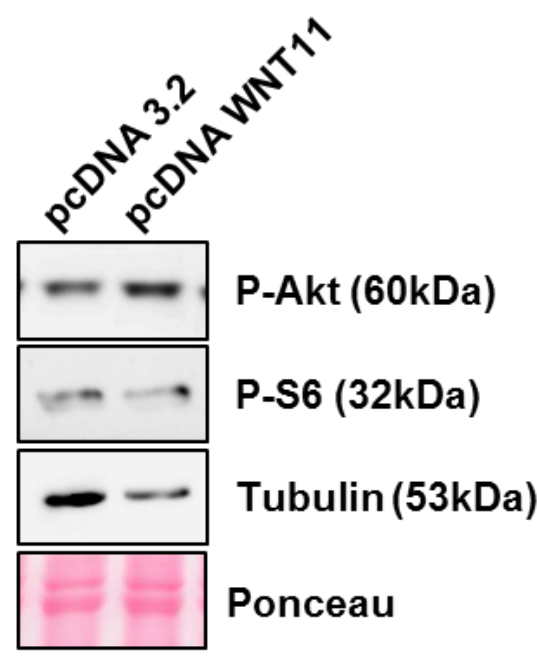

B

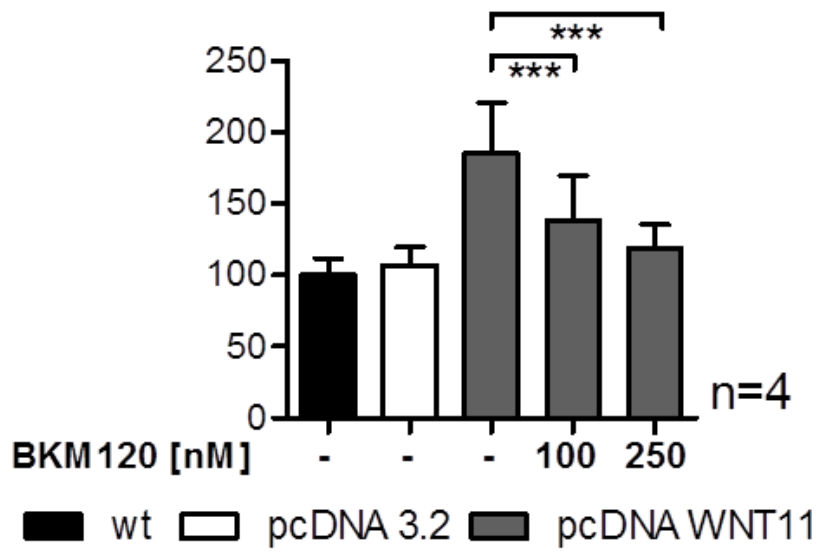

Abb. 3.20: Einfluss von WNT11 auf die Aktivierung des PI3K Signalwegs in $\mathbf{4 1 0 . 4}$.

A) Die Aktivierung des PI3K Signalwegs wurde mittels Western Blot innerhalb der Signalweiterleitung analysiert. B) Die Hemmung des PI3K Signalwegs wurde durch die Inhibition mit BKM120 in der Boyden-Kammer-Assay geprüft. Dargestellt sind Mittelwert von mindestens vier unabhängigen Experimenten $\left(n=4,{ }^{* \star *} p<0,001\right)$.

Zusammenfassend kann man sagen, dass WNT11 Überexpression die Zellinvasivität steigert, während keine Veränderungen der Zelleigenschaften wie Zellmorphologie, Zelladhäsion und anheftungsunabhängige Wachstum auftraten.

\subsubsection{Etablierung der ROR2 modulierten Tumorzelllinien}

\subsection{Charakterisierung der stabil transfizierten Zellen}

Im Folgenden sollte untersucht werden, über welchen Mechanismus WNT11 die Tumorinvasion erhöht. Wie unter 3.1.2 erwähnt, kommt als möglicher Rezeptor ROR2 in Frage. Aus diesem Grund analysierten wir die Auswirkungen einer ROR2 Überexpression in der ansonsten ROR2-negativen Mammakarzinomzellinie 410.4. Zu diesem Zweck erfolgte eine Überexpression von humanem ROR2 in den Zellen mittels Nukleofektion und der Nachweis der jeweiligen Überexpression mittels Western Blot und qRT-PCR Analyse. Dabei zeigte sich sowohl im Western Blot als auch in der qRTPCR Analyse eine deutliche Zunahme der Expression von ROR2 (s. Abb. 3.21 A, B). 
A

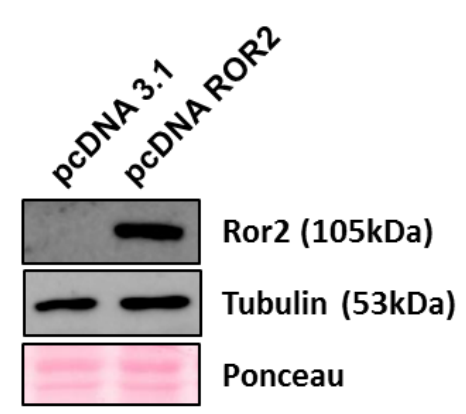

B

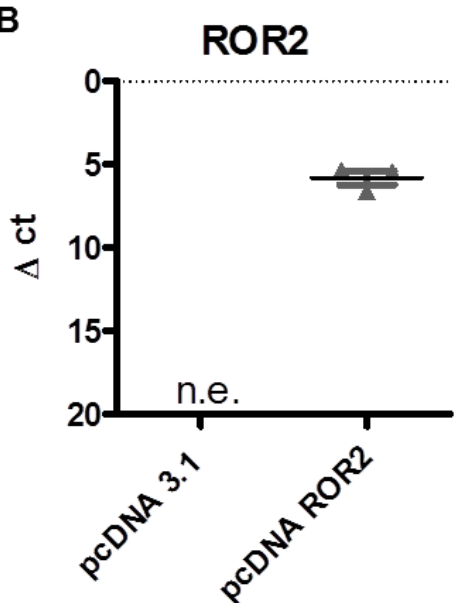

Abb. 3.21. ROR2 Überexpression in 410.4 .

410.4 Zellen wurden mittels Nukleofektion mit dem Leervektor, pcDNA3.1 oder mit dem Plasmid pcDNA ROR2 transfiziert. Zum Nachweis der erfolgreichen Transfektion wurde die ROR2 Expression sowohl mittels Western Blot (A) als auch mittels qRT-PCR (B) überprüft.

\subsection{Einfluss von ROR2 auf Invasion, Proliferation, anheftungsunabhängige Wachstum und Adhäsion}

Anschließend wurde untersucht, inwieweit Invasion, Proliferation, anheftungsunabhängiges Wachstum und Adhäsion der Zellen durch gesteigerte Expression von ROR2 beeinflusst werden. Das Invasionsverhalten wurde mittels Boyden Kammer Assays über 96 h durchgeführt. Dabei führte die Überexpression von ROR2 zu einer signifikanten Steigerung der Invasionsrate um ca. $200 \%$ (s. Abb. 3.22 A). Für die Untersuchung der Proliferation wurde die xCELLigence-Messung über 48 h durchgeführt. Dabei konnte eine Zunahme der Proliferation für ROR2 überexprimierende Zellen beobachtet werden (s. Abb. 3.22 B). Außerdem wurden die ROR2 überexprimierenden Zellen auf ihre Fähigkeit, anheftungsunabhängig wachsen zu können, untersucht. Das Wachstum und die Größe von Kolonien der Zellen wurden nach 2 Wochen Inkubation dokumentiert (s. Abb. 3.22 C). Wie in der Abbildung gezeigt, haben die Kolonien unterschiedliche Morphologie und Größe. Während die Kontrolle wenige, große Kolonien aufwies, bildeten die ROR2-überexprimierenden Zellen viele kleine Kolonien. Eine ROR2 Überexpression lieferte eine höhere Anzahl an Kolonien im Vergleich zu den Kontrollen (s. Abb. 3.22 D). 
A

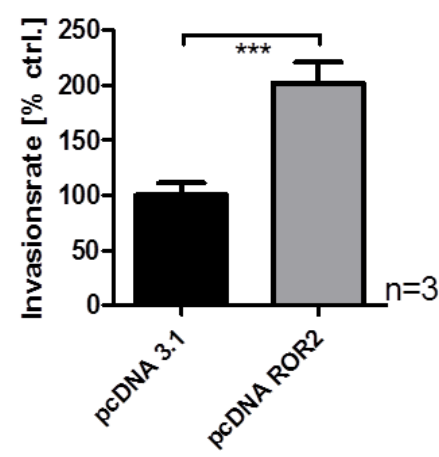

C

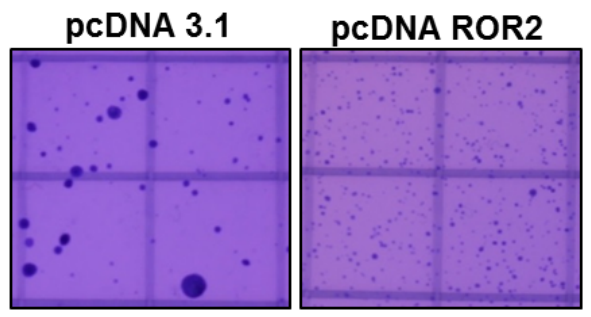

E

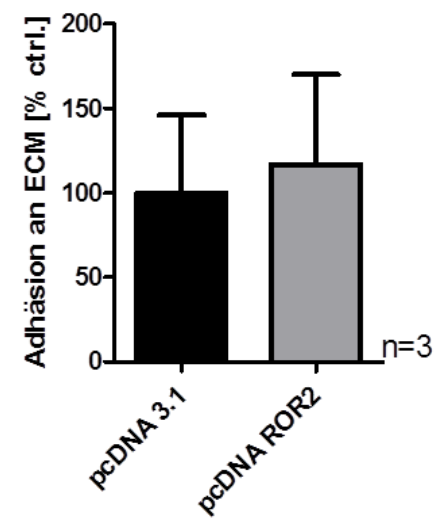

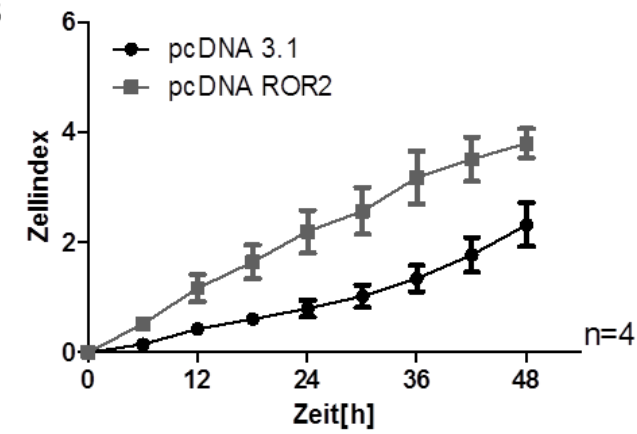

D

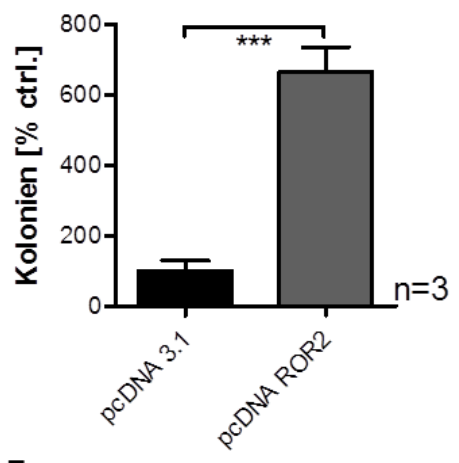

$\mathbf{F}$

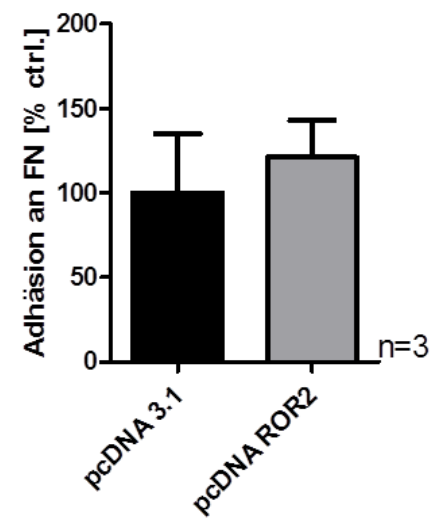

Abb. 3.22: Einfluss von ROR2 auf Invasion, Proliferation, anheftungsunabhängige Wachstum und Adhäsion in 410.4.

A) Die Zellen wurden in der Boyden-Kammer für $96 \mathrm{~h}$ kultiviert, die Invasionsrate wurde auf die Kontrolle bezogen. B) Die Proliferation wurde mittels xCELLigence Messung für $48 \mathrm{~h}$ ermittelt. C, D) Die Zellen wurden in einem semi-soliden Kulturmedium ausgesät und für 2 Wochen inkubiert. Anschließend wurde das Wachstum der Kolonien dokumentiert und auf die Kontrolle normalisiert. E, F) Die Adhäsionsfähigkeit der Zellen an ECM und FN wurde nach 30 min ermittelt, wobei die gemessenen Extinktionswerte der Leervektorkontrollen bei $562 \mathrm{~nm}$ auf 100\% gesetzt wurden. Dargestellt sind Mittelwerte aus drei unabhängigen Experimenten.

Neben dem Einfluss von ROR2 auf das anheftungsunabhängige Wachstum sollte auch der Einfluss auf die Adhäsionsfähigkeit untersucht werden. Hierzu wurden die Zellen sowohl auf ECM (s. Abb. 3.22 E) als auch auf FN (s. Abb. 3.22 F) ausgesät. Dargestellt sind die nach 30 min Inkubation gemessenen Extinktionswerte der Leervektorkontrollen und der ROR2 überexprimierenden Zellen, bei der die Kontrolle 
auf $100 \%$ gesetzt wurde. Sowohl für ECM als auch für FN war kein signifikanter Unterschied zwischen Kontrollen und die Zellen zu beobachten, obwohl die ROR2 überexprimierenden 410.4 Zellen eine Tendenz zu einer erhöhten Adhäsion, verglichen mit den Leervektorkontrollen, zeigten.

\subsection{Einfluss von ROR2 auf die Aktivierung des WNT Signalwegs und Expression von EMT-Markern}

Auch im Falle der ROR2 Überexpression wurde der Einfluss auf die Komponenten des kanonischen und nicht-kanonischen WNT Signalwegs mittels Western Blot bestimmt (s. Abb. 3.23 A). Die Western Blot Analyse zeigte keinen Unterschied der Gesamt $\beta$ Catenin Proteinmenge zwischen Kontrollzellen und ROR2 überexprimierenden Zellen. Die Komponenten des nicht-kanonischen WNT Signalwegs wie PKC und JNK blieben ebenfalls weitgehend unverändert, während eine deutliche Zunahme der RHOA Expression in den ROR2 überexprimierenden Zellen erkennbar war.

Wie in Abb. 3.22 A zu erkennen ist, führte eine gesteigerte Expression von ROR2 zu einer erhöhten Invasionsrate von 410.4 Zellen. Um die Rolle des kanonischen und nicht-kanonischen WNT Signalwegs bei der Invasion zu untersuchen, wurden Invasionsassays mit Zugabe der WNT-Inhibitoren SFRP1, und DKK-1 sowie dem JNKInhibitor II, SP600125 durchgeführt. Der pro-invasive Effekt von ROR2 konnte durch die Anwesenheit dieser Inhibitoren in der Boyden-Kammer inhibiert, aber nicht komplett aufgehoben werden (s. Abb. 3.23 B). Durch unsere Arbeitsgruppe konnte schon gezeigt werden, dass in Hirnmetastasen von Brust- und Lungenkrebs Wnt11, ROR1 und ROR2 hoch exprimiert sind. Aus diesem Grund wurde die Expression von Wnt11 und ROR1 in ROR2 überexprimierenden 410.4 Zellen mittels qRT-PCR untersucht. Eine gesteigerte Expression von ROR2 führte zur Reduktion der mRNAExpression von ROR1, wohingegen keine Auswirkungen auf die WNT11 Expression nachzuweisen war (s. Abb. 3.23 C). 
A

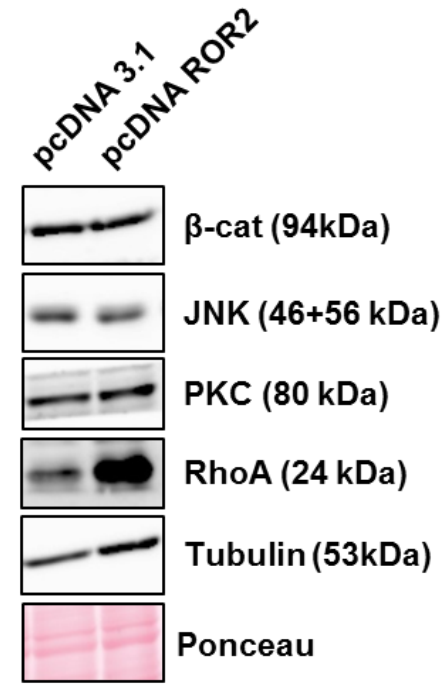

B

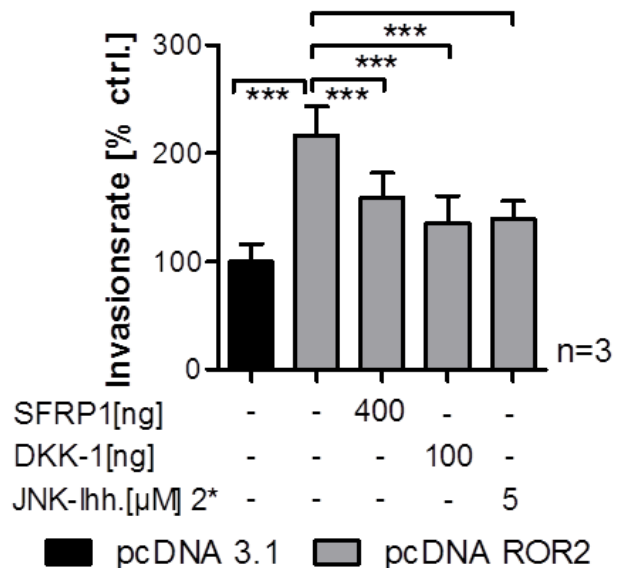

C

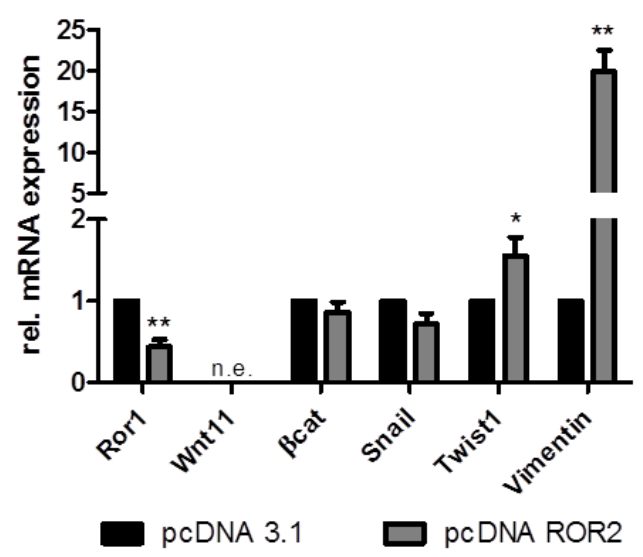

Abb. 3.23: Einfluss von ROR2 auf die Aktivierung des WNT Signalwegs und die Expression von EMT-Markern in 410.4.

A) Die Aktivierung des kanonischen und nicht-kanonischen WNT Signalwegs wurde mittels Western Blot innerhalb der Signalweiterleitung analysiert. B) Die Hemmung des kanonischen und nichtkanonischen WNT Signalwegs wurde durch die Inhibition mit verschiedenen WNT-Inhibitoren im Boyden-Kammer-Assay geprüft. Dargestellt sind Mittelwert von mindestens drei unabhängigen Experimenten $\left(n=3,{ }^{* * *} p<0,001\right)$. C) Die Expression von gekennzeichneten Genen wurde mittels qRTPCR ermittelt. Auf der y-Achse ist die relative Genexpression, bezogen auf die Kontrolle, als Mittelwert von drei Experimenten \pm Standardabweichung dargestellt; n.e. $=$ nicht exprimiert.

Im Weiteren sollte untersucht werden, ob die Überexpression von ROR2 eine verstärkte Expression von EMT-Markern zur Folge hat. Dazu wurde eine qRT-PCR Analyse für Snail, Twist1 und Vimentin sowie $\beta$-Catenins durchgeführt. Wie in Abb. 3.23 C dargestellt, konnte keine veränderte Expression von Snail und $\beta$-Catenin nachgewiesen werden, während Twist1 und Vimentin im Rahmen einer gesteigerten ROR2 Expression signifikant hochreguliert waren. Die gesteigerte Invasion der ROR2 überexprimierenden Zellen könnte somit auf einen Shift der Zellen zu einem mesenchymalen Phänotyp zurückzuführen sein. 


\subsection{Einfluss von ROR2 auf die Aktivierung des PI3K Signalwegs}

Zur Analyse, ob ROR2 in den 410.4 Zellen zu einer Aktivierung des PI3K Signalwegs führt, wurde weiterführend die mögliche Phosphorylierung der downstream Komponente Akt mittels Western Blot untersucht. Dies ergab eine Zunahme von P-Akt im Vergleich zu den Kontrollen (s. Abb. 3.24 A). Aus diesem Grund wurde versucht, den über ROR2 vermittelten pro-invasiven Effekt durch den Antagonisten des PI3K Signalwegs, BKM120, zu hemmen. Die Steigerung der Invasion durch ROR2 konnte durch die Anwesenheit von BKM120 partiell inhibiert werden (s. Abb. 3.24 B). In diesem Zusammenhang wurde ebenfalls ein Viabilitätstest mit BKM120 in Form des MTT-Assays durchgeführt. Dabei wurden die Zelllinien, Leervektorkontrollen und ROR2 überexprimierenden Zellen mit unterschiedlichen Konzentrationen von BKM120 behandelt. Es konnte gezeigt werden, dass die ROR2 überexprimierenden Zellen eine signifikant erhöhte Vitalität gegenüber BKM120 im Vergleich zu den Kontrollen zeigten (s. Abb. $3.24 \mathrm{C}$ ). Die hohe Aktivierung des PI3K Signalwegs scheint die ROR2 überexprimierenden Zellen in gewissem Maße vor dem PI3K-Inhibitor, BKM120, zu schützen.
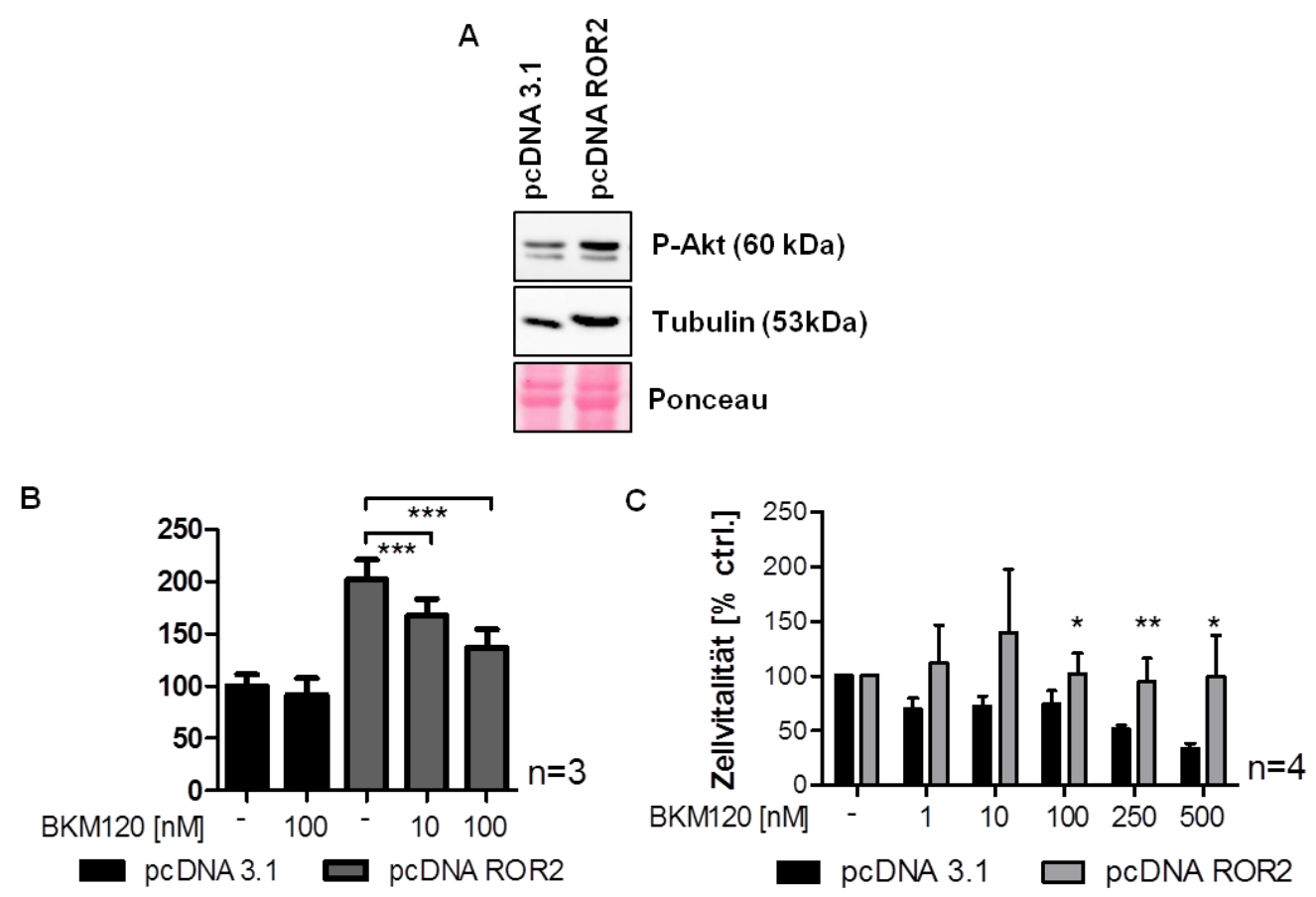

Abb. 3.24: Einfluss von ROR2 auf die Aktivierung des PI3K Signalwegs in $\mathbf{4 1 0 . 4 .}$

A) Die Aktivierung des PI3K Signalwegs wurde mittels Western Blot für P-Akt analysiert. B) Die Auswirkung der Hemmung des PI3K Signalwegs wurde durch die Inhibition mit BKM120 in der BoydenKammer-Assay geprüft. Dargestellt sind Mittelwerte von mindestens drei unabhängigen Experimenten $\left(n=3,{ }^{* * *} p<0,001\right)$. C) Die Zellvitalität nach Behandlung mit BKM120 wurde in der MTT-Assay überprüft. Auf der $x$-Achse ist die Zeit in Stunden (h) aufgetragen, auf der y-Achse die relative Zellvitalität in \%, bezogen auf die Kontrolle, als Mittelwert von vier Versuchen mit jeweils zwei technischen Replikaten. 


\subsection{Anwendbarkeit im Mausmodell}

Zur Analyse des WNT und EGFR Signalwegs wurden in Frage kommenden murine Mamma- und kolorektale Tumorzelllinien charakterisiert. Bei der Charakterisierung der Zelllinien war die Entwicklung von Metastasen im Tiermodell in einem akzeptablen Zeitrahmen von entscheidender Bedeutung. Dafür wurde das Kolonisationsverhalten der Zelllinien in vivo durch die Injektion in die Leber bzw. in das Gehirn von syngenen Mäusen studiert. Als erstes wurde die Zelllinie CMT-93 (CMT-93Var) durch eine Kooperation mit Fr. Dr. med. Christina Hackl aus der Uniklinik Regensburg zur Verfügung gestellt. Aufgrund der Authentifizierung der Zelllinien für die Publikationen wurde die Zelllinie bei ATCC gekauft und für unsere Mausmodelle genutzt. Im Rahmen der Zusammenarbeit mit den Teilprojekten WP3 und 4 hat sich herausgestellt, dass die originale ATCC Zelllinie nach Implantation sowohl in der Leber als auch im Gehirn gar kein oder nur ein geringes Tumorwachstum erzeugte (s. Abb. 3.25). Die CMT-93Var hingegen kolonisierte nach Implantation in Mäuse deutlich besser als die OriginalZelllinie.

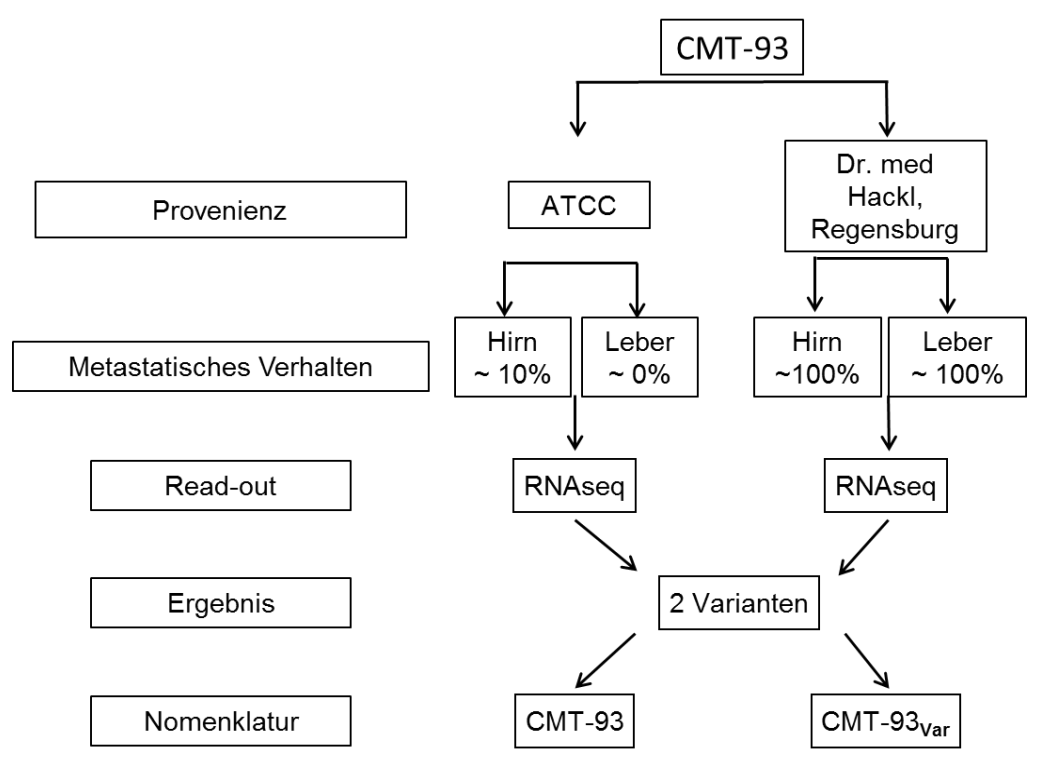

Abb. 3.25: Zusammenfassung der Ergebnisse von CMT-93 im Mausmodell (in Zusammenarbeit mit WP 3, 4 und 9)

Um den Unterschied bezüglich ihres metastatischen Verhaltens besser zu verstehen, wurden die beiden Zelllinen durch RNA Seq. Analysen in Zusammenarbeit mit WP9 untersucht. Diese beiden Linien wiesen eine differentielle Expression von vielen Genen auf, sodass die Zelllinie aus Regensburg eine durch die prolongierte Zellkultur entstandene Variante der Original-Zelllinie zu sein scheint. Dennoch konnte in Clusteranalysen der Zelllinien auf Entitäten in Zusammenarbeit mit WP9 gezeigt 
werden, dass es sich bei der CMT-93Var um eine kolorektale Zelllinie handelt. Dies ließ sich auch durch histologische Untersuchungen der Metastasen durch die Pathologen bestätigen. Somit war diese Variante für unser Konsortium geeignet. Aufgrund des besseren Kolonisierungsverhaltens in den in vivo Experimenten wurde entschieden, die CMT-93var für weitere Experimente im Tiermodell zu verwenden. Aus diesem Befund stellte sich die Frage, welche Determinanten in der CMT-93var Zelle eine signifikant erhöhte Metastasierung bewirkt hatten. Um dieser Frage nachzugehen, wurde eine heatmap der hoch signifikant differentiell exprimierten Gene in der OriginalZelllinie und in der Variante-Zelllinie aus der RNA Seq. Analyse erstellt wurde (Zusammenarbeit mit WP9). Auffallend war $u$. a. die hohe Expression von Cadherin16 (Cdh16) in der CMT-93var Zelle. Cdh16 ist ein Adhäsionsprotein, welches eine Rolle bei der Stabilisierung von Zell-Zell-Kontakten spielt. Seine Funktion in der Stabilisierung der Zellkontakte könnte eine gute Erklärung für das unterschiedliche Anwachsen in den Mäusen sein.

A

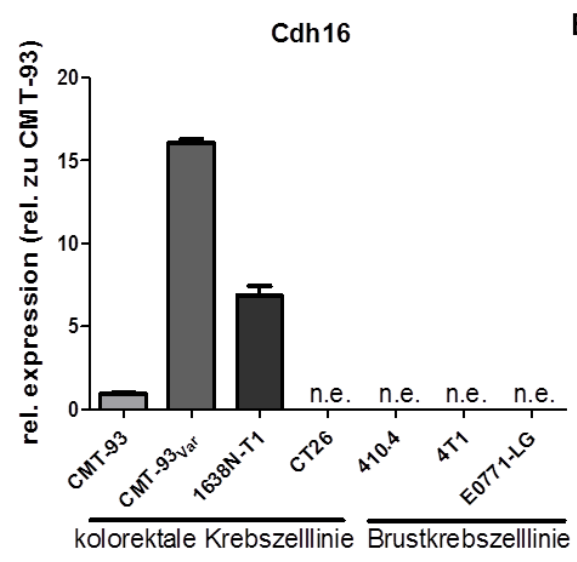

B

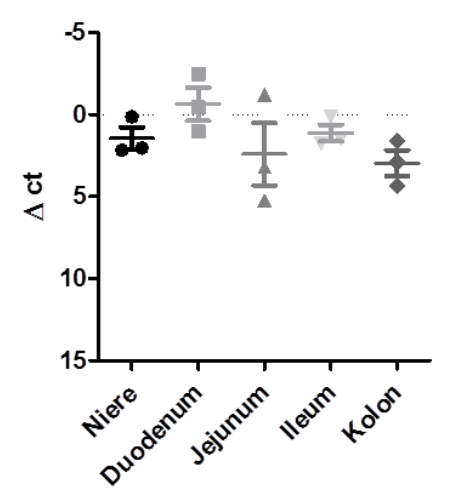

C

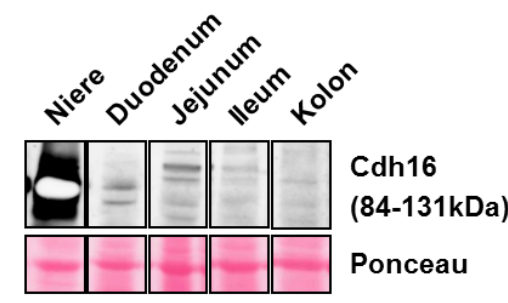

Abb. 3.26: Cadherin16 Expression in Tumorzelllinien und in Geweben.

A) qRT-PCR Analyse für Cdh16 in murinen Brust- und kolorektalen Krebszelllinien. Auf der y-Achse ist die relative Genexpression (fold change) als Mittelwert von drei Experimenten \pm Standardabweichung, bezogen auf die CMT-93 (fold change = 1), dargestellt. B) qRT-PCR Analyse für Cdh16 in murinen intestinalen Geweben. Auf der y-Achse ist das $\Delta \mathrm{Ct}$, d.h. Ct (Gen von Interesse (GOI)) - Ct (Referenzgen $(\mathrm{HK})$ ), als Mittelwert von drei Experimenten \pm Standardabweichung dargestellt. C) In der Niere und in den Verdauungstrakten wurde die basale Proteinexpression von Cdh16 mittels Western Blot untersucht.

Aufgrund dieser Erkenntnis haben wir angefangen, die Rolle von Cdh16 in der Metastasierung näher zu charakterisieren. Demzufolge analysierten wir die Cdh16 Expression in murinen Mamma- und kolorektalen Tumorzellinien mittels qRT-PCR (s. Abb. 3.26 A). In der hoch invasiven CMT-93var war eine 15-fache Steigerung der Cdh16 Expression zu erkennen. Interessanterweise wurde das Gen in den wenig invasiven 1638N-T1 Zellen ebenfalls exprimiert, während es in der mesenchymalen kolorektalen Zelllinie CT26 und in den untersuchten Brustkrebszelllinien gar nicht 
vorhanden war. Ursprünglich wurde das Gen als ein nierenspezifisches Mitglied der Cadherin Familie, auch Ksp-cadherin (kidney-specific cadherin) genannt, in der Spezies Kaninchen von der Arbeitsgruppe Thomson et al. (1995) identifiziert. Die Northern Blot Analyse hatte gezeigt, dass die Cdh16 Expression nur auf die basolaterale Membranen von Nierenepithelien des Tubulus beschränkt war. Die abgeleiteten Aminosäuresequenzen des Menschen- und des Mausisoforms sind 79\% und 75\% identisch zur ursprünglich beschriebenen Kaninchenisoform von Cdh16 (Thomson et al., 1998). Dadurch, dass Cdh16 zusätzlich in einer anderen kolorektalen Zelllinie (s. Abb. 3.26 A) nachgewiesen wurde, wurde in gesunden murinen Geweben des Verdauungstrakts die Cdh16 Expression mittels qRT-PCR und Western Blot Analyse untersucht (s. Abb. 3.26 B-C). Es konnte gezeigt werden, dass die mRNA sowohl in der Niere als auch in den Verdauungstrakten deutlich gleichmäßig nachweisbar war. Im Gegenstaz dazu verdeutlichte die Western Blot Analyse, dass das Protein nur in der Niere zu detektieren war (s. Abb. 3.26 C).

Neben der Analyse einzelner Genen wurde im Rahmen des WP9 anhand der GeneSet-Enrichment-Analyse versucht, die dazugehörigen Signalwege aufzudecken. Das Ergebnis wies Signalwege des Metabolismus und des Immunsystems auf, darunter auch der WNT Signalweg unter den TOP 20 Signalwegen. Aus diesem Grund wurde unsererseits die Aktivierung des kanonischen WNT Signalwegs in der Original-Zelllinie und in der Variante mittels TOP/FOP Assay gemessen. Sowohl in CMT-93 als auch in den CMT-93var Zellen ließ sich keine signifikante Aktiviereung nachweisen. Als Positivkontrolle wurde die SW480 Zelllinie gewählt, da hier der kanonische WNT Signalweg durch eine Mutation im APC Gen konstitutiv aktiviert ist. Diese zeigte das erwartete hochpositive Signal (s. Abb. 3.27). 


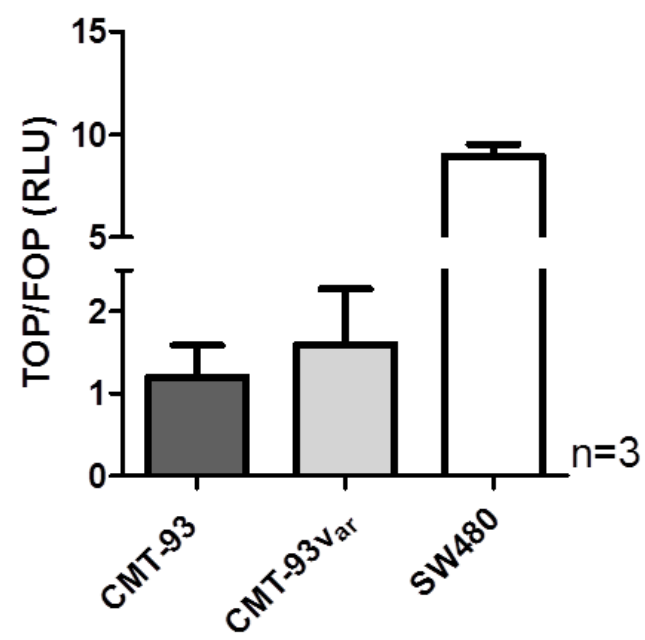

Abb. 3.27: Vergleich der CMT-93 Zelllinien auf die Aktivierung des kanonischen WNT Signalwegs. Die Aktivierung des kanonischen WNT Signalwegs wurde mittels TOP/FOP Assay untersucht. Auf der y-Achse ist das Verhältnis der TOPflash und FOPflash Aktivität als Mittelwert von mindestens drei unabhängigen Experimenten aufgetragen.

Das Ergebnis deutete darauf hin, dass in den beiden Zelllinien keine unterschiedliche Aktivität des kanonischen WNT Signalwegs vorkommt und dieser Signalweg keine entscheidende Rolle bei der Kolonisation in CMT-93var Zellen spielt. 


\section{Diskussion}

\subsection{Identifikation der murinen Tumorzelllinien zur Analyse der Tumorprogression}

In dem BMBF "MetastaSys“ Projekt sollte die Mechanismen der Tumorprogression in zwei soliden Tumorzelllinien sowohl in vitro Experimenten in der Zellkultur als auch in vivo Tierversuchen untersucht werden. Nach Pagets Seed and Soil Theorie bevorzugen die Tumorzellen abhängig vom Ursprung des Primärtumors spezische Zielorgane. Beim kolorektalen Karzinom treten vermehrt Lebermetastasen auf, hingegen hat das Mammakarzinom eine Tendenz, in das Gehirn zu metastasieren. Es ist noch weitgehend unklar, ob das Metastasierungspotential entweder durch die Eigenschaften der Tumorzellen oder vom Zielorgan der Metastase vorangetrieben wird.

Das Hauptziel dieser Studie ist es, die Mechanismen der Metastasierung von Tumorzellen in spezifischen Organen besser zu verstehen. Obwohl es eine Menge an transgenen Mausmodellen für kolorektale - und Mammatumorinitiation gibt, wird hauptsächlich für Studien der Metastasierung auf Xenograft-Modell der Nacktmäuse zurückgegriffen. Mehrere Studien belegen, dass die stromale Mikroumgebung einen positiven Einfluss auf die Tumorprogression haben kann, indem sie nicht nur die Proliferation maligner Zellen induzieren, sondern auch die Migration und Invasion sowie die Intravasation fördern kann. Hinzu kommt, dass das Modell mit den Nacktmäusen aufgrund eines fehlenden funktionierenden Immunsystems nicht geeignet ist, wenn man die Interaktion zwischen Tumorzellen und Immunzellen in den Untersuchungen mit einbeziehen möchte. Aus diesem Grund sollte im Konsortium mit einem syngenen Mausmodell gearbeitet werden. Infolge dieser Tatsache war die Auswahl an murinen Mamma- und kolorektale Tumorzellinien begrenzt.

Folgende Kriterien wurden jeweils für eine optimale Zelllinie zugrunde gelegt: Die Zellen sollten typische Charakteristika der jeweiligen Tumorentität aufweisen. Z. B. sollten kolorektale Tumorzelllinien, die gewöhnlich eine Hochregulation von $\beta$-Catenin aufweisen, und Mammakarzinomzelllinien, wo oft eine vermehrte Bildung von EGFR beschrieben wird, diese typischen Veränderungen auch zeigen. Überdies sollten die Zellen nach Inokulation in die Mäuse in einem akzetablen Zeitrahmen Metastasen erzeugen. 
In diesem Konsortium sollten die Mechanismen der Tumorprogression in Bezug auf den EGFR und WNT Signalweg untersucht werden. Dementsprechend wurden verfügbare murine Mamma- und kolorektale Karzinomzellinien sowohl morphologisch als auch molekular charakterisiert.

Trotz der oft in Mammakarzinomzellinien nachweisbaren EGFR Überexpression zeigte die molekulare Charakterisierung der vorhandenen Zelllinien nur eine sehr schwache EGFR Expression (s. Abb. 3.2 B-C). Anhand der weiterführenden Charakterisierung bzgl. Hormonrezeptorexpression und HER2-Status konnten die Zellen den molekularen Subtypen des Mammakarzinoms zugeordnet werden. 410.4 und die davon abgeleitete 4T1 erwiesen sich eher als triple-negative Subtypen, während E0771-LG positiv für HER2 war (s. Abb. 3.2 A). Der triple-negative Subtyp des Mammakarzinoms korreliert oft mit einer Gehirnmetastasierung (Alvarez et al., 2010; Rimawi et al., 2010) und ist daher gut geeignet für unsere Fragestellung.

Zudem wurden die Zellen auf die Aktivierung des kanonischen und nicht-kanonischen WNT Signalwegs untersucht. Mehrere Studien belegen, dass die Aktivierung des kanonischen WNT Siganlwegs oft mit der Tumorinitiation und Metastasierung assoziiert sind (Fodde et al., 2001; Brabletz et al., 1998). Alle untersuchten Zellen außer E0771-LG wiesen einen erhöhten $\beta$-Catenin Spiegel auf, weshalb E0771-LG für diese Studie ausgeschlossen werden konnte (s. Abb. 3.2 D).

Ein weiterer morphologischer Aspekt für geeignete Zelllinien war ein epithelialer Phänotyp. Da nach Literatur (Thiery, 2002) Tumorzellen während der Metastasierung im Rahmen der sog. EMT zu einem mesenchymalen Phänotyp transformieren können, sollten Zellen, die noch einen epithelialen Charakter aufweisen in dieser Untersuchungsreihen bevorzugt werden. Sowohl morphologische als auch molekulare Untersuchungen auf Zelladhäsionsprotein wie E-Cadherin zeigten, dass 410.4 und 4T1 epithelialen Phänotyp aufwiesen (s. Abb. 3.1; 3.4 A-B). E0771-LG zeigte einen robusten mesenchymalen Phänotyp, ein weiterer Grund, diese nicht für diese Studie anzuwenden. Alle untersuchten Mammakarzinomzelllinien wiesen einen tumorigenen Phänotyp im Tiermodell auf.

Die parentale Zellinie 410.4 und ihre metastatisches Derivat 4T1 erwiesen sich somit anhand der geschilderten Kriterien als geeignete Zelllinien. Für die Entität Brustkrebs wurde die Tumorzelllinie 410.4 aus den charakterisierten Zelllinien ausgewählt, da sie 
moderat invasiv im Gegensatz zu 4T1 ist und mit den genetischen Modifikationen eine verstärkte Tumorprogression zu erwarten war.

Eine vermehrte Aktivierung des $\beta$-Catenin abhängigen WNT Signalwegs ist mehrfach in kolorektalen Karziomen beschrieben. Dies kann durch eine Mutation im APC oder im $\beta$-Catenin verursacht werden, sodass eine Hochregulation von $\beta$-Catenin in diesen Tumorzelllinien vorliegt. Alle untersuchten kolorektalen Zelllinien zeigten eine Hochregulation von $\beta$-Catenin, wobei CMT-93 $\beta$-Catenin deutlich stärker exprimiert (s. Abb. 3.2 B;D). Die Untersuchung der einzelnen kanonischen und nicht-kanonischen WNT Liganden und Targetgenen wiesen in 1638N-T1 und CMT-93 Zellen teilweise das Vorhandensein des kanonischen und nicht-kanonischen WNT Signalwegs nach, während CT26 sowohl gar keine messbare Expression von kanonischen und nichtkanonischen WNT Targetgenen als auch keine von alternativen WNT Liganden nachwies (s. Abb. 3.3). Für 1638N-T1 Zellen war eine Hochregualtion von $\beta$-Catenin erwartet und nachgewiesen, da diese Zellen eine Mutation im Apc Gen beinhalten und somit eine konstitutive Aktivierung des kanonischen WNT Signalwegs bewirken können. Weitere Mutationen wie z. B. im k-Ras Gen konnten durch die RNA Seq. Analyse ausgeschlossen werden.

Der epitheliale Charakter konnte sowohl in 1638N-T1 als auch in CMT-93 Zellen nachgewiesen werden. Die morphologische Analyse und die fehlende Expression des E-Cadherins von CT26 weisen auf einen massiven mesenchymalen Phänotyp der Zellen hin (s. Abb. 3.4 A-B). In dieser Linie offenbarte sich in der RNA Seq. Analyse eine aktivierende Mutation im $k$-Ras Gen, so dass diese Linie nicht für die Modulation des upstream gelegenen EGFR geeignet ist.

Während die Aktivierung des kanonischen WNT Signalwegs in 1638N-T1 Zellen bestätigt werden konnte, resultierte dies in den in vivo Experimenten des WP4 nicht in einem tumorigenen Phänotyp. Somit stellt diese Linie zwar eine Ausgangsbasis für die Einführung weiterer Alterationen, d.h. EGFR Überexpression, dar, ist aber zunächst nur für in vitro Studien verwendbar, jedoch nicht für das BMBF Verbundprojekt.

Für die Entität kolorektale Karzinom wurden die CMT-93 Zellen aufgrund ihres epithelialen Charakters, des hohen $\beta$-Catenin Spiegels ausgewählt. 


\subsection{Die Charakterisierung der EGFR modulierten Tumorzelllinien auf die Tumorprogression}

In der vorliegenden Studie sollte anhand gain of function and loss of function des EGFR seine Rolle in der Tumorprogression in soliden Tumorzelllinien der ausgewählten zwei Entitäten in vitro untersucht werden. Anschließend sollten die genetisch modifizierten Zelllinien auf ihre Rolle in der spezifischen Organkolonisation in vivo untersucht werden. Aufgrund der Tatsache, dass die Zellen über einen bestimmten Zeitraum im Tiermodell verweilen, wurde eine stabile anstatt transiente Transfektion durchgeführt. Hierfür wurde die lentivirale Transduktion sowohl für Knockdown als auch für Überexpression angewendet. Im Zuge der molekularen Charakterisierung wurde in der Mammakarzinomzelllinie 410.4 wenig oder gar keine EGFR Expression nachgewiesen, so dass ein Knockdown von EGFR in diesen Zellen keinen Sinn macht (s. Abb. 3.2 B-C).

\subsubsection{Funktionelle Auswirkungen des EGFR Knockdowns in CMT-93}

Der Knockdown von EGFR in CMT-93 führte tatsächlich zu einer verminderten EGFR Expression sowohl auf Protein Ebene als auch auf mRNA Ebene (s. Abb. 3.5). und war somit erfolgreich. Auf funktioneller Seite war dadurch, dass der EGFR Signalweg zelluläre Prozesse wie Proliferation und Überleben reguliert, ein vermindertes Wachstum der Zellen zu erwarten. Dennoch führte die Herunterregulation des EGFR $z u$ einer erhöhten Proliferation mittels xCELLigence und andererseits zu einer verminderten Vitalität der Zellen mittels MTT Assay (s. Abb. 3.6 A-B). Eine denkbare Erklärung könnte sein, dass die Zellen u. U. die Proliferation oder die Invasion beeinflussen. Wie in bisherigen Arbeiten gezeigt werden konnte, proliferieren oder migrieren die Zellen, aber nicht beides gleichzeitig (Fedetov et al., 2007; Gosh et al., 2010). Um diese Hypothese zu bestätigen, wurden die so genannten BoydenKammer-Assays durchgeführt, bei denen die Zellen mit EGF als Stimulation behandelt wurden. Die Resultate zeigten, dass die Invasionsrate von Zellen der shRNA transduzierten Zellen im Vergleich zu Leervektoren mit EGF vermindert war (s. Abb. 3.6 C). Diese Ergebnisse stehen in Übereinstimmung mit den Ergebnissen von Nie et al., die zeigen konnten, dass EGFR in MDA-MB-231 Zellen verstärkt eine Rolle sowohl in der Zellmigration und Invasion als auch in der Zellproliferation in vitro und in der Gehirmetastasierung in vivo spielen (Nie et al., 2012). 
Um die nachgeschalteten Effekte des Signalwegs nach EGFR Knockdown zu bestätigen, wurde die Aktivierung von downstream Protein S6 untersucht. Die Phosphorylierung von S6 in den EGFR Knockdown Zellen war sowohl konstitutiv als auch nach Zugabe von EGF im Vergleich zu Leervektorkontrollen deutlich erniedrigt (s. Abb. 3.6 D).

Im Rahmen dieser Untersuchungen konnte gezeigt werden, dass die Alteration von EGFR in CMT-93 einen Einfluss auf die Migration bzw. Invasion hat. Somit wurde das erwartete Bild für die Rolle des EGFR durch diese Versuche bestätigt. Zusammenfassend konnte dem effizienten Knockdown mittels dieser in vitro Assays eine funktionelle Wirksamkeit zugeschrieben werden. Es wäre sehr interessant zu wissen, ob diese Zelllinie ebenfalls bei Tiermodellversuchen eine verminderte Tumorigenität aufweist. Dies bleibt im weiteren Verlauf des Gesamtprojektes zu klären.

\subsubsection{Funktionelle Auswirkungen der EGFR Überexpression in 410.4 und CMT-93}

Beide transduzierte Tumorzellinien wiesen im Vergleich zu den Leervektoren sowohl auf Protein als auch auf mRNA Ebene eine erhöhte EGFR Expression auf. Da die Zellen zur Entwicklung von Metastasen für einen längeren Zeitraum im Tiermodell verweilen, wurde die Stabilität der Transduktion getestet. Dabei zeigte sich in beiden Zelllinien eine Plasmidbeständigkeit bis zu 4 Wochen, während nach 8 Wochen eine leichte Reduktion von EGFR nachzuweisen war (s. Abb. 3.7). Diese Reduktion an EGFR nach 8 Wochen wurde nicht als kritisch beurteilt, da für die Initiation der Metastasierung 4 Wochen als ausreichend angesehen werden können.

Um sicher zu gehen, dass die Funktionalität des humanen EGFR in murinen System nicht eingeschränkt ist, wurde die Aktivierung des EGFR Signalwegs downstream überprüft. Das Targetgen c-Jun war in den beiden überexprimierenden Zelllinien im Vergleich zu den Leervektorkontrollen hochreguliert, während das Targtegen c-Myc nur in den kolorektalen Zelllinien hoch exprimiert war. Zudem wurde die Aktivierung nachgeschalteter Kinasen unter Stimulation mit EGF untersucht. Generell lässt sich eine hohe endogene Expression von P-p38 und P-S6 in EGFR überexprimierenden Zellen nachweisen. Nach einer Stimulation mit EGF waren p38 und S6 generell aktivierbar (s. Abb. 3.8). Zusammenfassend lassen diese Daten feststellen, dass eine Weiterleitung des EGFR Signals in den Tumorzelllinien stattfindet. 
Als eine weitere funktionelle Auswirkung der effizienten Überexpression von EGFR wurde die Invasion der Zellen untersucht. Die Stimulation mit EGF in 410.4 Zellen steigert die Invasion sowohl in Leervektorkontrollen als auch nach Überexpression von EGFR. Davon unabhängig war jedoch kein signifikanter Unterschied zwischen den EGFR überexprimierenden Zelllinien und Leervektorkontrollen feststellbar. In CMT-93 Zellen konnte gar kein Einfluss auf die Invasion nachgewiesen werden (s. Abb. 3.8). Es konnte bereits gezeigt werden, dass die Überexpression von EGFR die Brustepithelzellen transformieren kann, wobei TGF- $\beta$ EGFR-abhängig EMT induziert und somit die Tumorprogression der Mammakarzinomzelllinien fördert (Wendt et al., 2010). Eine andere Studie konnte zeigen, dass EGF durch Endozytose von ECadherin die Zell-Zell-Adhäsion zerstört und EMT in humanen Tumorzellen verursacht. Gleichzeitig wird die $\beta$-Catenin Aktivität und folglich die Invasion der Tumorzellen erhöht (Lu et al., 2003). Mehrere Studien belegen, dass WNT und EGFR über Rezeptortyrosinkinasen wechselseitig transaktivieren, wobei eine EGFRvermittelte Aktivierung des PI3K/AKT Signalwegs die Translokation von $\beta$-Catenin in den Zellkern und folglich die Invasion der Prostatatumorzellen fördert (Sharma et al., 2002).

Die Ergebnisse der Invasionsassays waren unerwartet und stehen im Gegensatz zu den oben genannten Studien. Interessanterweise konnte neulich die Arbeitsgruppe von Wendt zeigen, dass der tumorfördernde Charakter von EGFR auf eine tumorsuppressive Eigenschaft während der späteren Stadien der metastatischen Kaskade umgeschaltet wird und dass diese tumorhemmende Eigenschaft von dem EGFR inhibierenden Molekül Mig6 reguliert wird (Wendt et al., 2015). Möglicherweise könnte dies der Grund für den fehlenden Effekt in vitro in den Invasionsassays und in vivo im Tiermodell sein. So zeigten überraschenderweise die Mäuse aus dem Teilprojekt WP3 in den Lebermetastasen mit Leervektorkontrolle wesentlich größere Tumore im Vergleich zu Mäusen mit EGFR überexprimierenden Zellen.

\subsection{Die Charakterisierung der $\beta$-Catenin modulierten Tumorzelllinien auf die Tumorprogression}

Seit vielen Jahren ist bekannt, dass der WNT Signalweg eine entscheidende Rolle bei der Entstehung von Tumoren im Menschen spielt (Lustig und Behrens, 2003). Das Schlüsselprotein des klassischen WNT Signalwegs ist $\beta$-Catenin, welches eine duale Funktion in Signalwegen und in Zell-Zell-Kontakten ausübt. Als membranöser 
Bestandteil bildet $\beta$-Catenin einen Komplex mit E-Cadherin, welches ein entscheidender Vermittler von Zell-Zell-Kontakten und Zytoskelett ist (Guarino et al., 2007). Ein deregulierter WNT Signalweg, welcher die Erhöhung der zytosolischen und nukleären Konzentration des $\beta$-Catenins zur Folge hat, ist oft in den kolorektalen Karzinomen beschrieben (Brabletz et al., 1998). Die nukleäre Akkumulation von $\beta$ Catenin induziert EMT und die Expression von pro-invasiven Genen (Sanchez-Tillo et al., 2011). Nach immunhistochemischen Analysen wurden in etwa $60 \%$ der Brusttumoren nukleäres $\beta$-Catenin gefunden (Lin et al., 2000). Zudem konnte nachgewiesen werden, dass die zerebrale Metastasierung des Lungenadenokarzinoms auf einer nukleäre Akkumulation von $\beta$-Catenin beruht (Nguyen et al., 2009).

In der vorliegenden Arbeit wurde analog zu EGFR anhand von gain of function und loss of function von $\beta$-Catenin seine Rolle in der Tumorprogression in soliden Tumorzelllinien der ausgewählten zwei Entitäten in vitro untersucht. Zu diesem Zweck wurden die Mamma- und kolorektale Tumorzelllinien sowohl für Knockdown als auch für Überexpression mit den entsprechenden Plasmiden lentiviral transduziert.

\subsubsection{Funktionelle Auswirkungen des $\beta$-Catenin Knockdowns in $\mathbf{4 1 0 . 4}$ und CMT-93}

Um ein $\beta$-Catenin Knockdown in den Zellen herbeizuführen, wurden mit verschiedenen shKonstrukten gegen $\beta$-Catenin einfach und doppelt transduziert. Der Nachweis des jeweiligen Knockdowns wurde sowohl im Western Blot als auch in der qRT-PCR Analyse ermittelt. Überraschenderweise hat die doppelte Transduktion im Vergleich mit einfachem Konstrukt nicht zu einer höheren Effizienz geführt (s. Abb. 3.10 A-B). Möglicherweise kam es hier zu einer Fehlpaarung von shRNAs untereinander, sodass die Ziel-RNAs nicht von shRNA gebunden werden konnte. Dennoch konnte ein Knockdown von $\beta$-Catenin mit dem Konstrukt \#4 bis zu $25 \%$ erzielt werden. Seine funktionelle Auswirkung auf das invasive Verhalten wurde untersucht. Da eine Aktivierung des WNT Signalwegs mit steigender Invasion assoziiert ist, wurde hier eine Reduktion der Invasion erwartet. Überraschenderweise erfolgte kein Einfluss auf die Invasion der Zellen sowohl ohne Stimulation als auch mit Stimulation mit rhWNT3a (s. Abb. 3.11 A). Eventuell kann dieses Ergebnis durch die duale Funktion von $\beta$-Catenin erklärt werden. 410.4 Zellen weisen eine starke Expression von $\beta$-Catenin und ECadherin auf, und somit könnte $\beta$-Catenin in diesen Zellen eine verstärkte Rolle in der 
Zell-Zell-Adhäsion spielen (s. Abb. 3.2 B;D; 3.4 A-B). Um diese Hypothese zu untermauern, wurde die Aktivierung des kanonischen WNT Signalwegs anhand TOP/FOP Assay gemessen. Diese Untersuchung bestätigte, dass der kanonische WNT Signalweg in 410.4 Zellen generell sehr wenig aktiv ist. Aufgrund der Tatsache, dass der Knockdown keinen Einfluss auf die Invasion und keine Aktivierung des kanonischen WNT Signalwegs nachgewiesen hat, erwiesen sich die 410.4 Zellen für weitere Untersuchungen in Bezug auf unsere Fragesstellung als ungeeignet.

Der Knockdown von $\beta$-Catenin in CMT-93 Zellen war leider nicht erfolgreich. Möglicherweise hat diese Modifikation durch shRNAs zu unspezifischen Effekten geführt.

Zusammenfassend konnte eine detaillierte Analyse des $\beta$-Catenin Knockdowns im Rahmen der Tumorprogression sowohl in in vitro Experimenten als auch im Tiermodell in vivo nicht vorgenommen werden.

\subsubsection{Funktionelle Auswirkungen der $\beta$-Catenin Überexpression in $\mathbf{4 1 0 . 4}$ und CMT-93}

Analog sollten die Folgen der $\beta$-Catenin Überexpression in den beiden Zelllinien und damit die Aktivierung des WNT Signalwegs untersucht werden. Hierfür wurde ebenfalls die lentivirale Transduktion mehrmals angewendet, jedoch konnte eine Überexpression von $\beta$-Catenin weder in 410.4 noch in CMT-93 nachgewiesen werden (s. Abb. 3.12 A). Dadurch, dass das Konstrukt ein GFP als Reportergen enthält, wurden die GFP-positiven Zellen nach der Transfektion mittels Durchflusszytometrie sortiert und für eine weitere Woche kultiviert. Die Überexpression von $\beta$-Catenin wurde wiederholt mittels Durchflusszytometrie kontrolliert. Überraschenderweise haben die Zellen das Konstrukt verloren, sodass anzunehmen ist, dass das Konstrukt von den Zellen rasch eliminert wurde. Eine sehr starke Expression von GFP wurde bereits als belastend und schädlich für die Zelle beschrieben. Möglicherweise waren daher die effektiv transfizierten Zellen nicht ausreichend viabel und wurden negativ selektioniert. Aus diesem Grund konnte keine $\beta$-Catenin-abhängige Modulation vorgenommen werden, stattdessen konnte diese Arbeit die Wichtigkeit des nicht-kanonischen WNT Signalwegs herausarbeiten. 


\subsection{WNT11 und ROR2 charakterisiert Tumorprogression}

Dieser Teil der Arbeiten ergab sich im Laufe der Untersuchungen und beruht auf den Beobachtungen unserer Arbeitsgruppe, dass eine Überexpression von ROR2 in MCF7 die Invasion der Zelllinien und die Expression von WNT11 steigert (Kerstin Menck; Annalen Bleckmann und Micaela Bayerlova, nicht veröffentlicht). Zusätzlich konnte eine klinische Relevanz vermutet werden, da die Genexpressionsanalyse zerebraler Metastasen des Mamma- und Lungenkarzinoms eine starke Expression von WNT11, ROR1 und ROR2 zeigte (Kerstin Menck, nicht veröffentlicht). Ausserdem hatten frühere Ergebnisse unserer Arbeitsgruppe in den wenig invasiven MCF-7 und hoch invasiven MDA-MB231 sowie in Hirnmetastasen gezeigt, dass die gesteigerte Expression von WNT5a/b und alternativen WNT Rezeptoren ROR1 und ROR2 mit vermehrter Malignität korreliert (Klemm et al., 2011). In Neuroblastoma wurde ROR2 in allen Tumorstadien exprimiert und dies mit einer schlechteren Prognose korreliert (Asgharzadeh et al., 2006). Ein analoges Ergebnis wurde auch für Brustkrebs nachgewiesen. Die gesteigerte Expression von ROR2 in dieser Entität korreliert mit einer schlechteren Prognose (Henry et al., 2015).

Somit wurde im Rahmen der vorliegenden Studie auch die Rolle von WNT11 und ROR2 untersucht. Zunächst wurde die basale Wnt11 Expression in murinen Mammaund Kolonkarzinomzelllinien analysiert (s. Abb. 3.13). Die Charakterisierung der murinen Mammakarzinomzelllinien ergab, dass eine deutliche Expression von Wnt11 in den hoch invasiven Zelllinien 4T1 und E0771-LG nachzuweisen ist. Dieses Ergebnis lässt vermuten, dass Wnt11 eine wichtige Rolle in der Invasion dieser Entität spielt. Im Gegensatz dazu ergab die Charakterisierung der untersuchten murinen Kolonkarzinomzelllinen eine unterschiedlich ausgeprägte Wnt11 Expression. Die Studie von Nishioka et al. zeigte eine starke Expression von Wnt11 in der Genexpressionsanalyse von humanen kolorektalen Tumorzellinien und primären Kolon Tumorgeweben (Nishioka et al., 2013).

\subsubsection{WNT11 und ROR2 steigern die Invasion von 410.4 Zellen}

Um die funktionellen Auswirkungen einer gesteigerten WNT11 und ROR2 Expression analysieren zu können und anschließend ihre Rolle in der Tumorprogression zu untersuchen, wurden 410.4 Zellen stabil transfiziert. Anschließend analysierten wir die 410.4 Zellen nach konstitutiver Überexpression von WNT11 und ROR2 auf die 
Invasion. Erwartungsgemäß induzierte eine vermehrte Expression von WNT11 und ROR2 eine signifikant erhöhte Invasion der Zellen (s. Abb. 3.17 A; 3.22 A). Diese Ergebnisse bestätigen die vorliegende Hypothese, dass WNT11 und ROR2 einen großen Einfluss auf die Invasion von Tumorzellen haben. Dies stimmt wiederum mit der Studie von Luga et al. überein, welche zeigt, dass der Wnt11-induzierte PCP Signalweg in Mammakarzinomzelllinien zu einer höheren Motilität und Invasion der Zellen führt (Luga et al., 2012). Überdies korreliert der Knockdown von ROR2 mit einer verminderten Invasion in Osteosarcomazelllinien (Enomoto et al., 2009). In vitro Untersuchungen zeigen, dass der Knockdown von ROR2 die Migration und Invasion in Ovarialkarzinomzelllinien inhibiert (Ford et al., 2015).

\subsubsection{Der Einfluss von WNT11 und ROR2 auf die Proliferation}

Es wurde bereits nachgewiesen, dass WNT11 die Zellproliferation und Migration in IEC6 Darmepithelzellen stimuliert (Ouko et al., 2004). Überraschenderweise führte die Überexpression von WNT11 in 410.4 vielmehr zu einer erniedrigten Proliferation der Zellen (s. Abb. 3.17 B). Dieses Ergebnis steht im Gegensatz zu den Resultaten von Ouko et al. und Christiansen et al., die zeigten, dass WNT11 in C57MG Brustdrüsenepithelzellen sowohl die Transformation der Zellen als auch das Wachstum fördert (Christiansen et al., 1996). Andererseits bestätigten andere Studien dieses Phänomen, dass WNT11 das Wachstum in MCF-7, CHO-K1 und LNCap/PC-3 Zellen nicht begünstigt, aber zu einem höheren Zellüberleben durch reduzierte Apoptose führen kann (Railo et al., 2008; Uysal-Onganer et al., 2010; Lin et al., 2007).

Diese Diskrepanz der Ergebnisse weist darauf hin, dass die Tumor fördernde Eigenschaft von WNT11 vom Typ der Zelle und möglicherweise vom gebundenen Rezeptor abhängt.

Anders als bei der Überexpression von WNT11 zeigte die Überexpression von ROR2 in 410.4 vielmehr eine erhöhte Proliferation der Zellen (s. Abb. 3.22 B). Dieses Ergebnis lässt sich weitgehend auch in der Studie von Morioka et al. wiederfinden, nämlich, dass der Knockdown von ROR2 einen hemmenden Effekt auf die Proliferation und Migration der Osteosarkomazelllinien ausübt (Morioka et al., 2009) In Ovarialkarzinomzelllinien verursacht der Knockdown von ROR2 ebenfalls einen inhibierenden Effekt auf die Proliferation, Migration und Invasion (Henry et al., 2015). 


\subsubsection{WNT11 hat keinen Einfluss auf das anheftungsunabhängige Wachstum / ROR2 hat Einfluss auf das anheftungsunabhängige Wachstum}

Van den Ven et al. zeigten bei dem invasiven lobulären Karzinom (ILC), dass autokrine WNT11 durch die Aktivierung von RHOA das anheftungunsunabhängige Wachstum und die Metastasierung verursacht (van den Ven et al., 2015). Wright et al. zeigten ebenso, dass der Knockdown von ROR2 in Nierenkarzinomzelllinien nicht nur die Migration, sondern auch das anheftungsunabhängige Wachstum der Zellen hemmt (Wright et al., 2009). Diese beiden Studien vedeutlichen eine wichtige Rolle von WNT11 und ROR2 in der Tumorprogression. Aber in dieser Arbeit wies die erhöhte Expression von WNT11 in 410.4 keine Veränderung im anheftungsunabhängigen Koloniewachstum nach (s. Abb. 3.17 C,D). An dieser Stelle ist es anzunehmen, dass die Ursache dieser Abweichung auf die unterschiedliche Zelltypen zurückzuführen sein und dass die WNT11 induzierte Invasionssteigerung von 410.4 auf einem anderen Mechanismus basieren könnte. Die Anlayse des anheftungsunabhängigen Wachstums bei der Überexpression von ROR2 resultiert im Gegensatz zu WNT11 in einer hohen Anzahl an Kolonien (s. Abb. 3.22 C,D). Diese Ergebnisse deuten darauf hin, dass WNT11 keine Auswirkung auf das anheftungsunabhängige Wachstum hat, während ROR2 doch eine positive Auswirkung hat.

\subsubsection{WNT11 und ROR2 haben keinen Einfluss auf die Adhäsion an ECM und FN}

Wie bereits über die Bedeutung von WNT11 in der Motilität erwähnt, reguliert WNT11 die Zellmigration durch die Modulation der Zell-Zell- und Zell-Substrat-Adhäsion in Verbindung mit Veränderungen in der Zytoskelett-Organisation (Uysal und Kypta, 2012). Bartis et al. (2013) fanden Wnt11 und Wnt5a als wichtige Regulatoren der ECadherin Expression heraus, die wiederum durch den $\beta$-Catenin-abhängigen Signalweg eine verminderte Zelladhäsion in Lungenkarzinomzelllinien verursacht. Aus diesem Grund wurde der Effekt der Zelladhäsion an ECM und FN und der ZytoskelettOrganisation bei einer gesteigerten WNT11 und ROR2 Expression in 410.4 Zellen analysiert. Die Analyse zeigte, dass die Überexpression von WNT11 und ROR2 weder die Adhäsion an ECM noch an FN beeinflusst (s. Abb. 3.18 A-B; 3.22 E-F). Diese Resultate belegen auch die vor kurzem erschienene Studie von Henry et al.. Es zeigt 
sich, dass der Knockdown von ROR2 in Zellen des Ovarialkarzinoms keine Auswirkung auf die Adhäsion an Kollagen und FN hat (Henry et al., 2015).

Wie vorerwähnt, verursacht WNT11 die morphologische Transformation der Darmepithelzellen (Ouko et al., 2004). Um das überraschende Ergebnis von WNT11 bei der Zellproliferationsassay besser zu erklären, wurde die Organisation des Zytoskeletts näher untersucht. Die Analyse der Strukturierung des Zytoskeletts in WNT11 überexprimierenden Zellen zeigt keinen Unterschied in der Reorganisation (3.18 C). In diesen Untersuchungen konnte kein Einfluss von WNT11 und ROR2 auf die Zelladhäsion und Zytoskelett nachgewiesen werden.

\subsubsection{WNT11 und ROR2 steigern die Invasion $\beta$-Catenin-unabhängig}

Zahlreiche Studien belegen, dass Wnt11und ROR2 den $\beta$-Catenin-abhängigen WNT Signalweg inhibieren können. Folglich gilt WNT11 als ein nicht-kanonisches Wnt Ligand und inhibiert den kanonischen WNT Signalweg (Maye et al., 2004). Überdies zeigt die Studie von Railo et al., dass Wnt11 den kanonischen WNT Signalweg in chinese hamster ovary $(\mathrm{CHO})$ Zellen herunterreguliert und infolgedessen die Vitalität der Zellen erhöht (Railo et al., 2008). Dagegen wies die Arbeitsgruppe von Cha nach, dass die sezernierten Xenopus Komplexe aus Wnt11 und Wnt5a zusammen eine stärkere Aktivierung des kanonischen WNT Signalwegs auslösen als eine einzelne Stimulation jeweils durch Wnt11 oder Wnt5a (Cha et al., 2009). In den in vivo Versuchen zeigte der Knockdown von ROR2 eine erhöhte Aktivierung des kanonischen WNT Signalwegs, und somit wurde ROR2 eine inhibierende Funktion auf den kanonischen WNT Signalweg zugeteilt (Mikels et al., 2009). Aus diesem Grund wurde die Aktivierung der $\beta$-Catenin-abhängigen Signalkaskade durch den Expressionslevel von Gesamt $\beta$-Catenin und TOP/FOPflash Reporterassay ermittelt. Erwartungsgemäß wurde in dieser Untersuchung der Expressionslevel von Gesamt $\beta$ Catenin in WNT11 und ROR2 überexprimierenden Zellen weder verändert noch eine Aktivierung des kanonischen WNT Signalwegs im Reporterassay nachgewiesen (s. Abb. 3.19 A-B; 3.23 A,C). Diese Resultate belegen, dass WNT11 und ROR2 die Invasionssteigerung nicht durch den kanonischen WNT Signalweg verursachen, stattdessen könnte der nicht-kanonische WNT Signalweg als alternativer Weg in Betracht gezogen werden. 


\subsubsection{WNT11 und ROR2 steigern die Invasion durch den RHOA/ROCK Signalweg}

Die Arbeitsgruppe von Cha belegt, dass die Depletion von Wnt11 die Aktivierung von JNK reduziert und infolgedessen Wnt11 den nicht-kanonischen WNT Signalweg aktiviert (Cha et al., 2008). Eine Überexpression von WNT11 in der humanen kolorekatalen Zelllinie HCT-116 offenbarte eine erhöhte Phosphoryierung von JNK und c-Jun (Nishioka et al., 2013). Wie bereits oben erwähnt, vermindern CHO-K1 Zellen die Migration nach der Überexpression von WNT11 und reduzieren den Phosphorylierungsstatus von JNK und c-Jun (Railo et al., 2008). Dies bedeutet, dass WNT11 teilweise die Zellmigration je nach Zelltyp entweder durch die Aktivierung oder die Inaktivierung des WNT/JNK Signalwegs reguliert. Darüber hinaus konnte die Arbeitsgruppe von Toyama zeigen, dass eine stabile Überexpression von Wnt11 in hepatozellulären Karzinomzelllinien die Freisetzung von $\mathrm{Ca}^{2+}$ ins Zytosol verursacht, und demzufolge wird PKC aktviert. Eine ektopische Expression von Wnt11 fördert die Aktvierung von RHOA/RHO Kinase (Toyama et al., 2010). Ebenso wurde in einigen Studien die Bedeutung von ROR2 in dem nicht-kanonischen WNT Signalweg belegt. Der WNT5a/ROR2 Signalweg fördert die Zellmigration durch die Aktivierung der GTPasen RHOA/RAC und aktiviert folglich JNK (Oishi et al., 2003; Nomachi et al., 2008). Aus diesem Grund wurde der Expressionslevel von PKC, JNK und RHOA im Western Blot analysiert (s. Abb. 3.19 A; 3.23 A). Der Expressionslevel von PKC und JNK blieb unverändert, wogegen RHOA in WNT11 und ROR2 überexprimierenden Zellen stark exprimiert war. Dieses Ergebnis weist darauf hin, dass WNT11 und ROR2 die Invasionssteigerung in 410.4 durch die Aktivierung von RHOA induziert.

Um zu klären, ob der kanonische und nicht-kanonische WNT Signalweg an der Invasionssteigerung beteiligt sind, wurde die Wirkung der Hemmstoffe DKK-1, SFRP1 und eines JNK-Inhibitors auf die Invasion untersucht. Die ROR2 induzierte Invasion konnte durch alle Inhibitoren weitgehend aufgehoben werden (s. Abb. 3.23. B). DKK1 ist überwiegend ein Hemmstoff des kanonischen WNT Signalwegs. Die Beteiligung des kanonischen WNT Signalwegs wurde durch das Expressionslevel von $\beta$-Catenin im Western Blot und in der qRT-PCR Analyse untersucht. Die Ergebnisse zeigen keine Veränderungen im Gesamt $\beta$-Catenin-Gehalt im Zytosol (s. Abb. 3.23. A, C). Es ist nicht ersichtlich, warum DKK-1 als Antagonist des kanonischen WNT Signalwegs die ROR2 vermittelte Invasion hemmen kann. Es gibt jedoch eine Studie, die zeigt, dass DKK-1 das Zellwachstum hemmt, die Apoptose in $\beta$-Catenin-defizienten Zelllinien 
fördert und das Inhibitormolekül von JNK die Apoptose in DKK-1 überexprimierenden Zellen reduziert (Lee et al., 2004). Dies bedeutet, dass DKK-1 den nicht-kanonischen WNT/JNK Signalweg hemmen kann. Ein anderer physiologischer Wnt-Inhibitor SFRP1 blockiert die Signalwege durch die Bindung an verschiedene Wnt Liganden. Ebenso zeigt diese Untersuchung, dass der Inhibitor die ROR2 induzierte Invasion hemmen kann. Die Analyse des JNK-Inhibitors zeigt ebenfalls die Hemmung der ROR2 induzierten Invasion. Alle oben genannten Resultate zeigen, dass ROR2 die Invasion durch den nicht-kanonischen WNT Signalweg veranlasst haben könnte.

\subsubsection{WNT11 und ROR2 haben einen Einfluss auf den PI3K Signalweg}

Die Studie von Jannesari-Ladani weist bei Ovarialkarzinomzelllinien nach, dass WNT11 über die Aktivierung des PI3K Signalwegs die Induktion von Apoptose unterbindet und das Zellüberleben fördert (Jannesari-Ladani et al., 2014). Der WNT5a/ROR2 Signalweg führt zur Aktivierung des PI3K Signalwegs (Schambony und Wedlich, 2007). Neben der Auswirkung auf den kanonischen und nicht-kanonischen WNT Signalweg wurde daher der Einfluss von WNT11 und ROR2 auf den PI3K Signalweg untersucht. Die Proteinexpressionsanalyse zeigt eine erhöhte Phospohorylierung von Akt nach der Überexpression von WNT11 und ROR2, während S6 unverändert bleibt (s. Abb. 20 A; 24 A). Es lässt sich somit eine Aktivierung des PI3K Signalwegs vermuten. Dies wird ebenso in der Analyse des PI3K Inhibitors BKM120 auf die Invasion bestätigt. Sowohl die WNT11 als auch die ROR2 induzierte Invasion wurden durch den Inhibitor teilweise gehemmt. Weiterhin wurde der Einfluss von BKM120 auf die Viabilität der Zellen untersucht. Es zeigt sich eine erhöhte Vitalität in ROR2 überexprimierenden Zellen im Vergleich zum Leervektor. Dieses Resultat stimmt mit der Arbeit von Morioka et al. überein, die zeigen, dass der Knockdown von ROR2 die Viabilität und das Überleben der Zellen reduziert (Morioka et al., 2009). Demgemäß ist anzunehmen, dass sich die Vitalität durch den erhöhten PI3K Signalweg in ROR2 überexprimierenden Zellen sich stabilisiert. Solange das BKM120 Medikament Krebspatienten oral verabreicht wird, ist es nach diesem Ergebnis denkbar, dass das Medikament in ROR2 überexprimierenden Karzinomen die Tumorprogression fördert, statt sie zu hemmen. 


\subsubsection{ROR2 hat einen Einfluss auf die Expression von EMT-Markern}

In der Tumorprogression spielt der EMT eine entscheidende Rolle und steht in Verbindung mit gesteigerter Invasion (Yang und Weinberg, 2008). Mehrere Studien belegen die Auswirkung von ROR2 auf die Expression von EMT-Marker, ECM Reorganisation und folglich die Migration. Der Wnt5a/ROR2 Signalweg reguliert die Invasion der Osteosarcomazelllinien durch verstärkte Expression von MMP13 (Yamagata et al., 2012; Enomoto et al., 2009). Die ROR2 Expression in Nierenkarzinomzellinien reguliert die Expression des EMT-Markers Twist und der Matrixmetalloprotease MMP2. Der Knockdown von ROR2 in diesen Zellen verminderte die Expression von MMP2 und die Invasion (Wright et al., 2009). Aufgrund dieser Ergbenisse wurde in dieser Studie untersucht, ob die ROR2 induzierte Invasionssteigerung auf die verstärkte Expression von EMT-Markern zurückzuführen ist. Die Genexpressionsanalyse der klassischen mesenchymalen Marker zeigt keine veränderte Expression von Snail, während Twist1 und Vimentin signifikant hochreguliert sind (s. Abb. $23 \mathrm{C}$ ). So ist dieses Ergebnis in Übereinstimmung mit den zitierten Literaturergebnissen.

Die Vorarbeiten unserer Arbeitsgruppe zeigten, dass eine Überexpression von ROR2 in MCF-7 Zelllinien in einer gesteigerten Expression von WNT11 und ROR1 resultiert. Demnach wurde die Auswirkung von ROR2 Überexpression in murinen Zelllinien 410.4 auf die Expression von Wnt11 und ROR1 untersucht. Es wurde erwartet, dass Wnt11 und Ror1 nach einer Überexpression von ROR2 hochreguliert werden. Die Ergebnisse dieser Untersuchung aber zeigen eine verminderte Expression von ROR1 und keine veränderte Expression von WNT11 (s. Abb. 3.23 C). Das unterschiedliche Ergebnis lässt auf unterschiedliche Auswirkungen innerhalb verschiedenen Zelltypen vermuten.

\subsubsection{Zusammenfassung der Ergebnisse von WNT11 und ROR2}

Die Ergebnisse unserer und einiger anderer Arbeitsgruppen unterstreichen die Bedeutung von WNT11 und ROR2 in der Tumorprogression in verschiedenen Karzinomen. Im Rahmen dieser Forschung konnte ihre Rolle in der Tumorprogression in der Mammakarzinomzellinien nachgewiesen werden. Eine vermehrte Expression von WNT11 und ROR2 in 410.4 Zellen verursacht eine gesteigerte Invasion in vitro. Eine gesteigerte Expression von ROR2 steht ebenfalls in Korrelation mit einer 
erhöhten Proliferation und anheftungsunabhängigen Wachstum der Zellen. Zugleich vermindert eine vermehrte Expression von WNT11 die Proliferation und hat keine Auswirkung auf das anheftungsunabhängige Wachstum. Sowohl in ROR2 als auch in WNT11 Überexpression konnte kein Einfluss auf die Adhäsionskapazität nachgewiesen werden. Um herauszufinden, welche Signalwege die gesteigerte Invasion initiiert, wurden die WNT Signalwege näher untersucht. Sowohl eine Anreicherung von WNT11 als auch von ROR2 hat keinen Einfluss auf den kanonischen WNT Signalweg, stattdessen ist der RHOA/ROCK Signalweg aus dem nicht-kanonischen WNT Signalweg verstärkt aktiviert. Außerdem weisen die Ergebnisse darauf hin, dass auch der PI3K Signalweg positiv beeinflusst wird. Dies verdeutlicht, dass es sich hierbei nicht um ein lineares System handelt, sondern eher um ein komplexes Netzwerk von Signalwegen. Überdies konnte in ROR2 überexprimierenden Zellen nachgewiesen werden, dass die gesteigerte Invasion EMT abhängig ist.

Es konnte anhand von gain-of-function Experimenten sowohl mit WNT11 als auch mit ROR2 bewiesen werden, dass die funktionellen Auswirkungen in Bezug auf die Tumorprogression zum größten Teil dieselben Resultate zeigten, sodass Rückschlüsse gezogen werden können, dass der nicht-kanonische Wnt Ligand WNT11 möglicherweise über seinen Rezeptor ROR2 durch die Aktivierung des RHOA/ROCK Signalwegs die Tumorprogression fördert. 


\section{Fazit}

Das Ziel, je eine murine Tumorzelllinie, welche sich als charakteristisch für die jeweilige Entität darstellt, zu identifizieren, wurde passend für das Kolonkarzinom mit der Zelllinie CMT-93 und weitgehend für das Mammakarzinom mit der Linie 410.4 erreicht. Die gründliche Charakterisierung der beiden Zelllinien in Bezug auf den EGFR und WNT Signalweg und die Tumorentwicklung im Mausmodell diente als Grundlage für das nachfolgende Arbeitsprogramm.

Es war bereits bekannt, dass sowohl der EGFR als auch der WNT Signalweg eine die Tumorprogression fördernde Rolle in der Interaktion zwischen Tumorzellen und ihrer Mikroumgebung spielen. Um dies weiter zu untersuchen, wurden die Zelllinien durch lentivirale Überexpression oder Knockdown des jeweils komplementären Signalwegs genetisch modifiziert.

Sowohl ein EGFR Knockdown in CMT-93 Zellen als auch eine EGFR Überexpression in 410.4 und CMT-93 Zellen konnten etabliert werden. Aus dem Knockdown von EGFR resultierte erwartungsgemäß eine verminderte Invasion der Zellen in vitro. Im Gegensatz dazu führte die EGFR Überexpression nicht zur postulierten vermehrten Invasion in vitro. In Mausversuchen im Rahmen des Gesamtkonsortiums erzeugten diese Zellen überraschenderweise sogar eine geringere Organkolonisation sowohl in der Leber als auch im Gehirn im Vergleich zur Leervektorkontrolle. Dies würde darauf hindeuten, dass der EGFR im speziellen Kontext der verwendeten Zelllinien und des jeweiligen Modells eher eine Hemmung im Rahmen der Kolonisation vermittelt. Dies müsste jedoch durch weitere Experimente erhärtet werden.

Ein Knockdown von $\beta$-Catenin konnte in 410.4 etabliert werden, wobei sich jedoch kein Einfluss auf Invasion der Zelllinien und auf die Aktivierung des WNT Signalwegs in den funktionellen Assays nachweisen ließ. Leider konnte im Rahmen dieser Arbeit eine stabile Überexpression von $\beta$-Catenin nicht erfolgreich etabliert werden, da dies offenbar mit der Viabilität der Zellen interferierte. Die Relevanz des $\beta$-Cateninabhängigen WNT Signalwegs in den beiden gewählten Zelllinien konnte somit nicht abschließend geklärt werden. Möglicherweise sind transiente Transfektionen für diese Fragestellung geeigneter.

Im ersten Teil dieser Doktorarbeit konnte sowohl in vitro als auch in vivo gezeigt werden, dass eine EGFR Überexpression in den untersuchten Zelllinien eher eine 
tumor hemmende Funktion vermitteln, als bisher aus den Literaturangaben angenommen. Eine Aufklärung dieser neuen Ergebnisse durch weitere Analysen würde das Verständnis des EGFR-vermittelten Signalwegs in der Metastasierung vertiefen und möglicherweise bessere Therapeutika für Tumorpatienten ermöglichen.

Im Rahmen des Konsortiums ergaben sich aus der Analyse zerebraler Metastasen von Brustkrebspatientinnen Hinweise auf eine Rolle von ROR2, Wnt11 und nichtkanonischem WNT Signalweg. Dies wurde nun weiter untersucht. Entsprechend erhöhte die Überexpression von WNT11 und ROR2 in 410.4 Zellen deren Invasion durch einen RHOA-abhängigen Mechnismus mit Beteiligung des PI3K Signalwegs. Angesichts der Gleichartigkeit des Effektes einer ROR2- bzw. Wnt11-Überexpression lässt sich spekulieren, dass WNT11 als downstream Target über ROR2 induziert wird und über einen positiven Feedback-Loop via ROR2 eine autokrine Stimulation ausübt. Dazu müsste jedoch die genaue Natur der Interaktion zwischen ROR2 und WNT11 weiter abgeklärt werden.

Im zweiten Teil dieser Arbeit konnte festgestellt werden, dass WNT11 und ROR2 die Invasion fördern, wobei der Zusammenhang zwischen den beiden Komponenten im Einzelnen noch ungeklärt ist. Die in dieser Arbeit erlangten Daten verdeutlichen, dass die durch WNT11 und ROR2 vermittelte Invasion über die Aktivierung des RHOAabhängigen Signalwegs stattfindet. Der WNT11/ROR2 Signalweg könnte daher ein Ziel von Tumortherapien sein, um Invasion und Metastasierung von Tumorzellen in verschiedenen Tumorentitäten zu hemmen. Somit gewinnt der nicht-kanonische WNT Signalweg in der Tumorprogression und Metasatasierung immer mehr an Bedeutung. 


\section{Literaturverzeichnis}

Aberle, H.; Bauer, A.; Stappert, J.; Kispert, A.; Kemler, R. (1997): beta-catenin is a target for the ubiquitin-proteasome pathway. In: The EMBO journal 16 (13), S. 37973804. DOI: 10.1093/emboj/16.13.3797.

Alcock, Helen E.; Stephenson, Timothy J.; Royds, Janice A.; Hammond, David W. (2003): Analysis of colorectal tumor progression by microdissection and comparative genomic hybridization. In: Genes, chromosomes \& cancer 37 (4), S. 369-380. DOI: 10.1002/gcc.10201.

Alvarez, Ricardo H.; Valero, Vicente; Hortobagyi, Gabriel N. (2010): Emerging targeted therapies for breast cancer. In: Journal of clinical oncology : official journal of the American Society of Clinical Oncology 28 (20), S. 3366-3379. DOI: 10.1200/JCO.2009.25.4011.

Arnold, Paul M.; Floyd, Heather E.; Anderson, Karen K.; Newell, Kathy L. (2010): Surgical management of carcinoid tumors metastatic to the spine: Report of three cases. In: Clinical neurology and neurosurgery 112 (5), S. 443-445. DOI: 10.1016/j.clineuro.2010.01.008.

Asgharzadeh, Shahab; Pique-Regi, Roger; Sposto, Richard; Wang, Hong; Yang, Yujun; Shimada, Hiroyuki et al. (2006): Prognostic significance of gene expression profiles of metastatic neuroblastomas lacking MYCN gene amplification. In: Journal of the National Cancer Institute 98 (17), S. 1193-1203. DOI: 10.1093/jnci/djj330.

Aslakson, C. J.; Miller, F. R. (1992): Selective events in the metastatic process defined by analysis of the sequential dissemination of subpopulations of a mouse mammary tumor. In: Cancer research 52 (6), S. 1399-1405.

Bacac, Marina; Stamenkovic, Ivan (2008): Metastatic cancer cell. In: Annual review of pathology 3, S. 221-247. DOI: 10.1146/annurev.pathmechdis.3.121806.151523.

Barber, Thomas D.; Vogelstein, Bert; Kinzler, Kenneth W.; Velculescu, Victor E. (2004): Somatic mutations of EGFR in colorectal cancers and glioblastomas. In: The New England journal of medicine 351 (27), S. $2883 . \quad$ DOI: 10.1056/NEJM200412303512724. 
Bartis, Domokos; Csongei, Veronika; Weich, Alexander; Kiss, Edit; Barko, Szilvia; Kovacs, Tamas et al. (2013): Down-regulation of canonical and up-regulation of noncanonical Wnt signalling in the carcinogenic process of squamous cell lung carcinoma. In: PloS one 8 (3), S. e57393. DOI: 10.1371/journal.pone.0057393.

Behrens, J.; Kries, J. P. von; Kühl, M.; Bruhn, L.; Wedlich, D.; Grosschedl, R.; Birchmeier, W. (1996): Functional interaction of beta-catenin with the transcription factor LEF-1. In: Nature 382 (6592), S. 638-642. DOI: 10.1038/382638a0.

Bhargava, Rohit; Gerald, William L.; Li, Allan R.; Pan, Qiulu; Lal, Priti; Ladanyi, Marc; Chen, Beiyun (2005): EGFR gene amplification in breast cancer: correlation with epidermal growth factor receptor mRNA and protein expression and HER-2 status and absence of EGFR-activating mutations. In: Modern pathology : an official journal of the United States and Canadian Academy of Pathology, Inc 18 (8), S. 1027-1033. DOI: 10.1038/modpathol.3800438.

Birnboim, H. C.; Doly, J. (1979): A rapid alkaline extraction procedure for screening recombinant plasmid DNA. In: Nucleic acids research 7 (6), S. 1513-1523.

Bos, J. L.; Fearon, E. R.; Hamilton, S. R.; Verlaan-de Vries, M.; van Boom, J. H.; van der Eb, A J; Vogelstein, B. (1987): Prevalence of ras gene mutations in human colorectal cancers. In: Nature 327 (6120), S. 293-297. DOI: 10.1038/327293a0.

Bos, Paula D.; Zhang, Xiang H-F; Nadal, Cristina; Shu, Weiping; Gomis, Roger R.; Nguyen, Don X. et al. (2009): Genes that mediate breast cancer metastasis to the brain. In: Nature 459 (7249), S. 1005-1009. DOI: 10.1038/nature08021.

Boutros, M.; Paricio, N.; Strutt, D. I.; Mlodzik, M. (1998): Dishevelled activates JNK and discriminates between JNK pathways in planar polarity and wingless signaling. In: Cell 94 (1), S. 109-118.

Brabletz, T.; Jung, A.; Hermann, K.; Günther, K.; Hohenberger, W.; Kirchner, T. (1998): Nuclear overexpression of the oncoprotein beta-catenin in colorectal cancer is localized predominantly at the invasion front. In: Pathology, research and practice 194 (10), S. 701-704.

Brattain, M. G.; Strobel-Stevens, J.; Fine, D.; Webb, M.; Sarrif, A. M. (1980): Establishment of mouse colonic carcinoma cell lines with different metastatic properties. In: Cancer research 40 (7), S. 2142-2146. 
Cha, Sang-Wook; Tadjuidje, Emmanuel; Tao, Qinghua; Wylie, Christopher; Heasman, Janet (2008): Wnt5a and Wnt11 interact in a maternal Dkk1-regulated fashion to activate both canonical and non-canonical signaling in Xenopus axis formation. In: Development (Cambridge, England) 135 (22), S. 3719-3729. DOI: 10.1242/dev.029025.

Cha, Sang-Wook; Tadjuidje, Emmanuel; White, Jody; Wells, James; Mayhew, Christopher; Wylie, Christopher; Heasman, Janet (2009): Wnt11/5a complex formation caused by tyrosine sulfation increases canonical signaling activity. In: Current biology: CB 19 (18), S. 1573-1580. DOI: 10.1016/j.cub.2009.07.062.

Christiansen, J. H.; Monkley, S. J.; Wainwright, B. J. (1996): Murine WNT11 is a secreted glycoprotein that morphologically transforms mammary epithelial cells. In: Oncogene 12 (12), S. 2705-2711.

Clevers, Hans (2006): Wnt/beta-catenin signaling in development and disease. In: Cell 127 (3), S. 469-480. DOI: 10.1016/j.cell.2006.10.018.

Cohen, S.; Carpenter, G.; King, L. (1980): Epidermal growth factor-receptor-protein kinase interactions. Co-purification of receptor and epidermal growth factor-enhanced phosphorylation activity. In: The Journal of biological chemistry 255 (10), S. 48344842.

Coleman, William B.; Tsongalis, Gregory J. (2006): Molecular mechanisms of human carcinogenesis. In: EXS (96), S. 321-349.

Coussens, L.; Yang-Feng, T. L.; Liao, Y. C.; Chen, E.; Gray, A.; McGrath, J. et al. (1985): Tyrosine kinase receptor with extensive homology to EGF receptor shares chromosomal location with neu oncogene. In: Science (New York, N.Y.) 230 (4730), S. 1132-1139.

Dawood, Shaheenah; Broglio, Kristine; Buzdar, Aman U.; Hortobagyi, Gabriel N.; Giordano, Sharon H. (2010): Prognosis of women with metastatic breast cancer by HER2 status and trastuzumab treatment: an institutional-based review. In: Journal of clinical oncology: official journal of the American Society of Clinical Oncology 28 (1), S. 92-98. DOI: 10.1200/JCO.2008.19.9844.

De Nardo, David G.; Johansson, Magnus; Coussens, Lisa M. (2008): Immune cells as mediators of solid tumor metastasis. In: Cancer metastasis reviews 27 (1), S. 11-18. DOI: 10.1007/s10555-007-9100-0. 
Dey, Nandini; Barwick, Benjamin G.; Moreno, Carlos S.; Ordanic-Kodani, Maja; Chen, Zhengjia; Oprea-llies, Gabriella et al. (2013): Wnt signaling in triple negative breast cancer is associated with metastasis. In: BMC cancer 13, S. 537. DOI: 10.1186/14712407-13-537.

Dunnwald, Lisa K.; Rossing, Mary Anne; Li, Christopher I. (2007): Hormone receptor status, tumor characteristics, and prognosis: a prospective cohort of breast cancer patients. In: Breast cancer research : BCR 9 (1), S. R6. DOI: 10.1186/bcr1639.

Ekstrand, A. J.; James, C. D.; Cavenee, W. K.; Seliger, B.; Pettersson, R. F.; Collins, V. P. (1991): Genes for epidermal growth factor receptor, transforming growth factor alpha, and epidermal growth factor and their expression in human gliomas in vivo. In: Cancer research 51 (8), S. 2164-2172.

Enomoto, M.; Hayakawa, S.; Itsukushima, S.; Ren, D. Y.; Matsuo, M.; Tamada, K. et al. (2009): Autonomous regulation of osteosarcoma cell invasiveness by Wnt5a/Ror2 signaling. In: Oncogene 28 (36), S. 3197-3208. DOI: 10.1038/onc.2009.175.

Fearon, E. R.; Vogelstein, B. (1990): A genetic model for colorectal tumorigenesis. In: Cell 61 (5), S. 759-767.

Fedotov, Sergei; lomin, Alexander (2007): Migration and proliferation dichotomy in tumor-cell invasion. In: Physical review letters 98 (11), S. 118101. DOI: 10.1103/PhysRevLett.98.118101.

Fodde, R.; Smits, R.; Clevers, H. (2001): APC, signal transduction and genetic instability in colorectal cancer. In: Nature reviews. Cancer 1 (1), S. 55-67. DOI: $10.1038 / 35094067$.

Ford, C. E.; Henry, C.; Llamosas, E.; Djordjevic, A.; Hacker, N. (2015): Wnt signalling in gynaecological cancers: A future target for personalised medicine? In: Gynecologic oncology. DOI: 10.1016/j.ygyno.2015.09.085.

Franks, L. M.; Hemmings, V. J. (1978): A cell line from an induced carcinoma of mouse rectum. In: The Journal of pathology 124 (1), S. 35-38. DOI: 10.1002/path.1711240108.

Gan, Hui K.; Kaye, Andrew H.; Luwor, Rodney B. (2009): The EGFRvIll variant in glioblastoma multiforme. In: Journal of clinical neuroscience: official journal of the 
Neurosurgical Society of Australasia 16 (6), S. 748-754. DOI: 10.1016/j.jocn.2008.12.005.

Ghosh, Pradipta; Beas, Anthony O.; Bornheimer, Scott J.; Garcia-Marcos, Mikel; Forry, Erin P.; Johannson, Carola et al. (2010): A G\{alpha\}i-GIV molecular complex binds epidermal growth factor receptor and determines whether cells migrate or proliferate. In: Molecular biology of the cell 21 (13), S. 2338-2354. DOI: 10.1091/mbc.E10-010028.

Glinka, A.; Wu, W.; Delius, H.; Monaghan, A. P.; Blumenstock, C.; Niehrs, C. (1998): Dickkopf-1 is a member of a new family of secreted proteins and functions in head induction. In: Nature 391 (6665), S. 357-362. DOI: 10.1038/34848.

Goswami, Sumanta; Sahai, Erik; Wyckoff, Jeffrey B.; Cammer, Michael; Cox, Dianne; Pixley, Fiona J. et al. (2005): Macrophages promote the invasion of breast carcinoma cells via a colony-stimulating factor-1/epidermal growth factor paracrine loop. In: Cancer research 65 (12), S. 5278-5283. DOI: 10.1158/0008-5472.CAN-04-1853.

Graham, F. L.; Smiley, J.; Russell, W. C.; Nairn, R. (1977): Characteristics of a human cell line transformed by DNA from human adenovirus type 5 . In: The Journal of general virology 36 (1), S. 59-74. DOI: 10.1099/0022-1317-36-1-59.

Gross, Julia Christina; Chaudhary, Varun; Bartscherer, Kerstin; Boutros, Michael (2012): Active Wnt proteins are secreted on exosomes. In: Nature cell biology 14 (10), S. 1036-1045. DOI: 10.1038/ncb2574.

Guarino, Marcello; Rubino, Barbara; Ballabio, Gianmario (2007): The role of epithelialmesenchymal transition in cancer pathology. In: Pathology 39 (3), S. 305-318. DOI: 10.1080/00313020701329914.

Habas, Raymond; Dawid, Igor B.; He, Xi (2003): Coactivation of Rac and Rho by Wnt/Frizzled signaling is required for vertebrate gastrulation. In: Genes \& development 17 (2), S. 295-309. DOI: 10.1101/gad.1022203.

Hagemann, Thorsten; Robinson, Stephen C.; Schulz, Matthias; Trümper, Lorenz; Balkwill, Frances R.; Binder, Claudia (2004): Enhanced invasiveness of breast cancer cell lines upon co-cultivation with macrophages is due to TNF-alpha dependent upregulation of matrix metalloproteases. In: Carcinogenesis 25 (8), S. 1543-1549. DOI: 10.1093/carcin/bgh146. 
Hamburger, A. W.; Salmon, S. E. (1977): Primary bioassay of human tumor stem cells. In: Science (New York, N.Y.) 197 (4302), S. 461-463.

Hampf, Mathias; Gossen, Manfred (2006): A protocol for combined Photinus and Renilla luciferase quantification compatible with protein assays. In: Analytical biochemistry 356 (1), S. 94-99. DOI: 10.1016/j.ab.2006.04.046.

Hanahan, D. (1983): Studies on transformation of Escherichia coli with plasmids. In: Journal of molecular biology 166 (4), S. 557-580.

Hanahan, D.; Weinberg, R. A. (2000): The hallmarks of cancer. In: Cell 100 (1), S. 5770.

He, T. C.; Sparks, A. B.; Rago, C.; Hermeking, H.; Zawel, L.; da Costa, L. T. et al. (1998): Identification of c-MYC as a target of the APC pathway. In: Science (New York, N.Y.) 281 (5382), S. 1509-1512.

Hedley, Benjamin D.; Chambers, Ann F. (2009): Tumor dormancy and metastasis. In: Advances in cancer research 102, S. 67-101. DOI: 10.1016/S0065-230X(09)02003$\mathrm{X}$.

Heinemann, Volker; Stintzing, Sebastian; Kirchner, Thomas; Boeck, Stefan; Jung, Andreas (2009): Clinical relevance of EGFR- and KRAS-status in colorectal cancer patients treated with monoclonal antibodies directed against the EGFR. In: Cancer treatment reviews 35 (3), S. 262-271. DOI: 10.1016/j.ctrv.2008.11.005.

Heitz, Florian; Harter, Philipp; Lueck, Hans-Joachim; Fissler-Eckhoff, Annette; LorenzSalehi, Fatemeh; Scheil-Bertram, Stefanie et al. (2009): Triple-negative and HER2overexpressing breast cancers exhibit an elevated risk and an earlier occurrence of cerebral metastases. In: European journal of cancer (Oxford, England : 1990) 45 (16), S. 2792-2798. DOI: 10.1016/j.ejca.2009.06.027.

Henry, C.; Quadir, A.; Hawkins, N. J.; Jary, E.; Llamosas, E.; Kumar, D. et al. (2015): Expression of the novel Wnt receptor ROR2 is increased in breast cancer and may regulate both $\beta$-catenin dependent and independent Wnt signalling. In: Journal of cancer research and clinical oncology 141 (2), S. 243-254. DOI: 10.1007/s00432-0141824-y.

Henry, Claire; Llamosas, Estelle; Knipprath-Meszaros, Alexandra; Schoetzau, Andreas; Obermann, Ellen; Fuenfschilling, Maya et al. (2015): Targeting the ROR1 
and ROR2 receptors in epithelial ovarian cancer inhibits cell migration and invasion. In: Oncotarget. DOI: 10.18632/oncotarget.5643.

Hicks, David G.; Short, Sarah M.; Prescott, Nichole L.; Tarr, Shannon M.; Coleman, Kara A.; Yoder, Brian J. et al. (2006): Breast cancers with brain metastases are more likely to be estrogen receptor negative, express the basal cytokeratin CK5/6, and overexpress HER2 or EGFR. In: The American journal of surgical pathology 30 (9), S. 1097-1104. DOI: 10.1097/01.pas.0000213306.05811.b9.

Hikasa, Hiroki; Shibata, Mikihito; Hiratani, Ichiro; Taira, Masanori (2002): The Xenopus receptor tyrosine kinase Xror2 modulates morphogenetic movements of the axial mesoderm and neuroectoderm via Wnt signaling. In: Development 129 (22), S. 52275239.

Hiratsuka, Sachie; Watanabe, Akira; Aburatani, Hiroyuki; Maru, Yoshiro (2006): Tumour-mediated upregulation of chemoattractants and recruitment of myeloid cells predetermines lung metastasis. In: Nature cell biology 8 (12), S. 1369-1375. DOI: $10.1038 / \mathrm{ncb} 1507$.

Huang, Cheng-Long; Liu, Dage; Nakano, Jun; Ishikawa, Shinya; Kontani, Keiichi; Yokomise, Hiroyasu; Ueno, Masaki (2005): Wnt5a expression is associated with the tumor proliferation and the stromal vascular endothelial growth factor--an expression in non-small-cell lung cancer. In: Journal of clinical oncology: official journal of the American Society of Clinical Oncology 23 (34), S. 8765-8773. DOI: 10.1200/JCO.2005.02.2871.

Hutchinson, Lisa (2010): Breast cancer: challenges, controversies, breakthroughs. In: Nature reviews. Clinical oncology 7 (12), S. 669-670. DOI: 10.1038/nrclinonc.2010.192.

lacopetta, Barry (2003): TP53 mutation in colorectal cancer. In: Human mutation 21 (3), S. 271-276. DOI: 10.1002/humu.10175.

Janku, Filip; Stewart, David J.; Kurzrock, Razelle (2010): Targeted therapy in nonsmall-cell lung cancer--is it becoming a reality? In: Nature reviews. Clinical oncology 7 (7), S. 401-414. DOI: 10.1038/nrclinonc.2010.64.

Jannesari-Ladani, Farnaz; Hossein, Ghamartaj; Izadi-Mood, Narges (2014): Differential Wnt11 expression related to Wnt5a in high- and low-grade serous ovarian 
cancer: implications for migration, adhesion and survival. In: Asian Pacific journal of cancer prevention : APJCP 15 (3), S. 1489-1495.

Jonas, S.; Thelen, A.; Benckert, C.; Spinelli, A.; Sammain, S.; Neumann, U. et al. (2007): Extended resections of liver metastases from colorectal cancer. In: World journal of surgery 31 (3), S. 511-521. DOI: 10.1007/s00268-006-0140-3.

Kim, Gun-Hwa; Her, Jung-Hyun; Han, Jin-Kwan (2008): Ryk cooperates with Frizzled 7 to promote Wnt11-mediated endocytosis and is essential for Xenopus laevis convergent extension movements. In: The Journal of cell biology 182 (6), S. 10731082. DOI: $10.1083 /$ jcb.200710188.

Kinzler, K. W.; Vogelstein, B. (1996): Lessons from hereditary colorectal cancer. In: Cell 87 (2), S. 159-170.

Kirikoshi, H.; Sekihara, H.; Katoh, M. (2001): Molecular cloning and characterization of human WNT11. In: International journal of molecular medicine 8 (6), S. 651-656.

Klaus, Alexandra; Birchmeier, Walter (2008): Wnt signalling and its impact on development and cancer. In: Nature reviews. Cancer 8 (5), S. 387-398. DOI: 10.1038/nrc2389.

Klemm, F.; Bleckmann, A.; Siam, L.; Chuang, H. N.; Rietkötter, E.; Behme, D. et al. (2011): $\beta$-catenin-independent WNT signaling in basal-like breast cancer and brain metastasis. In: Carcinogenesis 32 (3), S. 434-442. DOI: 10.1093/carcin/bgq269.

Korinek, V.; Barker, N.; Morin, P. J.; van Wichen, D.; Weger, R. de; Kinzler, K. W. et al. (1997): Constitutive transcriptional activation by a beta-catenin-Tcf complex in APC/- colon carcinoma. In: Science (New York, N.Y.) 275 (5307), S. 1784-1787.

Kraus, M. H.; Issing, W.; Miki, T.; Popescu, N. C.; Aaronson, S. A. (1989): Isolation and characterization of ERBB3, a third member of the ERBB/epidermal growth factor receptor family: evidence for overexpression in a subset of human mammary tumors. In: Proceedings of the National Academy of Sciences of the United States of America 86 (23), S. 9193-9197.

Kühl, M.; Sheldahl, L. C.; Malbon, C. C.; Moon, R. T. (2000): Ca(2+)/calmodulindependent protein kinase II is stimulated by Wnt and Frizzled homologs and promotes ventral cell fates in Xenopus. In: The Journal of biological chemistry 275 (17), S. 12701-12711. 
Kypta, Robert M.; Waxman, Jonathan (2012): Wnt/ $\beta$-catenin signalling in prostate cancer. In: Nature reviews. Urology 9 (8), S. 418-428. DOI: 10.1038/nrurol.2012.116. Laemmli, U. K. (1970): Cleavage of structural proteins during the assembly of the head of bacteriophage T4. In: Nature 227 (5259), S. 680-685.

Lee, Amie Y.; He, Biao; You, Liang; Xu, Zhidong; Mazieres, Julien; Reguart, Noemi et al. (2004): Dickkopf-1 antagonizes Wnt signaling independent of beta-catenin in human mesothelioma. In: Biochemical and biophysical research communications 323 (4), S. 1246-1250. DOI: 10.1016/j.bbrc.2004.09.001.

Lee, Y. T. (1983): Breast carcinoma: pattern of metastasis at autopsy. In: Journal of surgical oncology 23 (3), S. 175-180.

Leibovitz, A.; Stinson, J. C.; McCombs, W. B.; McCoy, C. E.; Mazur, K. C.; Mabry, N. D. (1976): Classification of human colorectal adenocarcinoma cell lines. In: Cancer research 36 (12), S. 4562-4569.

Lin, K.; Wang, S.; Julius, M. A.; Kitajewski, J.; Moos, M.; Luyten, F. P. (1997): The cysteine-rich frizzled domain of Frzb-1 is required and sufficient for modulation of Wnt signaling. In: Proceedings of the National Academy of Sciences of the United States of America 94 (21), S. 11196-11200.

Lin, S. Y.; Xia, W.; Wang, J. C.; Kwong, K. Y.; Spohn, B.; Wen, Y. et al. (2000): Betacatenin, a novel prognostic marker for breast cancer: its roles in cyclin D1 expression and cancer progression. In: Proceedings of the National Academy of Sciences of the United States of America 97 (8), S. 4262-4266. DOI: 10.1073/pnas.060025397.

Lin, Zhihong; Reierstad, Scott; Huang, Chiang-Ching; Bulun, Serdar E. (2007): Novel estrogen receptor-alpha binding sites and estradiol target genes identified by chromatin immunoprecipitation cloning in breast cancer. In: Cancer research 67 (10), S. 5017-5024. DOI: 10.1158/0008-5472.CAN-06-3696.

Liu, Chunming; Li, Yiming; Semenov, Mikhail; Han, Chun; Baeg, Gyeong Hun; Tan, Yi et al. (2002): Control of beta-catenin phosphorylation/degradation by a dual-kinase mechanism. In: Cell 108 (6), S. 837-847.

Lu, Zhimin; Ghosh, Sourav; Wang, Zhiyong; Hunter, Tony (2003): Downregulation of caveolin-1 function by EGF leads to the loss of E-cadherin, increased transcriptional 
activity of beta-catenin, and enhanced tumor cell invasion. In: Cancer cell 4 (6), S. 499-515.

Lu, Zhimin; Ghosh, Sourav; Wang, Zhiyong; Hunter, Tony (2003): Downregulation of caveolin-1 function by EGF leads to the loss of E-cadherin, increased transcriptional activity of beta-catenin, and enhanced tumor cell invasion. In: Cancer cell 4 (6), S. 499-515.

Luga, Valbona; Zhang, Liang; Viloria-Petit, Alicia M.; Ogunjimi, Abiodun A.; Inanlou, Mohammad R.; Chiu, Elaine et al. (2012): Exosomes mediate stromal mobilization of autocrine Wnt-PCP signaling in breast cancer cell migration. In: Cell 151 (7), S. 15421556. DOI: 10.1016/j.cell.2012.11.024.

Lustig, B.; Behrens, J. (2003): The Wnt signaling pathway and its role in tumor development. In: Journal of cancer research and clinical oncology 129 (4), S. 199-221. DOI: 10.1007/s00432-003-0431-0.

Luzzi, K. J.; MacDonald, I. C.; Schmidt, E. E.; Kerkvliet, N.; Morris, V. L.; Chambers, A. F.; Groom, A. C. (1998): Multistep nature of metastatic inefficiency: dormancy of solitary cells after successful extravasation and limited survival of early micrometastases. In: The American journal of pathology 153 (3), S. 865-873. DOI: 10.1016/S0002-9440(10)65628-3.

Malone, K. E.; Daling, J. R.; Thompson, J. D.; O'Brien, C. A.; Francisco, L. V.; Ostrander, E. A. (1998): BRCA1 mutations and breast cancer in the general population: analyses in women before age 35 years and in women before age 45 years with first-degree family history. In: JAMA 279 (12), S. 922-929.

Mann, B.; Gelos, M.; Siedow, A.; Hanski, M. L.; Gratchev, A.; llyas, M. et al. (1999): Target genes of beta-catenin-T cell-factor/lymphoid-enhancer-factor signaling in human colorectal carcinomas. In: Proceedings of the National Academy of Sciences of the United States of America 96 (4), S. 1603-1608.

Maye, Peter; Zheng, Jie; Li, Lin; Wu, Dianqing (2004): Multiple mechanisms for Wnt11mediated repression of the canonical Wnt signaling pathway. In: The Journal of biological chemistry 279 (23), S. 24659-24665. DOI: 10.1074/jbc.M311724200.

Menck, Kerstin; Klemm, Florian; Gross, Julia Christina; Pukrop, Tobias; Wenzel, Dirk; Binder, Claudia (2013): Induction and transport of Wnt 5a during macrophage-induced 
malignant invasion is mediated by two types of extracellular vesicles. In: Oncotarget 4 (11), S. 2057-2066. DOI: 10.18632/oncotarget.1336.

Mikels, A. J.; Nusse, R. (2006): Wnts as ligands: processing, secretion and reception. In: Oncogene 25 (57), S. 7461-7468. DOI: 10.1038/sj.onc.1210053.

Mikels, Amanda; Minami, Yasuhiro; Nusse, Roel (2009): Ror2 receptor requires tyrosine kinase activity to mediate Wnt5A signaling. In: The Journal of biological chemistry 284 (44), S. 30167-30176. DOI: 10.1074/jbc.M109.041715.

Miller, F. R.; Miller, B. E.; Heppner, G. H. (1983): Characterization of metastatic heterogeneity among subpopulations of a single mouse mammary tumor: heterogeneity in phenotypic stability. In: Invasion \& metastasis 3 (1), S. 22-31.

Minami, Yasuhiro; Oishi, Isao; Endo, Mitsuharu; Nishita, Michiru (2010): Ror-family receptor tyrosine kinases in noncanonical Wnt signaling: their implications in developmental morphogenesis and human diseases. In: Developmental dynamics : an official publication of the American Association of Anatomists 239 (1), S. 1-15. DOI: $10.1002 / d v d y .21991$.

Morin, P. J.; Sparks, A. B.; Korinek, V.; Barker, N.; Clevers, H.; Vogelstein, B.; Kinzler, K. W. (1997): Activation of beta-catenin-Tcf signaling in colon cancer by mutations in beta-catenin or APC. In: Science (New York, N.Y.) 275 (5307), S. 1787-1790.

Morioka, Kazuhito; Tanikawa, Chizu; Ochi, Kensuke; Daigo, Yataro; Katagiri, Toyomasa; Kawano, Hirotaka et al. (2009): Orphan receptor tyrosine kinase ROR2 as a potential therapeutic target for osteosarcoma. In: Cancer science 100 (7), S. 12271233. DOI: 10.1111/j.1349-7006.2009.01165.x.

Moscatello, D. K.; Holgado-Madruga, M.; Godwin, A. K.; Ramirez, G.; Gunn, G.; Zoltick, P. W. et al. (1995): Frequent expression of a mutant epidermal growth factor receptor in multiple human tumors. In: Cancer research 55 (23), S. 5536-5539.

Mosmann, T. (1983): Rapid colorimetric assay for cellular growth and survival: application to proliferation and cytotoxicity assays. In: Journal of immunological methods 65 (1-2), S. 55-63.

Nagane, M.; Coufal, F.; Lin, H.; Bögler, O.; Cavenee, W. K.; Huang, H. J. (1996): A common mutant epidermal growth factor receptor confers enhanced tumorigenicity on 
human glioblastoma cells by increasing proliferation and reducing apoptosis. In: Cancer research 56 (21), S. 5079-5086.

Navarro-Alvarez, Nalú; Kondo, Eisaku; Kawamoto, Hironobu; Hassan, Wael; Yuasa, Takeshi; Kubota, Yasuhiro et al. (2010): Isolation and propagation of a human CD133() colon tumor-derived cell line with tumorigenic and angiogenic properties. In: Cell transplantation 19 (6), S. 865-877. DOI: 10.3727/096368910X508997.

Neuwelt, Edward; Abbott, N. Joan; Abrey, Lauren; Banks, William A.; Blakley, Brian; Davis, Thomas et al. (2008): Strategies to advance translational research into brain barriers. In: The Lancet. Neurology 7 (1), S. 84-96. DOI: 10.1016/S14744422(07)70326-5.

Nguyen, Anthony; Rosner, Andrea; Milovanovic, Tatjana; Hope, Christopher; Planutis, Kestutis; Saha, Baisakhi et al. (2005): Wnt pathway component LEF1 mediates tumor cell invasion and is expressed in human and murine breast cancers lacking ErbB2 (her2/neu) overexpression. In: International journal of oncology 27 (4), S. 949-956.

Nguyen, Don X.; Chiang, Anne C.; Zhang, Xiang H-F; Kim, Juliet Y.; Kris, Mark G.; Ladanyi, Marc et al. (2009): WNT/TCF signaling through LEF1 and HOXB9 mediates lung adenocarcinoma metastasis. In: Cell 138 (1), S. 51-62. DOI: 10.1016/j.cell.2009.04.030.

Nicholson, R. I.; Gee, J. M.; Harper, M. E. (2001): EGFR and cancer prognosis. In: European journal of cancer (Oxford, England: 1990) 37 Suppl 4, S. S9-15.

Nie, Fang; Yang, Jian; Wen, Song; An, Yan-Li; Ding, Jie; Ju, Sheng-Hong et al. (2012): Involvement of epidermal growth factor receptor overexpression in the promotion of breast cancer brain metastasis. In: Cancer 118 (21), S. 5198-5209. DOI: 10.1002/cncr.27553.

Nieto, Yago; Nawaz, Fatima; Jones, Roy B.; Shpall, Elizabeth J.; Nawaz, Samia (2007): Prognostic significance of overexpression and phosphorylation of epidermal growth factor receptor (EGFR) and the presence of truncated EGFRvIll in locoregionally advanced breast cancer. In: Journal of clinical oncology: official journal of the American Society of Clinical Oncology 25 (28), S. 4405-4413. DOI: 10.1200/JCO.2006.09.8822.

Nishikawa, R.; Ji, X. D.; Harmon, R. C.; Lazar, C. S.; Gill, G. N.; Cavenee, W. K.; Huang, H. J. (1994): A mutant epidermal growth factor receptor common in human 
glioma confers enhanced tumorigenicity. In: Proceedings of the National Academy of Sciences of the United States of America 91 (16), S. 7727-7731.

Nishioka, Mitsuaki; Ueno, Koji; Hazama, Shoichi; Okada, Toshiyuki; Sakai, Kouhei; Suehiro, Yutaka et al. (2013): Possible involvement of Wnt11 in colorectal cancer progression. In: Molecular carcinogenesis 52 (3), S. 207-217. DOI: 10.1002/mc.21845.

Nomachi, Akira; Nishita, Michiru; Inaba, Daisuke; Enomoto, Masahiro; Hamasaki, Mayumi; Minami, Yasuhiro (2008): Receptor tyrosine kinase Ror2 mediates Wnt5ainduced polarized cell migration by activating c-Jun N-terminal kinase via actin-binding protein filamin A. In: The Journal of biological chemistry 283 (41), S. 27973-27981. DOI: $10.1074 / j b c . M 802325200$.

Nusse, R.; Varmus, H. E. (1982): Many tumors induced by the mouse mammary tumor virus contain a provirus integrated in the same region of the host genome. In: Cell 31 (1), S. 99-109.

Nüsslein-Volhard, C.; Wieschaus, E. (1980): Mutations affecting segment number and polarity in Drosophila. In: Nature 287 (5785), S. 795-801.

Oishi, Isao; Suzuki, Hiroaki; Onishi, Nobuyuki; Takada, Ritsuko; Kani, Shuichi; Ohkawara, Bisei et al. (2003): The receptor tyrosine kinase Ror2 is involved in noncanonical Wnt5a/JNK signalling pathway. In: Genes to cells : devoted to molecular \& cellular mechanisms 8 (7), S. 645-654.

Olayioye, M. A.; Neve, R. M.; Lane, H. A.; Hynes, N. E. (2000): The ErbB signaling network: receptor heterodimerization in development and cancer. In: The EMBO journal 19 (13), S. 3159-3167. DOI: 10.1093/emboj/19.13.3159.

Olson, D. J.; Gibo, D. M. (1998): Antisense wnt-5a mimics wnt-1-mediated C57MG mammary epithelial cell transformation. In: Experimental cell research 241 (1), S. 134141. DOI: $10.1006 /$ excr.1998.4030.

Ouko, Lillian; Ziegler, Thomas R.; Gu, Li H.; Eisenberg, Leonard M.; Yang, Vincent W. (2004): Wnt11 signaling promotes proliferation, transformation, and migration of IEC6 intestinal epithelial cells. In: The Journal of biological chemistry 279 (25), S. 2670726715. DOI: 10.1074/jbc.M402877200. 
Panáková, Daniela; Sprong, Hein; Marois, Eric; Thiele, Christoph; Eaton, Suzanne (2005): Lipoprotein particles are required for Hedgehog and Wingless signalling. In: Nature 435 (7038), S. 58-65. DOI: 10.1038/nature03504.

Pedersen, M. W.; Meltorn, M.; Damstrup, L.; Poulsen, H. S. (2001): The type III epidermal growth factor receptor mutation. Biological significance and potential target for anti-cancer therapy. In: Annals of oncology: official journal of the European Society for Medical Oncology / ESMO 12 (6), S. 745-760.

Perou, C. M.; Sørlie, T.; Eisen, M. B.; van de Rijn, M.; Jeffrey, S. S.; Rees, C. A. et al. (2000): Molecular portraits of human breast tumours. In: Nature 406 (6797), S. 747752. DOI: $10.1038 / 35021093$.

Pinson, K. I.; Brennan, J.; Monkley, S.; Avery, B. J.; Skarnes, W. C. (2000): An LDLreceptor-related protein mediates Wnt signalling in mice. In: Nature 407 (6803), S. 535-538. DOI: 10.1038/35035124.

Plowman, G. D.; Culouscou, J. M.; Whitney, G. S.; Green, J. M.; Carlton, G. W.; Foy, L. et al. (1993): Ligand-specific activation of HER4/p180erbB4, a fourth member of the epidermal growth factor receptor family. In: Proceedings of the National Academy of Sciences of the United States of America 90 (5), S. 1746-1750.

Polakis, P. (2000): Wnt signaling and cancer. In: Genes \& development 14 (15), S. 1837-1851.

Polakis, P. (2012): Wnt signaling in cancer. In: Cold Spring Harbor perspectives in biology 4 (5). DOI: 10.1101/cshperspect.a008052.

Prigent, S. A.; Lemoine, N. R. (1992): The type 1 (EGFR-related) family of growth factor receptors and their ligands. In: Progress in growth factor research 4 (1), S. 1-24.

Radinsky, R.; Risin, S.; Fan, D.; Dong, Z.; Bielenberg, D.; Bucana, C. D.; Fidler, I. J. (1995): Level and function of epidermal growth factor receptor predict the metastatic potential of human colon carcinoma cells. In: Clinical cancer research : an official journal of the American Association for Cancer Research 1 (1), S. 19-31.

Railo, Antti; Nagy, Irina I.; Kilpeläinen, Pekka; Vainio, Seppo (2008): Wnt-11 signaling leads to down-regulation of the Wnt/beta-catenin, JNK/AP-1 and NF-kappaB pathways and promotes viability in the CHO-K1 cells. In: Experimental cell research 314 (13), S. 2389-2399. DOI: 10.1016/j.yexcr.2008.04.010. 
Rigo-Watermeier, T.; Kraft, B.; Ritthaler, M.; Wallkamm, V.; Holstein, T.; Wedlich, D. (2012): Functional conservation of Nematostella Wnts in canonical and noncanonical Wnt-signaling. In: Biology open 1 (1), S. 43-51. DOI: 10.1242/bio.2011021.

Rijsewijk, F.; Schuermann, M.; Wagenaar, E.; Parren, P.; Weigel, D.; Nusse, R. (1987): The Drosophila homolog of the mouse mammary oncogene int-1 is identical to the segment polarity gene wingless. In: Cell 50 (4), S. 649-657.

Rimawi, Mothaffar F.; Shetty, Priya B.; Weiss, Heidi L.; Schiff, Rachel; Osborne, C. Kent; Chamness, Gary C.; Elledge, Richard M. (2010): Epidermal growth factor receptor expression in breast cancer association with biologic phenotype and clinical outcomes. In: Cancer 116 (5), S. 1234-1242. DOI: 10.1002/cncr.24816.

Roock, Wendy de; Claes, Bart; Bernasconi, David; Schutter, Jef de; Biesmans, Bart; Fountzilas, George et al. (2010): Effects of KRAS, BRAF, NRAS, and PIK3CA mutations on the efficacy of cetuximab plus chemotherapy in chemotherapy-refractory metastatic colorectal cancer: a retrospective consortium analysis. In: The Lancet. Oncology 11 (8), S. 753-762. DOI: 10.1016/S1470-2045(10)70130-3.

Roy, Hemant K.; Olusola, Bola F.; Clemens, Dahn L.; Karolski, William J.; Ratashak, Anne; Lynch, Henry T.; Smyrk, Thomas C. (2002): AKT proto-oncogene overexpression is an early event during sporadic colon carcinogenesis. In: Carcinogenesis 23 (1), S. 201-205.

Saini, Kamal S.; Azim, Hatem A.; Metzger-Filho, Otto; Loi, Sherene; Sotiriou, Christos; Azambuja, Evandro de; Piccart, Martine (2011): Beyond trastuzumab: new treatment options for HER2-positive breast cancer. In: Breast (Edinburgh, Scotland) 20 Suppl 3 , S. S20-7. DOI: 10.1016/S0960-9776(11)70289-2.

Salahshor, S.; Woodgett, J. R. (2005): The links between axin and carcinogenesis. In: Journal of clinical pathology 58 (3), S. 225-236. DOI: 10.1136/jcp.2003.009506.

Sánchez-Tilló, Ester; Barrios, Oriol de; Siles, Laura; Cuatrecasas, Miriam; Castells, Antoni; Postigo, Antonio (2011): $\beta$-catenin/TCF4 complex induces the epithelial-tomesenchymal transition (EMT)-activator ZEB1 to regulate tumor invasiveness. In: Proceedings of the National Academy of Sciences of the United States of America 108 (48), S. 19204-19209. DOI: 10.1073/pnas.1108977108. 
Schambony, Alexandra; Wedlich, Doris (2007): Wnt-5A/Ror2 regulate expression of XPAPC through an alternative noncanonical signaling pathway. In: Developmental cell 12 (5), S. 779-792. DOI: 10.1016/j.devcel.2007.02.016.

Schirripa, Marta; Cremolini, Chiara; Loupakis, Fotios; Morvillo, Manfredi; Bergamo, Francesca; Zoratto, Federica et al. (2015): Role of NRAS mutations as prognostic and predictive markers in metastatic colorectal cancer. In: International journal of cancer. Journal international du cancer 136 (1), S. 83-90. DOI: 10.1002/ijc.28955.

Schirrmacher, V. (1985): Cancer metastasis: experimental approaches, theoretical concepts, and impacts for treatment strategies. In: Advances in cancer research 43, S. $1-73$.

Schmiegel, W.; Adler, G.; Frühmorgen, P.; Fölsch, U.; Graeven, U.; Layer, P. et al. (2000): Kolorektales Karzinom: Prävention und Früherkennung in der asymptomatischen Bevölkerung--Vorsorge bei Risikopatienten--Endoskopische Diagnostik, Therapie und Nachsorge von Polypen und Karzinomen. In: Zeitschrift für Gastroenterologie 38 (1), S. 49-75. DOI: 10.1055/s-2000-14850.

Senkus, E.; Kyriakides, S.; Penault-Llorca, F.; Poortmans, P.; Thompson, A.; Zackrisson, S.; Cardoso, F. (2013): Primary breast cancer: ESMO Clinical Practice Guidelines for diagnosis, treatment and follow-up. In: Annals of oncology: official journal of the European Society for Medical Oncology / ESMO 24 Suppl 6, S. vi7-23. DOI: 10.1093/annonc/mdt284.

Sethi, Jaswinder K.; Vidal-Puig, Antonio (2010): Wnt signalling and the control of cellular metabolism. In: The Biochemical journal 427 (1), S. 1-17. DOI: 10.1042/BJ20091866.

Sharma, Manju; Chuang, William W.; Sun, Zijie (2002): Phosphatidylinositol 3kinase/Akt stimulates androgen pathway through GSK3beta inhibition and nuclear beta-catenin accumulation. In: The Journal of biological chemistry 277 (34), S. 30935 30941. DOI: 10.1074/jbc.M201919200.

Slamon, D. J.; Clark, G. M.; Wong, S. G.; Levin, W. J.; Ullrich, A.; McGuire, W. L. (1987): Human breast cancer: correlation of relapse and survival with amplification of the HER-2/neu oncogene. In: Science (New York, N.Y.) 235 (4785), S. 177-182. 
Smid, Marcel; Wang, Yixin; Zhang, Yi; Sieuwerts, Anieta M.; Yu, Jack; Klijn, Jan G. M. et al. (2008): Subtypes of breast cancer show preferential site of relapse. In: Cancer research 68 (9), S. 3108-3114. DOI: 10.1158/0008-5472.CAN-07-5644.

Smith, Gillian; Carey, Francis A.; Beattie, Julie; Wilkie, Murray J. V.; Lightfoot, Tracy J.; Coxhead, Jonathan et al. (2002): Mutations in APC, Kirsten-ras, and p53-alternative genetic pathways to colorectal cancer. In: Proceedings of the National Academy of Sciences of the United States of America 99 (14), S. 9433-9438. DOI: 10.1073/pnas.122612899.

Smits, R.; Kartheuser, A.; Jagmohan-Changur, S.; Leblanc, V.; Breukel, C.; Vries, A. de et al. (1997): Loss of Apc and the entire chromosome 18 but absence of mutations at the Ras and Tp53 genes in intestinal tumors from Apc1638N, a mouse model for Apc-driven carcinogenesis. In: Carcinogenesis 18 (2), S. 321-327.

Smits, R.; Kielman, M. F.; Breukel, C.; Zurcher, C.; Neufeld, K.; Jagmohan-Changur, S. et al. (1999): Apc1638T: a mouse model delineating critical domains of the adenomatous polyposis coli protein involved in tumorigenesis and development. In: Genes \& development 13 (10), S. 1309-1321.

Sorlie, T.; Perou, C. M.; Tibshirani, R.; Aas, T.; Geisler, S.; Johnsen, H. et al. (2001): Gene expression patterns of breast carcinomas distinguish tumor subclasses with clinical implications. In: Proceedings of the National Academy of Sciences of the United States of America 98 (19), S. 10869-10874. DOI: 10.1073/pnas.191367098.

Spano, J-P; Lagorce, C.; Atlan, D.; Milano, G.; Domont, J.; Benamouzig, R. et al. (2005): Impact of EGFR expression on colorectal cancer patient prognosis and survival. In: Annals of oncology : official journal of the European Society for Medical Oncology / ESMO 16 (1), S. 102-108. DOI: 10.1093/annonc/mdi006.

Sparks, A. B.; Morin, P. J.; Vogelstein, B.; Kinzler, K. W. (1998): Mutational analysis of the APC/beta-catenin/Tcf pathway in colorectal cancer. In: Cancer research 58 (6), S. $1130-1134$.

Sporn, M. B. (1996): The war on cancer. In: Lancet (London, England) 347 (9012), S. 1377-1381.

Staal, Frank J. T.; van Noort Mv, Mascha; Strous, Ger J.; Clevers, Hans C. (2002): Wnt signals are transmitted through $\mathrm{N}$-terminally dephosphorylated beta-catenin. In: EMBO reports 3 (1), S. 63-68. DOI: 10.1093/embo-reports/kvf002. 
Talaat, Adel M.; Howard, Susan T.; Hale, Walker; Lyons, Rick; Garner, Harold; Johnston, Stephen Albert (2002): Genomic DNA standards for gene expression profiling in Mycobacterium tuberculosis. In: Nucleic acids research 30 (20), S. e104.

Tamai, Keiko; Zeng, Xin; Liu, Chunming; Zhang, Xinjun; Harada, Yuko; Chang, Zhijie; $\mathrm{He}, \mathrm{Xi}$ (2004): A mechanism for Wnt coreceptor activation. In: Molecular cell 13 (1), S. 149-156.

Tetsu, O.; McCormick, F. (1999): Beta-catenin regulates expression of cyclin D1 in colon carcinoma cells. In: Nature 398 (6726), S. 422-426. DOI: 10.1038/18884.

Thiery, Jean Paul (2002): Epithelial-mesenchymal transitions in tumour progression. In: Nature reviews. Cancer 2 (6), S. 442-454. DOI: 10.1038/nrc822.

Thiery, Jean Paul; Sleeman, Jonathan P. (2006): Complex networks orchestrate epithelial-mesenchymal transitions. In: Nature reviews. Molecular cell biology 7 (2), S. 131-142. DOI: 10.1038/nrm1835.

Thomson, R. B.; Igarashi, P.; Biemesderfer, D.; Kim, R.; Abu-Alfa, A.; Soleimani, M.; Aronson, P. S. (1995): Isolation and cDNA cloning of Ksp-cadherin, a novel kidneyspecific member of the cadherin multigene family. In: The Journal of biological chemistry 270 (29), S. 17594-17601.

Thomson, R. B.; Ward, D. C.; Quaggin, S. E.; Igarashi, P.; Muckler, Z. E.; Aronson, P. S. (1998): cDNA cloning and chromosomal localization of the human and mouse isoforms of Ksp-cadherin. In: Genomics 51 (3), S. 445-451. DOI: 10.1006/geno.1998.5402.

Towbin, H.; Staehelin, T.; Gordon, J. (1979): Electrophoretic transfer of proteins from polyacrylamide gels to nitrocellulose sheets: procedure and some applications. In: Proceedings of the National Academy of Sciences of the United States of America 76 (9), S. 4350-4354.

Toyama, Takashi; Lee, Han Chu; Koga, Hironori; Wands, Jack R.; Kim, Miran (2010): Noncanonical Wnt11 inhibits hepatocellular carcinoma cell proliferation and migration. In: Molecular cancer research : MCR 8 (2), S. 254-265. DOI: 10.1158/15417786.MCR-09-0238. 
Uysal-Onganer, P.; Kypta, R. M. (2012): Wnt11 in 2011 - the regulation and function of a non-canonical Wnt. In: Acta physiologica (Oxford, England) 204 (1), S. 52-64. DOI: 10.1111/j.1748-1716.2011.02297.x.

Uysal-Onganer, Pinar; Kawano, Yoshiaki; Caro, Mercedes; Walker, Marjorie M.; Diez, Soraya; Darrington, R. Siobhan et al. (2010): Wnt-11 promotes neuroendocrine-like differentiation, survival and migration of prostate cancer cells. In: Molecular cancer 9 , S. 55. DOI: 10.1186/1476-4598-9-55.

Valastyan, Scott; Weinberg, Robert A. (2011): Tumor metastasis: molecular insights and evolving paradigms. In: Cell 147 (2), S. 275-292. DOI: 10.1016/j.cell.2011.09.024. Van Amerongen, Renée (2012): Alternative Wnt pathways and receptors. In: Cold Spring Harbor perspectives in biology 4 (10). DOI: 10.1101/cshperspect.a007914.

Van de Ven, Robert A H; Tenhagen, Milou; Meuleman, Wouter; van Riel, Jeske J G; Schackmann, Ron C. J.; Derksen, Patrick W. B. (2015): Nuclear p120-catenin regulates the anoikis resistance of mouse lobular breast cancer cells through Kaisodependent Wnt11 expression. In: Disease models \& mechanisms 8 (4), S. 373-384. DOI: 10.1242/dmm.018648.

Van de Vijver, M J; Nusse, R. (1991): The molecular biology of breast cancer. In: Biochimica et biophysica acta 1072 (1), S. 33-50.

Vogelstein, B.; Kinzler, K. W. (1993): The multistep nature of cancer. In: Trends in genetics : TIG 9 (4), S. 138-141.

Wang, H-Y; Malbon, C. C. (2004): Wnt-frizzled signaling to G-protein-coupled effectors. In: Cellular and molecular life sciences: CMLS 61 (1), S. 69-75. DOI: 10.1007/s00018-003-3165-x.

Weber, Georg F. (2008): Molecular mechanisms of metastasis. In: Cancer letters 270 (2), S. 181-190. DOI: 10.1016/j.canlet.2008.04.030.

Weeraratna, Ashani T.; Jiang, Yuan; Hostetter, Galen; Rosenblatt, Kevin; Duray, Paul; Bittner, Michael; Trent, Jeffrey M. (2002): Wnt5a signaling directly affects cell motility and invasion of metastatic melanoma. In: Cancer cell 1 (3), S. 279-288.

Weigelt, B.; Wessels, L. F. A.; Bosma, A. J.; Glas, A. M.; Nuyten, D. S. A.; He, Y. D. et al. (2005): No common denominator for breast cancer lymph node metastasis. In: British journal of cancer 93 (8), S. 924-932. DOI: 10.1038/sj.bjc.6602794. 
Weil, Robert J.; Palmieri, Diane C.; Bronder, Julie L.; Stark, Andreas M.; Steeg, Patricia S. (2005): Breast cancer metastasis to the central nervous system. In: The American journal of pathology 167 (4), S. 913-920. DOI: 10.1016/S0002-9440(10)61180-7.

Wendt, M. K.; Smith, J. A.; Schiemann, W. P. (2010): Transforming growth factor- $\beta-$ induced epithelial-mesenchymal transition facilitates epidermal growth factordependent breast cancer progression. In: Oncogene 29 (49), S. 6485-6498. DOI: 10.1038/onc.2010.377.

Wendt, Michael K.; Williams, Whitney K.; Pascuzzi, Pete E.; Balanis, Nikolas G.; Schiemann, Barbara J.; Carlin, Cathleen R.; Schiemann, William P. (2015): The antitumorigenic function of EGFR in metastatic breast cancer is regulated by expression of Mig6. In: Neoplasia (New York, N.Y.) 17 (1), S. 124-133. DOI: 10.1016/j.neo.2014.11.009.

Willert, Karl; Brown, Jeffrey D.; Danenberg, Esther; Duncan, Andrew W.; Weissman, Irving L.; Reya, Tannishtha et al. (2003): Wnt proteins are lipid-modified and can act as stem cell growth factors. In: Nature 423 (6938), S. 448-452. DOI: 10.1038/nature01611.

Wong, A. J.; Bigner, S. H.; Bigner, D. D.; Kinzler, K. W.; Hamilton, S. R.; Vogelstein, B. (1987): Increased expression of the epidermal growth factor receptor gene in malignant gliomas is invariably associated with gene amplification. In: Proceedings of the National Academy of Sciences of the United States of America 84 (19), S. 6899 6903.

Wright, T. M.; Brannon, A. R.; Gordan, J. D.; Mikels, A. J.; Mitchell, C.; Chen, S. et al. (2009): Ror2, a developmentally regulated kinase, promotes tumor growth potential in renal cell carcinoma. In: Oncogene 28 (27), S. 2513-2523. DOI: 10.1038/onc.2009.116.

Wu, Yaojiong; Wu, Philip Yuguang (2009): CD133 as a marker for cancer stem cells: progresses and concerns. In: Stem cells and development 18 (8), S. 1127-1134. DOI: $10.1089 / \mathrm{scd} .2008 .0338$.

Yaeger, Rona; Cowell, Elizabeth; Chou, Joanne F.; Gewirtz, Alexandra N.; Borsu, Laetitia; Vakiani, Efsevia et al. (2015): RAS mutations affect pattern of metastatic spread and increase propensity for brain metastasis in colorectal cancer. In: Cancer 121 (8), S. 1195-1203. DOI: 10.1002/cncr.29196. 
Yamagata, Kaoru; Li, Xin; Ikegaki, Shunkichi; Oneyama, Chitose; Okada, Masato; Nishita, Michiru; Minami, Yasuhiro (2012): Dissection of Wnt5a-Ror2 signaling leading to matrix metalloproteinase (MMP-13) expression. In: The Journal of biological chemistry 287 (2), S. 1588-1599. DOI: 10.1074/jbc.M111.315127.

Yan, Dong; Lin, Xinhua (2009): Shaping morphogen gradients by proteoglycans. In: Cold Spring Harbor perspectives in biology 1 (3), S. a002493. DOI: 10.1101/cshperspect.a002493.

Yanagawa, S.; van Leeuwen, F.; Wodarz, A.; Klingensmith, J.; Nusse, R. (1995): The dishevelled protein is modified by wingless signaling in Drosophila. In: Genes \& development 9 (9), S. 1087-1097.

Yang, Jing; Weinberg, Robert A. (2008): Epithelial-mesenchymal transition: at the crossroads of development and tumor metastasis. In: Developmental cell 14 (6), S. 818-829. DOI: 10.1016/j.devcel.2008.05.009.

Zuo, Jian-Hong; Zhu, Wei; Li, Mao-Yu; Li, Xin-Hui; Yi, Hong; Zeng, Gu-Qing et al. (2011): Activation of EGFR promotes squamous carcinoma SCC10A cell migration and invasion via inducing EMT-like phenotype change and MMP-9-mediated degradation of E-cadherin. In: Journal of cellular biochemistry 112 (9), S. 2508-2517. DOI: 10.1002/jcb.23175. 